Portland State University

PDXScholar

Spring 6-11-2018

\title{
Assessment of Policy Alternatives for Mitigation of Barriers to EV Adoption
}

Bilgehan Yildiz

Portland State University

Follow this and additional works at: https://pdxscholar.library.pdx.edu/open_access_etds

Part of the Technology and Innovation Commons

Let us know how access to this document benefits you.

\section{Recommended Citation}

Yildiz, Bilgehan, "Assessment of Policy Alternatives for Mitigation of Barriers to EV Adoption" (2018). Dissertations and Theses. Paper 4376.

https://doi.org/10.15760/etd.6260

This Dissertation is brought to you for free and open access. It has been accepted for inclusion in Dissertations and Theses by an authorized administrator of PDXScholar. Please contact us if we can make this document more accessible: pdxscholar@pdx.edu. 
Assessment of Policy Alternatives for Mitigation of Barriers to EV Adoption

\title{
by
}

Bilgehan Yildiz

A dissertation submitted in partial fulfillment of the requirements for the degree of

\author{
Doctor of Philosophy \\ in \\ Technology Management
}

Dissertation Committee:

Dundar F. Kocaoglu, Chair

Tugrul U. Daim

Loren Lutzenhiser

Jisun Kim

Portland State University

2018 


\begin{abstract}
Electric Vehicle (EV) has become an increasingly important topic in recent years due to energy and environmental concerns. Governments started to focus on remedies to the upcoming climate change threat and seek solutions through policies and regulations. The negative impact of carbon emissions along with pressure from governmental and social organizations force automotive manufacturers to shift to alternative energy sources. However, EV transition is a complex problem because its stakeholders are very diverse including governments, policy makers, EV manufacturers, and Non-Government Organizations (NGOs). Consequently, the barriers to EV adoption are not only consumer oriented, rather exist under many categories. The literature has yet to offer a comprehensive, quantified list of barriers to EV adoption. Although the enacted policies are known, the effectiveness of these policies in mitigating EV adoption is not known.
\end{abstract}

The objective of this research is to assess policy alternatives for mitigation of EV adoption barriers by developing a comprehensive evaluation model. Barriers are grouped under Social, Technical, Environmental, Economic and Political (STEEP) perspectives that are perceived by decision makers as important for adoption process. The decision model of research links the perspectives to barriers, and policy alternatives. The research implements the hierarchical decision model (HDM) to construct a generalized policy assessment framework.

Data for EV adoption barriers were collected from the abovementioned stakeholders.

Experts' qualitative judgments were collected and quantified using the pair-wise comparison method. The final rankings and effectiveness of policy alternatives were calculated. This 
research's results showed that the most important perspective is Economic. The top three most important barriers to EV adoption were identified as Initial Cost, Battery Cost, and Entrenched Technology Resistance, respectively. The most effective policy in mitigating EV adoption barriers is R\&D Incentives. The research also extended the policy effectiveness research with Policy Effectiveness Curves by reaching out to additional experts. These curves helped determine the effectiveness of each of the 6 policies at different implementation levels. Based on these results, 25 scenarios were applied by combinations of policies at different implementation levels to investigate how the effectiveness of policies can change compared to today's conditions. 


\section{ACKNOWLEDGEMENTS}

My first and utmost gratitude is for my family who showed full support and patience during the course of my study.

I also want to present my special thanks to my committee chair, Professor Dundar Kocaoglu, who spent countless hours to guide me in my research. His continuous support during the whole course of my study and also my professional career was one of a kind.

I would like to thank the committee members, Dr. Tugrul Daim, Dr. Kim, and Dr. Loren Lutzenhiser for their precious time and feedbacks during the meetings. I also thank Shawn Wall and the great office staff for their efficient service. I thank all my fellow students at the ETM Department for their invaluable inputs and support during my research.

This study would be impossible without the contributions of 30 some experts from all over the world. I thank all the C-level executives, directors, engineers, academicians, EV owners who provided me expert judgments, particularly Tesla employees who agreed to spend time on my project despite their very busy schedules. 


\section{TABLE OF CONTENTS}

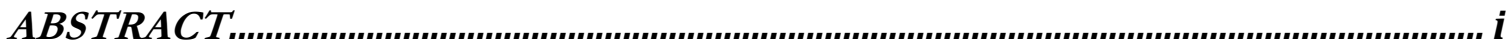

ACKNOWLEDGEMENTS ................................................................................ii

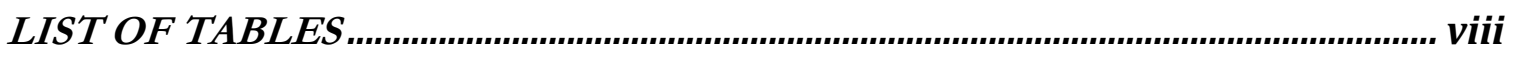

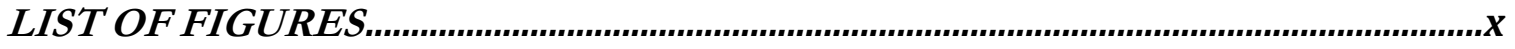

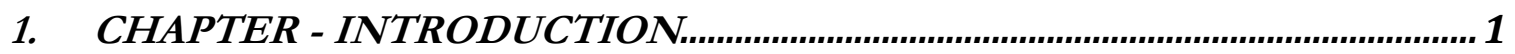

2. CHAPTER - RESEARCH OBJECTIVE \& OUTPUTS..................................... 3

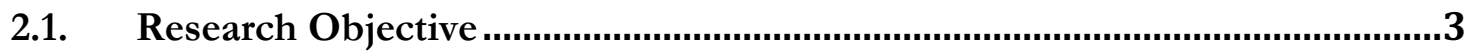

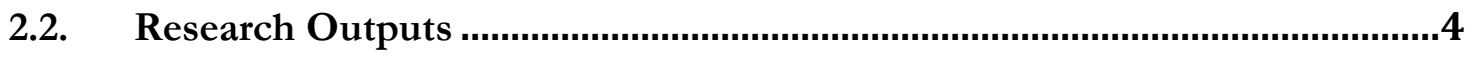

3. CHAPTER - LITERATURE REVIEW.......................................................... 5

3.1. EV Adoption ........................................................................................6

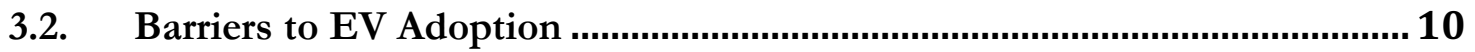

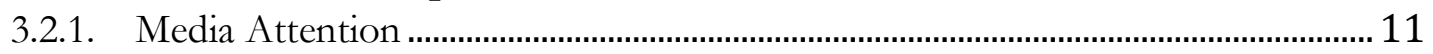

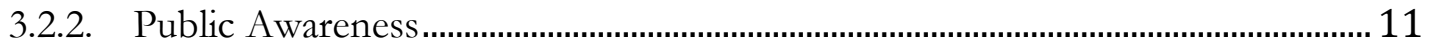

3.2.3. Public Perception.................................................................................................. 12

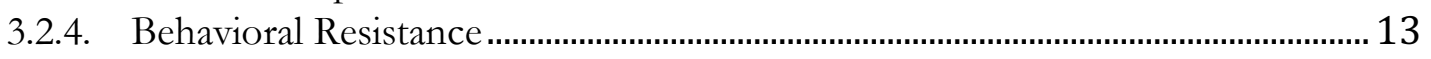

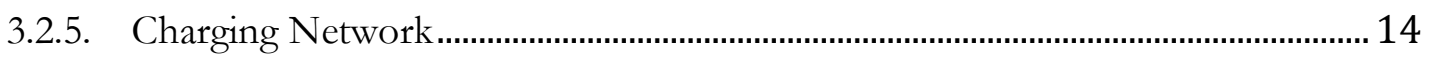

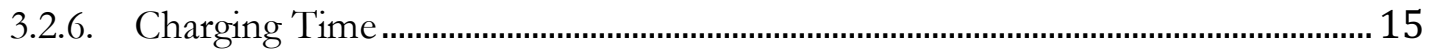

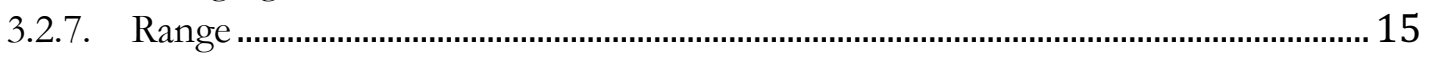

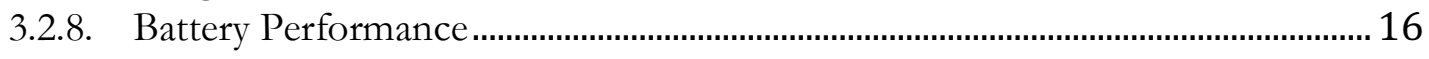

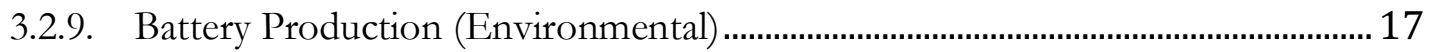

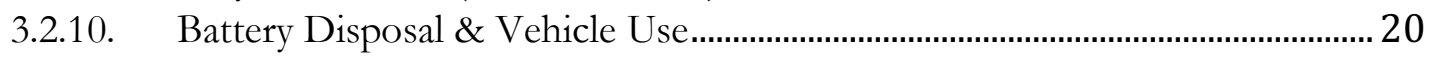

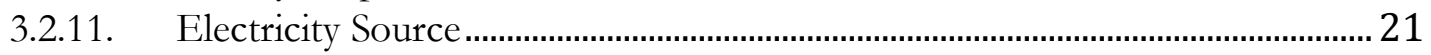

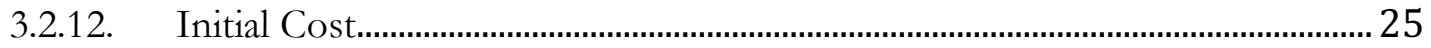

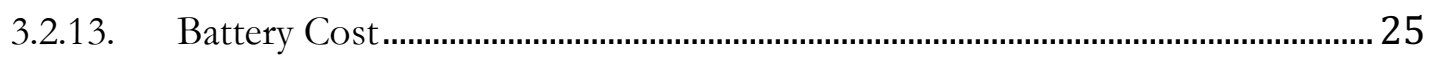

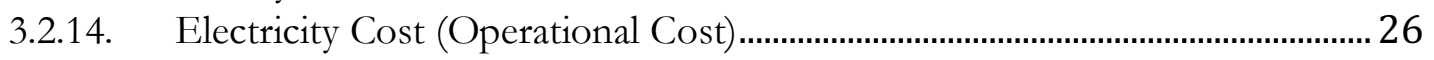

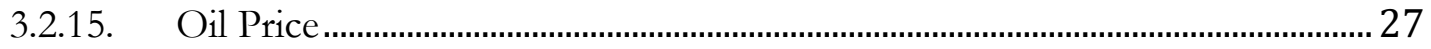

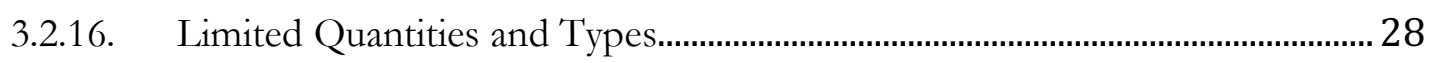

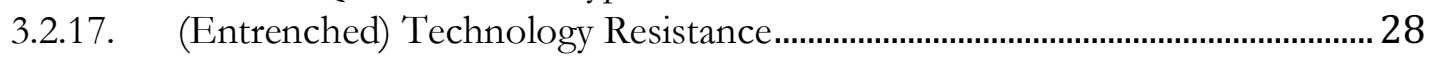

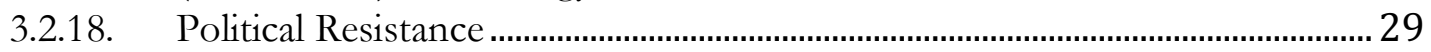

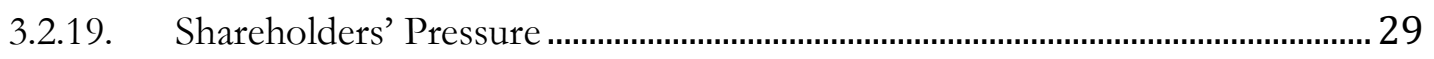

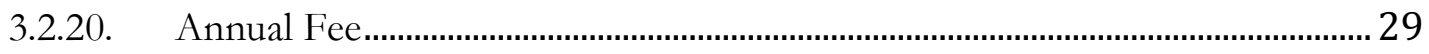

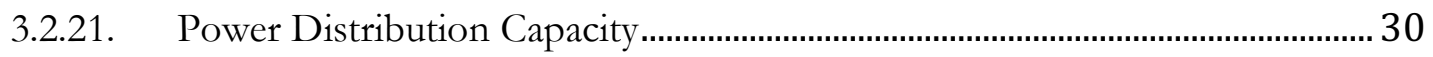

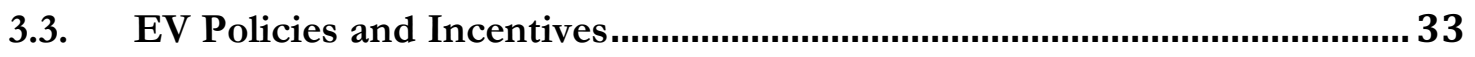

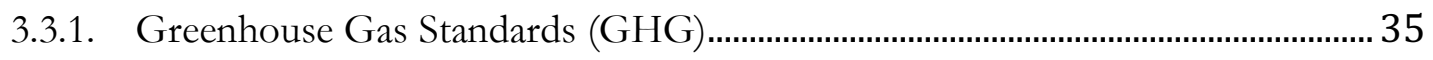

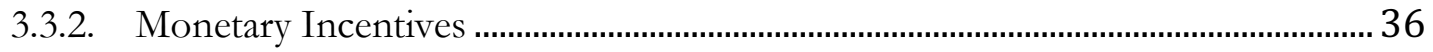




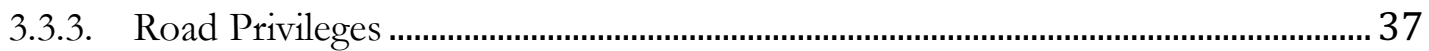

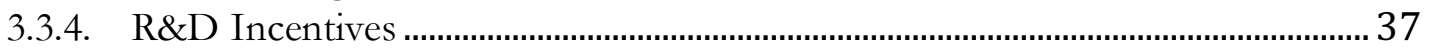

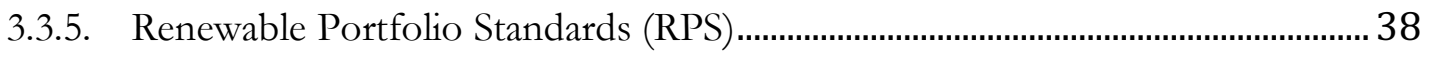

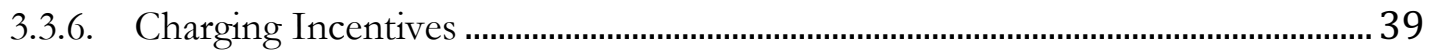

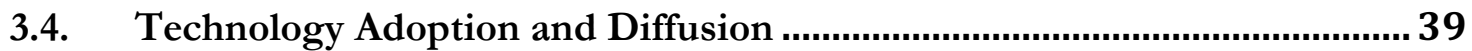

3.5. Technology Adoption and Diffusion Models ........................................ 54

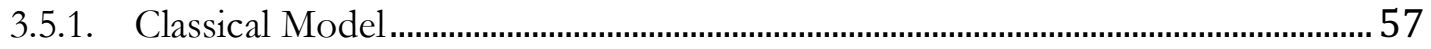

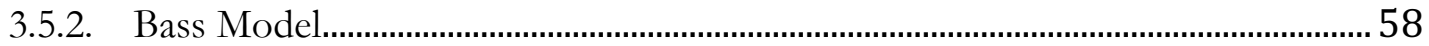

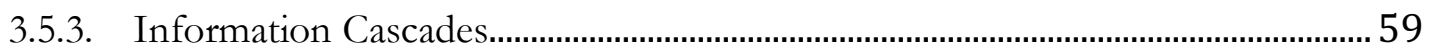

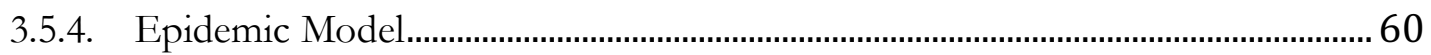

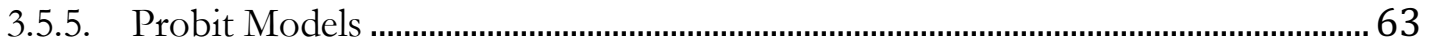

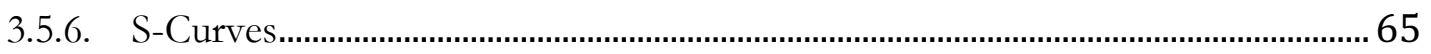

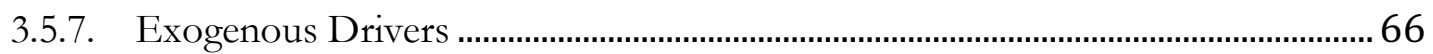

3.5.8. Technology Adoption Models and Technology Adoption Policy ........................ 68

3.6. Technology Adoption Methodologies ..................................................... 72

3.6.1. Forecasting Methods (Bass, Gompertz \& Pearl) ......................................................... 72

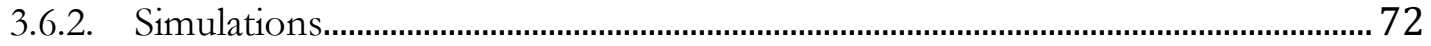

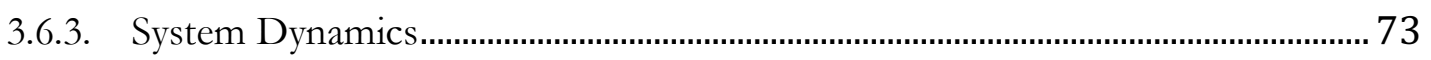

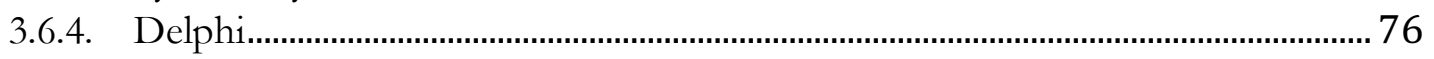

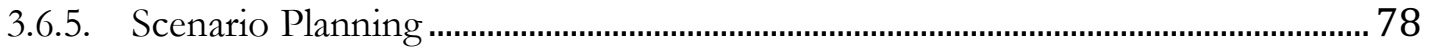

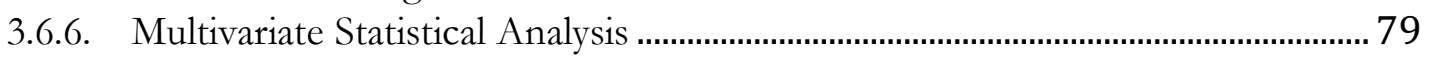

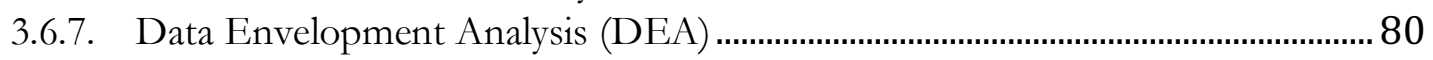

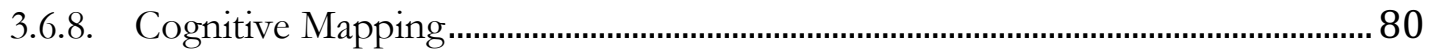

3.6.9. Multi-criteria Decision Models (MCDM) and Multi-Criteria Utility Theory

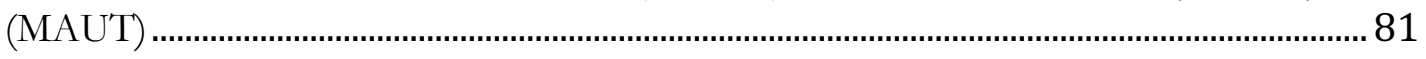

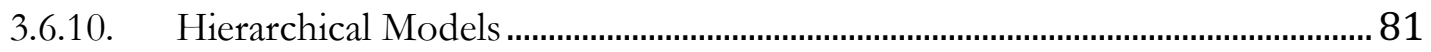

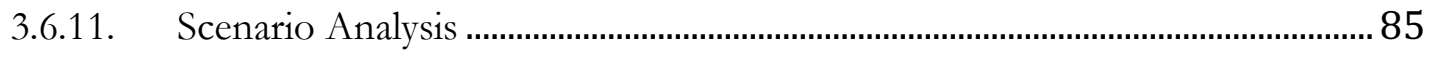

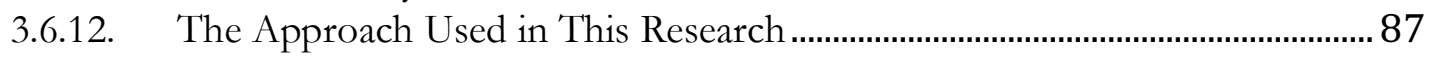

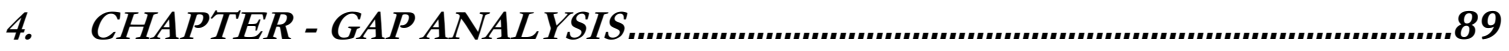

4.1. Linking Research Objectives to Research Gaps \& Research Outputs ....... 89

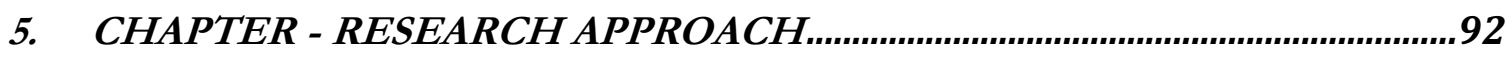

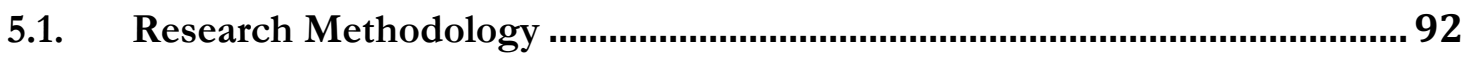

5.2. Research Framework............................................................................ 95

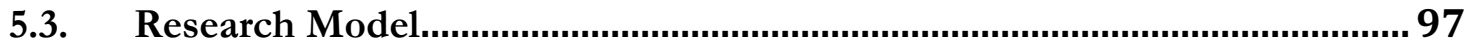

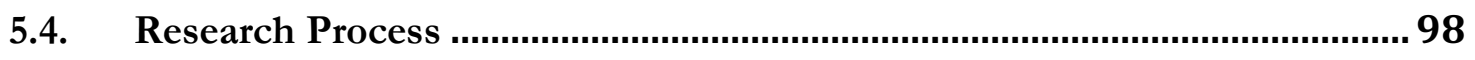

5.5. HDM-JQ (Judgment Quantifications) .................................................. 98

5.6. Expert Inconsistencies and Disagreements............................................... 99 


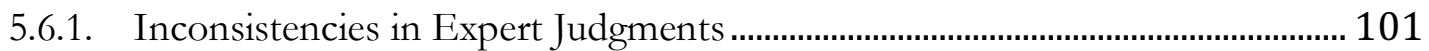

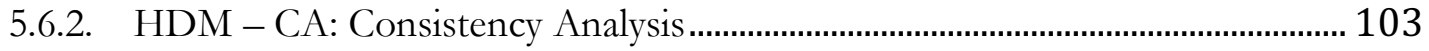

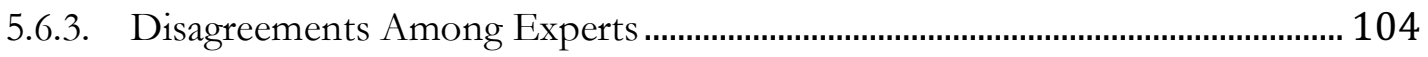

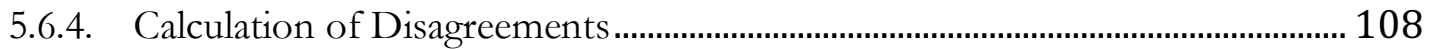

5.6.5. Intraclass Correlation Coefficient (ICC) ............................................................... 109

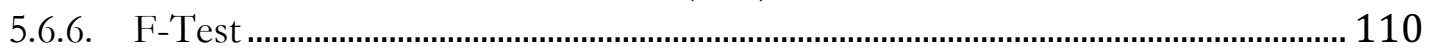

5.7. HDM SA........................................................................................................113

6. CHAPTER - RESULTS and ANALYSIS....................................................... 118

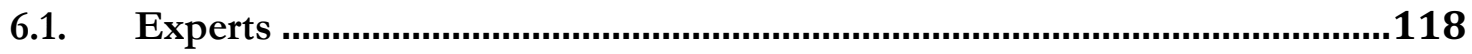

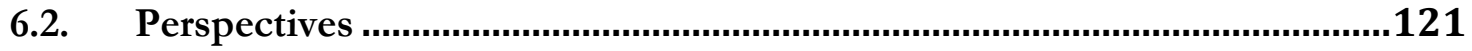

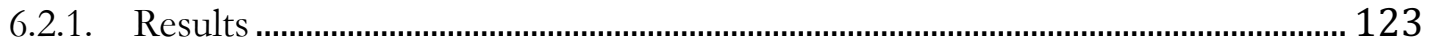

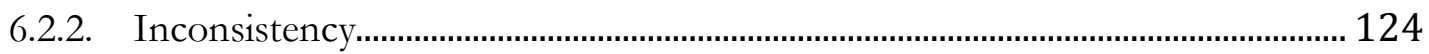

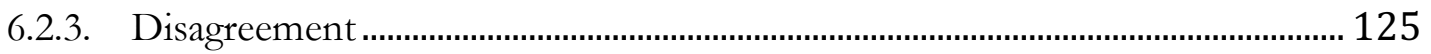

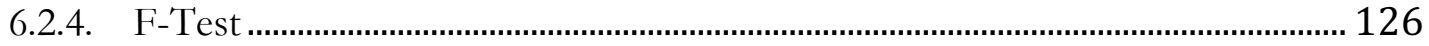

6.3. Barriers ...................................................................................................126

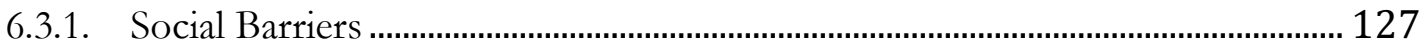

6.3.2. Technical Barriers ......................................................................................... 128

6.3.3. Environmental Barriers...................................................................................... 129

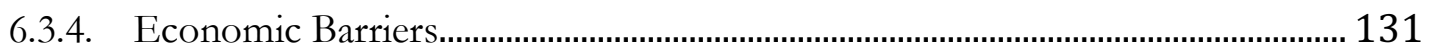

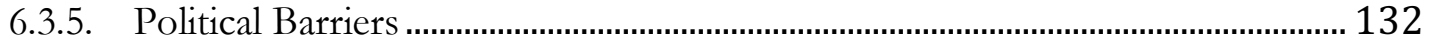

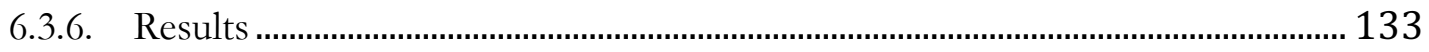

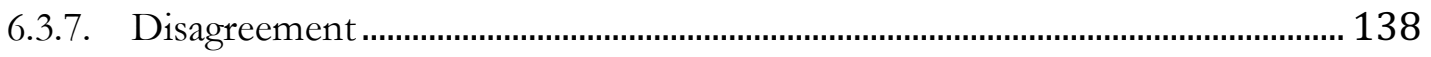

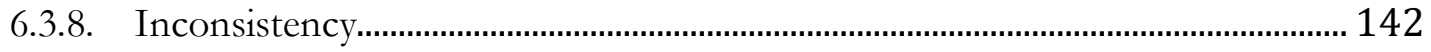

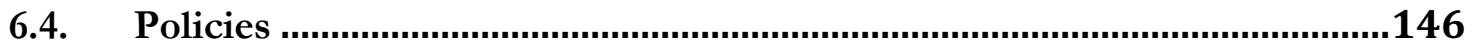

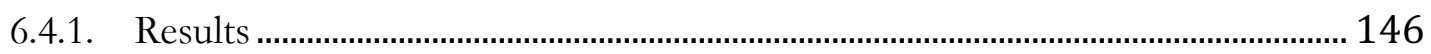

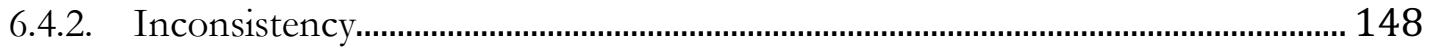

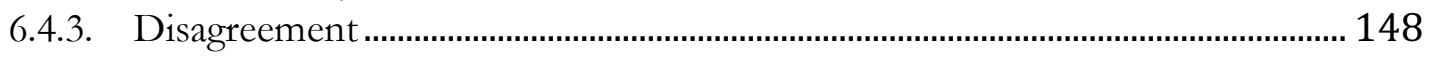

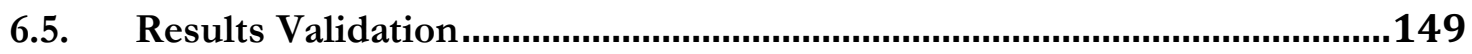

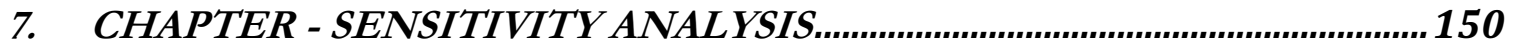

7.1. Modifying the Perspectives ...................................................................150

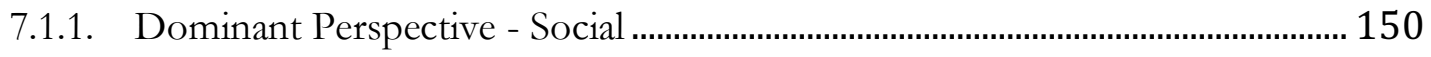

7.1.2. Dominant Perspective - Technical..................................................................... 151

7.1.3. Dominant Perspective - Environmental............................................................... 152

7.1.4. Dominant Perspective - Economic.................................................................... 153

7.1.5. Dominant Perspective - Political .............................................................................. 154

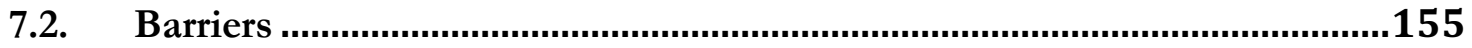

7.2.1. Environmental - Group 1 Decision..................................................................... 157

7.2.2. Environmental - Group 2 Decision......................................................................... 157 


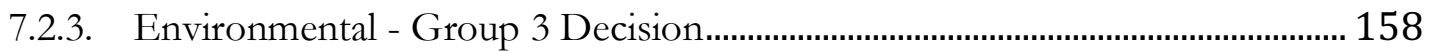

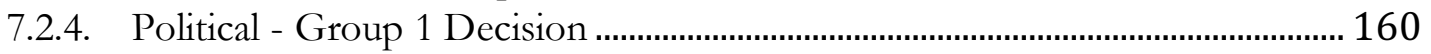

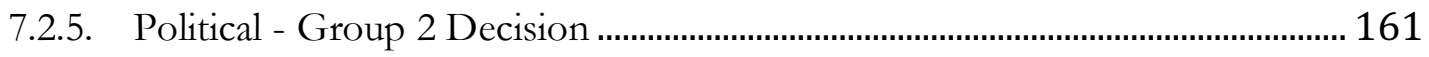

8. CHAPTER - POLICY EFFECTIVENESS CURVES......................................162

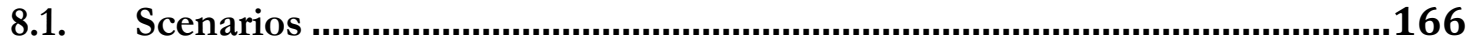

9. CHAPTER-CONCLUSION, CONTRIBUTIONS, LIMITATIONS \&

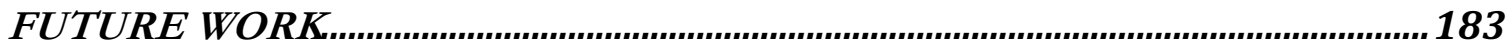

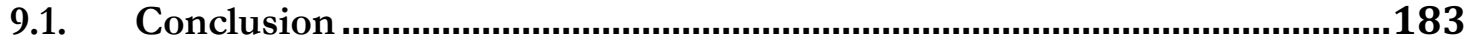

9.1.1. Discussion on Perspectives .............................................................................. 184

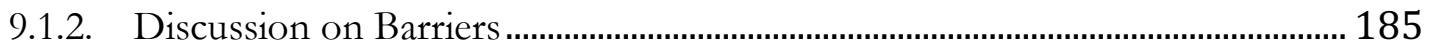

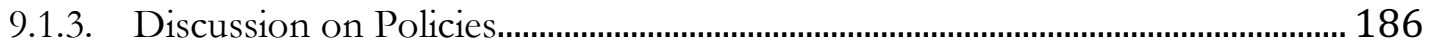

9.1.4. Discussion on Policy Effectiveness Curves \& Scenarios .................................... 187

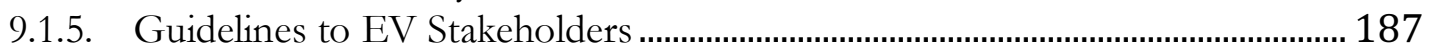

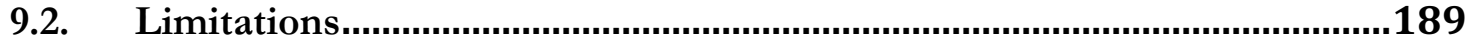

9.3. Future Work..................................................................................................189

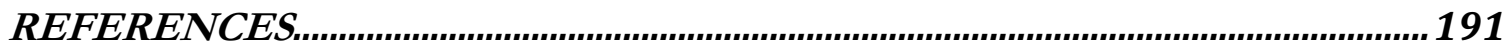

APPENDIX - DESCRIPTIONS OF BARRIERS AND POLICIES...................... 217 


\section{LIST OF TABLES}

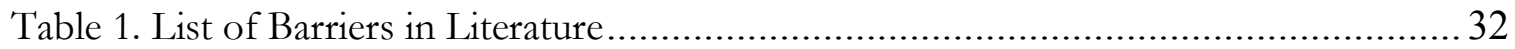

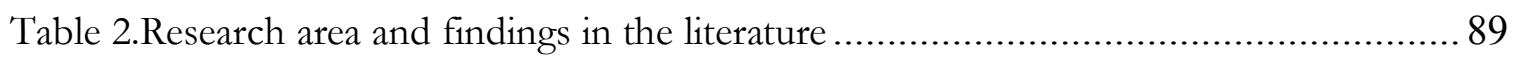

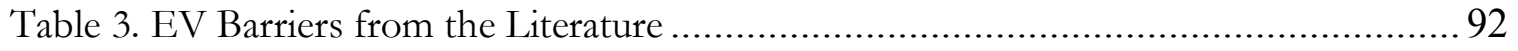

Table 4. Barriers under five perspectives (Social, Technical, Environmental, Economic,

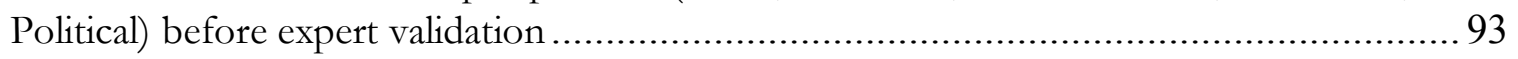

Table 5. EV Policy Alternatives, Abbreviations and their linkage to Barriers.................... 95

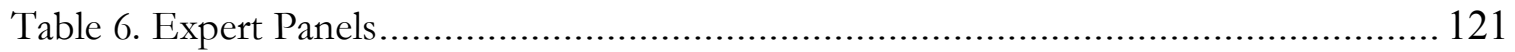

Table 7. Individual weights and inconsistencies for the Perspective level...................... 122

Table 8. F-Test values for disagreements at the perspectives level ............................... 126

Table 9. Individual weights and disagreements for Social Barriers .............................. 127

Table 10. Individual weights and disagreements for Technical Barriers........................ 128

Table 11. Individual weights and disagreements for Environmental Barriers................... 129

Table 12. Individual weights and disagreements for Economic Barriers........................ 131

Table 13. Individual weights and disagreements for Political Barriers ........................... 132

Table 14. F-Test values for Social Barriers ................................................................... 139

Table 15.F-Test values for Technical Barriers .......................................................... 140

Table 16. F-Test values for Environmental Barriers .................................................... 140

Table 17. F-Test values for Economic Barriers ........................................................ 141

Table 18. F-Test values for Political Barriers ............................................................. 142

Table 19. : Inconsistency Threshold Limits for $3-12$ Decision Variables at $\alpha=0.01$ to

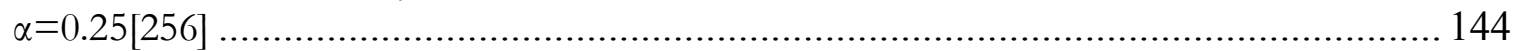

Table 20. F-Test Values for Policy Level ................................................................ 148

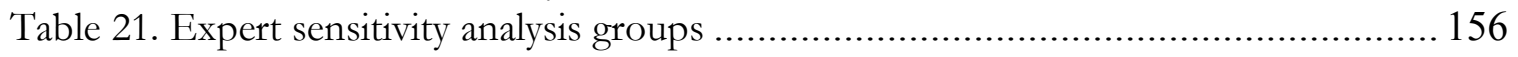

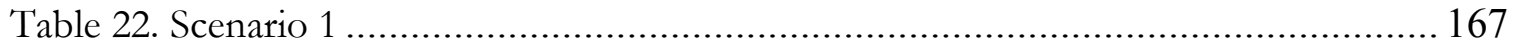

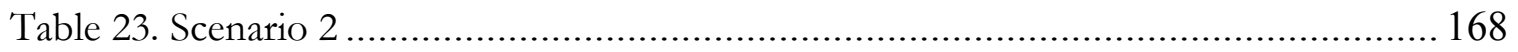

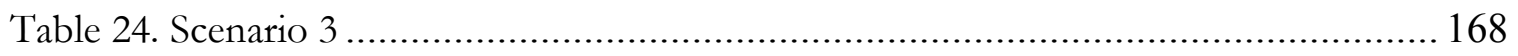

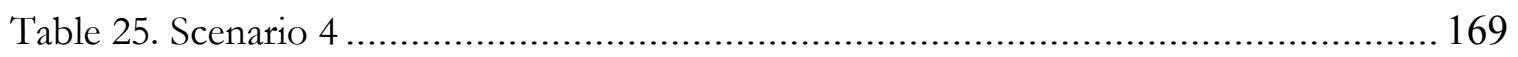

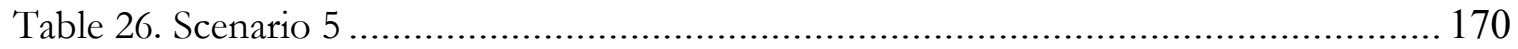

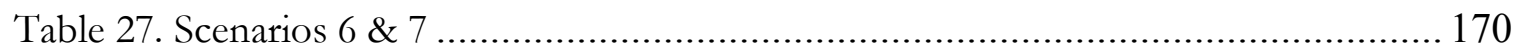

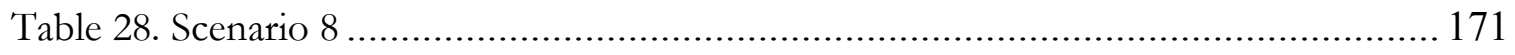

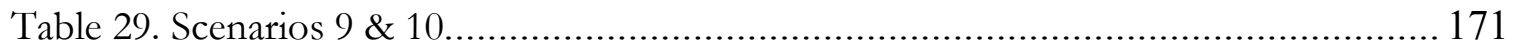

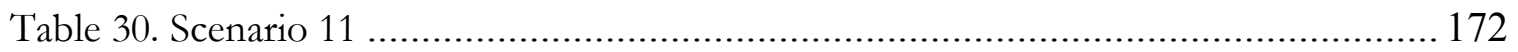

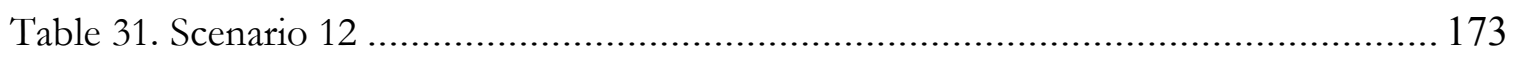

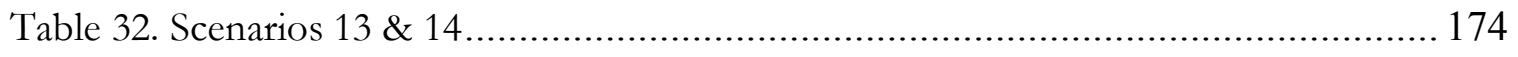

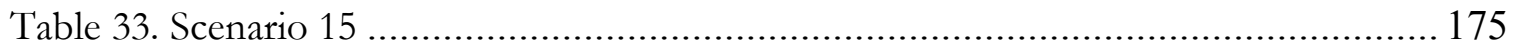

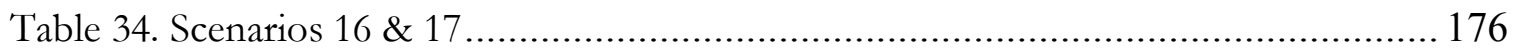

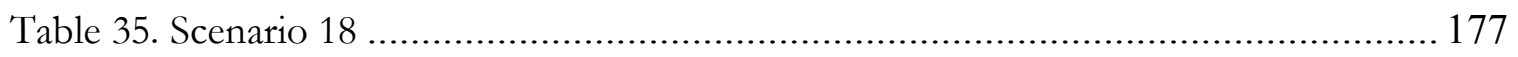

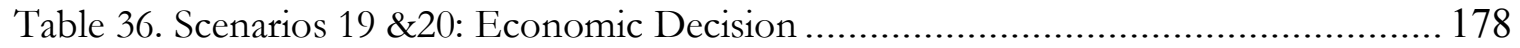

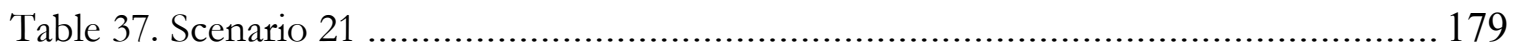

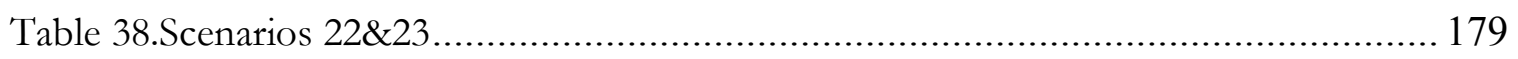

Table 39.Scenario 24: Suggested Scenario ........................................................... 180

viii 
Table 40. Scenario 25: Next Implementation levels .................................................... 181

Table 41. Summary of Scenario Scores \& Ratios ......................................................... 182 


\section{LIST OF FIGURES}

Figure 1. Adopter categorization on the basis of innovativeness - [147]....................... 50

Figure 2. Linking Research Objective to Research Gaps and Research Outputs................91

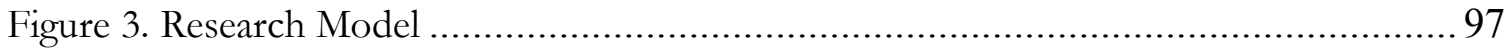

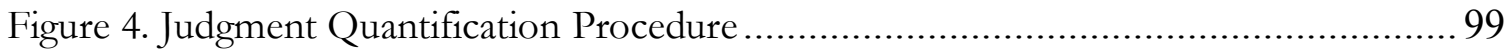

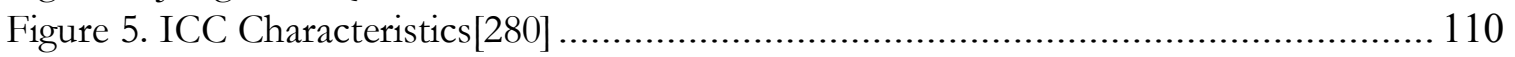

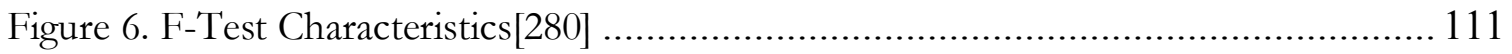

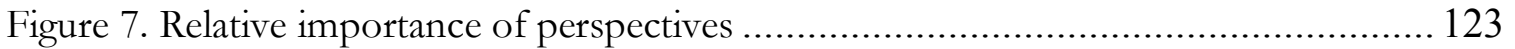

Figure 8. Relative Importance Weights for the Barriers ........................................... 133

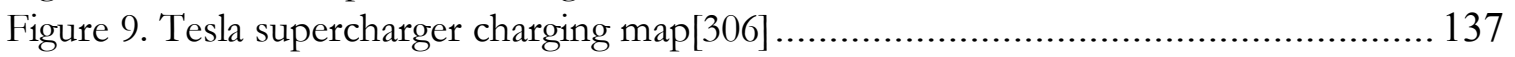

Figure 10. Inconsistency Threshold Limits for 3 - 12 Decision Variables [256] ............... 143

Figure 11. Relative Importance Weights of Policies ............................................ 147

Figure 12. Policy priorities when Social is dominant perspective ................................. 151

Figure 13. Policy priorities when Technical is dominant perspective ............................. 152

Figure 14. Policy priorities when Environmental is dominant perspective ..................... 153

Figure 15. Policy priorities when Economic is dominant perspective ........................... 154

Figure 16. Policy priorities when Political is dominant perspective................................. 155

Figure 17. Policy Alternatives' priorities - Environmental Group 1 Decision .................. 157

Figure 18. Policy Alternatives' priorities - Environmental Group 2 Decision .................. 158

Figure 19. Policy Alternatives' priorities - Environmental Group 3 Decision .................. 159

Figure 20. Policy Alternatives' priorities - Political Group 1 Decision............................ 160

Figure 21. Policy Alternatives' priorities - Political Group 2 Decision........................... 161

Figure 22. Road Privileges Policy Effectiveness Curves ........................................... 163

Figure 23. GHG Policy Effectiveness Curve............................................................. 164

Figure 24. Monetary Incentives Policy Effectiveness Curve ....................................... 164

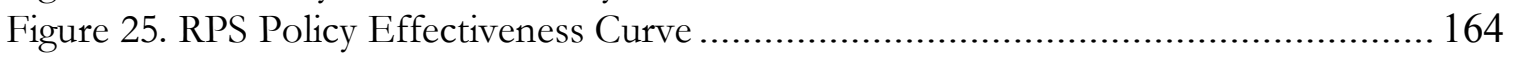

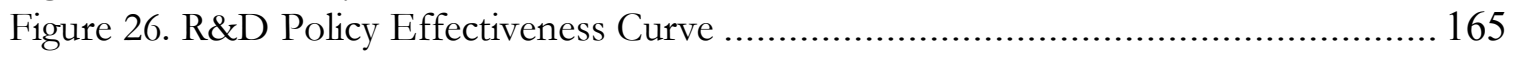

Figure 27. Charging Incentives Policy Effectiveness Curve........................................ 165 


\section{CHAPTER - INTRODUCTION}

The volatility in the oil prices forces multinational corporations to seek price competitive technologies for the automotive industry [1]. The increasing Greenhouse gases (GHG), the global warming, and energy security have forced governments and Multinational Corporations to seek for alternative energy sources. As world's vehicle population grows toward 2 billion, motorized transportation is challenged to contribute to protecting the global climate system, enhancing energy security and reducing the adverse health effects of local air pollution [2]. The rise of EV in most of the energy crises that occurred in the past showed that Internal Combustion Engine (ICE) is not a sustainable energy solution for transportation anymore. Therefore, transitioning to a more sustainable energy system is inevitable.

Many authors suggest that transitioning to sustainable energy systems is an essential element of a physically and economically sustainable global society [3]. However, wide adoption of new technologies is extremely complex, particularly if they involve energy transitions. Major energy transitions take decades and require a new paradigm for environmental policy. One needs to fully understand technology adoption in order to comprehend all aspects of this energy transition that concerns many stakeholders from various fields. It also requires technological progress beyond the current state of the art, and that is inherently uncertain. Hughes [4] came up with a philosophical basis for this concept as: A technological system comprises of a complex network of cultural, organizational and technological units jointly focused on a particular productive or political goal. He gives examples to explain further: the system for generating, distributing and using electricity or the system surrounding the production and use 
of automobiles. Based on his philosophy; human choices and ideologies affect the early life of such systems because the ideology of inventors shapes these technologies. However, as they become institutionalized -in other words, reach main stream customers- their development takes their own course as material-determinists believe [4]. As EV adoption increases it is more likely that EV will not require policy support. Marketplace incentives were enacted in the early years however, and once the adoption reaches to $20 \%$ of the customer set, the incentives are no longer needed to spur sales [5].

Standards that are forced by metropolitan cities paved the way for alternative energy solutions for transportation. Despite other alternatives including hydrogen fuel cell cars and biofuel energy, EV appears to be the most promising technology. In fact, Obama administration terminated support for hydrogen fuel car project due to high upfront infrastructure costs, and decided to fully support EV deployment [6]. In addition, many countries in European Union including Netherlands, Britain, France, Norway and Estonia have already completed a substantial infrastructure for EV [7].

In this study, we assess the effective policies to mitigate barriers to EV adoption. This is a very complex problem and one needs to have a comprehensive understanding of technology adoption models in order to include all adoption elements when defining his/her model. Wellarticulated models, grounded in research and literature, have the most potent kinds of frameworks, yielding clear and lasting outcomes [8]. In addition to the EV literature review, we conducted a comprehensive literature review on technology adoption and technology adoption models to come up with a robust framework. 


\section{CHAPTER - RESEARCH OBJECTIVE \& OUTPUTS}

\subsection{Research Objective}

The objective of this research is to assess policy alternatives for mitigation of barriers to EV adoption. This objective was achieved by developing a hierarchical decision model to provide guidelines for EV policy makers, EV manufacturers and Non-Government Organizations (NGO).

The EV adoption problem is complex due to EV's nature, since it has limited historical data, its future is uncertain, and its stakeholders are very diverse. Although there is a market demand for a sustainable energy source in auto industry, the complexity of this energy transition requires significant government intervention, and all stakeholders need to be on the same page to carry it out.

Although there are some studies in the literature, listing some of the EV adoption barriers, there are no studies to determine the criticality of the barriers, and the policies needed to help alleviate them.

The literature has yet to propose a decision model, which the stakeholders (including governments, manufacturers, policy makers and NGOs) can use as a guideline for developing technology policies and strategies to mitigate the barriers to EV adoption. Because of the scarcity of the available quantitative data, there is a need for a tool that can transform the qualitative data into quantitative data by utilizing judgments of experts from various fields in evaluating and linking the barriers to the policies. 


\subsection{Research Outputs}

The outputs of this research are;

1. A comprehensive list of barriers to EV adoption

2. The relative importance of each barrier to EV adoption

3. The relative importance of policies for removal of barriers.

4. The disagreements among experts from different fields on relative importance of barriers and policies.

5. The expected impacts of the policies at various levels of implementation.

Figure 2 in page 91 shows the relationships among the gaps identified in the literature, the objective and the outputs of this research. 


\section{CHAPTER - LITERATURE REVIEW}

In today's ever-changing world, technologies change rapidly, and adoption of new technologies continually accelerates. Barley [9] explains in his highly cited article that the chances are that within the first 20 pages of any recent studies (especially popular textbooks) on technical and economic change, there will be a statement (if not an entire chapter), on incredible speed of things changing, and further states:

"people who were 50 years old in 1930 were born into a world of horses and wagons where people could only talk face-to-face, where flying was reserved for birds, where fire remained the only means of chasing off the night, where firms were small, and where management was an unknown occupation. At 50, the same people probably drove automobiles, worked for a large corporation, had electricity in their homes, routinely talked to friends and neighbors from remote locations via telephone and if they had sufficient income, could even fly from one place to another. From our position in time it is easy to underestimate the way in which electricity and automobiles, in particular, changed social structures, family structures, temporal structures, patterns of mobility and ultimately the tenor of everyday life and people's images of themselves."

When the author was writing these sentences over 15 years ago, the internet and social media were not even utilized as it is today. One can argue that the rate of diffusion, and society's ability to adopt technologies got even higher.

In fact, the President's Research Committee on Social Trends wrote of the automobile in 1933: "It is probable that no invention of such far reaching importance was ever diffused with such 
rapidity or so quickly exerted influences that ramified through the national culture transforming even habits of thought and language" [10]. Now, EV is expected to diffuse as it replaces the old automobile technology. However, will the diffusion rate be as fast as the first automobile? Without governments' intervention, it doesn't appear to be.

\subsection{EV Adoption}

Increases in gasoline prices in 2007 and 2008 occurred not only because of crude oil price hikes, but also due to refining capacity shortages. Furthermore, there are more motivations for Multinational Corporations and governments including savings due to the avoidance of wealth transfer from oil consumers to producers (particularly foreign producers in a way that exasperates the national trade deficit), and the reduced risk of shocks (or macroeconomic dislocations) caused by wars, hurricanes, or accidents that spur huge fluctuations in the price of oil. According to studies, these savings could reach as high as $\$ 13$ trillion over a period of 25 years $[11,12]$. Economists have stated that even if crude oil were free, high prices for fuel would still exist because refineries cannot produce enough gasoline [13]. Greater market penetration of EV would immediately curtail gasoline usage, easing refinery shortages, and likely depress prices. Also, the consumers have the perception that gas prices will continue to rise in the future. According to a survey [14], as gas prices rise, more people consider EV to be a worthwhile investment.

In addition to economic concerns, oil usage also raises environmental concerns. The US Energy Information Administration estimates indicate that approximately 67\% of the oil consumption in the US occurs in transportation throughout the country [15]. Concerns on increasing GHG emissions and security of oil supply prioritize the development of low-carbon 
and carbon-free technologies for transportation for policy makers around the world. GHG is expected increase up to $45 \%$ in the next 20 years, and this threat coerces several states in the US to pass regulations for a zero-carbon-emissions standard. Los Angeles, the most intense metropolitan area in terms of car density, has led the way in seeking solutions for air pollution. The transportation sector accounts for approximately 14\% of GHG and this is projected to increase to $50 \%$ by 2030 [16]. The IEA [17] projects that $20 \%$ of global primary energy use and $25 \%$ of energy-related carbon dioxide $\left(\mathrm{CO}_{2}\right)$ emissions are attributable to the automotive sector alone. If current trends continue, global energy demand for transport and energy related $\mathrm{CO}_{2}$ emissions are estimated to double by the year 2050. Due to severe air pollution in the Los Angeles metropolitan area (caused mostly by motor vehicles), California already received an exemption from the federal government to update its own automobile emission standards [18]. Then, other states including New Jersey, New York, Connecticut, Oregon, Washington referred to as the "CARB" states followed California's lead and adopted the emission standards [19]. As far as fuel consumption is concerned, even Plug-in Hybrid Electric Vehicle (PHEV), which consumes partially gas and electric, could reduce the consumption of liquid fuels by at least 70 percent compared to ICE. There is also a concern in the literature that electricity that fuels EV is not entirely clean due to the fact that coal/gas is the main source of electricity-generation. However, analyses by Egbue and Long [14] suggest that EV cause 50\% less greenhouse gas compared to gasoline and diesel vehicle fuels, even when coal is the primary source of electricity. Another study by Carnegie Mellon Electricity Industry Center shows that even when powered entirely by coal-fired electricity, EV still produces around 25\% fewer greenhouse-gas emissions per mile than do conventional vehicles [20]. The portfolio of electricity that is used by EV consists of $60 \%$ coal and $40 \%$ wind [12]. According to NRDC 
large deployment of EV can play a significant role in addressing some of the aforementioned problems [21]. The Environmental Protection Agency (EPA) took California's emission standards and set it as the national standard of 2016. This accelerated the adoption of green technologies by corporations [22]. The American Recovery and Reinvestment Act of 2009 also provided over $\$ 2$ billion for electric vehicle and battery technologies, geared toward achieving a goal of one million electric vehicles on US roads by 2015 [23].

Additionally, the US Department of Defense is investing about $\$ 20$ million to demonstrate the concept of using a fleet of electric vehicles with the premise that EV will compensate the high purchasing costs [24].

Conspicuously, one of the main dynamics of EV adoption is price of gasoline. Van Bree, et al. [25] found that increase in gas prices have an effect on consumer behavior. In a study on consumer adoption of EV, Gallagher and Muehlegger [26] found that consumers usually make the decision to buy EV in response to increase in gas prices and government incentives. Along with the cost element, non-financial reasons, especially those that are attributed to environment and energy can have an influence on consumer decisions to purchase EV [27]. Kahn [28] suggested that environmentalists are more likely to purchase EV compared to nonenvironmentalists. Similarly, Gallagher and Muehlegger [26] found that social preferences for environmental quality and energy security were major factors to EV adoption. Srivastava, et al. [29] summarized the various reasons of EV adoption including, low operating costs, reduction in air pollution and diminish global warming, less dependence on gasoline, backup power for the household, and vehicle-to-grid applications. 
Particularly, 'EV sales' is becoming a popular topic among academicians, who use various methods including scenario analysis and other models. Weiss, et al. [30] suggests that as more EVs are sold, more electric recharging and hydrogen refueling stations are built. As more stations are built, the attractiveness of EV increases. At the same time, as more vehicles are sold, costs benefit from scale economies and learning-by-doing. Sikes, et al. [31] projected that 425,000 EV would be sold in 2015 alone. However, the 2015 reports show that only 115,000 EVs were sold in that year [32]. Romm and Frank [33] suggest that a market change will occur in 2020, particularly when EV becomes the dominant alternative fuel vehicle on the road. Lebeau, et al. [34] projected that 7\% of the market in 2020 will be EV. As of 2018, the market share of $\mathrm{EV}$ is around $2 \%$ in the US, which is one of the leaders of EV industry [35]. Greene [36] forecasts sales of approximately 385,000 Battery Electric Vehicle (BEV) alone through 2025. This will likely be surpassed as Tesla alone received over 400,000 Model 3 reservations and promises to deliver in 2019. Greene, et al. [11] suggest through their scenario analysis that EV eventually will prevail, however, their annual sales will not surpass 20,000 units per year until after 2035. After that point, sales ramp up, eventually capturing approximately $38 \%$ of the market in California and many other states by 2050. This eventual market success of EV is attributable to their low operating costs and low initial price, which from 2040 to 2050 is below that of advanced ICEs. Also, the study points a different aspect of EV that by 2030 $\mathrm{BEV}$ will no longer be viewed by majority consumers as a risky new technology. This will help increase the rate of $\mathrm{EV}$ adoption.

Transition stage from established technologies to novel technologies is a painstaking effort due to great uncertainty. According to many studies, policymaking is the pivotal dynamic underlying the successful adoption of EV. According to Gallagher, et al. [37] transitioning to 
$\mathrm{EV}$ is a very complex process that entails policy initiatives of various types, including adjusting codes, standards and mandates or subsidies for vehicles and fuels. Analysis of optimal strategies especially when great uncertainty is present has shown that adaptive strategies that have the ability to change in response to future developments are more robust and can perform almost as well as the optimal strategies based on a full knowledge of future events. There is little doubt that public policy will have to adapt in order to successfully accomplish a transition to sustainable EV [38]. Greene, et al. [11] analysis indicate that EV transition can possibly produce benefits that exceed the excess costs of a transition by an order of magnitude. Therefore, they state: "transition policymaking must balance the need to establish long-term goals and supporting policies with the need to adapt policies as society learns about the progress of new technologies and the market's responses".

\subsection{Barriers to EV Adoption}

With the government incentives and technological advancement, EV's transition stage has been studied by a number of scholars. The transition to EV requires replacing an entrenched technology and its physical and human infrastructure with new technologies that deliver superior public goods. At present the new technologies are not superior in the eyes of most potential buyers. However, with continued technological progress they have the potential to become superior from a private perspective as well. Considering all the factors mentioned, Greene, et al. [11]state that EV technologies face six major economic barriers: "1) Current technological limitations of electric drive power-trains and fuels. 2) High costs that can be reduced through experience (i.e., learning by doing). 3) High costs that can be reduced by volume production (i.e., scale economies). 4) Consumers' aversion to the risk of novel 
products. 5) Lack of diversity of choice in the early market for electric EV. 6) Lack of an energy supply infrastructure for hydrogen and a limited infrastructure for plug-in electric vehicles".

We investigated EV adoption barriers that were studied in the literature in this section. The list acquired from the literature review created the framework of our model.

\subsubsection{Media Attention}

Along with many challenges, EV has been facing negative media attention due to misconceptions of poor performances in compare to ICE. One of EV's primary challenges was to change the misconception in the media and in the markets by offering a competitive advantage over ICE in three categories: 1) drivability, 2) braking behavior, and 3) practical design [39].

Scholars argue that general public perception and the media attention play an important role in reducing the risk related to adoption of a novel technology. The general public's perception of risk is based on experience, emotions, the media and other non-technical sources [40]. In general, media and social networks often influence values that affect consumer choices [ 41 , 42]. Additionally, poor cost and performance charts along with negative media attention are some of the barriers that hinder EV adoption the most [43]. Media attention that received some attention in the literature was added to our initial framework.

\subsubsection{Public Awareness}

Uncertainty about new technologies is one of the major factors hindering adoption. This is factored into our model through two barriers: public awareness and public perception. Literature review on Technology adoption models suggest that diffusion of knowledge is one 
of the major factors of technology adoption. Therefore, it is necessary to investigate whether public awareness was mentioned in the EV adoption literature.

Even though EV progressed rapidly in the last decade, it is considered at the initial stages of the technology adoption cycle [39]. Consumer acceptance is crucial to the continuing success of a sustainable transportation sector [44]. Other studies also confirm lack of knowledge by potential adopters is a common barrier to the adoption of any new technology [45]. A public opinion research in Oregon shows that many of the respondents are uncertain about the general knowledge of EV [46].

Greene, et al. [11] Monte Carlo simulation, identified two points as particularly important: (1) future market for EV is highly uncertain, (2) if policies do not adapt to market conditions there is a substantial likelihood of missing a tipping point that leads to a successful transition.

Zhang, et al. [47] public survey results show that most of the consumers only have a limited acquaintance with EV. According to their results, consumers do not know much about the "performance, the maintenance cost, or the charging interval of EV". Therefore, it is necessary to enhance consumers' awareness of EV in order to promote the development of EV industry. Public Awareness was added to our initial framework.

\subsubsection{Public Perception}

Technologists and policymakers usually separate technical concerns from social concerns while describing technological development. However, the social barriers may be as challenging as technical barriers in the development of EV for the mainstream consumer market [12]. 
According to Modahl [48], 50\% of Americans are technology pessimists; and they are averse to technology. Historical trends in technology adoption indicate that while new technology will continue to be attractive to a few early adopters, including visionaries and technology enthusiasts, the majority of consumers will continue to be biased about it [49]. This bias can be best alleviated by bettering the public perception. Oliver \& Olsen state that consumer acceptance of EV is limited partly due to perceived risks with new products and tradeoffs between vehicle fuel efficiency, size and price Oliver and Rosen [50]. Consumer doubts about the manufacturers' capabilities hinder EV adoption in global markets [39]. As a result, public awareness was added to our initial framework.

\subsubsection{Behavioral Resistance}

Most consumers follow notions of tradition and familiarity instead of embracing a new technology while making choices [12]. Egbue and Long [14] stated that the fact that consumers tend to resist new technologies is a barrier for EV adoption. Behavioral reasoning theory studies relative influence of both reasons for and reasons against adoption in order to provide guidelines for innovation researchers and managers [51]. According to Gourville [52] many new products fail because companies do not delve enough into the psychology of behavior change. He further states:

"A lifetime of driving gasoline-powered cars, heating homes with oil, and reading paper- back novels has led people to treat those familiar options as the status quo. As a result, the losses consumers will incur in switching to electric cars, obtaining power from wind turbines, and scrolling through e-books will have a far greater psychological impact than will the gains from using them." 
Rolim, et al. [53] state that behavior change stands out as a critical factor because mere improvements in technology will not be sufficient. Taylor, et al. [54] state that it is crucial to educate people even after their choice of adopting EV, to change the way they use them and their driving patterns. Therefore, behavioral resistance was added to the initial framework of our model.

\subsubsection{Charging Network}

The distribution of electric charging stations, and the availability of home charging are a critical aspect of EV adoption. Without a sufficient charging network, consumers who are tentative to the new technology will not be able to make the decision to adopt. According to Hall and Lutsey [55], EV charging infrastructure remains as a barrier as of 2017. Schefter [56] studied ways to accelerate EV Vehicle Adoption in 2018 and identified charging infrastructure as an important barrier.

The availability of electrical outlets outside garages for apartment dwellers and the tiered rate structure for electricity bills are additional infrastructure concerns that must be confronted [57]. The lack of charging infrastructure was considered one of the critical barriers to EV adoption. EV charging infrastructure is one of the apparent dynamics of the EV transition. Egbue and Long [14] mentioned along with other infrastructural elements, there is also a need for EV charging infrastructure to charge EV during trips. Also, Sierzchula, et al. [58] Sweda and Klabjan [59], and Rezvani, et al. [60] show charging infrastructure as a key barrier. Other studies that mentioned this as a barrier are listed in Table 1. 


\subsubsection{Charging Time}

Another barrier to EV adoption is the extremely long charging times in comparison to ICE. Charging time was mentioned along with charging network in several studies. Sweda and Klabjan [59], Sierzchula, et al. [58], Rezvani, et al. [60], Egbue and Long [14], Wirasingha, et al. [61] argue that charging time is a critical barrier.

At present, one of the fastest charging vehicles is Tesla (265 miles), and its battery can be fully charged at approximately 9-10 hours. Another challenge is the stability of the power grid with regard to the usage of high-power chargers [29]. Long charging times negatively impacts consumers' decision to adopt EV, especially when charging has to happen during the work days. It is unexpected that consumers will accept 9-10 hour charging time especially when they are on the move. Therefore, this barrier was added to our initial framework.

\subsubsection{Range}

The battery capacity, charging times and inconvenience of charging stations all contribute to the issue of insufficient driving range. Surveys suggest that, although majority of consumers in the US do not travel more than 50 miles a day, they still desire EV to have a longer range due to range anxiety. Egbue and Long [14] survey has interesting results on this matter. The majority of the respondents of his survey (71\%) travel fewer than 20 miles per day, $79 \%$ travel fewer than 30 miles per day while $87 \%$ travel fewer than 40 miles per day. These results are consistent with the findings of Santos, et al. [62], which shows that on average a person travels about 36 miles, but $45 \%$ of respondents still prefer ranges greater than 200 miles. The average desired minimum range by the consumers is 215 miles. Failure of EV manufacturers and policy makers to identify and overcome consumer issues may result in continued low acceptance of 
EV even after the technical problems are resolved. Chau and Wong [63] state that range has been a major adoption barrier for EV. Range is one of the most discussed issues in the EV adoption literature, therefore was added to our initial framework.

\subsubsection{Battery Performance}

Mainstream consumers are resistant to unproven technologies with great uncertainty [64]. Egbue and Long [14] associates uncertainty with the EV battery technology and states sustainability of fuel source as a major potential barrier to widespread EV adoption. Scholars state that the fundamental technological constraint to the commercialization of EV is energy storage [65]. Lead-acid technology is the most developed battery technology used on EV so far. It has a nominal specific energy of $30 \mathrm{Wh} / \mathrm{kg}$, while gasoline is about 93 times more than that [66]. Manufacturers are focused on battery density to increase the capacity to 200$250 \mathrm{Wh} / \mathrm{kg}$ by the year 2020 [67]. The additional cost, weight, size, and disposal problems caused by the larger battery pack are some of the major issues that hinder EV adoption [29]. According to Axsen, et al. [68], the current battery technology is limited by five major attributes: power, energy, longevity, cost and safety. Today there are many studies trying to address the limitations on performance caused by the weight, bulk and storage capacity of EV batteries $[12,44]$. Also, battery management such as thermal ratings, safety, and cell balancing, are important issues that need close attention [29]. The battery challenge shows itself in multiple aspects. The insufficient capacity of EV batteries limits the range of EV at one charge. All of these issues contribute to barrier of battery performance; therefore, it was added to our initial framework. 


\subsubsection{Battery Production (Environmental)}

Environmental aspect of the EV is also critical to widespread EV Adoption. One of the reasons why EV is a good renewable energy alternative for transportation sector is that it is environmentally sound and has the premise to reduce the negative effects of transportation sector. However, there are multiple concerns raised by media and literature on whether EV transition really reduces the negative effects of transportation sector to environment, or this transition replaces one problem with another.

According to findings of González and Prada [69], the methodology for the environmental impact could be divided in three areas, where all of them fully cover the needed "cradle to grave" analysis: Production of the vehicle: taking into account the raw materials and manufacturing and assembly process ("cradle"), Operation or Use: according to the classical well-to-wheel analysis in ICE vehicles (Well-to-Tank, plus Tank-to-Wheel), and the maintenance, and finally

Dismantling: the end-of-life analysis (EOL) ("grave"). Dismantling phase is also called Battery disposal. The Vehicle Use (Wells-to-Wheel) part is divided into two categories: Originating Power Source (Wells-to-Tank) and Vehicle Operation (Tank-to-Wheel). The issues other than battery production will be explained in their own section.

Environmental Protection Agency (EPA) and the U.S. Department of Energy (DOE) conducted a research investigating environmental impact of lithium-ion batteries produced for $\mathrm{EV}$. The research results indicated that batteries that the use of cathodes with nickel, cobalt, and solvent-based electrode processing have the highest potential for environmental impacts. These impacts can be listed as resource depletion, global warming, ecological toxicity, and 
jeopardizing human health. Among major problematic processes those associated with the production are cobalt and nickel metal compounds. The environmental aspect of the processes is as important as the production material. Li-ion batteries that contain nickel and cobalt have a significant effect on health and the environment [70]. More specifically, this includes Panasonic's automotive grade li-ion batteries, which contain lithium, nickel, cobalt, and aluminum, and proprietary cathode geometry developed jointly by Panasonic and Tesla - and is currently used in the Model S [71]. According to 2015 data, most of the lithium that the U.S. uses is procured from other countries including Argentina (46\%), Chile (50\%), and finally China (3\%) [72]. Although EV currently is not (and cannot) be the lead to use lithium, when it becomes the dominant alternative, it will raise the lithium demand significantly considering world's vehicle population is growing towards 2 billion. As EV becomes the dominant alternative and gain more share in the auto industry this may become an issue, therefore, has been voiced in the literature.

Salar brines is the most popular way of acquiring lithium. Salar brines are pumped from beneath the saline crust in two different areas of the salar. "In one of them, extracted salar brines contain unprecedented concentration levels of potassium and lithium. In the other, salar brines obtained contain high concentrations of sulphate and boron" [73]. The Australia Inventory of Chemical Substances [74] has classified metallic lithium as a health, physiochemical and/or ecotoxicological hazard with respect to hazardous substance criteria of the National Occupational Health and Safety Commission (NOHSC) [75]. According to Notter, et al. [76], the processes used to extract lithium from brines are very simple and have a low energy demand. Their results are valid only as long as Li2CO3 is produced from brines. 
If the lithium components were based on spodumene, a silicate of lithium and aluminum, the extraction of the lithium would require a considerable amount of process energy.

Polytetrafluoroethylene production is responsible for more than $97 \%$ of the ozone depletion potential of all three batteries, along with $1415 \%$ of the GWP of the two Li-ion batteries, mostly due to the halogenated methane emissions of this value chain. Results indicate the significance of the functional unit for batteries. Production of NiMH causes the least GWP impact per kilogram, however its lower energy density makes it score worst both relative to its nominal energy capacity and our storage-based functional unit [76].

The major impact to the environmental burden for battery production comes from metal supply and process energy. Metals used in the production are copper for the anode, and aluminum for the cathode are also potential burden when battery production is scaled up. The battery pack and the battery management system (BMS) contain different metals such as copper, gold, and tin. A high-energy demand occurs in the production of aluminum, the production of wafers for the battery management system, the production of graphite [76].

Notter, et al. [76] study also revealed the environmental impact of the EV batteries. According to their study, the share of the total environmental impact of E-mobility caused by the battery is $15 \%$. The negative effect of the extraction of lithium for the components of the Li-ion battery is less than $2.3 \%$. The major contributor to the environmental burden caused by the battery is the supply of copper and aluminum for the production of the anode and the cathode, plus the required cables or the battery management system. Other substantial contributors regardless of the impact assessment method used - are metal supply and process energy. The 
production of aluminum, also the production of wafers for the battery management system, and the production of graphite require substantial energy [76].

\subsubsection{Battery Disposal \& Vehicle Use}

Other aspects of EV battery's environmental impact are when the battery is in use and when it is disposed. A source of lithium posing impact to the environment is spent lithium batteries. Consumers routinely dispose of batteries along with other garbage in the municipal solid waste [77]. Consumed lithium batteries - that have completed their lifecycle - disposed in this manner are considered not to pose environmental or safety hazards. This is based on the assumption that lithium metal is no longer reactive as the metallic lithium and is converted into a nonreactive lithium oxide once the battery is discharged [78]. However, other scholars investigated specific lithium-ion technologies and their impact to environment. Majeau-Bettez, et al. [79] investigated battery systems with a functional unit based on energy storage, and environmental impacts were analyzed using midpoint indicators. On a per-storage basis, the $\mathrm{NiMH}$ technology was found to have the highest environmental impact, followed by NCM and then LFP, for all categories considered except ozone depletion potential.

According to these results, the environmental impacts attributable to the electricity consumed by the battery during the use phase represents more than $40 \%$ of global warming potential and fossil depletion impacts and between $27 \%$ to $45 \%$ of the eutrophication impacts.

There are mainly two methods concerning vehicle treatment at the end of life of EV components, especially battery. These methods are:

1) Method of Stocks

2) Avoided Impact Approach 
In method of stocks, the material recovered at end of life is stockpiled to be used in the production of recycled materials. No impact is taken into account when the recovered material is sent to the stockpile, or when material is used from the stockpile.

In Avoided Impact Approach, the recycling process is converted into a mono-functional process by removing from the system boundary the co-function that is not under analysis. For the end of life of a product at a recycling plant, co-function not under analysis is the production of secondary material they can replace with the production of primary material [69].

\subsubsection{Electricity Source}

The carbon footprint of EV is largely determined by the source of power they use for recharging. Despite their EV deployment, CARB states do not have uniformly low-carbon electricity footprints. In terms of the carbon intensity of electricity generation (in kgs. of $\mathrm{CO}_{2}$ per MWh), Vermont has by far the lowest carbon intensity-by an order of magnitude less than other states [80]. Washington and Oregon follow Vermont. Other metropolitans including Connecticut, Maine, New Jersey, and New York rank still better than average. Policy efforts in support of EV could focus on those states with the greatest potential to deliver carbon reductions.

Because there are environmental concerns related to power generation of EV, power generation becomes critical. Many scholars refer to source of electricity used for EV. Some of the forecasting literature responded to these concerns by using scenarios. Although in the Northwest most electricity is generated by hydropower, in general, a major percentage of electricity generated throughout the US comes from coal. 
Nuclear power is also used for power generation in the Midwest and East. Using nuclear and coal powered electricity in charging $\mathrm{EV}$ is being criticized by many, stating that one environmental problem is merely being replaced by another. Particularly, if EV prevails, the power required for EV will be another issue that needs to be addressed. This issue should be tackled by the energy sector ahead of time. However, the energy need is not the only issue related to this. The concern is that if EV prevails and becomes the major alternative to ICE, then the need for extra energy will be compensated by using more coal and nuclear power, which would defeat the purpose - at least the environmental aspect- of transitioning to EV. Therefore, addressing whether electricity is generated by clean energy sources or not is necessary and has been added to the model as a barrier for EV Adoption.

A study in Germany, created a power generation portfolio, where the life cycle Global Warming Potential (GWP) impacts for different power-grid mix scenarios. In German power generation portfolio, $43 \%$ comes from coal, $23 \%$ from nuclear, 13\% from renewables. We have compared this to the US power generation portfolio. In the US, 39\% of power is generated from coal, 20\% from nuclear, 6\% from renewables, and finally 7\% effrom hydropower [69]. One can notice that US electricity generation from coal is very close to that of Germany, nuclear is almost same as that of Germany's. It can be incurred that American power generation portfolio may be considered environmentally less sound in comparison to German power portfolio. Therefore, American Distribution Grid's Impact on Environment may be more critical than German's.

While coal once dominated American power generation, today many regions have much cleaner sources of electricity as part of their grid mix, which keeps the global warming emissions of today's EV lower than that of the average gasoline vehicle. It is important to note 
that, even in the states that depend largely on coal to generate electricity, EV do not cause more carbon emissions than conventional vehicles [81]. As renewable energy taking place of coal, EV will be even more attractive to governments and consumers with environmental concerns. Union of Concerned scientists' article suggests that there is a large window of variation in greenhouse gas emissions scale from utility power generation. The highest emission rate is more than 2.5 times that of the lowest [81]. By targeting EV policies at select regions, especially those with cleaner power production, the U.S. federal government can open the way to long-term benefits of EV use. Upstate New York, the Northwest, California, Virginia, the Mississippi River Valley, and New England are a few of the lower-carbon-utility regions [82].

Research into individual localities is needed to analyze how EV recharging induces marginal power demands and consequently emissions. If vehicles can be charged at low-peak hours, if they do not over-consume available low-carbon electricity supply, or if they provide more lowcarbon fuel supplies by providing battery storage space, EV will deliver a lower-carbon outcome [82].

Due to the ability to decouple demand and supply, energy storage systems are rated as promising candidates to address some of the critical issues caused by the integration of substantial number of renewables into the future grid [83-85]. Within the portfolio of available energy storage technologies, it is projected that batteries will play a promising role in future highly renewable electricity scenarios, especially for storages at distribution grid level [86]. Therefore, there is a renewed interest within the industry, $R \& D$ institutions and academia to develop and deploy advanced and environmentally sound batteries for stationary applications 
[87]. Tesla came up with their batteries under Tesla Energy (Powerwall and Powerpack), and these will be the energy storage for both residential and commercial use. Powerwall is designed for residential use, when Powerpack is for commercial use. There are three main drivers of Powerwall usage for the consumer. 1) it enables the customer to store electricity at the offpeak hours, 2) it allows the customer to utilize renewable energy systems for the household, 3) is that the energy stored in the battery can be transmitted back to grid, and this is a revenue generator for the customer. Powerpack is for the commercial use, and there are also 3 drivers to Powerpack usage: 1) the government regulation -in CA specifically - coerces utilities to generate certain percentage of their energy from stored energy, 2) unreliable energy infrastructure; where there are frequent electricity cuts, 3) peak vs off-peak hour advantage for the enterprises. Enterprises can store energy at the off-peak hours [88]. In particular for residential charging, this would be a remedy to benefit from low peak hours regardless of the time of the day.

Furthermore, utilizing the powerpack, the production of electricity during peak hours can be lowered, which means relying on electricity grid off of fossil fuels, coal and nuclear energy. According to Tesla, once we're able to rely on renewable energy sources for our power consumption, the top $50 \%$ of the dirtiest power generation resources could retire early. We would have a cleaner, smaller, and more resilient energy grid [89].

State public utility commissions must be encouraged to reassess their regulatory frameworks to harmonize technical standards, streamline the installation of household and commercial charging stations, and use electricity rate structures to promote charging at off-peak hours. Scheduling EV loads at night, for example, can actually improve the economics of power 
providers by making better use of existing assets. If utilities do so, increased numbers of EV could improve the efficiency of electricity systems and reduce rates.

According to our findings in the literature review, environmental concerns related to EV were classified under 4 categories in our initial framework:

1) Battery Production

2) Vehicle Operation (Tank-to Wheel)

3) Battery Disposal

4) Originating Power Source (Wells-to-Tank)

\subsubsection{Initial Cost}

Novel technologies have to cope with higher initial costs that temporarily prevent them from disrupting the incumbent entrenched technology [37]. Diamond [45] suggests that high initial costs is a common barrier for any new technology. According to Chau and Wong [63], initial costs have been a major adoption barrier since early days of EV. Initial costs are shown as one of the fundamental challenges of EV as it is still considered at the early phases. The fact that initial cost is an important barrier was discussed by key papers on EV adoption barriers literature including Greene, et al. [11], Egbue and Long [14] along with other studies [1, 39, $53,90,91]$. Some studies view initial costs as the major obstacle to rapid market penetration [92-95]. A comprehensive list of studies referring to initial costs is shown in Table 1.

\subsubsection{Battery Cost}

One of the major technical barriers is the battery. Technical bottlenecks have a direct impact on high production costs of battery systems and hinder EV's competitive advantage over ICE alternatives [96]. The US DOE's Energy Efficiency and Renewable Energy Program managers 
have emphasized the point, by noting that: "cost is the primary impediment and battery technology is a potential show stopper for production" [12]. According to Egbue and Long [14] battery cost is a major determinant for the viability of EV. Highlighting the importance of batteries for EV adoption, Catenacci, et al. [96] gathered expert assessments of the current technical state of batteries of EV and collected probabilistic estimates of their future costs and the uncertainty surrounding them and the impact of the public support programs.

\subsubsection{Electricity Cost (Operational Cost)}

The primary barriers to the widespread adoption in terms of residential charging of EV are cost and the effort of installing the wiring and charging apparatus [97]. At night, there is generally significant excess power plant capacity that is not earning the utility money. Nighttime recharging helps utilities and when the electricity is priced lower, it offsets EV's higher initial purchase price. A certain legislation regulating the electric utilities will positively impact operational costs of EV. During daytime, increased electricity use generally requires more generation capacity and utility investment. Through separate meters, EV can be charged at regulated lower rates, and this way these rates are not necessarily applied to other household utilities.

How utilities design their rates is a crucial tool for encouraging EV use and managing EV load demand growth. If drivers are burdened with excessive electricity rates for electric transport fuel, the transition to EV will be discouraged. State public utility commissions in particular have a major part to play. They license competitive electricity suppliers, set retail electricity rates for vertically integrated or distribution-only utilities on a cost-of-service basis, and can 
alter the "rate of return" afforded to regulated utilities based on a utility's efforts in obtaining reliable electricity at the lowest possible cost.

Marginal rates, which raise prices for additional usage, are a blunt tool to try to deal with variable conditions. Time-of-use rates are a more effective approach and can offer much less expensive electricity. As such, time-of-use, rather than marginal consumption, is a key criterion for electricity sold for transportation use. State public utility commissions should consider making this approach a core element of state strategy.

\subsubsection{Oil Price}

When investigating EV adoption barriers, one needs to take into account oil price ratio to electric unit price. Oil price is an exogenous factor for EV adoption, and it plays a pivotal role when it is compared to EV's operational cost at the time of consumer's decision making. The competition stemming from these will likely continue until the EV technology is legitimized. Although oil price is an exogenous factor to $\mathrm{EV}$, it has an indirect effect on EV adoption. When the oil price is lower, this will positively affect EV adoption, and when it is higher, vice versa. This raised some attention in media and in the literature [98]. Berthelsen and Arteaga [99] studied the relationship between oil prices and EV adoption. According to this study, "both EV sales and lithium prices are influenced by the fluctuations in the oil price, meaning that shocks such as increased demand or price would not have a noteworthy effect on the oil prices."

Oil price, along with electricity cost were added as separate barriers to our initial framework. 


\subsubsection{Limited Quantities and Types}

This barrier was identified in the Technology Adoption literature. As Moore mentioned, it is important for potential adopters to have multiple alternatives especially in the pragmatists phase in the technology adoption cycle. Although a number of manufacturers have released and announced new models, there is still a limited number of alternatives in comparison to ICE vehicles.

There needs to be a new reform in the utilities and infrastructure. Reform options comprise introduction of the recharging infrastructure market to utility participation, strategic partnerships, and the inclusion of third-party. This will likely promote competition, lower prices and more importantly, distribute the potential demand in a more balanced way. Oregon and California's recent developments merit particular attention. These two states can be considered leaders in EV policy innovation, so their respective choices may be instructive for policymakers in other states and at the national level who are seeking out new models [82]. This is one of the least discussed barriers in the EV adoption literature, however, it is supported by the technology adoption literature for new products entering the market.

\subsubsection{7. (Entrenched) Technology Resistance}

All novel technologies have to cope with the incumbent entrenched technologies [37]. Their resistance to the novel technology, in EV's case the incumbent oil companies' resistance, has to be considered for EV adoption. The government incentives to support wide EV adoption may naturally disturb the established ICE companies. With wide adoption of EV, immense resistance may come from automobile manufacturers and oil companies that have invested large amount of dollars into supply and production infrastructure for ICE. It is expected from 
these strong industries to influence policymakers and the public to maintain the status quo. In case EV prevails, petroleum companies and vertically integrated companies such as Exxon will lose revenues from the extraction of oil, refining, and sales of gasoline [12].

\subsubsection{Political Resistance}

As EV is becoming a more important dominant alternative to ICE, there are some resistance from government stakeholders, especially those that support the older technology. According to Nilsson and Nykvist [100] renewable energies receive great political resistance. There are some other studies in the literature that identify political resistance as a barrier $[60,101]$.

\subsubsection{Shareholders' Pressure}

According to Jeffrey Moore, visionaries, to whom EV is currently addressing, are always in a hurry. They see the future in terms of windows of opportunity, which is closing very rapidly. As a result, they tend to exert deadline pressures to drive the project faster. This plays into the classic weakness of entrepreneurs - lust after the big score and over-confidence in their ability to execute within any given time frame [102]. There are no studies in the EV literature that identify shareholders' pressure as a barrier to EV adoption. However, as this was supported by the technology adoption literature, we incorporated shareholder's pressure into our initial framework.

\subsubsection{Annual Fee}

Lost revenues that could provide barriers to $\mathrm{EV}$ commercialization is addressed in the literature. Ultimately, the solution would be to establish a carbon fee on vehicles or fuels. In the meantime, in some locales, pressure has already arisen to resolve the issue, with 
Washington and Oregon considering programs to tax EV use to replace lost revenues. Likewise, New Hampshire has established an Alternative Fuel Vehicle Study Commission to evaluate the impact advanced vehicles, such as EV, have on existing state taxation rules. Simply charging EV a shadow fuel tax does not reflect the differential climate benefits of EV compared to other vehicles.

Washington became the first state to charge a fee for electric vehicles. The governor signed a bill in March 2012 that levies $\$ 100$ annually on EV drivers in order to sustain a "user fee" model in electric transportation. The fee will not be applicable to hybrids, with the $\$ 100$ assessed on pure electric vehicles and deposited in the state highway fund. In Oregon, lawmakers are trying to legislate a bill that would charge drivers of EVs 1.43 cents for each mile they drive, compared to an average of 2 cents per mile in gas taxes currently paid by American drivers [82].

Today, motorists face an average gas tax of 18 cents as federal taxes and a total of 49 cents per gallon of gasoline including state taxes. For diesel, the motorists pay 24 cents for federal taxes and a total of 54 cents per gallon including state taxes [103]. Due to government incentives, EV owners are exempt of these taxes. Hence, in the long run many state officials concerned with tax revenue stream dry up, and some states are beginning to brainstorm potential solutions.

\subsubsection{Power Distribution Capacity}

Although EV only has negligible sales in compare to ICE, there are some concerns in the forecasting literature that when EV sales reach to a certain point, this will have an impact on 
the distribution networks. Several studies have raised this issue in assessing of the impact of EV on power distribution [104-107].

Table 1 summarizes all researches that discussed barriers in the literature. 


\begin{tabular}{|c|c|c|}
\hline \# & Barriers & Articles Studied \\
\hline 1 & Media Attention & {$[39],[42],[41],[108]$} \\
\hline 2 & Public Awareness & {$[39],[44],[46],[47],[45]$} \\
\hline 3 & Public Perception & $\begin{array}{c}{[11],[14],[90],[91],[109],[39],[110],[41],[45],[12],[29],[111],[40],[42],[12],[48],} \\
{[50]}\end{array}$ \\
\hline 4 & $\begin{array}{l}\text { Behavioral } \\
\text { Resistance }\end{array}$ & {$[12],[14],[51],[52],[53],[54]$} \\
\hline 5 & $\begin{array}{l}\text { Charging } \\
\text { Network }\end{array}$ & $\begin{array}{c}{[11],[112],[14],[90],[109],[39],[110],[113],[1],[111],[29],[58],[57],[59],[60]} \\
{[55],[56]}\end{array}$ \\
\hline 6 & Charging Time & $\begin{array}{c}{[11],[112],[14],[90],[39],[110],[39],[1],[12],[111],[29],[58],[114],[115],[116],} \\
{[29],[59],[60],[61]}\end{array}$ \\
\hline 7 & Range & $\begin{array}{c}{[11],[112],[14],[90],[110],[109],[108],[116],[39],[1],[12],[111],[58],[114],[115],} \\
{[62],[63]}\end{array}$ \\
\hline 8 & $\begin{array}{c}\text { Battery } \\
\text { Performance }\end{array}$ & $\begin{array}{c}{[14],[109],[39],[112],[113],[110],[12],[96],[114],[115],[117],[1],[12],[29],[58],} \\
{[111],[44],[116],[29],[65],[66],[67],[68]}\end{array}$ \\
\hline 9 & $\begin{array}{c}\text { Battery } \\
\text { Production }\end{array}$ & {$[69][70][71][72][73][74][76]$} \\
\hline 10 & Battery Disposal & {$[69],[77],[78],[79]$} \\
\hline 11 & Electricity Source & {$[69,80][81][82][83][84][85][86][87]$} \\
\hline 12 & Initial Cost & {$[11],[90],[91],[39],[53],[1],[12],[111],[92],[93],[94]$} \\
\hline 13 & Battery Cost & $\begin{array}{c}{[111,,[14],[90],[113],[109],[111],[29],[58],[39],[53],[45],[12],[29],[58],[44],} \\
{[116],[117]}\end{array}$ \\
\hline 14 & Electricity Cost & [97], [118],[119],[120] \\
\hline 15 & $\begin{array}{l}\text { Limited Models } \\
\text { Quantity }\end{array}$ & [82] \\
\hline 16 & $\begin{array}{l}\text { Technology } \\
\text { Resistance }\end{array}$ & [12] [37] [121] [122] \\
\hline 17 & $\begin{array}{c}\text { Political } \\
\text { Resistance }\end{array}$ & {$[60],[100],[101]$} \\
\hline 18 & $\begin{array}{l}\text { Shareholders } \\
\text { Pressure }\end{array}$ & [102] \\
\hline 19 & Annual Fee & {$[123],[124]$} \\
\hline 20 & $\begin{array}{c}\text { Power } \\
\text { Distribution } \\
\text { Capacity }\end{array}$ & {$[104],[105],[106],[107]$} \\
\hline 21 & Oil Price & {$[98],[99]$} \\
\hline 22 & $\begin{array}{c}\text { Vehicle Use } \\
\text { Environmental }\end{array}$ & [77] [78] [79] [69] \\
\hline
\end{tabular}

Table 1. List of Barriers in Literature 


\subsection{EV Policies and Incentives}

The policy literature on EV Adoption was scarce until 2010s, however starting with the success of brand name companies such as Tesla, many automotive giants started to announce their models. As discussed earlier, EV requires significant government intervention, therefore as manufacturers started to tap into EV market, the policy literature started to grow in mid 2010s.

As market share of EV is generally low across the world, many developed countries introduced incentives to accelerate EV adoption. Certain countries were faster in building the right infrastructure and providing with strong policy support. These countries enacted a wide range of incentives under few categories. Norway is shown as the world leader in this category [125].

Kley, et al. [95] summarizes these policies under 4 categories: Regulatory, Economic, Persuasive, Organizational. The following examples for our study can be given for these categories:

1. Regulatory: GHG standards;

2. Economic: Rebates;

3. Persuasive: Renewable Portfolio Standards;

4. Organizational: Charging infrastructure, and Road privileges

A year after Kley's research, Leurent and Windisch [126] published a study in 2011, classifying policies for EV under 5 categories: Command and control, Economic, Procurement, Collaborative, and Communication \& Diffusion. Jin, et al. [127] evaluated the state-level US EV incentives in 2014. They categorized the incentives as direct incentives, indirect incentives, disincentives, and other incentives. This study compared the total monetary benefits available to consumers through U.S. state incentives to EV sales in 2013. Their study used a methodology to monetize direct and indirect 
incentives they defined, by quantitatively comparing the total benefits. The study only focused on state level US policies from a consumer's perspective rather than looking policies' effect on the entire transportation sector transition.

Lévay, et al. [128] studied the effect of fiscal incentives on EV's market penetration. They utilized pairwise comparisons to examine role of fiscal incentives reducing the total cost of ownership and increasing EV sales.

Wang, et al. [129]'s research in 2017 examined the effectiveness of policy incentives for EV in China. They categorized the incentives under 4 categories: EV production, EV purchase, EV usage and Infrastructure. Their study conducted a discrete choice experiment with 247 respondents examining the effectiveness of potential policies. They excluded the subsidies in their study. Their study -like probit models which is discussed in the technology adoption models- focus on consumer centric adoption and do not study adoption with its barriers.

McDermott [130] investigated the effects of policy interventions on EV in California. His research confined EV barriers to Consumer Perception and Behavior, Technology, and Infrastructure; and policies to Purchase-Based Policies, Use-Based Policies, and Technology Forcing Regulations as policy groups. This study did not use any quantification method, and rather compared the different policy options and their effectiveness in a literature review format.

In the past decade, Norway became a global forerunner in the EV field. A major factor underlying this success is the government support. Norway and Denmark enacted strong monetary incentives as their new vehicle purchasing prices are the highest in the world. 
Norway enacted purchase rebates along with vehicle license fee and these policies can be directly adopted by other countries [131]. Along with Norway, France, India, Japan, the Netherlands, Spain and United States applied direct subsidies for EV purchase [132].

After wide adoption of California emission standards throughout the US, the EPA finally adopted as the National Standard by 2016 [22]. This added to the pace of green technology adoption by corporations because vehicles that are not dependent on gasoline have lowered the gas emissions in comparison to ICE [39]. According to the US DOE's Alternative Fuels and Advanced Data Center, in most areas of the US, emissions are likely to be less than those of a conventional ICE. As a new transportation technology, EV will have to overcome a number of barriers to achieve widespread adoption. It needs serious aid from the federal and state governments to help overcome these barriers. To mitigate some of these barriers, the US government has come up with a series of policies and incentives. According to a recent study by Greene, et al. [11], even when conditions change, two key policies in particular are assumed not only to remain in effect and but be strengthened over time, first being fuel economy and GHG emissions standards and the latter is renewable and low carbon fuels standards.

Technology policy is more than just a matter of shoveling funds into big science projects or uncritically supporting high tech defense spending. Policy making needs critical attention. Policy making that can help accelerate EV adoption, needs a thorough understanding of adoption barriers.

\subsubsection{Greenhouse Gas Standards (GHG)}

Although the source of electricity for EV would lower the GHGs, this would still be a critical issue considering that California Standards - now that it is adopted by many states - are aiming 
to reach zero carbon emissions due to high pollution. It is inescapable for governments to look for sustainable renewable energy systems. It is important to record that when EV becomes the lead alternative to ICE, there will be a pressing need for higher amount of electricity. With the current number of EVs on the road, energy sector and EV would mutually benefit from each other as spare energy produced at hydroplants -it is difficult to store electricity- however, energy generation may become a barrier as EV prevails.

\subsubsection{Monetary Incentives}

The Obama administration enacted several legislations and policies to accelerate EV adoption. The government set a goal of one million plug-in EVs on the road by 2015. Subsequently, several legislations and incentives were taken in action in order to reach this goal [116]. According to the US DOE, a substantial amount of a federal income tax credit may be eligible for the EVs bought after 2010 [133]. This energy policy subsidizes EV with a tax credit of up to $\$ 7500 /$ per vehicle based on battery size. Several states provide additional subsidy on top of the $\$ 7500$. California, for example, adds $\$ 3000$ for a total of $\$ 10,500$. The total price break aims to accelerate market activity, given potential US cost of gasoline, electricity and EV batteries [116]. US DOE also partnered up with private companies to fund the EV project that has helped install over 8,000 charging stations across the country [134].

IRS announced that "the qualified EV credit phases out for a manufacturer's vehicles over the one-year period beginning with the second calendar quarter in which at least 200,000 qualifying vehicles manufactured by that manufacturer have been sold for use in the US. The qualified $\mathrm{EV}$ that is manufactured by the manufacturer is eligible up to $50 \%$ of the credit in the phaseout period" [135]. 
Another initiative that is included under current energy initiatives (HB3291) is Business Energy Tax Credit (BETC) - Increased BETC to 50\% for Renewables manufacturing.

Business Energy Tax Credit: This tax credit is for businesses and many businesses can benefit from this tax credit through different uses. Currently, businesses in Oregon that purchase hybrid gasoline-electric vehicles may qualify for a tax credit [136].

\subsubsection{Road Privileges}

Furthermore, as of July 2013, 38 states have implemented incentives that provides high occupancy vehicle (HOV) lane exemptions, monetary incentives, vehicle inspections or emissions test exemptions and parking incentives [137]. As an example, to accelerate EV adoption, California has facilitated free access to HOV lanes through January 1, 2015 [39, 65]. States in metropolitan areas facilitated purchase rebates (in some cases, up to $\$ 3,000$ for an EV). Moreover, as the insufficient charging station network is a critical barrier for wide EV adoption, state governments aim to alleviate its negative impact by providing permits. Some US cities including Los Angeles, San Francisco, San Jose, and Oakland already started to take action [138].

\subsubsection{R\&D Incentives}

Loan support for EV and EV components, as well as associated engineering integration costs is another essential part of incentives. Approximately $\$ 2.4$ billion has been given to three firms for their EV manufacturing: Nissan, Tesla, and Fisker [82]. The Advanced Technology Vehicles Manufacturing program retains approximately $\$ 4$ billion in appropriated subsidies to help leverage further loan guarantees. However, unfavorable media coverage of other federal 
clean technology loans has caused governments to increasingly apply more stringent loan terms and larger amounts of required collateral, bringing recent disbursements to a pause [82].

\subsubsection{Renewable Portfolio Standards (RPS)}

Benchmarking and geographically targeting states with the lowest carbon emissions from electricity generation could help focus EV-adoption policy efforts. Policy priorities can largely lean on how each state currently measures up and on which policies it has in place to further reduce carbon emissions from its electricity grid. Electricity supply policies on the demand side include electricity efficiency programs, and on the supply side, clean energy standards, RPS, and energy efficiency resource standards [82].

Governments are keen on producing clean energy and many states have come up with policies that force states to produce a certain percentage of the total electricity from clean energy sources. For example, the state level energy legislation (SB838) for Oregon that was enacted to provide $25 \%$ of electricity from renewable energy by 2025 [136].

Other than Oregon, there are many states who enacted RPS. Database of State Incentives for Renewables \& Efficiency has studied the current RPS incentives and created a US map. It shows different states having RPS goals. 29 States, Washington DC, plus 3 territories already have RPS enacted [139].

This policy coerces companies to abide by a new standard:

“The 2007 Legislature created a renewable portfolio standard (RPS) that requires the largest utilities in Oregon to provide 25 percent of their retail sales of electricity from 
newer, clean, renewable sources of energy by 2025. Smaller utilities have similar, but lesser, obligations. Details on the RPS can be found on this page.” [140].

This policy will likely affect the environmental barrier, Electricity source. Therefore, we included this policy into our initial framework.

\subsubsection{Charging Incentives}

To help mitigate lack of charging infrastructure, the California Plug-in Electric Vehicle Collaborative reported that installation of more than 7500 residential and public recharging stations in California was receiving public support, including 50 public DC fast-charging stations [57].

Residential Energy Tax Credit: This residential credit should be increased and EV owners should be compensated for a certain percentage at the low peak hours. This incentive may be critical in reducing the load on peak hour electricity demand, because electricity usage would increase in the peak hours if charging stations are used. Incentives to encourage EV owners to charge their vehicles during nighttime will expectedly shift the loads to off-peak hours and will likely diminish EV transition's additional burden to on peak electricity demand. To help understand this incentive, the electricity used to charge up the EV can be provided from a separate outlet at a lower rate at off-peak hours.

\subsection{Technology Adoption and Diffusion}

We conducted a literature review on technology adoption and technology diffusion in order to investigate possible barriers that are currently present and may arise in the future. This helped construct a comprehensive framework for the problem. Adoption and diffusion are 
sometimes interchangeably used in the literature although their meanings are different. We studied both the adoption and the diffusion literature to explain both terminologies, and although they are interchangeably used in many studies, we chose to use the term "Technology Adoption" throughout this research to avoid confusion.

The technology diffusion and adoption literature is vast, and it crosses many conventional disciplinary boundaries [141]. Case studies on diffusion are developed regularly in social sciences and humanities, but it is difficult to theorize adoption and diffusion. Katz [142] states that this stems from the so-called "incommensurability" of diffusing items. Their interactions with the cultures, social structures, and media systems in which potential adopters are embedded are complex, and they lack a disciplinary home. There are only a few disciplines that focus explicitly on diffusion issues, and fewer still that perceive its inherent "interdisciplinarity". As a result, the diffusion research is not accumulated in one field, but spilled over to a variety of fields: education, anthropology, medical sociology, marketing, geography, and, most of all, rural sociology [143].

The multi-disciplinarity of this concept has resulted in different terminologies in different fields. We believe it is important to comprehend the terminology well. Adoption refers to the stage in which a technology is selected for use by an individual or an organization, while diffusion refers to the stage in which the technology spreads to general use and application [144]. However, the use of these terms often times is intermingled. Particularly, in the technology adoption literature, multiple terms are used in referring to the same concept: new product diffusion, technology diffusion, and technology adoption. According to many scholars, diffusion theory is not one, well-defined, unified, and comprehensive theory, but rather a large number of 
theories, from a wide variety of disciplines, each focusing on a different element of the innovation process, that creates a meta-theory of diffusion [145]. The scholar who had the most success to synthesize all the significant findings and compelling theories related to diffusion is Everett M. Rogers. Rogers' book, Diffusion of Innovations - first published in 1960 - is the closest any researcher has come to presenting a comprehensive theory of diffusion [146]. He describes diffusion slightly differently from the others. According to his description, diffusion is the process by which an innovation is communicated through certain channels over time among the members of a social system. It is a special type of communication through which the messages are concerned with new ideas [147]. Surry and Farquhar [146] also has a similar description: Diffusion is the process by which an innovation is adopted and gains acceptance by members of a certain community.

Moore [49] opens the first chapter, technology adoption cycle, of his famous book, 'Crossing the Chasm', with these sentences:

"As the revised edition of this book is being written, it is 1998, and for this time we have seen a commercial release of the electric car. General Motors makes one, and Ford and Chrysler are sure to follow. Let's assume the cars work like any other, except they are quieter and better for the environment. Now the question is: When are you going to buy one?"

In the early phases of technology adoption of a new technology - like EV -, what matters to everyone involved is whether the new technology will work, whether it is superior to any other new technologies which might arrive in the near future, whether there is a supply infrastructure available to support adopters, whether buyers will resist products made from the new 
technology, and so on [141]. In order for a wide range of consumers to adopt a product certain conditions must be fulfilled. In other words, diffusion has its own elements, and for a product to be diffused to the stages of general use and application, these elements must be fulfilled. We have studied these elements to create a better framework for our model.

When defining diffusion, it is important to mention communication, which is one of the most important elements, if not the most, of diffusion of new products. Rogers [147] defines communication as a process in which participants create and share information with one another in order to reach a mutual understanding. According to Stamatis [148], communication is a process of convergence or divergence as multiple individuals exchange information to move toward, or apart from each other in the meanings that they ascribe to certain events.

Communication is a critical concept for understanding diffusion. When constructing adoption models, Rogers [143] defines a psychological bias in diffusion research. This psychological bias may be caused by either its historical roots in academe or from the researchers' acceptance of the way social problems are defined. Several early communication scholars coming from psychological backgrounds suffered from this bias, and their models of diffusion largely ignored social-structural variables that affect communication. The transactional and relational nature of human communication tended to be overlooked. This shortcoming was also characteristic of diffusion research, at least until fairly recently.

Another important element of diffusion of new technologies is innovativeness. Rogers [147] following statement gives a better explanation of innovativeness:

"Innovativeness is defined as an idea, practice, or object that is perceived as new by 
an individual or other unit of adoption. It matters little, so far as human behavior is concerned, whether or not an idea is "objectively" new as measured by the lapse of time since its first use or discovery”.

Interpreting what Rogers said, innovation differs from the concept of 'newness'. The newness of an idea or product does not determine the individual's reaction to it, but rather the perceived newness of an idea or product does. An individual may be aware of an idea or product; however, he/she may not necessarily develop an attitude towards it. It should be noted that EV was developed even before ICE, but even over a century later it is perceived as a new technology by people. Here, marketing efforts become significant on converting the individual's attitude toward the idea or product into a decision to adopt. Hence, the perception of newness by individuals takes priority in the marketing efforts. The communication element gains more importance in persuasion of an individual's reaction towards the idea or product. He stresses an important limitation of the adoption/diffusion models. According to the study he conducted in 1976, in about $60 \%$ of all diffusion research, the dependent variable innovativeness is defined as "the degree to which a responding unit is relatively earlier in adopting an innovation than other units in the system" [147]. The independent variables lead to innovativeness, but it is uncertain whether independent variables have direct correlation with innovativeness. In addition to this, another particular problem is yesterday's innovativeness. In most diffusion surveys, innovativeness is measured at the present day, however the collected data is about past adoption behavior. The independent variables that actually belong to past data, are measured in the present tense. Conspicuously, it is not possible for individuals' attitudes, formed and measured now, to cause adoption of an innovation a few years previously [147]. That's why the concept, called yesterday's innovativeness, is significant for 
researchers who interpret technology adoption models.

The origin of diffusion of innovations research stems from two avenues: first the GermanAustrian and the British schools of diffusion in anthropology, and second the French sociologist Tarde [149], who proposed the renown S-shaped diffusion curve and introduced the role of 'opinion leaders' in the process of imitation. However the revolutionary paradigm for diffusion research occurred in the early 1940s when two sociologists, Ryan and Gross [150], published their seminal study of the diffusion of hybrid seed corn among Iowa farmers.

The research on diffusion of innovations was rare until mid $20^{\text {th }}$ century. Between early 50 s to early 60s, just a little over 100 studies in diffusion literature were completed [143]. The year 1960 was, in several respects, a turning point for research on the diffusion of innovations. For one thing, the old disciplinary boundaries began to break down, and diffusion research began to emerge as "a single, integrated body of concepts and generalizations" [151]. The diffusion studies grew very fast in developing countries after 1960. In those years, technology was assumed to be at the heart of development. The number of published studies jumped to 450 after early 1960s [143]. During those years, innovativeness was thought to be the best single indicator of the multi-faceted dimension called "modernization", the individual level equivalent of development at the societal or system level [152]. In 1970s until Rogers published his study in 1976, 1250 more papers were published about diffusion. The following decade added another 1250. Rogers [143] summarized the number of studies in his study as: 2700 publications about the diffusion of innovations, including about 1,800 empirical research reports and 900 other papers. One can notice that the amount of research made since 1940s has increased exponentially. Although diffusion models have had a long history in academia, 
their application in industry is not commensurate with their potential. There have been several successful applications, but there is still much potential left unutilized for increasing the adoption/diffusion for the use of models [153].

Rogers, who is one of the gurus of technology diffusion, discussed four theories that are among the most widely used theories of diffusion: Innovation Decision Process, Individual Innovativeness, Rate of Adoption, and Perceived Attributes [146].

Innovation Decision Process theory: Adopters of a technology progress over time through five stages in the adoption/diffusion process. 1) They must learn about the innovation (knowledge); 2) they must be persuaded of the value of the innovation (persuasion); 3) they then must decide to adopt it decision); 4) the innovation must be implemented implementation); 5) and lastly, the decision must be reaffirmed or rejected confirmation). The focus is on the user or adopter [147].

Individual Innovativeness theory: This theory is about risk takers who will adopt an innovation earlier in the of adoption/diffusion cycle [147].

Rate of Adoption theory: In this theory, diffusion occurs gradually in the initial stages, followed by dramatic and rapid growth, then a gradual stabilization and finally a decline [147].

Perceived Attributes theory: In this theory, innovation is judged by 5 characteristics: that it can be tried out (trialability), that results can be observed (observability), that it has an advantage over other innovations or the present circumstance (relative advantage), that it is not excessively complex to learn or use (complexity), that it is compatible with the circumstances into which it will be adopted (compatibility) [144]. According to this theory, adopters of an innovation have 
to learn about the innovation, be convinced by the merits of the innovation, decide to adopt, implement the innovation, and confirm/reject the decision to adopt the innovation [154].

The "top-down" and "bottom-up" models of adoption/diffusion create a directional perspective to the process. Another theory relates to the scale of innovation efforts by discerning macro-level theories and micro-level theories. Macro-level theories focus on the institution and systemic change initiatives, which is closer to EV adoption. In macro-level theories, innovation contains broad aspects of curriculum and instruction and may include a wide range of technologies and practices. Micro-level theories, however, investigate individual adopters, innovation or a product rather than a large-scale change [144]. Macro-level theories are likely to benefit EV adoption that includes many stakeholders form different fields. Surry and Farquhar [146] refers to Micro and Macro level concepts with different terminology: for Macro, he uses Systemic Change Theories, and for Micro, Product Utilization Theories. They represent the two main philosophies of technology and technological change: Technological Determinism and Technological Instrumentalism. The theoretical background of these two concepts rely on an ongoing philosophical discussion on two historical arguments: One is the problem of determinism vs. voluntarism, also known as the problem of 'free will'. This argument occurs from determinists holding the view that human behavior is caused by forces and conditions that exist independently of, and typically prior to, the behavior of interest. These forces are peripheral to the actors themselves. According to determinants humans are pawns of technological or cultural systems. The other pole of this discourse is the voluntarists. In contrast to determinists, they argue that human behavior is predicated on the choices that actors make. The second argument is between materialists and idealists. Materialists argue that human actions stem from physical contexts such as geography, biology, climate, and 
technology. Whereas, idealists hold that ideas, norms, values, ideologies and beliefs drive human action. These doctrines that caused the two historical arguments often times have led to confusion. Many scholars fail to distinguish between determinism \& materialism, and voluntarism \& idealism. The following explanation by Barley [9] helps discern these two confusing concepts. Idealistic determinists argue that socio-technical trajectories are driven by cultural ideologies. Supporting this fact, Braverman [155] argues that technologies have played a role in the historical degradation of work because that they have often been designed with this objective in mind and, therefore they are manifestations of ideology. On this topic Ellul and Wilkinson [156] argues that Western science and technology are driven by an infatuation with rationality and efficiency. This helps one comprehend that the technology diffusion especially in the West- may occur faster through logical choice of user and the efficiency of the product. Therefore, when technology adoption models are generalized for developing countries, this fact should be considered.

Materialistic voluntarists argue that technologies directly shape human behavior -just like materialistic determinists-, but unlike them they add that because technologies are designed and because designs can be altered, humans can affect the social impact of a technology by redesigning it or refusing to adopt it [156]. This also supports the theory of Moore [102], where he argues new technologies can be adopted by innovators - who adopt new technologies for the sake of their novelty- but can only cross chasm by getting the new technology to a level that it offers a $100 \%$ solution to main stream customers. Idealistic voluntarists argue that technology's effects are rooted in the beliefs and values of designers and contend that one can change the effects of the technology by changing designers' images of users [9]. Orlikowski [157] argued in his study that users shape technology's meaning and its constraints and 
affordances in the process of using the technology.

Hughes studied all these approaches that caused the historical debate and came up with an alternative approach. He used this philosophical background to explain a technological system -rather than only a product-. A technological system comprises of a complex network of cultural, organizational and technological units jointly focused on a particular productive or political goal. Hughes [4] suggests the following examples to explain technological systems: the system for generating, distributing and using electricity or the system surrounding the production and use of automobiles. One can argue that Hughes' philosophical stand is a hybrid approach merging other notions. He argues that human choices and ideologies affect the early life of such systems because the ideology of inventors shapes these technologies, however, as they become institutionalized -in other words reach main stream customers- their development takes their own course as material-determinists believe. Hughes in the abovementioned argument suggests that each approach is valid, but only at a certain phase of the technological adoption. Hughes' approach helped form our model's philosophical basis for three reasons. First, transition to EV will require many stakeholders from various fields to work together. Second, this transition has many overlapping dynamics where infrastructural changes, energy transition and governmental support are necessary. Because of this, EV diffusion is not about adopting a simple technological product, but rather is a technological system change. Finally, technology forecasting scholars argue that EV transition will require policy support only until a certain time, then the EV diffusion will take its own course without being in need of government support anymore.

It is important to investigate deeper into inner dynamics of diffusion. Burkman [158] suggests 
that in diffusion of a new technology, 5 adopter-focused steps should be accounted for: 1) potential adopter identification, 2) measurement of their relevant perceptions, 3) user-friendly product design and development, 4) informing the potential adopter of the product, and 5) support after adoption.

It is also important to study different technology adoption cycles that have been suggested in the literature. Rogers [154] set the fundamentals of the technology adoption cycle. He categorized and labeled adopters into 5 groups according to how they respond to innovations chronologically in the technology adoption cycle, starting from early adopters to laggards. Such distinctions are descriptive and explanatory, but do not provide deep insights into complex adoption processes. Innovativeness -abovementioned- is an important term because it determines the categories of adopters of a technology in terms of the speed of their adoption on the technology adoption cycle. The multi-disciplinarity of the field also affects the selection of the terminology -as it drives various theories of diffusion - when naming the types of adopters in the Technology adoption cycle. Although the concept is the same, there are several titles given to the types of adopters. The first group to adopt a new idea or product is those who perceive the innovation the fastest and they are given different names in the literature. This group sometimes is termed "progressists," "high-triers," "experimentals," "lighthouses," "advance scouts," and "ultraadopters". Similarly, the last consumers to adopt a technology who are the least innovative individuals were called "drones," "parochials," and "diehards" [147]. Rogers is the first scholar to define the adopters comprehensively in terms of their reaction (adopt or to wait) to innovativeness. He categorized five groups on the bell curve as follows: Innovators, Early Adopters, Early Majority, Late Majority and Laggards. This innovation dimension on a timeline where individual adopts a technology is continuous rather 
than discrete. The characteristics of the individuals of these groups are significantly different from each other.

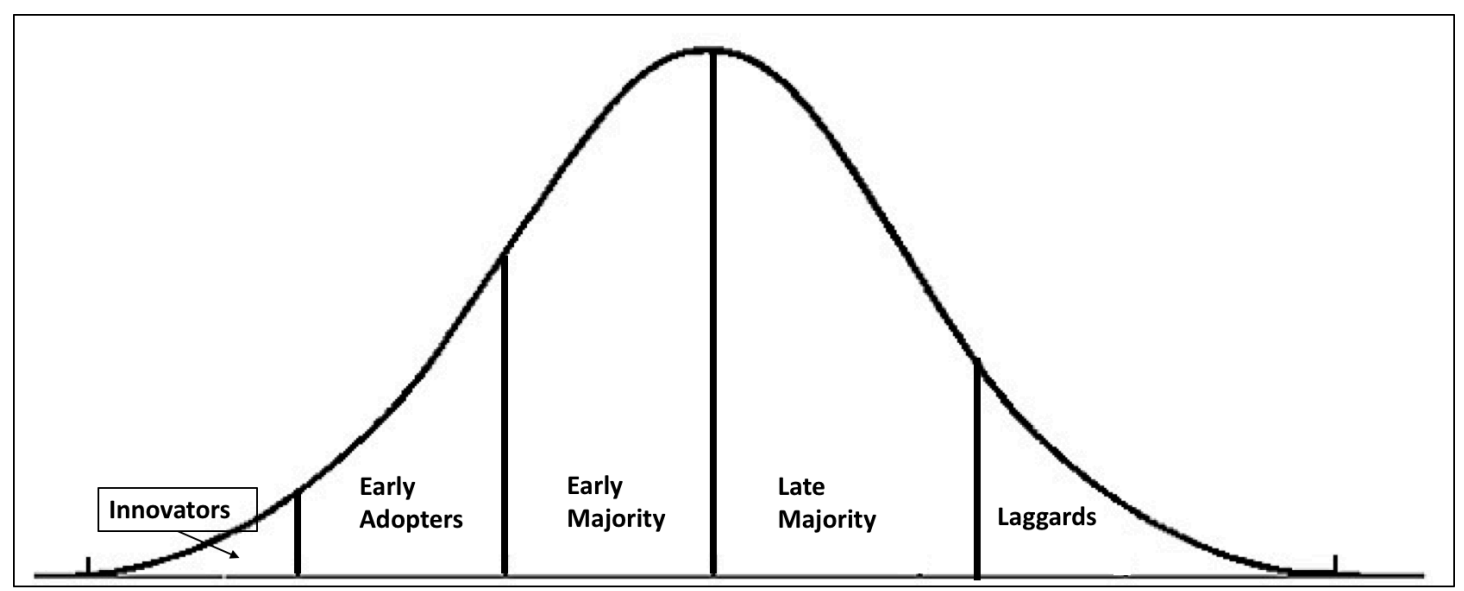

Figure 1. Adopter categorization on the basis of innovativeness - [147]

After Rogers' study, Moore [49] defined a chasm between two of these groups at the early stages of a technology. His theory suggests that most new technologies fail due to not being able to cross this so-called chasm. The primary reason of the chasm stems from the characteristics of these 5 categories. We use their terms interchangeably here to explain why the chasm occurs - the first term is by Rogers, the second term in parenthesis is by Moore-. Rogers' nomenclature consists of 5 categories with respect to their appearance in the timeline, whereas Moore's does by their qualities. Apart from the terminology they used, there are 3 key aspects of the terms: 1) socioeconomic status, 2) personality variables, and 3) communication behavior [49].

Innovators (Technology Enthusiasts): They are risk takers and are eager to try new things. They can deal with high degree of uncertainty about an innovation at the time of adoption. Rogers [147] suggests their ability to try new ideas leads them out of a local circle of peer 
networks and into more cosmopolite social relationships. This may help knowledge to diffuse out of their type of adopters and open communication channels to next phase in the technology adoption cycle.

Early Adopters (Visionaries): Visionaries' goal is a business goal in contrast to Innovators' goal - which is pure technology for innovators - and it also involves a feeling of high recognition and reward. They are probably the least price-sensitive throughout technology adoption cycle. Early adopters are a more integrated part of the local social system than are innovators. Rogers [147] state that their relatively scarce resources mean that most of the uncertainty about the innovation must be mitigated before the late majority feels that it is safe to adopt. The importance of communication at the local and regional level is critical to adoption of innovations. This is discussed more in depth later in this study. Moore's definition of qualities of this group differs from Rogers'. According to him visionaries are in a hurry. They see the future in terms of windows of opportunity. As a result, they are likely to apply deadline pressures to drive the project faster. This leads to the classic weaknesses of entrepreneurs-pursuing the big score and overconfidence or misjudgment in their ability to execute within any given time frame [159]. This leads to shareholders pressure (which also is discussed more in depth in this study).

Early Majority (Pragmatists): The early majority adopts new ideas a little earlier than the average mainstream adopters of a social system. The early majority often engages with their peers, but rarely holds leadership positions. The early majority's unique position between the very early and the relatively late to adopt makes them an important link in the technology adoption process [147]. 
Moore [159] elaborates more on this category by stating that they are mostly "vertically" oriented. They communicate more with others like themselves within their own industry, whereas technology enthusiasts and early adopters communicate "horizontally" across industry boundaries. This means it is very difficult to break into a new industry selling to pragmatists. Carr Jr [144] also states that there is a pressing need for vertical support structure to overcome technophobia. When technology adoption begins, innovators and early adopters may get by on their own initiative due to their strong technology orientation. Members of the early majority, however, are not interested in merely the technology and may display a form of technophobia. Their introduction to the technology should be in accordance with their perceived needs. Their vertical communication helps pragmatists transfer the knowledge to late majority and laggards. This is viewed as the core dynamic of Moore's Chasm theory.

Moore [159] considers 'Chasm' to be caused by this main characteristic difference between pragmatists and technology innovators. Pragmatists are also price-sensitive. Pragmatist adopters like to see competition particularly, and usually purchase from proven market leaders. They would not accept a technology without it reaching a 100\% solution to their needs. This may also be very important when understanding how EV can reach mainstream customers. Lack of EV market leader who can provide a $100 \%$ solution to the market may be a problem when crossing chasm.

Late Majority and Laggards that are the last two categories are the least important in the technology adoption cycle. Due to the stage of EV in the adoption cycle, this study does not focus on them.

They would not accept a technology if it does not provide a $100 \%$ solution to their needs. This 
may also be very important in the case of EV reaching to mainstream customers. Lack of EV market leader who can provide a 100\% solution to the market may be a problem when crossing chasm. Moore stated that each phase of the technology adoption cycle should be focused and passed carefully. Geoghegan stated about during designing diffusion strategies, addressing the differences of needs of early adopter \& early majority might help move a certain technology beyond the innovators and early adopters [160].

When passing these phases, one of the crucial points -among many Moore has listed- is that the visionary executives' expectation: “technology should provide the customer with a concrete return on investment that can be celebrated as a major step forward" [41]. The hurry of the visionary executives may impede the successful handling of this phase. Therefore, one of the additions from the literature review on Technology adoption was that the model should have the shareholders' pressure as a barrier to wide EV adoption. Shareholders' pressure of reaching the mainstream markets fast may push the technology to an early attempt to cross the chasm when the technology is still immature and cannot offer a $100 \%$ solution to the mainstream market adopters.

Adding shareholders' pressure to our model can also be supported by the following statement of Moore [159]:

"Executives and shareholders usually put very high expectations at early stages of a technology, and when there is a lack of revenue they shut down the project or transfer it to other companies for scrap value. The argument here is that "if it is a breakthrough product, then it is not ever going to create an early market. But perhaps it could serve as a supplementary product in an existing mainstream market. If that is indeed the 
case, then the right response is to swallow our pride, reduce our financial expectations, and subordinate ourselves to an existing mainstream-market company, who can put our product in play through its existing channels".

Carr Jr [144] points out the importance of transitioning from Visionaries phase to Pragmatists phase. By emphasizing the need for recognition and process involvement. The likelihood of pragmatic early majority to adopt an innovation will substantially boost if their differences are addressed in terms of their perceptions and needs. They should be recognized as a distinct group within the community and made a part of the planning and policy making process.

\subsection{Technology Adoption and Diffusion Models}

Various diffusion and adoption models have been used in the literature, especially after the 1960s in order to study diffusion trends in the form of mathematical equations [161]. These models have been applied to study various technologies' diffusion including cars, television, computers, consumer goods, etc. Besides technologies they are also used in other areas including frequency of economic booms and busts, number of fatal car accidents, incidence of major nuclear accidents, technological change in the computer industry and number of deaths from AIDS [162-164].

Technology diffusion models primarily originated from the theory of growth of a colony of biological cells in a medium. Limited nutrients and/or space would lead to limited growth of a cell; and therefore, a slowdown, and this would create an S curve pattern. Technology diffusion models assume that the growth of a technology or an innovation is dependent on the total potential adopters, and therefore their rate of growth is assumed to generate an S- 
curve in a similar fashion [165].

It is significant to take a look at how scholars categorize diffusion models. Meade and Islam [161] classify diffusion models as: models for cumulative adoption and non-linear autoregressive models. Mahajan and Peterson [166] define diffusion models in three large categories. Their paper has been cited by many other authors $[165,167,168]$. The three categories are summarized below:

1. Fundamental diffusion models: These models comprise internal, external and mixed influence. They assume that the diffusion process is binary. There is a distinct and constant total potential, and coefficients are constant over time.

2. Flexible diffusion models: In contrast to the fundamental diffusion model, this type of model is relatively flexible with respect to point of inflection or symmetry with respect to point of inflection.

3. Refinements and extensions: In this type of diffusion models, assumptions are modified to develop improved or revised diffusion models, which are classified under subcategories:

- Dynamic diffusion models suggest the maximum technical potential as dynamic and instead of static.

- Multi innovation diffusion models: the innovation is not completely independent of all other innovations, but independent in a functional sense. They serve as complementary, contingent and substitutes for other innovations.

- Space and time diffusion models which assumed primarily that the growth in the number of adoptions in each region would vary and the relative number of 
adoptions would be greater in those regions closest to the regions of innovation origination.

- Multistage diffusion models consider adoption as a multi stage process and rather than binary.

- Multi adoption models capture repeat purchases.

- Diffusion models with influencing/change agents: According to them, diffusion cannot be considered a function of time, but coefficients as a function of technology specific parameters.

There are many application areas of diffusion models. Mahajan and Peterson [166] divide them into three categories: normative, description, and forecasting applications. Mahajan explains the application areas further in another study he conducted 15 years after this study. He states that technology diffusion models have been used to aid strategic decision-making process through the phases of new product introduction to market including prelaunch, launch and post launch. Particularly new technologies where there is high uncertainty benefited from technology diffusion models in timing, pricing, and marketing decisions. An adoption analysis approach by Farquhar and Surry [169] considers the process from a broader perspective from user-perception and organization attributes - yielding a strategy for realizing technology adoption, which is rooted in an organizational context and at the same time addresses issues of user concerns. Product and application design and development are other factors that are affected by this approach.

Adoption theories have also been used for the renewable energy technologies in a few studies. Collantes [170] utilized the technological substitution model on the growth rate of market 
share of fuel cell vehicles. Lund [171] used epidemic diffusion model to study market penetration rates of new energy technologies. Rao and Kishore [172] utilized the Bass model to study diffusion of wind in different States of India by linking it to a policy index. Purohit and Kandpal [173] also used Bass model to research future dissemination of renewable energy technologies based on irrigation water pumping in India. Peter, et al. [174] used Rogers' Model to study marketing solar PV technology in developing countries. Gray [175] conducted a research for the diffusion of 12 public policy innovations among 48 contagious states in the US. However, there are no studies in the technology adoption literature on Electric Vehicles $(\mathrm{EV})$, let alone quantifying the policies and linking barriers to them.

The following section includes specific Technology Adoption and Diffusion Models that have been studied in the literature.

\subsubsection{Classical Model}

The classical diffusion model dominated the thinking of scholars, policy makers, and change agencies for decades. In this model, an innovation originates from some expert source, which diffuses the innovation as a uniform package to potential adopters who accept or reject innovation. The individual adopter of the innovation is a passive accepter [154]. This classical model gained popularity due to its nature that fits well to agricultural extension services. The basic paradigm for diffusion research spread from Ryan and Gross [150] famous hybrid corn study. This study is one of the most important innovations in mid-western agriculture. Data were gathered by personal interviews with all the Iowa farmers in two communities. The rate of adoption of the agricultural innovation followed an S-shaped curve when plotted on a cumulative basis over time. The first farmers to adopt were more cosmopolite - cosmopolite 
here refers to farmers who traveled more often - and of higher socioeconomic status than later adopters [143]. The study was made in the US where most of the agricultural diffusion is centralized where key decisions - which, to whom, how - are made about innovations to diffuse by experts. Nonetheless, most diffusion systems other than agriculture, according to Rogers [154], are still centralized.

There are four primary elements in the "classical model" of the diffusion of emerging new ideas: First is innovation defined as an idea, practice, or object perceived as new by an adopter. Second is communication, which is carried out through certain channels. Third is time which communication requires, and finally members of a social system, which communication is carried through [143]. We can generalize these findings as; 1) unit of adoption, 2) communication channels, 3) Time, 4) Social System. Diffusion research studies interaction of major factors, and a multitude of other factors, that facilitates or impedes the adoption of a specific product or technology among adopter groups [152].

\subsubsection{Bass Model}

As the diffusion processes are influenced by many decision variables, a generalized Bass model was developed. The analytical and empirical evidence for the existence of the S-shaped pattern to represent the first purchase growth of a new durable product in marketing was first presented by Fisher and Pry [176]. The simple Bass model is a mixed influence model with three parameters $\mathrm{p}, \mathrm{q}$ and $\mathrm{m}$. Among these parameters; $\mathrm{p}$ represents the coefficient of innovation, $\mathrm{q}$ is the coefficient of imitation and $\mathrm{m}$ is the total potential. Bass [177] records in his study that Bass model has been utilized in hundreds of applications. The use of these applications can be classified under three categories including study of general spread of new 
technology, examine pricing as a diffusion variable and forecasting. The first use of technology adoption models is related to our study in determining the barriers to EV adoption. He also utilized the first use of application in two of his studies dated at 1969, and 2004 [177, 178]. The first study focused on consumer products, and in the latter study he utilized the mixed influential model in understanding the general spread of satellite TV, radio, LCD projector, wireless phones and Internet phones technologies.

\subsubsection{Information Cascades}

"An Information cascade is a situation where each person makes a decision/choice based on the observations or choices of others while ignoring his own personal information" [179, 180]. A cascade occurs when people leave their own information for inferences based on earlier people's actions [181]. Geroski [141] explains Information cascades with an analogy of a bandwagon that is likely to develop, with latter adopters making the similar choices as former adopters bypassing learning by experience. If early users are reluctant to move first, that may delay the adoption bandwagon. Therefore, this model focuses more on the early adopters phase. However, there are three phases in a diffusion process driven by information cascades: 1) the first choice between alternative technologies - given example of A and B -, 2) the lockin to selected technology - A - 3) the bandwagon induced by imitation. Here, the network externalities can cause either the -abovementioned-lock-in effect, or a risk creating effect, which can delay diffusion. Through Information Cascades models, incentives to invest in information and network externalities can be used to help explain the lock-in to the first technology alternative -A-, however they are not comprehensive enough to explain EV adoption. One reason why A might be chosen is that it appears on the market before $\mathrm{B}$, and the expectations of early users at that time are that B is just not worth waiting for. That may 
explain the bandwagon effect after (A) being chosen. Once a choice is made by adopters, the lock-in occurs, and the early uncertainty is likely to fade away, and the subsequent dynamics of the system driven by an information cascade will look much more deterministic. In information cascades, - unlike the probit model that will be mentioned in the next sectionthe nature of the externalities, which drive diffusion when information cascades are present, means that the most important users are the first users. Without them there to start the bandwagon, not much happens at all [141].

\subsubsection{Epidemic Model}

Like many other scholars of technology adoption, Geroski [141] stated that the usage of new technologies typically follows an S-curve over time. The most common model that is accounted for S-curves is the epidemic model, which builds on the presumption that what limits the speed of usage is the lack of information available to the new technology.

Sarkar [182] suggests that the primary objective of the diffusion literature since the fifties has been to identify the presence of empirical regularities in the diffusion process and to explain in theory existing regularities as functions of different socio-economics factors at the macro and micro levels. Epidemic models are established on the differences in the goals, capabilities or actions of individual members of the population in order to evaluate diffusion of information in a simple, tractable, non-strategic setting [141].

There is a certain distinction between diffusion of technology and the diffusion of information. Technology adoption usually takes an order of magnitude far longer than it takes for information to spread. The scholars in the literature therefore define hardware and the software separately. According to Rogers, the hardware is the physical objects that embody 
the technology, whereas the software is the information base that enables the effective use of hardware. A certain level of information can be transmitted impersonally through written material, however, most information for a particular technology underlie in the experience of using it, and at least some of that valuable knowledge will be tacit. Hence, ideally it should be transmitted by word of mouth, and spreading from a common source is not as influential. In order to convey software knowledge, future adopters should communicate directly with current adopters who have acquired knowledge and experience with the new technology. This situation explains that epidemic models work best where software knowledge often spreads by person-to-person process where the primary source of information is previous adopters. However, for EV this may not be the case. EV diffusion is not merely adoption of a product, but rather it is a systematic transition of many components affecting government politics, energy systems, dynamics of economy, and finally infrastructural changes. Epidemic model's core, word of mouth, may be too simple to explain this transition.

Epidemic models have been criticized by many economists due to their weak theoretical foundations and restrictive assumptions [182]. This type of model generates an S-curve, however, it cannot be used for technologies that struggled the diffusion process - information diffusion, they cannot date the diffusion of an innovation back to when it is invented, but only can date it to the time when some number of early users have begun using it [141]. Particularly EV has been available for over a century -since its first invention is 1878 - one cannot explain what barriers have impeded the EV diffusion.

A useful information that we can acquire from this model's explanation regarding technology diffusion is the fact that diffusion tends to be faster for simpler technologies where adopters 
can easily learn and spread software knowledge easily, and especially in densely populated regions such as metropolitan areas that interaction and mixing is common [141]. Although EV is a relatively complex technology, due to external reasons such as air pollution, the demand has been higher for EV in the metropolitan areas in the US.

Reviewing diffusion models' literature, we borrowed the concept of "information superhighways" from economists and sociologists. This concept suggests knowledge flows are often regional. This is consistent with the word of mouth process that is explained under epidemic models and suggests that the speed of diffusion depends on how fast knowledge flows between different geographical regions. However, today the dynamics of information diffusion should be studied more in depth since the communication channels have changed drastically in the past decade. Today, social media, Internet, and other marketing channels have equal -if not more- importance as the regional word of mouth. Explaining this further with an example in EV field, due to various reasons it has been illegal to sell Tesla EV in Texas is [183]. Yet, there are many Teslas on Texas roads, -purchased in other states and then brought to Texas. This indicates that word of mouth at a regional level is not the only channel. According to media;

"Despite the legislative defeat, Tesla still manages to operate two stores (in Houston and Austin), three service centers (Dallas, Houston, and Austin), and three Superchargers in the state. They've also sold nearly a thousand cars to Texans. And it's all technically legal." [184]

It is also important to remind the fact that these figures are of 2013. One should expect to see more and more cars in Texas despite the ban. 
Another drawback of the Epidemic model is that it takes the potential users of a new technology and probability of them contacting new non-users of the new technology as fixed. The non-users who are contacted by users may decline over time due to number of reasons including users may become increasingly resistant to word of mouth communication, and late adopters may simply be less able to understand the new technology than early adopters [141].

\subsubsection{Probit Models}

When diffusion is thought as a social phenomenon, it involves many people making choices, often in an interdependent manner, and there are no basic reference points. When decisionmaking is on their plate, adopters try to think before they act and this can be a very slow and unpredictable process for some of them. Hence, sometimes it takes a long period of time for new technologies to be adopted by those who seem most likely to benefit from their use. The question of why things diffuse slowly may become very focused on a single stylized fact about that slowness, in other words, the time path of usage usually follows an S-curve: diffusion rates first rise and then fall over time, leading to a period of relatively rapid adoption sandwiched between an early period of slow take up and a late period of slow approach to satiation.

Probit model belongs to neoclassical equilibrium approach. Karshenas and Stoneman [185] used probit models in their paper that studied epidemic effects in the diffusion of new process technologies. The reason all potential adopters do not simultaneously decide to adopt is that, at any moment, the critical level to bring forth adoption is not a unique value that is acceptable to all members of the population [182]. Karshenas and Stoneman [185] explains comments on this as "Instead, the critical value is distributed heterogeneously across the population according to some density function, and adopters can be ranked in terms of the benefits to be 
obtained from the new technology. It is because of the 'ranking' dimension that probit models are also called 'rank effects' models'.

Probit models enable generating firm specific potential determinants of diffusion speeds. The fact that they further identify observable factors that set off an adoption decision enables to identify a number of levers that policy makers can use to accelerate the diffusion of products, processes or technologies [141].

Economists use probit models since these models more likely study individual decisionmaking. However, they are less transparent than population models in explaining communication that occur between individuals. The availability of information to potential users are exogenously driven in probit models; whereas in epidemic models a true endogeneity of this phenomenon occurs. If diffusion is a social process that is something more than the sum of its parts, which is the case for EV adoption, then the probit model appears to be not fit to comprehensively encompass all aspects [141].

A number of authors have analyzed the mechanics of diffusion using the probit approach. Davies [186] utilizing probit model, observed 8 out of 22 diffusion processes indicated a positive trend on the technology adoption cycle, and seven were symmetric. Dixon [187] extended the original data on the diffusion of hybrid seed corn and found that an asymmetric model like the Gompertz fitted the data better than the logistic model in 27 of the 31 US states examined.

When it comes to comparing probit models as individual adoption model, there is not much choice between population and probit models. There are no drivers of diffusion, which are 
present in population models that cannot be addressed in probit form. Therefore, one can argue that there is not much difference between these models. It is also important to note that, as new technologies continue to be adopted, a second set of forces hinders diffusion in the market. To explain this phenomenon, as more firms use the new technology, competition for the goods or services triggers decrease of returns earned by early adopters. This decrease returns that non-users can expect if they adopt. Altogether, this slows down diffusion rates and ultimately may impede the whole process [141]. Probit models provide a simple insight to market dynamics but they are too simple to explain the whole story on their own. The incentive structures are more complicated, and they require robust plan and strategy to cope with internal and external pressures. Consequently, these models are not considered candidates for our research.

\subsubsection{S-Curves}

If diffusion of technology models study anything more than adoption of a product, it is highly likely that they may involve many people making choices, often in an interdependent manner, and there are no basic reference points. Diffusion is slow at certain points because adoption of technologies usually follows an S-curve: diffusion rates first follow a slow and steady rate, then increase as they cross the chasm, immediately after an early period of slow take up they are utilized by the mainstream customer, and finally it ends up with to a late period of slow approach to satiation. Barley [9] comes up with a measure of the diffusion of five technologies with which most scholars are in agreement to have transformed society: the automobile and telephone, then about 50 years later radio and television and finally the symbol of contemporary technological change, the PC. He uses the S-curve for diffusion of all of these inventions. The plots appear to confirm popular perceptions of an increasing pace of 
technological change: the curves indicate that the lag between invention and significant diffusion was shorter for the personal computer than for prior technologies. Most technological diffusion can be explained by an S-curve however; one rarely encounters symmetric S-curves in the actual diffusion of new technology. Virtually in all cases, the later stages of diffusion occur much slower than what was initially predicted by a symmetric Scurve. Asymmetry generally occurs in heterogeneous populations and when diffusion involves progressively slower diffusion population groups.

Scholars from different fields have used S-curves to explain new product, process or technology diffusion, but there are many examples of new technology that they fail before having an actual S-curve. Needless to mention, only successful innovations have an S-curve. However, it is still important to point out that S-curves cannot be used to explain unsuccessful attempts of new technology entrants in the market. As a matter of fact most innovations fail before being diffused whatsoever, and it seems reasonable to insist that any serious model of diffusion ought to include failure as a possible outcome [141].

\subsubsection{Exogenous Drivers}

One needs to understand the adoption factors and types of drivers in technology adoption models in order to optimally utilize them. Especially, the exogenous drivers are essential to understand technology adoption.

Suppliers is one of the most important exogenous drivers. Suppliers are means that facilitate the information flow of the new technology. Their pricing and servicing policies have direct influence on the overall cost of new technology acquisition. They have also a decisive role in having a successful, rapid technology adoption or else a failure. They are critical to the 
competition between the entrenched and the disruptive technology. The new and disruptive technology does not tend to reach the market in its complete final form, hence technological expectations substantially influence technology adoption. Considering this, we include technical barriers, and the technology perception barriers - under social barriers - in our model.

Cost is another exogenous driver of diffusion. Those who come to probit models from the literature on epidemics will naturally focus in the first instance on learning and search costs. We include both initial costs and battery cost in our model.

Another exogenous driver is competition. Literature suggests that firms are often not fast enough to adopt new technologies especially if entry barriers are high, therefore competition from entrants may accelerate adoption. "The degree of competition is likely to be endogenous to the process of diffusion" [188]. As diffusion progresses, the nature of competition also changes. At first stages, competition is only between the entrenched technology and different variants of the disruptive technology. However, as disruptive technology is recognized and adopted by early adopters, competition changes its course and switches to being among the variants of new technology that is available on the market. Competition may speed up adoption, but perceived competition by the adopters and non-adopters depend on the rate of diffusion, which has already occurred up to that time [141]. The competition between the old and the new technology will most likely affect the EV adoption at this point, since one cannot claim that EV has been legitimized. Therefore, our model includes political factors including Entrenched technology resistance. 


\subsubsection{Technology Adoption Models and Technology Adoption Policy}

The adoption of renewable energy technologies (RETs) is prompted by policies and incentives due to their attributes including high upfront costs, lack of level playing field but distinct advantages from energy security, environmental and social considerations. Even after 30 years of promotion, most of their potential has yet to be achieved. The theory of diffusion modeling paves the way for analysis of diffusion processes and study of growth rates of different technologies and underlying diffusion factors. Majority of diffusion analysis for RETs have been based on RET barriers, and moreover techno-economic, learning and experience curve approaches [165]. These diffusion models do not deal with the issues of policy influences critical to RET diffusion - when applied to commercial products. However, for the case of EV, that may be different. Virtually all EV models including Tesla, Nissan Leaf, Chevy Volt, are commercial products, and EV adoption is based entirely on energy transition when considered entirely. Policies drive RETs, therefore diffusion models for RETs should allow establishing explicit relationships between the diffusion parameters and policies and their impact on diffusion rates. There is not much difference between the new technology development phase and the spreading usage of existing technology phase of the diffusion process. Consequently, there is generally not a clear-cut distinction between technology policies design for new technologies and increasing usage of existing technologies [141].

Diffusion of environmentally sound technologies is essential to realize sustainable development goals. The diffusion rates are context specific - dependent on socioeconomic, technological, and institutional factors. These factors that facilitate or hinder diffusion and drive the process are interlinked, making diffusion a more complex phenomenon [189]. As abovementioned in the theories section, we will take Hughes' philosophy of diffusion theory 
suggests that human choices and ideologies affect the early life of complex technological systems because the ideology of inventors shape these technologies. Jacobson \& Johnson [190] help us explain how the diffusion process can be influenced. They suggest that technological system perspective is most suitable for study of renewable energy technologies and apply an analytical framework based on three agents: 1) creating a knowledge base, 2) institutional changes, and 3) prime movers who are the key actors in the creation of new technological systems that could influence the diffusion process of renewable energy technology. Moore [102] holds that at the transition process between the visionaries' phase to pragmatists, there is a need for market leaders since pragmatists prefer superior product in terms of cost and engineering solution. Using the input of all these scholars, one can argue that there should be prime movers for successful technology diffusion, and these prime movers should be targeted in the policy making in order to influence the technology diffusion positively.

Another important study in the literature is by Reddy and Painuly [191], which collected information by interviewing stakeholders -including organizations, manufacturers, policy makers and individuals- on factors influencing the rate of penetration of renewable energy technologies. The authors confirmed one more time through their study that policies have a strong influence on technology diffusion.

However, not all policies impact positively; and the policy influence diminishes due to policy changes and the uncertainty of compliance period. Utilizing Roger's theory, Tsoutsos and Stamboulis [192] recognized the interaction of technological, social and organizational elements require a policy that will enhance supply, more importantly, the demand. The pattern of diffusion of the new paradigm they came up with requires the attention of policy makers. 
This shows that these theories need a more robust model indicating the critical diffusion elements. Therefore, quantifying barriers to EV adoption, which is one of our study's output, will be a tangible input for policy makers. According to Rao and Kishore [165], the projectbased measures fail to account for two dynamic aspects: first, the need for technological choice and regulation to exploit the role and the experience of users; and secondly the multiple economic impact of the mass diffusion of RETs, initially in the construction and service sectors of the economy. Particularly the first dynamic is crucial according to Moore as mentioned above. There is a pressing need for alternatives in the new technology to be adopted by pragmatists.

The epidemic model aforementioned is built on the assumption that diffusion happens too slowly, primarily because information diffuses slowly amongst potential adopters. Geroski [141] holds that policy makers might become the common source by promoting word of mouth communication or subsidizing the externalities involved with it. They may also try to identify key actors and try to support and motivate them. If the key actors turn out to be users or suppliers - as described in the external drivers' part -, subsidies may shower them or policy makers may hold forums where all stakeholders gather and communicate. As a result of all these, diffusion can be defined as a problem which public policy can remedy with a judicious mix of information provision and subsidies. He also mentions that probit model shuts down many policy options. If the problem really roots within firms, then what public policy makers can do is very limited to other than running the firms themselves. He argues that policies can extract opportunities to surface and to exploit them more, however there is no policy that can actually force them to act when they do not wish to [141]. Today, we know that California Standards have been adopted by many states and they indirectly dictate on manufacturers to 
manufacture zero emission vehicles.

Scholars argue that competition generally stimulates diffusion, but too much competition may slow down diffusion for one of the following reasons: first, because the population of users becomes too dense, it lowers the returns to adoption, second, because it muddles the initial choice between alternatives [141]. This factor, in a sense, has been tackled by a tax policy of government affecting manufacturers which manufacture over $200,000 \mathrm{EV}$. This means only larger manufacturers initially fully exploit the economic incentives and better position their models within the technology adoption phases. Policies are tools used to stimulate diffusion, but some of them are indirectly associated with diffusion process. This stresses more the importance of our research, which identifies what policies are most effective in terms of mitigating the barriers to EV adoption.

The comments on epidemic and probit models suggest that there is only a limited window in which policy can have important effects, and that is during the choice process.

Geroski [141] suggests that:

"public procurement is, in principle, a powerful tool of technology policy. Governments are very heavy users of new technologies, and they are often large, well informed and rather insensitive to price".

This makes them important potential agents in the band-wagon process, particularly when they insist that technology developments associated with their purchases are put in the public domain. 
Perhaps more fundamentally, legitimation and information cascade models of diffusion challenge the basis of the commonly made distinction between technology policies which are oriented towards the generate of new technology and those which are oriented towards diffusion. This distinction is sometimes used to make a helpful point that technology policy can be more than just a matter of shoveling funds into big science projects or uncritically supporting high tech defense spending.

\subsection{Technology Adoption Methodologies}

This section is dedicated to investigate the technology adoption methodologies for our research.

\subsubsection{Forecasting Methods (Bass, Gompertz \& Pearl)}

There are limited examples of the usage of Gompertz on technology adoption analysis. Dasgupta, et al. [193] test the impact of policy and urbanization by using Gompertz. In this

study, authors use an urban population model in order to test the hypothesis that network economies lead to fast growth of internet intensity in urbanized societies. The study uses internet subscribers, size of urban population, income per capita, vector of regional dummy variables and then add index of competition policy into the equation.

\subsubsection{Simulations}

Simulation is one of the methodologies in understanding technology adoption of new products. It can be used in wide range studies including military, manufacturing, queuing theory, and policies. The individual decision-making is typically aggregated at the regional or 
sector level for simulation models that evaluate policy options [194]. Discrete simulations usually model a discrete sequence of events in time.

Each event occurs at an instant in time and marks a change of state in the system [195]. In discrete simulations, it is assumed that there is no change in a system between consecutive events.

Continuous simulations, continuously track the system over time, where time is sliced into small chunks and the system is updated based on the set of activities that occur in the time slice [196]. Forrester [197] work on system dynamics suggests the use of continuous simulations, which is mentioned in the next section.

\subsubsection{System Dynamics}

System dynamics is a computer-aided approach to policy analysis and policy design. This approach, which is rooted in engineering and management fields, is used in order to understand complex social systems. Before it evolved into System Dynamics, Jay W. Forrester [197] established this concept under Industrial Dynamics where he studied the influence of feedback concepts on social and economic systems. In order to understand interrelated dynamics of company success, he pointed out the link between 5 flow systems: flows of information, materials, manpower, capital equipment and money. He argued that these flow systems are means to anticipate the effect of decisions, policies and organizational structure. He suggested to borrow the simulation tools from military and apply them in business to understand the interaction between the flow systems and corporate policy design [197]. A decade later Forrester [198] continued his focus on understanding the polarity of the feedback loops and how it influenced management and economics. 
It is based on the loop concept of underlying feedback and circular causality. Circular causality, which is also called pseudofeedback, refers to mutual interactions of causes and consequences, where the impact of an event indirectly affects the original itself through one or more intermediate events. If we explain this concept with respect to our study, manufacturing more EVs will require more charging stations, and opening up more charging stations will help reduce the risk factor and encourage buyers to buy more EVs. As petroleum and its related technologies evolved over time on the same loop concept, EV will follow a similar fashion.

System dynamics apply to dynamic problems that change over time, particularly that are complex including social managerial, economic systems. The interdependency of these systems lead to mutual interaction, therefore paves the way to abovementioned circular causality [199].

Richardson [199] argues that in daily lifelong experience, people perceive discrete events and make discrete decisions. However, Forrester [197] argues that a continuous view helps focus on significant aspects of dynamic social systems. Languages such as Ndtran, Dynamo and Dysmap are used for system simulations [200-202]. Other than these simulations, a MACbased application Stella is one of the most potent and popular simulation tools that is available [203].

Discrete-Continuous simulations have been used in several studies across various fields. Majority of these studies lie in Operations Research. Sáenz, et al. [204] used it for utility resource planning and optimization. There are multiple applications of discrete-continuous simulations in supply chain field. These examples comprise mostly designing, evaluating and optimizing supply chains [205]. Stroboscobe as a discrete simulation tool has been used in the 
literature in construction field [206], and Puri [207] utilized discrete event simulation for construction operations. Homer [208] used it for the analysis of the emergence of new medical technologies. Paich and Sterman [209] studied it with a narrower focus, on particular behavior aspects. They sought answers for subjects that improve on average but fail to gain insight into the dynamics of the system.

There are several examples of system dynamics being used for policy exploration and analysis. A micro analytic simulation is utilized for policy exploration that simulates changes on government policy or human behavior. In the study of Orcutt, et al. [210], the relationship of population growth and economics is studied through simulations. The abovementioned study of Berger [194] applied simulations in agricultural technology diffusion. Madoma [211] used system dynamics perspective in order to understand the relationship between auto pollution policy and the vehicle population. Vasarhelyi [212] used system dynamics to assess potential economic consequences of new accounting policies. Mohapatra [213] built on Forrester's work by investigating how to deal with the problem of realistic policy decisions' design in a Multistage production inventory system. He tested two different kinds of realistic policy decisions and compared the results with Forrester's ID simulation study. Bassi [214] completed his doctoral thesis on energy policy support by system dynamics methodology. He simulated 5 cases on various energy and climate policy options, revealed the potential unexpected side effects. Another contribution of his was to determine elements of policy resistance over the medium and longer term, due to the interrelations existing between energy and society, economy and environment. Hines and House [215] used system dynamics methodology in a slightly different angle. They studied the origins of poor policy in organizations. Their study focuses on two potential failure modes before policy design 
including 1) learning drift, and 2) premature consensus. The former describes the phenomenon when people learn without improving; the latter describes the process where managers have a consensus on a certain policy or policies before the best/most effective one emerged. The study investigates organizational level rather than governmental; however, it includes beneficial information for optimum policy making particularly with new products that are introduced to markets.

In 1980s most of system dynamics work were generally used in macro-economic field [216]. There are also other studies where system dynamics methodology is mapped to diffusion of innovations [217]. Milling coupled system dynamics with decision support systems. Maier [218] explained new product diffusion models in management with a system dynamics perspective. He explained the effect of adopters' demand on sales and market potential through feedback loops. In order to understand the interdependent relationship between adopters' behavior and sales, Maier separated the demand into two: innovative demand and imitative demand.

\subsubsection{Delphi}

"Delphi is a structured communication method, originally developed as a systematic, interactive forecasting method that relies on a panel of experts" [219]. This technique, that is used for obtaining, exchanging, and developing informed opinion about future event, was developed in 1948 by researchers at the RAND Corporation, and just like simulations, it was initially built for military purposes [220]. It is used for eliciting expert judgments where the experts are anonymous. The experts may or may not converge to a consensus. A typical output of Delphi is a range of emerging technologies and dates of their availability. 
Delphi has been used as a decision-making tool for various fields including technology selection and technology adoption. Daim, et al. [221] have touched upon Delphi as a methodology among many other methods in forecasting emerging technologies.

An aspect of Delphi has been criticized by Ayres [222] is that it more likely pushes experts to find a consensus. Disagreement among different panels is a useful output of research on EV adoption, since multiple stakeholders' perception on EV barriers and effective policies to mitigate them may differ, and it is important to document whether they are in agreement or not. The dynamics of Delphi prevent this disagreement to fully come to surface, and the stronger opinion may suppress the weaker opinion in many situations. Ideally, one would not want some experts to influence others' opinion for a highly uncertain technology.

Ewton [223] studied assessment of the impacts of e-commerce technologies on business processes. She coupled Delphi with HDM by using Delphi to identify initial e-commerce technologies, then HDM to quantify expert judgments. Gerdsri [224] studied roadmapping of emerging technologies by combining Delphi and HDM. His model comprised the concepts of technology forecasting, identification, assessment, evaluation, and selection. The Delphi method in his dissertation was used to generate strategic information on emerging technology development for estimating the introduction date and characteristics of emerging technologies.

Adler and Ziglio [225] gave several applications of Delphi to applications for Social Policy and Public Health. Lempert [226] discussed Delphi as a method for long-term Policy planning. Jillson [227] used Policy Delphi to explore national drug-abuse policy options for the next five years. Turoff $[228,229]$ wrote a number of articles on the use of Delphi with Policy analysis. 
He suggests in his book that among Delphi's intended use are 1) to delineate the pros and cons associated with potential policy options, and 2) developing causal relationships in complex economic or social phenomena [230].

\subsubsection{Scenario Planning}

Scenario planning is one of the tools, originated from strategic planning, particularly in the military area, and used in countless other fields. It is useful for identifying basic trends and uncertainties to help avoid overconfidence and tunnel vision, which are the most common mistakes in decision making process [231]. Scenario planning defines possible outcomes of various actions. The actions are varied one-by-one or in combination with each other to determine the changes in the outcomes.

Like all methodologies there are some limitations to scenario planning. Knowing the limitations of the tool helps one to decide if the use is right or not. Schoemaker [231] discusses this by classifying future knowledge into 3: 1) Things we know we know, 2) Things we know we do not know, 3) Things we do not know we do not know. Scenario planning becomes a very handy tool in Type 2 future information, however, the main challenge lies in converting Type 3 future information into Type 2 future information [232]. According to Lempert [226], scenario planning can crystallize the understanding that the long-term future may be different than present, and therefore help decision-makers choose among various strategies.

There are some examples of scenario-planning use with policy analysis. McCollum and Yang [233] utilized scenarios to "envision how such a significant decarbonization might be achieved through the application of advanced vehicle technologies and fuels, and various options for behavioral change". This study does not compare any policy options, but brings forth multiple 
scenarios for GHG reduction to help policymakers. Groves and Lempert [38] used policy relevant scenarios for long-term water planning in California. Bryan, et al. [234] used computer-based scenario planning to assess environmental, economic, and social impacts associated with achieving environmental targets on a landscape scale. The INTERAX (Interactive Cross-Impact Simulation), a scenario analysis methodology, facilitates both analytical models and human analysts to develop better understanding of alternative future environments. It generates scenarios one year at a time specific to policy makers' needs, so they can interact with each scenario in order to experiment the policy options. It is mostly utilized for corporate use, specifically to prepare income statement and balance sheet forecasts [235]. Volkery and Ribeiro [236] use scenario planning in public policy using environmental relevant policies as a case study.

\subsubsection{Multivariate Statistical Analysis}

Multivariate statistical analysis focuses on analyzing and understanding data in high dimensions [237]. The description of the tool from the classic book of Muirhead [238]:

"Multivariate statistical analysis is concerned with data that consists of sets of measurements on a number of individuals or objects."

Mukhopadhyay [239] suggests that many multivariate techniques are based on a probability model, known as multivariate normal distribution or a combination of these distributions. This methodology is generally used with surveys and/or historic data in order to identify relationships among policies and their outcome, however works on the premise of large amount of available data. There are not any examples in the literature that use Multivariate statistical analysis for policy assessment. 


\subsubsection{Data Envelopment Analysis (DEA)}

"DEA is a data oriented approach for evaluating the performance of a set of peer entities called decision making units" [240]. As it is apparent in the description of the tool, it is highly dependent on historic data. There are only a limited number of studies in the literature that utilize DEA for policy assessment. Cherchye [241] used it for assessing macroeconomic policy performance. Rather than assessing policy options, this study assesses policy performance of various countries. Karkazis and Thanassoulis [242] used DEA in a similar manner, assessing the effectiveness of public investment in infrastructure and investment incentives in various regions of Northern Greece. Rather than assessing the effectiveness of different policy options, the author assessed the performance of the existing development policies on different regions of Greece whether they attract private investment or not. There are no examples of DEA being used for assessing different policy options in the literature.

\subsubsection{Cognitive Mapping}

Cognitive maps have been studied in a number of fields including psychology, education, archaeology, planning, geography, cartography, architecture, landscape architecture, urban planning, management and history [243]. Perusich [244] used fuzzy cognitive maps for policy analysis. His study evaluated the changes in the state of affairs of a system given an initial state and gave guidelines for policy analysis on a limited scale. Eden and Ackermann [245] used analytical software, Decision Explorer, to experiment some aspects of the methodology in the public policy field and to identify any changes required to the approach to improve its applicability for policy options. The public prison system is used for the policy analysis in their paper. Hart [246] 'Cognitive maps of three Latin American policy makers' gives some insight into how cognitive maps can be used to predict how individuals make future policies. 


\subsubsection{Multi-criteria Decision Models (MCDM) and Multi-Criteria Utility Theory (MAUT)}

In its early years, MAUT applications studied public sector decisions and public policy issues. These decisions not only had multiple objectives, they also often involved multiple constituencies that would be affected in different ways by the decision [247]. Keeney [248], a pioneer in this field, has conducted a number of studies. In his early years he examined corporate policy using MAUT analysis. In one of his studies, he constructed an adaptive framework to help guide comparative analysis of climate change policies in order to help governments make wise policy choices [249]. Keeney, et al. [250] studied how to elicit public values for complex policy decisions. They combined elements of focus groups and direct MAUT techniques for setting long term energy policies. In his book in 1975, Keeney [251] used MAUT on specific set, energy policies, to address the tradeoff issues invariably present in selecting energy policy. Finally Keeney [252] wrote on framing public policy decisions, where he streamlined a structured process that is outlined to elicit and measure the consequences, which will be used to evaluate alternatives and identify the best ones. The foundation is the public values that are used to frame the policy decision. Keeney [251] Keeney, et al. [250] Keeney [252] Keeney and McDaniels [249]

\subsubsection{Hierarchical Models}

Hierarchical models analyze complex problems holistically by disaggregating strategic issues and then re-aggregating them. Available data are combined with quantified expert judgments, obtained by pairwise comparisons of the decision elements. 
AHP (Analytic Hierarchy Process) was introduced by Saaty [253] in early seventies, and has been widely used since then. It uses a nine-point scale for pairwise comparisons, and eigenvalues and eigenvectors for the quantification of expert judgments.

HDM is a variant of AHP. Kocaoglu [254] defines six components of HDM as follows.

1. HDM-JQ (Judgment Quantification): Expert judgments are quantified using a series of matrices based on Guilford's Constant Sum Analysis [255]. Inputs are the pairwise comparison values obtained from the experts using any of three methods [254]:

a) Constant Sum (CS): A total of 100 points is allocated to the two elements of the pair in the same proportion of the subjective values assigned to them by the expert, such as 20 vs. 80,45 vs. 55 , etc.

b) Direct Ratio (DR): One element of the pair is given the value of 1; the other element is assigned a value as a multiple of the first one, such as 1.8 vs. 1 , or 21.4 vs. 1 , etc.

c) Absolute Value (AV): If the actual values of the two elements are known, they are assigned to the elements, such as 15,000 vs. 64,000 , etc.

2. HDM-CA (Consistency Analysis): The values of n decision elements considered in pairwise comparisons are calculated in n! orientations (ABCDE, ACBDE, ADCBE, etc.). This results in $n$ ! values for each element. The relative value of each element is defined as the mean of the $n$ ! values; and the variance in the $n$ ! values is used for the calculation of the inconsistency of the expert providing the pairwise comparisons. The acceptable limit of the inconsistency was originally defined by Kocaoglu as 0.1 for the 
MSD (mean standard deviation), which is the mean of $\mathrm{n}$ standard deviations for the $\mathrm{n}$ elements [254]. A more robust measure has since been developed by using the RSV (root of the sum of the variances) of the $\mathrm{n}$ variables. The acceptable limits of RSV have been established for the number of elements (n) and the desired $\alpha$ level (probability of randomness in the expert's judgments expressed in pairwise comparison values) [256].

3. HDM-GD (Group Decisions): Arithmetic Mean of individual decisions is used for combining group decisions in HDM.

$$
\begin{aligned}
& \text { m } \\
& \text { i.e., } \mathrm{W}_{\text {j(group) }}=(1 / \mathrm{m}) \Sigma \mathrm{W}_{\mathrm{ij}} \quad \text { for each } \mathrm{j} \\
& \mathrm{i}=1 \quad \text { with } \mathrm{I}=1, \ldots . \mathrm{m} \text { experts, and } \quad \mathrm{j}=1, \ldots . \mathrm{n} \text { decision elements }
\end{aligned}
$$

The variance of each element's value is calculated for the $\mathrm{m}$ values obtained from $\mathrm{m}$ experts. The disagreement among the experts was originally defined by Kocaoglu as the mean of the standard deviations (MSD) for the n elements. The limit for acceptable disagreement is [254]. A more robust measure is available with the use of F-test for the nxm values. It tests the hypothesis that there is disagreement among the experts. The use of the F-test allows the definition of disagreement at various confidence levels [257].

4. HDM-SA (Sensitivity Analysis): The effects of changes in any combination of decision elements on the final decision can be analyzed by the HDM-SA algorithm developed in Hongyi Chen's $\mathrm{PhD}$ dissertation. The algorithm identifies the range of allowable changes before the final decision has to change, the criticality of the decision 
element for its sensitivity to changes, and the tolerance in each element before the decision changes $[258,259]$.

5. HDM-JD (Judgment Discrepancies): If actual values are known for the decision elements, the discrepancies in quantified judgments for the perceived values of those elements can be calculated as the RMS (Root Mean Square) of the difference between actual and perceived values:

$\mathrm{m}$

$$
\begin{aligned}
& \text { Discrepancy }=\left[(1 / \mathrm{m}) \sum\left[\mathrm{V}_{j, \text { actual }}-\mathrm{V}_{j, \text { perceived }}\right]^{2}\right]^{1 / 2} \\
& \text { Where } \mathrm{V}_{\mathrm{j} \text {,actual }}=\text { Actual value of element } \mathrm{j} \\
& \mathrm{V}_{\text {j,perceived }}=\text { Perceived value of element } j
\end{aligned}
$$

This is used only when the actual values of the elements are available. The objective is to test the accuracy with which the expert opinions are being quantified. The value of Discrepancy varies between 0 for no discrepancy, and 1 for extreme discrepancy [254].

6. HDM-DC (Desirability Curves): Desirability Curve is a curve defining the relationship between the level of a performance characteristic of a decision alternative and the desirability of that level measured on a 0 to 100 scale. When Desirability Curves are used: 
- Metrics and measurement processes for the decision elements at the subcriteria level (immediately above the alternatives) in the HDM must be determined when the model is developed.

- Each alternative must be defined by performance characteristics with one-toone correspondence to the measurable sub-criteria.

The following procedure is used for Desirability Curves [254]:

a) Develop a vector of performance values for the characteristics of each decision alternative

b) Convert the performance values to Desirability Values based on the Desirability Curves

c) Multiple the Desirability Value of each characteristic by the relative weight of that characteristic at the level immediately above the "Alternatives" level

d) Combine the matrices in the HDM to determine the "Technology Value" of the specific alternative

e) If a new alternative is identified after the model has been applied, start with stepa for that alternative.

\subsubsection{Scenario Analysis}

Greene, et al. [11] examine the transition zero emission vehicles in the US with different public policies. The authors utilize the scenario analysis to forecast the effects of different conditions. The focus is on social benefits, net costs and market adoption of EV vehicles. Their analysis of major energy transitions is characterized by major uncertainty due to the long-time constants for energy system change, the unpredictable nature of government policies and rapid 
technological, lack of understanding of market processes, and important positive feedback mechanisms that create tipping points. They use Monte Carlo tool to carry out the analysis.

Egbue and Long [14] utilize survey method in their research, to identify potential sociotechnical barriers to adoption of EVs and determines if sustainability issues influence consumer decision to purchase an EV. The premise is to help policymakers use the results as guidelines. However, this study merely utilizes a user perspective, whereas EV transition has many other key players as stated above.

Catenacci, et al. [96] seeks leading experts' judgment on the popular subject of future battery costs. In their study the authors collect expert judgment to provide insights on the inherently uncertain relationship between $\mathrm{R} \& \mathrm{D}$ efforts and the consequent technical progress in batteries. The analysis of the experts' data leads to a number of important policy recommendations to guide future $\mathrm{R} \& \mathrm{D}$ choices and target commitments. A total of 14 experts with the expertise of vehicle technology, battery technology and policy were surveyed. Experts' judgments were utilized for probabilistic decision-making. However, the results were merely about most cost-effective battery types, future battery costs, and R\&D's effect on those. This study is one of the very few studies consulting expert judgment on the EV field despite being very limited [260].

Sovacool and Hirsh [12] also researched barriers and possible policy implications. The article disputes the idea that the only important barriers facing the greater use of PHEVs and V2G systems are technical. Instead, it provides a broader set of barriers alongside with more subtle impediments relating to social and cultural values, including business practices, and political 
interests. The article sheds light into policy implications of such barriers, emphasizing what policymakers need to achieve a transition to a V2G and EV world.

Srivastava, et al. [29] tackles the same issue and make policy recommendations. These two articles use only literature review and make recommendations for policies based on that.

\subsubsection{The Approach Used in This Research}

The literature was reviewed for technology adoption methodology, but there are several reasons that limit the number of methodologies that can be used in this study. First, due to scarcity of historic data for EV, the classic forecasting models such as bass, gompertz and pearl would not work. Second, due the newness and novelty of the technology, the knowledge and experience for wide EV adoption are scattered among various government, research institutes and market leaders. Third, EV's introduction to the market cannot be studied as a simple new product diffusion but must be investigated as an energy transition due to its highly complex structure. Finally, most of adoption barriers and policies are not measurable. Consequently, the know-how, information, and experience have to be gathered and aggregated from experts in order to reach to a meaningful conclusion on barriers and effective policies.

According to Bastani, et al. [260], quantifying the uncertainties decision-makers face in managing a transition to energy sustainable vehicles and fuels will be useful. The results will shed light into the value of EV and reduce the uncertainty on the technological progress and market's likely response to it.

EV Adoption is a multi-dimensional problem, therefore in this study we have to consider multiple criteria and competing objectives simultaneously. In order to realize the objective of 
this research, we have to use a multi-criteria approach. Among the Multi-criteria decision models, HDM provides the opportunity to combine existing data with judgment quantification. EV is a new industry where the data are not available yet. Even though there are effective policies enacted today, we do not know their exact impact on mitigating barriers. Through HDM, we can convert the know-how of experts (who have been using these data) into quantitative measures. For the above reasons, HDM was used in this research.

This model for EV adoption is generalizable. Considering the fact that conditions are likely to change by time, and the policies will have to adapt those, the model has the flexibility to adapt. It can also work for different states and different countries. Different states, countries or conditions may bring new decision elements to the model. In that case, because the contribution matrices will change, a new HDM needs to be constructed and the contribution vector needs to be recalculated. 


\section{CHAPTER - GAP ANALYSIS}

\subsection{Linking Research Objectives to Research Gaps \& Research Outputs}

Several books, academic journals, conference papers, media substance, government reports and web articles on EV adoption barriers and policies were studied as literature review for this dissertation. As a result, Table 2 presents a summary of the research areas and findings.

\begin{tabular}{|c|c|c|}
\hline Research Areas & Findings & Authors \\
\hline $\begin{array}{l}\text { Addressing some } \\
\text { of the EV adoption } \\
\text { Barriers along with } \\
\text { some policy } \\
\text { alternatives }\end{array}$ & $\begin{array}{l}\text { Researches study only a few consumer- } \\
\text { oriented barriers along with some policies. } \\
\text { Majority of consumers are not aware of EV. } \\
\text { Low acceptance is because consumers do not } \\
\text { adopt due to perception of EV. }\end{array}$ & $\begin{array}{l}{[5],[47],[56],[60]} \\
{[91],[97],[110]} \\
{[95]}\end{array}$ \\
\hline $\begin{array}{l}\text { EV transition and } \\
\text { public policy }\end{array}$ & $\begin{array}{l}\text { A sophisticated set of policy tools need to spur } \\
\text { manufacturers, utilities, governments. } \\
\text { Experience and familiarization with new } \\
\text { technology is key. The effectiveness of policies } \\
\text { are not fully unfolded. }\end{array}$ & $\begin{array}{l}{[11],[36],[82],} \\
{[100],[101],[122]} \\
{[127],[128],[131]}\end{array}$ \\
\hline $\begin{array}{l}\text { EV Adoption } \\
\text { Barriers from } \\
\text { consumer } \\
\text { perspective }\end{array}$ & $\begin{array}{l}\text { The impact of consumer attitudes and } \\
\text { perceptions. The environmental impact of } \\
\text { GHG emissions perceptions. User's } \\
\text { satisfaction and adaptation to electric vehicle } \\
\text { (EV) on driving behavior and environmental } \\
\text { aspects. }\end{array}$ & $\begin{array}{l}{[14],[41],[20],[53],} \\
{[58],[121]}\end{array}$ \\
\hline $\begin{array}{l}\text { EV Adoption } \\
\text { Barriers from a } \\
\text { technical } \\
\text { perspective }\end{array}$ & $\begin{array}{l}\text { Battery costs and range will continue to be a } \\
\text { problem due to technical difficulties. There } \\
\text { will be a toll on electric grid with high EV } \\
\text { adoption. There is not enough data to assess } \\
\text { the actual impact of EV on energy systems. }\end{array}$ & $\begin{array}{l}{[96],[104],[105],[1} \\
06],[108],[109] \\
{[112],[113],[115]}\end{array}$ \\
\hline $\begin{array}{l}\text { Challenges/Effecti } \\
\text { veness of policy } \\
\text { options related to } \\
\text { some EV barriers }\end{array}$ & $\begin{array}{l}\text { Current policies are not effective enough to } \\
\text { increase diffusion. Monetary Incentives may } \\
\text { be effective to accelerate adoption. }\end{array}$ & $\begin{array}{l}{[23],[26],[28],[45],} \\
{[54]}\end{array}$ \\
\hline $\begin{array}{l}\text { Forecasts on } \\
\text { Market sales }\end{array}$ & $\begin{array}{l}\text { EV will have greater market share in the next } \\
\text { decades }\end{array}$ & {$[34]$} \\
\hline
\end{tabular}

Table 2.Research area and findings in the literature

Several research gaps were identified in these studies on EV and technology adoption: 
- The identified barriers are only limited to consumer perspective, technological limitations and cost limitations. Researches do not offer a wholistic understanding of EV adoption barriers.

- Although several researches suggest a sporadic list of EV adoption barriers, there are no studies that quantify the importance level of barriers in hindering the adoption.

- Researches focused on collecting data from surveys, analyzing or projecting the consumer demand. There isn't a comprehensive multi criteria decision making model which measures the policy effectiveness to mitigate EV adoption barriers in a quantitative and systematic way. No MCDM model were found for policies.

- Current assessment models on EV adoption assess the effectiveness of monetary policies only. Other studies on policies focused on drivers of adoption from a limited point of view. Researches do not link the policies to the barriers. No researches assessed the effectiveness of policies at different implementation levels.

We aim to provide a measurable description of challenges that hinder the transition to EV. A study that identifies critical policies to overcome EV barriers would have a vital contribution to the literature.

The identified gaps led to the research objective of this dissertation, which is to assess policy alternatives for mitigation of barriers to EV adoption. This research will yield primarily 5 outputs: 1) A comprehensive list of barriers to EV adoption, 2) Relative importance of each barrier to EV adoption, 3) Relative importance of policy alternatives for removal of barriers, and 4) Disagreements among experts from different fields on relative importance of barriers 
and policy alternatives. 5) Policy Effectiveness curves that will help determine the effectiveness of policies at different levels of implementation.

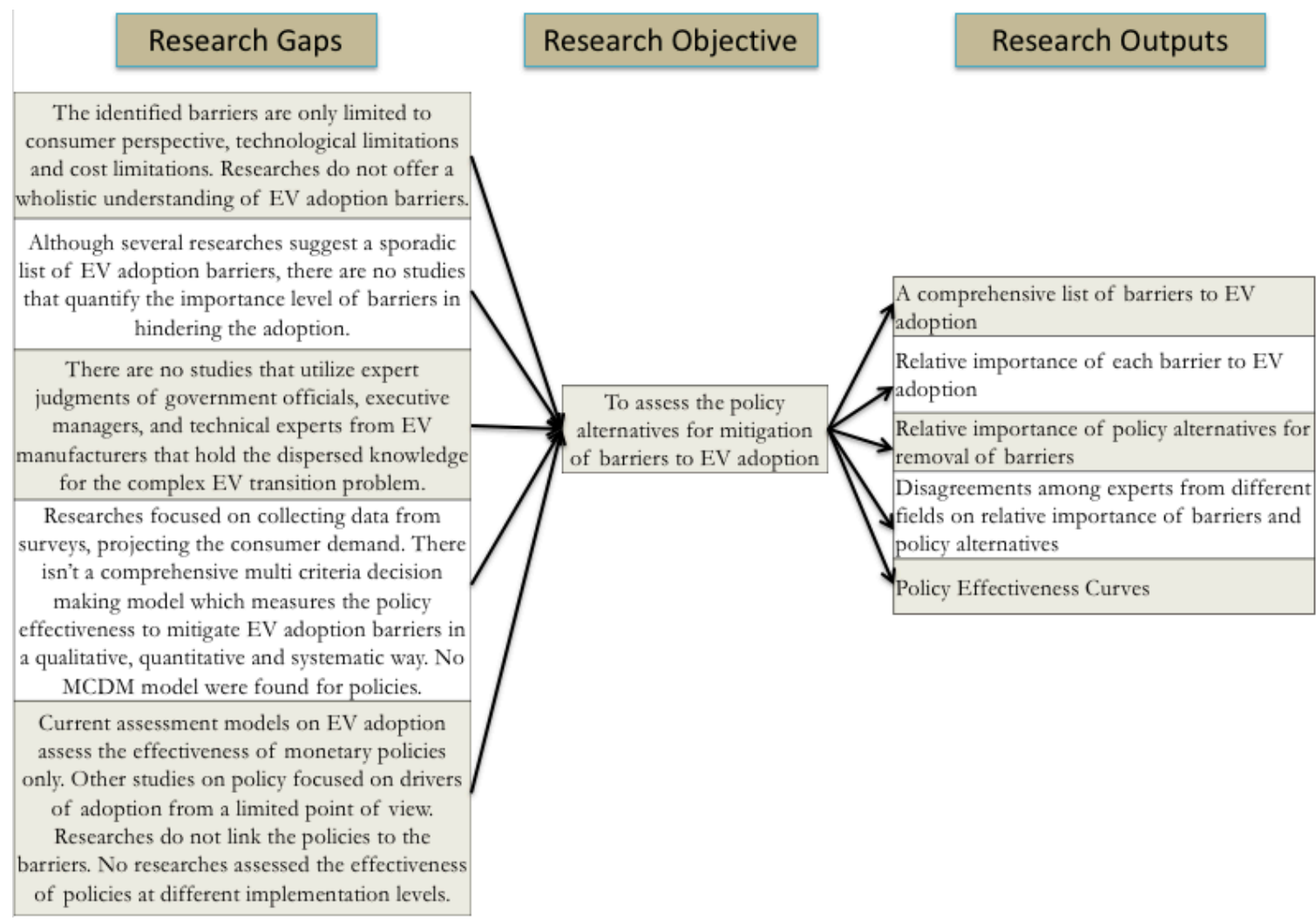

Figure 2. Linking Research Objective to Research Gaps and Research Outputs 


\section{CHAPTER - RESEARCH APPROACH}

\subsection{Research Methodology}

We started researching EV literature to identify barriers to wide EV adoption. Initially 10 barriers were identified as summarized in Table 3. We then interviewed several experts in the field and used snowball sampling technique to reach out to more experts.

\begin{tabular}{|c|c|c|c|c|c|c|c|c|c|c|}
\hline \multirow[b]{2}{*}{ Articles / Reports } & \multicolumn{10}{|c|}{ Most Rated Electric Vehicle Barriets } \\
\hline & $\begin{array}{c}\text { Battery } \\
\text { Pefformance }\end{array}$ & Bastery Cost & Range & Chatging time & $\begin{array}{l}\text { Negative Public } \\
\text { Petception of EV }\end{array}$ & Initial Cost & $\begin{array}{l}\text { Charging } \\
\text { Network }\end{array}$ & $\begin{array}{l}\text { Negative Media } \\
\text { Attention }\end{array}$ & \begin{tabular}{|c|} 
Incumbent oil \& \\
ICE firms' \\
tesistante
\end{tabular} & $\begin{array}{l}\text { Low Resiale } \\
\text { Market }\end{array}$ \\
\hline Green \& Park, 2014 & & - & • & - & - & - & - & & & \\
\hline Pasooglu, 2014 & & & - & - & & & - & & & \\
\hline Eghoue \& Long, 2012 & - & - & $\cdot$ & - & - & & - & & & \\
\hline Krusse, 2013 & & - & $\bullet$ & - & - & - & - & & & \\
\hline Lousse \& Lodberg, 2013 & & - & - & 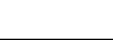 & $\cdot$ & & - & & & $\cdot$ \\
\hline Nigra, 2014 & & - & $\cdot$ & . & & & - & & & - \\
\hline Incekara \& Yildit, 2014 & - & - & - & - & - & - & - & - & & - \\
\hline Carley, 2013 & $\cdot$ & - & $\cdot$ & - & - & - & - & & & \\
\hline Ustagla \& Y Yditiz, 2011 & $\cdot$ & & $\cdot$ & $\cdot$ & & $\cdot$ & $\cdot$ & & & \\
\hline Dimond, 2009 & & - & & & - & & & & & \\
\hline Sorvacod \& Hirsh, 2009 & - & - & $\bullet$ & - & - & - & & & - & \\
\hline Lave \& Mclean, 2001 & & - & $\cdot$ & - & & & - & & & \\
\hline Srivestan, 2010 & $\cdot$ & - & & - & - & & - & & & \\
\hline Serxchula, 2014 & - & - & - & - & & & & & & \\
\hline Oxki \& Sersygnanowa, 2011 & & & & & - & - & & & & \\
\hline Catenace, 2013 & - & - & $\cdot$ & - & - & - & - & & - & \\
\hline Soberg, 1998 & $\cdot$ & $\cdot$ & $\cdot$ & - & $\cdot$ & - & - & - & & \\
\hline Payton, 1988 & - & - & & & & & & & & \\
\hline Durvall, 2002 & $\cdot$ & & - & - & & - & & & & \\
\hline Pearre, 2011 & $\cdot$ & & $\cdot$ & $\cdot$ & & & & & & \\
\hline Roger, 2003 & & & & & - & & & - & & \\
\hline Lane \& Potta, 20007 & & & & & - & & & - & & \\
\hline Vouldect, 2010 & . & & & & & & & - & & \\
\hline Caroll, 2011 & & & & & & & & - & & \\
\hline Hidrue, 2010 & - & - & - & - & & & & & & \\
\hline \multicolumn{11}{|l|}{ Andermian, 2007} \\
\hline TOTAL & 13 & 16 & 17 & 16 & 14 & 10 & 13 & 6 & 2 & 3 \\
\hline
\end{tabular}

Table 3. EV Barriers from the Literature

As a result of these interviews we have identified 12 more barriers. We call this the initial framework. Initial framework is summarized in Table 4. 


\begin{tabular}{|c|c|c|c|c|c|c|}
\hline Perspectives & \multicolumn{6}{|c|}{ Barriers } \\
\hline Social Barriers & $\begin{array}{c}\text { Media } \\
\text { Attention }\end{array}$ & $\begin{array}{c}\text { Public } \\
\text { Awareness }\end{array}$ & $\begin{array}{c}\text { Public } \\
\text { Perspective }\end{array}$ & $\begin{array}{l}\text { Behavioral } \\
\text { Resistance }\end{array}$ & & \\
\hline Abbreviation & NgMed & PubAw & PubPer & BebRs & & \\
\hline $\begin{array}{c}\text { Technical } \\
\text { Barriers }\end{array}$ & $\begin{array}{l}\text { Charging } \\
\text { Network }\end{array}$ & $\begin{array}{l}\text { Charging } \\
\text { Time }\end{array}$ & Range & $\begin{array}{c}\text { Battery } \\
\text { Performance }\end{array}$ & $\begin{array}{c}\text { Power } \\
\text { Capacity }\end{array}$ & \\
\hline Abbreviation & ChNtw & ChTime & Rnge & BtPerf & PDistC & \\
\hline $\begin{array}{c}\text { Environmental } \\
\text { Barriers }\end{array}$ & $\begin{array}{c}\text { Battery } \\
\text { Production }\end{array}$ & $\begin{array}{c}\text { Vehicle } \\
\text { Operational }\end{array}$ & $\begin{array}{l}\text { Battery } \\
\text { Disposal }\end{array}$ & $\begin{array}{l}\text { Originating } \\
\text { Source of } \\
\text { Electricity }\end{array}$ & & \\
\hline Abbreviation & BtProd & $V e b O p$ & BtDis & OrSrc & & \\
\hline $\begin{array}{c}\text { Economic } \\
\text { Barriers }\end{array}$ & Initial Costs & Battery Costs & $\begin{array}{l}\text { Operational } \\
\text { Costs }\end{array}$ & Oil Price & $\begin{array}{l}\text { Limited } \\
\text { Types } \\
\text { and } \\
\text { Quantiti } \\
\text { es }\end{array}$ & $\begin{array}{c}\text { Loss of } \\
\text { Annual } \\
\text { Fee }\end{array}$ \\
\hline Abbreviation & InCst & BtCst & OpCst & OilP & $T / Q$ & AnFee \\
\hline Political Barriers & $\begin{array}{l}\text { Entrenched } \\
\text { Technology } \\
\text { Resistance }\end{array}$ & $\begin{array}{c}\text { Government } \\
\text { Stakeholders } \\
\text { Resistance }\end{array}$ & $\begin{array}{c}\text { Shareholder's } \\
\text { Pressure }\end{array}$ & $\begin{array}{l}\text { Loss of } \\
\text { Annual Fee }\end{array}$ & & \\
\hline Abbreviation & TcRes & GSRes & ShPres & AnFee & & \\
\hline
\end{tabular}

Table 4. Barriers under five perspectives (Social, Technical, Environmental, Economic, Political) before expert validation

The next step was to identify the experts for each of the expert panels that would provide quantified judgments. After developing expert panels, we asked the experts to validate/modify the barriers under each of 5 perspectives: Social, Technical, Environmental, Economic, and Political, along with 6 policy alternatives that stemmed from our literature review. Their suggestions were incorporated into the model.

Policy literature and government websites helped us create an initial list of policies. Although there are several policies enacted for $\mathrm{EV}$, as a result of expert validations we limited them to 
6. Experts also validated our initial framework that has barriers categorized under 5 perspectives, and the links between policies and barriers.

Table 4 was taken to the EV experts for their validation of barriers. If a barrier was approved by $75 \%$ of the experts it was kept, whereas when the validation was lower than that, it was removed from the model. As a result of this validation and modification process, 5 perspectives were all validated. 22 barriers were dropped to 18.

Oil Price and Operational Cost was combined into one single barrier under the name Relative cost, which denotes the fuel cost ratio of oil and electricity. Vehicle Operational Environmental and Annual Fee barriers were removed as they were negligible and not relatable to wide adoption. Power Distribution Capacity was viewed by the majority of experts as not a critical barrier until after EV diffuses deeply in the market.

Table 5 shows each of the policy alternatives and their linked barriers. The final model that has all perspectives, barriers and policies is in the Research Model Section in Figure 3. The descriptions of barriers and policies that were used in the final model can be found at the Appendix in page 217. 


\begin{tabular}{|c|c|c|c|}
\hline Policy Alternatives & Linked Barriers & Abbreviation & Comments \\
\hline Road Privileges & $\begin{array}{l}\text { MedAttn, PubAw, PubPer, } \\
\text { BehRs }\end{array}$ & Road Privileges & In Effect in the US \\
\hline $\begin{array}{c}\text { Californian/EU Carbon Emission } \\
\text { Standards (GHG) }\end{array}$ & $\begin{array}{l}\text { MedAttn, PubAw, BehRs, } \\
\text { BtCst, RelCst, ModQty, } \\
\text { TecRes, PolRes }\end{array}$ & GHG & In Effect in the US \\
\hline $\begin{array}{l}\text { Monetary Incentives (Federal and } \\
\text { State Rebates) }\end{array}$ & $\begin{array}{l}\text { MedAttn, PubAw, BehRs, } \\
\text { InCost, ModQty, ShrPres }\end{array}$ & MI & In Effect in the US \\
\hline $\mathrm{R} \& \mathrm{D}$ Incentives & $\begin{array}{l}\text { ChNtw, ChTime, Rnge, } \\
\text { BtPerf, BattProd, BattDisp, } \\
\text { BattCost, ShPres }\end{array}$ & $\mathrm{R} \& \mathrm{D}$ & In Effect in the US \\
\hline Renewable Portfolio Standard & $\begin{array}{l}\text { MedAttn, PubPer, BehRs } \\
\text { ElcSrce, RelCost, BtDis, } \\
\text { TecRes, PolRes }\end{array}$ & RPS & In Effect in the US \\
\hline Charging Incentives & $\begin{array}{l}\text { MedAttn, BehRes, ChNtw, } \\
\text { RelCos, TechRes }\end{array}$ & CI & In Effect in the US \\
\hline
\end{tabular}

Table 5. EV Policy Alternatives, Abbreviations and their linkage to Barriers

\subsection{Research Framework}

The HDM developed in this research has 4 levels: Objective, Perspectives, Barriers, and Policy Alternatives. The full research model is shown in Figure 3. The full list of decision elements at each level is given below:

\section{Objective:}

To evaluate the policies to mitigate the barriers to EV adoption.

\section{Perspectives:}

Social, Technical, Environmental, Economic, Political

\section{Barriers:}

Social: Media Attention, Public Awareness, Public Perception, Behavioral Resistance 
Technical: Charging Network, Charging Time, Range, Battery Performance

Environmental: Battery Production, Battery Disposal, Source of Electricity

Economic: Initial Costs, Battery Costs, Relative Cost, Limited Types and Quantities

Political: Entrenched Technology Resistance, Political Resistance, Shareholders' Pressure

\section{Policies}

Policy alternatives are linked to certain barriers (in Table 5):

1- Road Privileges

2- Carbon Emission (GHG) Standards

3- Monetary Incentives (Rebates, Tax Credit)

4- $\mathrm{R} \& D$ Incentives

5- Renewable Portfolio Standard (RPS)

6- Charging Incentives 


\subsection{Research Model}

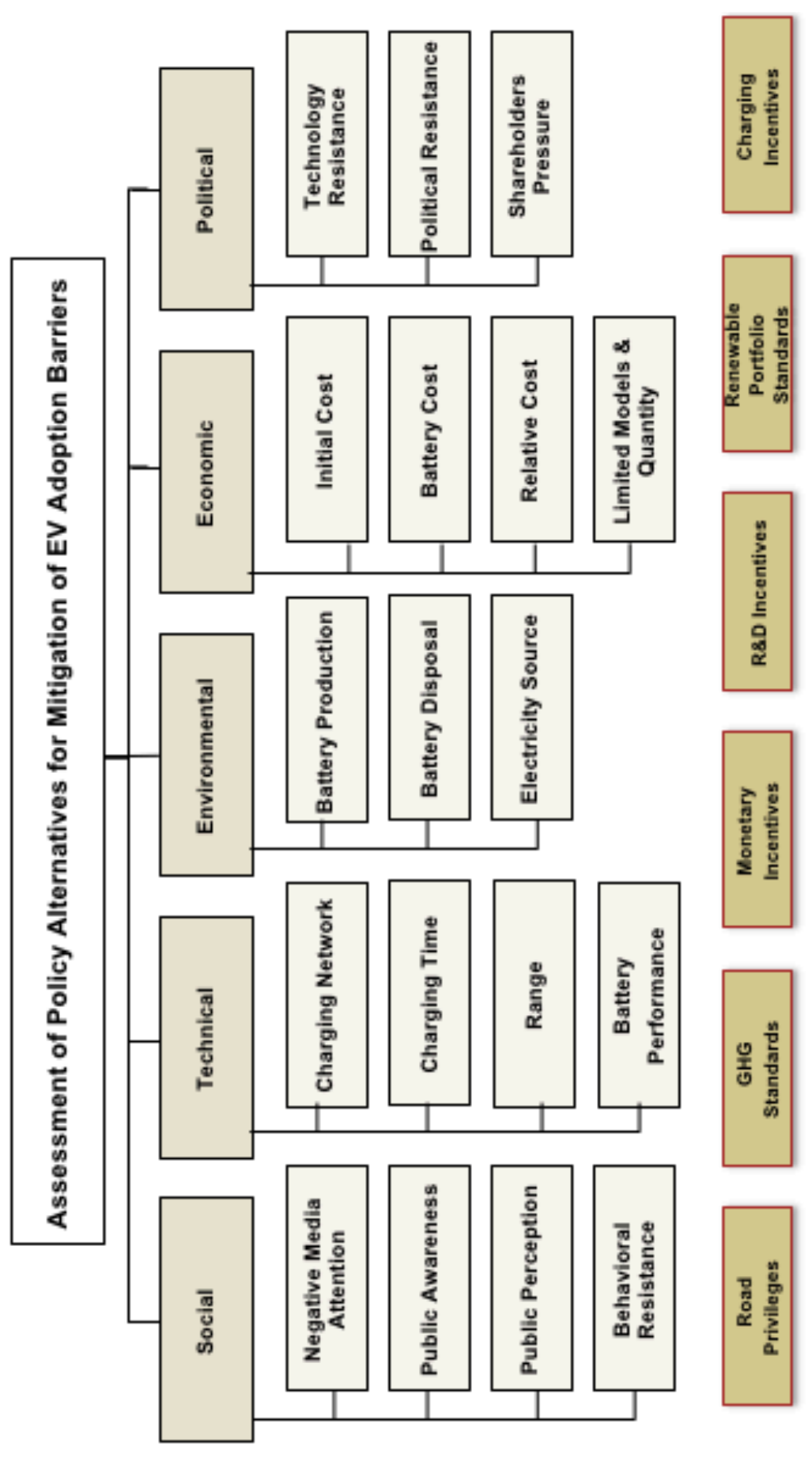

\begin{tabular}{|c|c|c|c|}
\hline uo!̨s!W & รจห!podsuad & ร.คตฺนอg & se!̣!| \\
\hline
\end{tabular}

Figure 3. Research Model 


\subsection{Research Process}

In order to create the framework, the following steps have been followed:

1. A literature review was conducted to identify the barriers to EV, and the policies that the governments have enacted to help accelerate EV adoption.

2. The identified Barriers were listed in a table with their frequency in the literature. Experts in the EV field reviewed this list. Their feedback has helped to modify the list.

3. Snowball sampling was used to identify the key EV experts in the Northwest and California area. These experts were included in the expert panels.

4. The modified list of barriers, and policies were used to create the initial HDM.

5. The HDM has been run by experts to verify the validity.

6. Expert Panels from NGOs, Academia, manufacturers and policy makers were formed.

7. Once all experts and expert panels are determined, the initial version of HDM was taken to these experts for verification and modifications.

8. The modifications based on these experts' feedback that resulted in the final version of HDM.

9. The judgment quantification instruments were sent to the experts.

10. The collected data was analyzed after inspecting the inconsistencies and disagreements. Some experts were contacted again for anomalies in their data such as inconsistency.

11. Policy Effectiveness Curves were developed to determine to determine the expected effectiveness of policies at various levels of implementation.

12. The model was tested for various policy implementation levels.

\subsection{HDM-JQ (Judgment Quantifications)}

Expert judgments are quantified at different levels of the decision hierarchy [254]. 

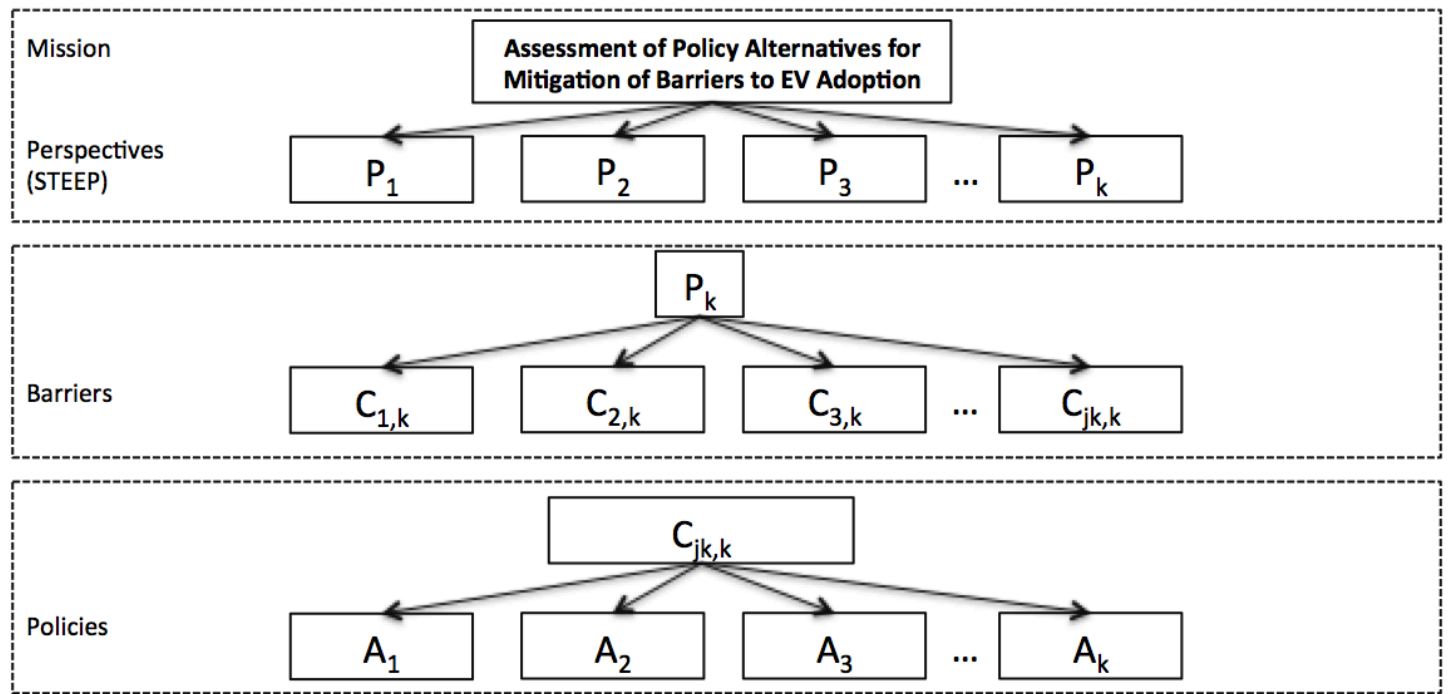

Figure 4. Judgment Quantification Procedure

Step 1: Quantification of relative importance of high-level perspectives (STEEP): to obtain relative importance of $\mathrm{Pk}$.

Step 2: Quantification of relative importance of Barriers to obtain relative importance of $\mathrm{C}_{\mathrm{k}, \mathrm{k}}$ with respect to $P_{k}$.

Step 3: Quantification of relative importance of Policies to obtain relative importance of $A_{k}$ with respect to $\mathrm{C}_{\mathrm{k}, \mathrm{k}}$.

The study employed pairwise comparisons to quantify expert judgment. The ratio-scale measurements of the constant sum method allowed experts to allocate 100 points between pairs of decision variables, with respect to their relative importance to a decision variable at the next higher level that they were associated with.

\subsection{Expert Inconsistencies and Disagreements}

We identified the barriers to wide EV adoption, and effective policies that tackle them. We utilized HDM to measure the weights of barriers to EV adoption through multiple expert panels. These panels completed pairwise comparisons at different sections of the model. Since 
experts are from various areas of expertise, it is likely that they do not retain the same type of knowledge. Expert judgment has been used for various problems in the literature and it proved to be very useful especially when quantitative data is scarce. As Shanteau and Stewart [261] suggest that "experts presumably exhibit the highest levels of judgmental ability, expertise has been and is a prominent topic in the behavioral study of judgement and decision making processes. Despite the effectiveness of it, consolidating judgments of different expertise brings different views along with potential solutions. Understanding disagreement better would help create ways to reduce it or at least cope with it.

Mumpower and Stewart [262] examined expert judgment and expert disagreement with special emphasis on public policy problems that contain a scientific or technical component a few decades ago. The intellectual argument they suggested in their paper helped us construct a better understanding of disagreement among experts.

It is important to note that many believe that experts given the same data will produce same or similar results. This misconception stems from confusing the approach of experiments in the hard sciences -where reproducibility of results confirm the validity of model - with the approach where various experts' body of knowledge is joint through a model. Meyer \& Booker $[263,264]$ argue that this statement would be misleading for two reasons:

1. Although the source of information may be the same, because experts acquire knowledge through different experience, and they realize their knowledge through different means and methods they are likely to have different bodies of knowledge and different skillset of problem solving [264]. 
2. Unlike hard sciences, expert judgment may deal with areas where there are no clear standards or well-developed theories [263].

To add to what Meyer \& Booker stated, the expert opinions on technologies where there is great uncertainty and less analogous examples, the knowledge lies in experts' intuitive knowledge. Lack of quantitative measures in conducting pairwise comparisons between two criteria also may lead to differences in expert judgment depending on their personal experience. In particular, policies is a great example where the impact of policies cannot be measured by quantitative means, therefore are likely to underlie in experts' intuitive knowledge. In addition, studies have shown that mathematically combining expert judgments provide a higher probability of reaching to a more accurate answer than does the use of single expert [263].

Expert disagreement may occur from either systematic or non-systematic differences in judgment processes. Those that are systematic are relatively stable differences in how people integrate information into a judgment. Those that are non-systematic refer to inconsistency or unreliability that introduces a random component into the process [262].

\subsubsection{Inconsistencies in Expert Judgments}

Inconsistency is related to an individual expert's response to the judgment quantification instrument and it is generally accepted that the recommended value of inconsistency is between 0.0 and 0.1 for valid results $[265,266]$.

Kocaoglu [265] developed the following procedure for calculating inconsistency: For $n$ decision elements there are $n$ ! orientations with vectors $r 1, r 2 \ldots$, rn. For 4 decision elements 
where $n=4$ there are 24 orientations (i.e ABCD ABDC ACBD ACDB,.., DBCA). Assuming expert judgment was completely consistent, all the orientations would have the same relative values. However, due to differences in individual judgment process among experts, each orientation is expected to have slightly different relative values assigned to each decision variable. Original Inconsistency measure calculates the variance of the relative values of the elements in each orientation [265].

Inconsistency value is measured by calculating the variance among the relative values assigned in each orientation. The formula to measure inconsistency is as follow:

$$
\bar{r}_{i}=\left(\frac{1}{n !}\right) \sum_{j=1}^{n !} r_{i j}
$$

Where;

$r i j$ is the relative value of the $i^{\text {th }}$ element in the $j^{\text {th }}$ orientation of an expert

$r i$ is mean relative value of the $i^{\text {th }}$ element for the same expert

Inconsistency of the $i^{\text {th }}$ element is formulated as:

$$
\frac{1}{n !} \sum_{j=1}^{n !}\left(\bar{r}_{i}-r_{i j}\right)^{2}
$$

for $i=1,2, \ldots, \mathrm{n}$ where $\mathrm{n}$ is the number of elements compared. The variance of the expert in providing relative values for $\mathrm{n}$ elements is the inconsistency index is formulated as: 


$$
\frac{1}{n} \sum_{i=1}^{n} \sqrt{\frac{1}{n !} \sum_{j=1}^{n !}\left(\bar{r}_{i}-r_{i j}\right)^{2}}
$$

This is the mean of the standard deviations of the mean of each of the $n$ variables in $n$ ! orientations. Kocaoglu originally recommended 0.1 as the limit for acceptable inconsistency for any number of decision elements.

\subsubsection{HDM - CA: Consistency Analysis}

Abbas [256] recent dissertation proposes a more robust inconsistency model to HDM. We are using both the original method and Abbas' approach for calculation of inconsistencies.

What Abbas suggests is to use square root of sum of the variances, instead of the mean standard deviation as the inconsistency measure. The inconsistency in his approach is defined as the Root of the Sum of Variances (RSV) in n decision elements:

$$
R S V=\sqrt{\sum_{i=1}^{n} \sigma_{i}^{2}}
$$

$\sigma_{i}^{2}$ denotes the variance of the mean of the $i^{\text {th }}$ decision element where $\mathrm{n}$ represents the number of decision elements:

$$
\sigma_{\mathrm{i}}=\sqrt{\frac{1}{n !} \sum_{j=1}^{n !}\left(x_{i j}-\bar{x}_{i j}\right)^{2}} \forall i=1, \ldots, n
$$

where;

$x_{i j:}$ normalized relative value of the variable $i$ for the $j^{\text {th }}$ orientation (in $n$ factorial orientations)

$\bar{x}_{i j:}$ the mean of the normalized relative value of the variable $i$ for the $j^{\text {th }}$ orientation 


$$
\bar{x}_{i j}=\frac{1}{n !} \sum_{j=1}^{n !} x_{i j}
$$

To explain Abbas' method for four decision elements A,B,C and D; $\sigma^{2}$ of A, B, C, D are calculated for their values in $\mathrm{A}$ ! orientations, then the square root of the sum of these four $\sigma^{2}$ is taken under square root. The result is the RSV.

\subsubsection{Disagreements Among Experts}

When experts disagree, it can be interpreted in different ways. First, disagreement may mean that the experts took the posed question to mean differently. Another reason would be that they solved it using different methodology or based on different data source. If the data indicate that an expert has interpreted the question in a different way, then one way to fix the disagreement is to have the expert readdress the question using the agreed upon definition. The expert's previous response may be discarded as a response to a different question [263]. Needless to mention, based on this information, the pairwise comparisons judgment quantification instrument should be designed and articulated carefully to lower the chances of experts to misinterpret the posed questions. Working closely with experts and explaining each criterion in an articulate manner also will help.

Mumpower and Stewart [262] groups factors to expert disagreement into four categories: 1) poor quality or missing feedback, 2) poor quality or missing information, 3) inability to learn about the quality of one's own judgment, and 4) causal texture of the environment. Brunswik [267] lens model suggests that experts' disagreement may be affiliated with one or more of the below four reasons: 
1. Different organizing principles. Two experts may disagree concerning the appropriate way to combine information.

2. Different weights. Experts may believe that different pieces of information are more important.

3. Different function forms. Two experts may disagree concerning the appropriate functional relationship between levels of cues and judgments.

4. Differences in bias. Even if two experts use the same organizing principle and their relative weights and function forms are identical, they may still make different judgments because of differences in the mean and variance of their judgments.

Meyer and Booker [263] identified similar pitfalls regarding disagreements between experts. Two of them may be related to the causes of disagreement:

\section{Interviewers, knowledge engineers and analysts can introduce bias: Experts} may introduce bias based on either training bias or they may force data to fit models. Boose and Gaines [268] suggested to do anchor a three step to to counter availability bias: 1) to ask experts to describe how other experts might disagree with their responses, 2) to ask experts to temporarily forget recent events, 3) aggregate outcomes with small probabilities in to a single larger class.

2. Experts are limited in the number of things that they can mentally juggle: Miller [269] defined a magic number that human short-term memory can process information with a limit of $7( \pm 2)$. When models are too complex the number of pairwise comparisons grow exponentially. If the model is not built carefully, this may 
affect their ability to answer pairwise comparisons less accurately, which may cause disagreements. In other words, the level of granularity should be chosen carefully.

One of the valid interpretations on experts' disagreement is that they may have done their problem solving in different manners. If the records to their judgment were kept, it may be easier to pinpoint the reasons of the differences. Based on these differences it may be easier to make a decision on inclusion or exclusion of that particular expert's provided answers. In our case, there is not much problem solving and most of the data relies on experts' level of understanding on certain subjects and they may do approximations in most cases.

According to Hammond [270] there are 3 traditional interpretations for experts' disagreement: incompetence, venality, and ideology. The incompetence explanation investigates the qualifications, credentials, or intelligence of alleged experts. According to this view, disagreements occur due to one or multiple disputants being not really considered an expert. Another explanation to this specific phenomenon is that the competent experts not investing the required effort due to lack of time, resources, or motivation. To support this view, Marcus [271] argued that lack of resources gave birth poor performance by toxicologists in the pesticide division of the EPA, who were overtaxed by the need to re-register more than 50,000 substances. According to venality explanation, experts take positions that serve their immediate self-interests, or the interests of others who have the power to reward them. In our case, since we will be gathering expert judgment from manufacturers, their group of experts is similar to this explanation. The ideology interpretation is built on the presumption that experts' positions on policy-relevant scientific or technical issues are determined by political, religious, or ethical values or beliefs. In other words, experts take stand influenced largely by their personal sympathies, and then 
prioritize evidence that supports their opinions [272]. In our case, the government officials and policy makers will be similar to this group of people.

Another reason of disagreements may stem from choosing one of two approaches: 1) to include expert names apparent or 2) preserving anonymity. The first view argues that if one keeps expert names, this will increase the robustness and the credibility of the model. At the same time, experts will be more careful in giving their answers when their names are attached to their answers. Whereas, the second group that favors preserving anonymity believes that experts will not reflect their true responses if others will be able to trace the answers back to their resources. This may create disagreement among experts. The suggested solution to this by Meyer and Booker [263] is to have the experts decide how they wish to have their judgments identified.

Furthermore, Social Judgment Theory (SJT), and Cognitive Continuum Theory (CCT) help understand interpersonal disputes and how to handle them [273, 274]. n Hammond [270] studied the interpersonal conflict paradigm and added the domain of expert judgment. They argued that SJT be a powerful tool in public policy disagreement among experts.

There are also studies conducted in the literature regarding the degree of disagreement at different levels throughout the decision-making model hierarchy. Stewart [275] argued about the disagreement at different levels of hierarchy that:

a. "Scientific disagreement and uncertainty are likely greater at higher levels of the hierarchy than at lower levels; 
b. Individual disputes among scientists may emerge with regard to their uncertainty about and confidence in their judgments both within and across levels;

c. Individual disputes among scientists may emerge about choosing and accumulating information at lower levels to form a judgment at the next-higher level;

d. The abovementioned individual differences help interpret significant disagreements at higher levels of the hierarchy."

Looking further into industry, there are studies that specifically focused on how experts who are expected to provide their judgment which potentially effect policymaking. If the face value of judgment components is not formulated in the clearest manner, there is a great chance that it may blur expert judgment. According to Hammond and Adelman [276], when experts are particularly asked to address questions of "what should be" regarding policies, they mostly respond, although it is simply impractical for them to respond objectively or scientifically. When questions of facts and values are intermixed, pressure mounts for policy makers to attempt to become "amateur scientists" and/or for scientists to assume the role of so called "de facto" policy makers.

\subsubsection{Calculation of Disagreements}

As explained above, it is expected to have disagreements. If the disagreement among experts is too large, then the first step is to determine whether the disagreement stemmed from a weakness in the elicitation or from the natural differences between the experts. To solve this 
problem, expert's processes should be inspected -if they kept record of their processes-. If the questions were loosely defined, the experts will often make their own definitions based on their experience. This may be identified as a true problem. If data indicates that experts used the same definitions and assumptions, then this is not considered a problem, rather it should be considered as difference in perception [263].

If the experts gave different responses because they answered different questions, then there are not many options. One way to fix this issue is to separate the experts' answers according to the questions they answered. Another way is to re-contact the experts to have them reconsider the pairwise comparisons again.

Unwanted disagreements that are not related to difference of opinions, can be proactively dealt with when selecting tools and methods. Delphi, which is used widely to obtain expert judgment, is a method that allows experts to feed their answers iteratively with repeated rounds. The process is repeated until a pre-determined consensus is reached through. However, a drawback of this method is that it may push experts to have a bias. Therefore, the author will not be using this method.

\subsubsection{Intraclass Correlation Coefficient (ICC)}

"ICC is a descriptive statistic that can be used when quantitative measurements are made on units that are organized into groups" [277]. It indicates the strength of units in the same group that is similar to each other. It is considered as a type of correlation, however as opposed to most other correlation measures it operates on data structured as groups, rather than data structured as paired observations [278]. ICC is commonly used to quantify the degree to which 
individuals with a fixed degree of relatedness resemble each other in terms of a quantitative trait [279]. In our case this will be expert responses resembling each other.

When these tests are implemented, if the intraclass correlation coefficients $\left(r_{i c}\right)$ of all subgroups of Expert Panel are close to 1, then that means there is a perfect agreement among that expert panel. If this value is close to zero, then there is a substantial difference among experts. When $r_{i c}$ is negative, then the negative it is considered as zero. According to Sheskin [278], when $r_{i c}$ is greater than 0.7 , this means a there is strong agreement among the experts. Figure 5 summarizes the fundamentals of ICC.

\begin{tabular}{lll|}
$\begin{array}{lll}\text { ICC } \\
\text { Characteristic }\end{array}$ & Description & Comments /Formulas \\
\hline Range & $-\frac{1}{(k-1)}<r_{i c}<+1$ & $\begin{array}{l}r_{i c}=\mathrm{ICC} \\
\mathrm{k}=\text { number of judges (experts) } \\
\mathrm{n}=\text { number of subjects (criteria) }\end{array}$ \\
& & $r_{i c}<0$ then it is considered as 0 \\
Values & $r_{i c}=1:$ When all judges in agreement & \\
& $r_{i c}=0:$ When judges are in maximum disagreement \\
& $r_{i c} \geq 0:$ Higher $r_{i c}$ values indicate higher agreement & \\
& level $\left(r_{i c}>0.7\right.$ is considered strong agreement) & \\
\hline
\end{tabular}

Figure 5. ICC Characteristics[280]

\subsubsection{F-Test}

Using F-test is a better approach since the ICC only gives a guideline to interpret the degree of agreement/disagreement among experts. Shrout \& Fleiss [257, 281] utilized F-test to investigating whether there is a statistically significant disagreement among the experts. They enhanced ICC evaluation by using an F-Test to determine whether or not there is absolute disagreement among the judges [257]. 
The figure below summarizes the F-Test characteristics. Note that statistical significance level can also be referred to as Confidence level. If Statistical significance level is $5 \%(a=0.05)$, this means the level of confidence is $95 \%$.

\begin{tabular}{|c|c|c|}
\hline $\begin{array}{l}\text { ICC } \\
\text { Characteristic }\end{array}$ & \multicolumn{2}{|l|}{ Description } \\
\hline Range & $H_{0}: r_{k}=0$ & $\begin{array}{l}\text { There is disagreement (i.e. there } \\
\text { is no correlation of the } \\
\text { judgments by judges on the } \\
\text { subjects) }\end{array}$ \\
\hline Values & $H_{a}: r_{k}>0$ & $\begin{array}{l}\text { There is statistically significant } \\
\text { evidence that there is some level } \\
\text { of agreement (Alternative } \\
\text { Hypothesis) }\end{array}$ \\
\hline F-Value & $F_{B S}=\frac{M S_{B S}}{M S_{r e s}}$ & $\begin{array}{l}\mathrm{MS}_{\mathrm{BS}} \text { : Mean square between } \\
\text { subjects } \\
\mathrm{MS}_{\mathrm{res}} \text { : Mean square residual }\end{array}$ \\
\hline F-Critical & \multicolumn{2}{|c|}{$\begin{array}{l}\text { The critical F-value statistic must exceed to reject the test. In this case a } \\
\text { significance level of } 5 \%(\alpha=0.05) \text { is considered. } \\
\text { (An } \alpha \text { of } 0.05 \text { indicates there is only one chance in twenty that this event happened } \\
\text { by coincidence and } 0.05 \text { level of statistical significance is being implied. The lower } \\
\text { the significance level, the stronger the evidence required. It is conventional to use a } \\
5 \% \text { of significance for many applications. }\end{array}$} \\
\hline Hypothesis Test & If $F_{B S}>F_{\text {critical }}$ at $\alpha=0.05$ then $F$ & \\
\hline
\end{tabular}

Figure 6. F-Test Characteristics[280]

These two tests are powerful statistical methods to investigate disagreement between experts within the group. The F-Test value indicates whether there is significant disagreement between experts. The HDM tool that we used in this research include F-Test, which reveals the disagreement among experts. Although it is important to determine whether there is a disagreement between experts, the real challenge starts after identifying the disagreement. In order to deal with the disagreement, one should identify which experts are in disagreement and which experts are in agreement. A method to carry this out is using a statistical cluster 
process called Hierarchical Cluster Analysis (HCA). "HCA is a method of cluster analysis, which seeks to build a hierarchy of clusters" [282]. IC is a widely used data analysis tool. Through HCA, a binary tree of the data is built that merges similar groups of points. Visualizing this tree provides a useful summary of the data [283]. In our case, the tree structure can be constructed to observe the relationship among experts. This method builds the hierarchy from the individual elements by progressively merging clusters. The first step is to determine which elements to merge in a cluster. It is preferable to take the two closest elements, according to the chosen distance [284]. In our case, HCA groups experts in clusters according to their similarity in judgment. Experts in different clusters are significantly different in their judgments. The largest cluster can be assigned as the base cluster and contains the maximum number of experts. The smaller clusters represent experts in disagreement with the base cluster. One of the ways to reach a meaningful solution is to use consensus clustering to integrate results from several clustering attempts, which creates a cluster ensemble into a unified consensus answer. This yields robust and accurate results [285]. There are multiple software programs to carry our HCA including, Hierarchical Clustering explorer, Hierarchical Clustering, JMP, and programs developed in R. The SPSS software can also be used to carry out ICC and F-test.

Once the clusters are defined, the experts in disagreement are contacted to better understand the cause of disagreement. One option - as aforementioned - is retaking of the judgment quantification measurements. 


\subsection{HDM SA}

Governments are enacting policies and incentives in order to provide necessary conditions that will make EV an attractive option for adopters. Because there is great uncertainty about the technology, governments are seldom sure whether the incentives will have the expected impact on EV adoption. This opens the door for possible changes in the policies; certain policies can be removed, or new policies are introduced over time. For example, disruptive technologies can have a significant impact on the development of high tech industries, as well as on the decision-making in technology policies [286]. Uncertainty also impacts the judgment of experts. They cannot provide their judgments with 100\% confidence due to novelty of the technology. For these reasons, it is critical to know how sensitive the model is to changes in inputs. Sensitivity analysis has been used in various fields. Chen and Kocaoglu [258] state that Sensitivity Analysis is key to making all sorts of decision models requisite by yielding insights that are otherwise not available or intuitively recognizable. Hence, the solution of a problem is not thoroughly complete solely with determination of a rank order of decision alternatives.

In order to develop an overall strategy to meet the various contingencies, it is critical to conduct a Sensitivity Analysis for the HDM results [258]. It is important to conduct Sensitivity Analysis for any hierarchical decision models to help derive a complete solution and develop a comprehensive strategy that meets various contingencies [287]. Nasir [280] stated that the relative priority among all STEEP perspectives and the relative contribution of the STEEP criteria are based on a point in time. The priorities, preferences, and judgments are a reflection of the time that of when the expert judgments are made. These priorities and preferences are prone to changes by time. Therefore, if the decision makers observe changes that can affect 
the decision outcomes, it may be necessary to re-evaluate priorities and relative contributions. This can be carried out through sensitivity analysis.

"Sensitivity analysis is the study of how the uncertainty in the output of a mathematical model or system can be apportioned to different sources of uncertainty in its inputs" [288]. Knowing the tolerance of expert pair-wise judgments may help experts reach consensus with acceptable disagreement levels. Developing “what-if' scenarios through Sensitivity Analysis would help decision makers observe the impact of changing the relative values of perspectives or key criteria on the ranking of their technology [280]. The subjective values could change over time, but the sensitivity of the results to changes in any decision element can be determined, and tolerance limits can be identified before any change will take place in the final results [258]. Sensitivity Analysis was used by Phan to test the sensitivity of the output indicators by calculating the allowable range of changes in the output indicators to preserve the priority of the sub-factors [281]. Ho [289] utilized Chen [259] HDM SA algorithms, to explore whether the differences in each pair of experts change the rank order of the alternatives.

Our model for assessing the effective policies to mitigate EV adoption barriers uses alternatives. Conducting Sensitivity Analysis will help our model become robust in multiple aspects. According to Ho [289], Sensitivity Analysis enables researchers to investigate the effect of changes at the policy and strategy levels on decisions at the operational level. Winebrake and Creswick [290] state that the most contribution that Sensitivity Analysis does to HDM model is that it helps generate scenarios of possible rankings of decision alternatives under different conditions. 
There are three alternative approaches to conducting Sensitivity Analysis on HDM: 1) Numerical Incremental Analysis, 2) Simulations Approach, and 3) Mathematical Deduction. Mathematical Deduction is better than the other two for various reasons. It has a precisely defined threshold value to any decimal place and is accurate once the deduction process has been verified. In addition to this, it has less computational complexity since it does not depend on repetitive iterations or large replications [259].

The literature is not rich regarding Sensitivity Analysis applications in HDM, but the HDMSA algorithm of Chen \& Kocaoglu is very comprehensive.

Chen and Kocaoglu [258] explain allowable range of perturbations at top level, middle levels, and the bottom level of the decision hierarchy. Sensitivity Analysis is an accurate and comprehensive method to examine the impact of changes in different levels of a hierarchical decision model on the ranking of the alternatives.

"Tolerance analysis of mechanical assemblies is an essential step in the design and manufacturing of high quality products. The appropriate allocation of tolerances among the separate parts in an assembly can result in lower costs per assembly and higher probability of fit, reducing the number of rejects or the amount of rework required on components" [291]. Tolerance analysis methods were used on other applications that are subject to accumulated variation. It is also used in multi-criteria decision-making tools such as AHP, HDM and TOPSIS. In HDM, tolerance is defined as the allowable range in which the value of any of the elements in the hierarchy can vary without changing the rank order of decision alternatives at the bottom level. In order to determine the tolerance, the allowable ranges of perturbations are always calculated first [292]. Rankings for alternatives will not change as long as the values 
of the perturbations remain within the allowable range of values. Any changes beyond that allowable range will change the rank of the output indicators and sub-factors [281].

There are different sensitivity coefficients (SCs) proposed in the literature for HDM. SCs are conversion factors that help convert the units of an input quantity into the units of the measurand. SCs are also measures of how much change is produced in the measurand by changes in an input quantity [293]. Chen and Kocaoglu [258] utilized two different approaches to sensitivity analysis: the operating point sensitivity coefficient (OPSC) and the total sensitivity coefficient (TSC). The first describes the SC as the shortest distance from the current contribution value to the edges of its tolerance. It is dependent on the contribution's current value and directions of the change. The latter describes SC as the shorter the tolerances of a decision element's contributions are; the more sensitive the final decision is to variations of that decision element. According to these explanations, the smaller the sensitivity coefficients of a decision element are, the more sensitive the decision is to variations of that element.

It is an axiom of certain decision theories that, when new alternatives are introduced to a decision problem, the ranking of the old alternatives must not change, in other words, rank reversal must not occur [294]. The rationality of this axiom for all applications is questionable, since there are real-world examples where adding new alternatives can change the rank of the existing ones. There are certain circumstances where it is inadmissible for the rank of existing elements to change when a new element is added for consideration [295]. Rank Reversal issue has been discussed for various decision-making models including AHP, HDM, TOPSIS and even Data Envelopment Analysis (DEA). In particular, AHP has been criticized for its 
possible rank reversal phenomenon. Rank reversal means that the relative rankings of two decision alternatives could be reversed when a decision alternative is added or deleted.

The debate on rank reversal includes other MCDM tools as well. In the Borda-Kendall method. In this method rank reversal issue occurs when a candidate is added or dropped out from consideration [296]. Another MCDM model is Simple Additive Weighting (SAW). In this method, it is also observed that rank reversal phenomenon occurs when an alternative is added or removed [297]. TOPSIS, another very widespread MCDM model, is also subject to rank reversal issue. In this method, the ideal solution (IS) - a.k.a. positive-ideal solution - is the solution that maximizes the benefit attributes or criteria and minimizes the cost attributes or criteria. The negative ideal solution (NIS), however, - a.k.a. anti-ideal solution - maximizes the cost attributes or criteria and minimizes the benefit attributes or criteria [298]. This method also suffers from rank reversal -ranks of IS and NIS - when a new decision alternative is added.

According to Chen and Kocaoglu [258], "tolerance is defined as the allowable range in which a contribution value can vary without changing the rank order of decision alternatives". Chen in her dissertation stated that, the shorter the tolerances of a decision element's contributions are, the more sensitive the final decision is to variations of that decision element [259]. "If the Total Sensitivity Coefficient (TSC) of a decision element is one, meaning the tolerance is from zero to one, the decision is not sensitive at all to changes that occur to the contributions of this element" [258].

All this being said, the fundamentals of how to deal with Tolerances, and adding New decision alternatives to an HDM are established by Chen and Kocaoglu [258] studies. 


\section{CHAPTER - RESULTS and ANALYSIS}

24 experts from EV manufacturers, academic institutions, and NGOs provided expert judgments for our research model. This section shows and analyzes the results.

\subsection{Experts}

The experts are listed below. Their names will not be identified in this study to protect their identities.

Expert 1: Academician. Department Chair of Economics.

Expert 2: Manufacturer. Expert has converted an ICE vehicle to an EV, worked in EV manufacturing.

Expert 3: NGO. Working in one of the leading NGOs in the field and has researched all aspects of EV. Publishes and meets with policy makers and government officials for EV Adoption on a regular basis.

Expert 4: Manufacturer. Executive level in Engineering in an EV company. Has several years of experience in EV companies and has knowledge in all aspects of EV adoption.

Expert 5: Academician. Author of highly cited academic papers on EV Adoption and Subsidies. Has PhD in Public Policy. Worked in a vehicle manufacturing.

Expert 6: NGO/Academician. Works closely with university, city planning and transportation decision makers.

Expert 7: CEO of EV Manufacturer. 
Expert 8: Academician. Has several research papers on EV.

Expert 9: Academician. Has several papers on EV and the field of Electric Utility. His EV paper was cited over 400 times.

Expert 10: Academician in Economics. Has several research papers on EV.

Expert 11: Academician. Has several research papers on EV.

Expert 12: Academician. Has several research papers on EV.

Expert 13: Academician researching in transportation field. His EV paper was cited over 200 times.

Expert 14: Manufacturer. Specialized on Energy and Battery technologies.

Expert 15: Manufacturer. Lead Engineer, specialized on Battery technologies.

Expert 16: Manufacturer. Executive level in an EV company.

Expert 17: Manufacturer. PhD holder battery engineer. Expert on different chemistries, sourcing and cost aspect of batteries.

Expert 18: Manufacturer. Program manager of sustainable energy and environmental aspect in an EV company.

Expert 19: Manufacturer. Manager of Environmental and Safety.

Expert 20: Manufacturer. Senior Manager, Strategy and Business Development. 
Expert 21: Manufacturer. Senior Manager, Business Planning.

Expert 22: Manufacturer. Senior Manager, Business Planning and Operations.

Expert 23: Academician. EV Adoption expert.

Expert 24: Manufacturer. Senior Manager, Manager of Environmental and Safety.

Expert 25: Manufacturer. PhD holder in Engineering and Public Policy, Senior Modeling Engineer.

Below is a table that summarizes expert panels including which experts provided expert judgments and which validated the model. 


\begin{tabular}{|c|c|c|c|c|}
\hline $\begin{array}{l}\text { EXPERT } \\
\text { PANELS }\end{array}$ & $\begin{array}{l}\text { Experts } \\
\text { provided } \\
\text { Judgments }\end{array}$ & $\begin{array}{l}\text { Total Experts } \\
\text { Provided } \\
\text { Judgments }\end{array}$ & $\begin{array}{l}\text { Experts validated } \\
\text { the Model }\end{array}$ & $\begin{array}{c}\text { Total Experts } \\
\text { Provided } \\
\text { Validated }\end{array}$ \\
\hline Perspectives & $\begin{array}{l}\text { Expert 1, 2, 3, } \\
4,5,6,7,8,9 \\
10,11,16\end{array}$ & 12 & $\begin{array}{l}\text { Expert } 1,2,3,4,5,6,7 \\
8,9,10,11,16,20,25\end{array}$ & 14 \\
\hline Social Barriers & $\begin{array}{l}\text { Expert } 1,2,3 \text {, } \\
4,5,6,7,8,9 \\
10,11,12\end{array}$ & 12 & $\begin{array}{l}\text { Expert 1, 2, 3, 4, 5, 6, 7, } \\
8,9,10,11,12,20,21 \\
22,23,25\end{array}$ & 17 \\
\hline $\begin{array}{l}\text { Technical } \\
\text { Barriers }\end{array}$ & $\begin{array}{l}\text { Expert } 1,2,3, \\
4,5,6,7,8,9 \\
10,11,13,14 \\
15,16,17\end{array}$ & 16 & $\begin{array}{l}\text { Expert } 1,2,3,4,5,6,7 \\
8,9,10,11,13,14,15 \\
16,17,20,23,25\end{array}$ & 19 \\
\hline $\begin{array}{l}\text { Environmental } \\
\text { Barriers }\end{array}$ & $\begin{array}{l}\text { Expert 1, 2, 3, } \\
4,5,6,7,8,9 \\
10,11,13,14 \\
17,18\end{array}$ & 14 & $\begin{array}{l}\text { Expert } 1,2,3,4,5,6,7 \\
8,9,10,11,13,14,17 \\
18,19,20,23,24,25\end{array}$ & 20 \\
\hline $\begin{array}{l}\text { Economic } \\
\text { Barriers }\end{array}$ & $\begin{array}{l}\text { Expert 1, 2, 3, } \\
4,5,6,7,8,9 \\
10,11,12,14 \\
17\end{array}$ & 14 & $\begin{array}{l}\text { Expert } 1,2,3,4,5,6,7 \\
8,9,10,11,12,14,17 \\
20,23,25\end{array}$ & 17 \\
\hline $\begin{array}{l}\text { Political } \\
\text { Barriers }\end{array}$ & $\begin{array}{l}\text { Expert } 1,2,3 \text {, } \\
4,5,6,7,8,9 \\
10,11,12\end{array}$ & 12 & $\begin{array}{l}\text { Expert 1, 2, 3, 4, 5, 6, 7, } \\
8,9,10,11,12,20,21 \\
22,23,25\end{array}$ & 17 \\
\hline Policies & $\begin{array}{l}\text { Expert 1, 2, 3, } \\
4,5,6,7,8,9 \\
10,11\end{array}$ & 11 & $\begin{array}{l}\text { Expert } 1,2,3,4,5,6,7 \\
8,9,10,11,25\end{array}$ & 12 \\
\hline
\end{tabular}

Table 6. Expert Panels

\subsection{Perspectives}

For the perspectives level, 12 experts provided their judgments. 


\begin{tabular}{|c|c|c|c|c|c|c|}
\hline \multirow[b]{2}{*}{ Expert Alias } & \multicolumn{5}{|c|}{ PERSPECTIVES } & \multirow[b]{2}{*}{ INCONSIST } \\
\hline & Social & Technical & Environmental & Economic & Political & \\
\hline Expert 1 & 0.11 & 0.22 & 0.10 & 0.34 & 0.22 & 0.01 \\
\hline Expert 2 & 0.25 & 0.14 & 0.29 & 0.14 & 0.18 & 0.01 \\
\hline Expert 3 & 0.2 & 0.25 & 0.06 & 0.35 & 0.15 & 0.01 \\
\hline Expert 4 & 0.21 & 0.12 & 0.11 & 0.24 & 0.31 & 0.01 \\
\hline Expert 5 & 0.25 & 0.12 & 0.09 & 0.33 & 0.21 & 0.02 \\
\hline Expert 6 & 0.25 & 0.14 & 0.10 & 0.28 & 0.24 & 0.02 \\
\hline Expert 7 & 0.24 & 0.3 & 0.09 & 0.27 & 0.1 & 0.09 \\
\hline Expert 8 & 0.11 & 0.24 & 0.17 & 0.31 & 0.17 & 0.02 \\
\hline Expert 9 & 0.17 & 0.17 & 0.15 & 0.25 & 0.26 & 0.02 \\
\hline Expert 10 & 0.21 & 0.2 & 0.07 & 0.41 & 0.1 & 0.06 \\
\hline Expert 11 & 0.1 & 0.23 & 0.13 & 0.34 & 0.2 & 0.01 \\
\hline Expert 16 & 0.19 & 0.22 & 0.18 & 0.31 & 0.11 & 0.08 \\
\hline AVERAGE & 0.19 & 0.20 & 0.13 & 0.30 & 0.19 & \\
\hline Max & 0.25 & 0.3 & 0.29 & 0.41 & 0.31 & \\
\hline Min & 0.10 & 0.12 & 0.06 & 0.14 & 0.10 & \\
\hline ST Dev & 0.06 & 0.06 & 0.06 & 0.07 & 0.07 & \\
\hline
\end{tabular}

Table 7. Individual weights and inconsistencies for the Perspective level

For expert judgments on perspectives, the experts were selected from high level executives who have overall knowledge on EV.

After consolidating the experts' judgments, the results are summarized in Figure 7 for the 5 perspectives.

For Social perspective, the maximum value of 0.25 is given by Experts 2,5,6 by 0.25, and the minimum value of 0.10 given by Expert 11 .

For Technical perspective, the maximum is 0.30 by Expert 7 , and the minimum is 0.12 by Expert 5. 
For Environmental perspective, the maximum is 0.29 by Expert 2, and the minimum is 0.16 by Expert 3.

For Economic perspective, the maximum is 0.41 by Expert 10, and the minimum is 0.06 by Expert 3.

For Political perspective, the maximum is 0.31 by Expert 4, and the minimum is 0.10 by Expert 7.

\subsubsection{Results}

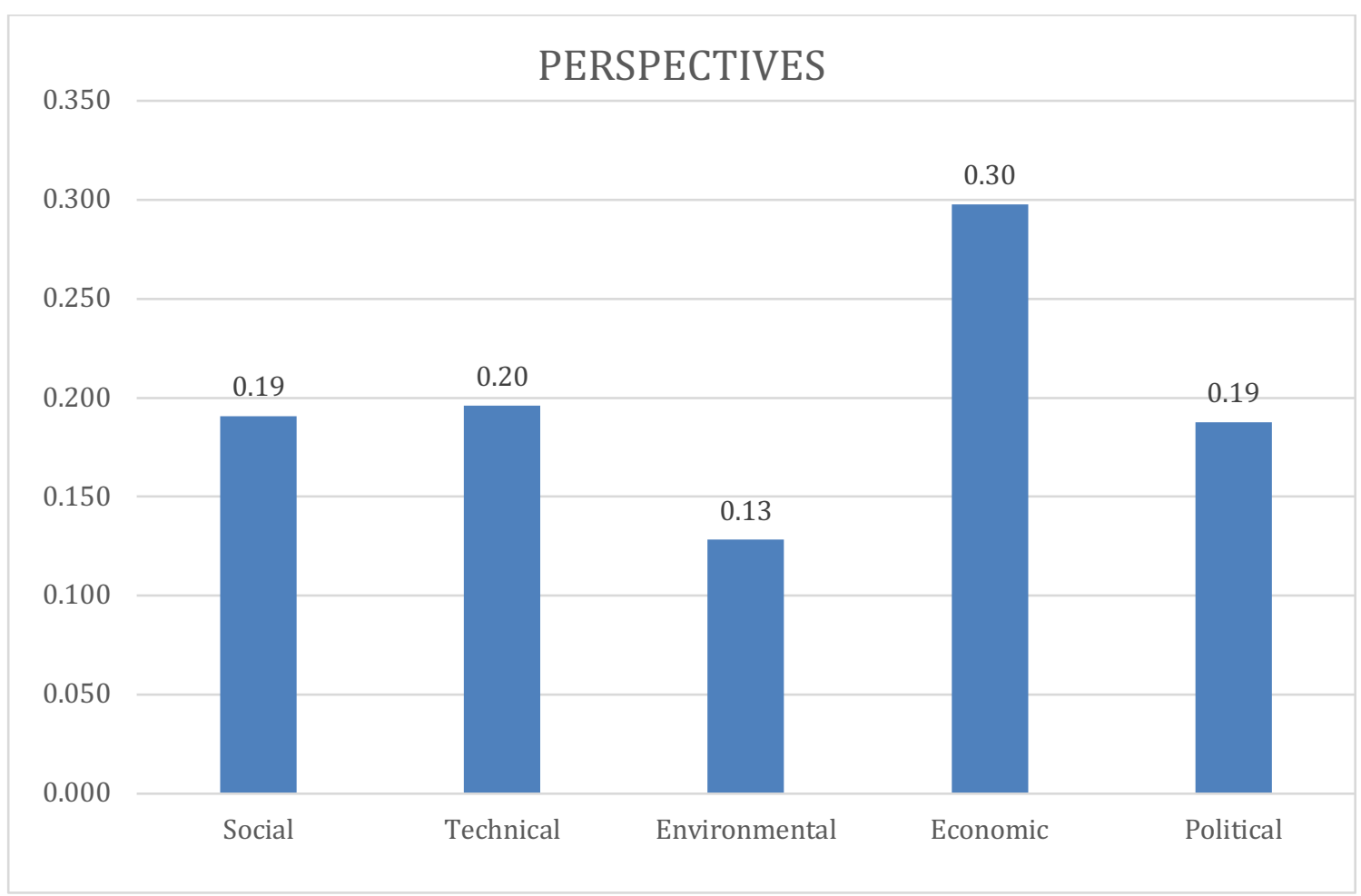

Figure 7. Relative importance of perspectives

The result of expert judgment quantification shows that the leading perspective is the

Economic perspective with the weight of $\mathbf{0 . 3 0}$. The second perspective Technical, received

0.20. This means the importance of leading perspective is perceived by experts $50 \%$ more of 
the closest perspective Technical. Following Technical perspective, Social and Political perspectives share the third place by $\mathbf{0 . 1 9}$. The result indicates that the least important is Environmental perspectives.

Economic, the most important perspective, is 1.5 times more important as the 2 nd most important perspective, Technical. Technical is 1.05 times more important as the two perspectives that share the $3 \mathrm{rd}$ place, Social \& Political, which, in turn are 1.46 times as important as the least important perspective, Environmental. The highest perspective (Economic) is 2.30 times more important as the least important perspective (Environmental).

This means the economic perspective, and the barriers under economic perspective should be the focal point for governments, manufacturers and NGOs in order to facilitate wide EV adoption. The barriers under the economic perspective are Initial Cost, Battery Cost, Relative Cost and Limited models and quantity. Although there were no previous studies in the literature that quantified expert judgments and multiple perspectives, this result confirms what the author has observed in the literature review. In numerous papers, economic factors such as battery and initial cost was mentioned as one of the most important challenges for EV adoption. Quantified expert judgments confirm this statement.

\subsubsection{Inconsistency}

The limit for individual inconsistency measured as the mean standard deviation of the $\mathrm{n}$ ! values calculated for $\mathrm{n}$ elements based on each expert's pairwise comparisons, is 0.1 for expert judgments to be considered viable. For perspective level, Expert 1, 2, 3, 4 and 11 had the lowest inconsistency which is 0.01 . Expert 5, 6, 8 and 9 had also very low inconsistency which is 0.02. Expert 10 had 0.06. Expert 16, and Expert 7 had 0.08 and 0.09 respectively. These two 
experts are executive level experts at EV manufacturers. The time they can invest in the study is far more limited than any other expert. This may be the reason which explain their slightly higher inconsistency, even though their inconsistency is still within the acceptable limit.

\subsubsection{Disagreement}

In our study, we used mean of standard deviation to identify disagreements occurred in perspectives, barriers, and policies section. However, especially when high disagreement was detected in areas by the mean standard deviation, F-Test was useful as a secondary measure to find out to which degree disagreement occurred.

Although F-Test is useful to use as a secondary tool, it has few drawbacks. First, when experts provide identical judgments F-Test result in very high disagreement. Second, if underlying distributions vary greatly from normal distribution, F-Test may not give accurate results.

The disagreement measured as the mean standard deviation of the $\mathrm{m}$ values obtained from $\mathrm{m}$ experts for each of the $\mathrm{n}$ elements at the perspective level, is 0.06 which is very low. This means the disagreement among manufacturers, NGOs, academicians are on the same page for the most part. Given that 0.1 is the cutoff point for disagreements, and the experts being from different regions and different backgrounds yet having low disagreement is a notable result. This strengthens the previous views by some research in the EV literature. Since EV is fighting to gain market share against automotive giants which have developed roots in the market as incumbent companies for over a century and working to change the infrastructure to make the technology a viable option, experts agree that the Economic barriers are the most important barriers. 


\subsubsection{F-Test}

F-test was also utilized for the perspectives level to analyze disagreement among experts. Different experts assigned different values, however the disagreements in the panel can be measured and tested for statistical significance [299].

\begin{tabular}{|l|c|c|c|c|}
\hline Source of Variation & Sum of Square & Deg. of freedom & Mean Square & F-test value \\
\hline Between Subjects: & 0.18 & 4 & .045 & $\mathbf{9 . 1 5}$ \\
\hline Between Conditions: & 0.00 & 11 & 0.000 & \\
\hline Residual: & 0.22 & 44 & 0.005 & \\
\hline Total: & $\mathbf{0 . 3 9}$ & $\mathbf{5 9}$ & & \\
\hline Critical F-value with degrees of freedom 4 \& 44 at 0.01 level: & $\mathbf{3 . 7 8}$ \\
\hline Critical F-value with degrees of freedom 4 \& 44 at 0.025 level: & $\mathbf{3 . 0 9}$ \\
\hline Critical F-value with degrees of freedom 4 \& 44 at 0.05 level: & $\mathbf{2 . 5 8}$ \\
\hline Critical F-value with degrees of freedom 4 \& 44 at 0.1 level: & $\mathbf{2 . 0 8}$ \\
\hline
\end{tabular}

Table 8. F-Test values for disagreements at the perspectives level

The F-Test value is 9.15 for perspectives level. The null hypothesis is to be rejected at 0.01 respectively since all is less than 9.15 . This is consistent with our conclusion in the previous paragraph.

\subsection{Barriers}

For the barriers level, a total of 18 experts provided their judgments.

The figure below shows the result of individual expert judgments, the combined weights for the barriers, the global weights of the barriers after multiplied by their perspectives' weight, and the disagreement among experts.

Because barriers are linked to a specific perspectives (STEEP), they are grouped under their corresponding perspective as shown in the research model. 


\subsubsection{Social Barriers}

\begin{tabular}{|c|c|c|c|c|}
\hline PERSPECTIVES & \multicolumn{4}{|c|}{ SOCIAL } \\
\hline EXPERTS & $\begin{array}{c}\text { Media } \\
\text { Attention }\end{array}$ & $\begin{array}{c}\text { Public } \\
\text { Awarenes } \\
\text { s }\end{array}$ & $\begin{array}{c}\text { Public } \\
\text { Perception }\end{array}$ & $\begin{array}{c}\text { Behavioral } \\
\text { Resistanc } \\
\text { e }\end{array}$ \\
\hline Expert 1 & 0.21 & 0.30 & 0.27 & 0.21 \\
\hline Expert 2 & 0.15 & 0.31 & 0.24 & 0.30 \\
\hline Expert 3 & 0.07 & 0.40 & 0.30 & 0.23 \\
\hline Expert 4 & 0.24 & 0.36 & 0.16 & 0.24 \\
\hline Expert 5 & 0.05 & 0.12 & 0.08 & 0.75 \\
\hline Expert 6 & 0.06 & 0.41 & 0.25 & 0.29 \\
\hline Expert 7 & 0.21 & 0.28 & 0.29 & 0.22 \\
\hline Expert 8 & 0.23 & 0.28 & 0.24 & 0.24 \\
\hline Expert 9 & 0.19 & 0.23 & 0.24 & 0.34 \\
\hline Expert 10 & 0.28 & 0.32 & 0.30 & 0.10 \\
\hline Expert 11 & 0.21 & 0.26 & 0.32 & 0.21 \\
\hline Expert 12 & 0.09 & 0.15 & 0.20 & 0.56 \\
\hline \multicolumn{5}{|l|}{ Expert 13} \\
\hline \multicolumn{5}{|l|}{ Expert 14} \\
\hline \multicolumn{5}{|l|}{ Expert 15 } \\
\hline \multicolumn{5}{|l|}{ Expert 16 } \\
\hline \multicolumn{5}{|l|}{ Expert 17} \\
\hline \multicolumn{5}{|l|}{ Expert 18} \\
\hline Local Weights & 0.17 & 0.29 & 0.24 & 0.31 \\
\hline Max & 0.28 & 0.41 & 0.32 & 0.75 \\
\hline Min & 0.05 & 0.12 & 0.08 & 0.10 \\
\hline St. Dev & 0.08 & 0.09 & 0.07 & 0.18 \\
\hline Disagreement & \multicolumn{4}{|c|}{0.10} \\
\hline
\end{tabular}

Table 9. Individual weights and disagreements for Social Barriers

Table 9 shows the expert judgments, local weights and disagreement for Social Barriers. It also shows the minimum and maximum expert judgments for each barrier. The disagreement among experts for Social Barriers is 0.10 , which can be considered high. This mainly stems from expert judgments on Behavioral Resistance. The standard deviation for this barrier is 0.18 which drives the disagreement higher. One can notice that the min and the max values 
by experts are from a broad spectrum. There are experts who rated this barrier as very critical, and others held that it is not as critical.

The Analysis of Social Barriers show that Expert 5 and 10 are at the other ends of the spectrum. The fact that Expert 5 has worked with EV companies in China may have weighed in when comparing the social barriers.

\subsubsection{Technical Barriers}

\begin{tabular}{|c|c|c|c|c|}
\hline PERSPECTIVES & \multicolumn{4}{|c|}{ TECHNICAL } \\
\hline EXPERTS & $\begin{array}{l}\text { Charging } \\
\text { Network }\end{array}$ & $\begin{array}{c}\text { Charging } \\
\text { Time }\end{array}$ & Range & $\begin{array}{c}\text { Battery } \\
\text { Performance }\end{array}$ \\
\hline Expert 1 & 0.13 & 0.27 & 0.28 & 0.32 \\
\hline Expert 2 & 0.20 & 0.28 & 0.35 & 0.17 \\
\hline Expert 3 & 0.23 & 0.14 & 0.56 & 0.07 \\
\hline Expert 4 & 0.27 & 0.27 & 0.27 & 0.18 \\
\hline Expert 5 & 0.05 & 0.49 & 0.38 & 0.08 \\
\hline Expert 6 & 0.16 & 0.26 & 0.36 & 0.22 \\
\hline Expert 7 & 0.15 & 0.21 & 0.57 & 0.07 \\
\hline Expert 8 & 0.13 & 0.22 & 0.48 & 0.17 \\
\hline Expert 9 & 0.25 & 0.13 & 0.37 & 0.26 \\
\hline Expert 10 & 0.12 & 0.41 & 0.13 & 0.34 \\
\hline Expert 11 & 0.20 & 0.23 & 0.33 & 0.23 \\
\hline \multicolumn{5}{|l|}{ Expert 12} \\
\hline Expert 13 & 0.12 & 0.21 & 0.40 & 0.27 \\
\hline Expert 14 & 0.27 & 0.49 & 0.15 & 0.09 \\
\hline Expert 15 & 0.21 & 0.12 & 0.33 & 0.33 \\
\hline Expert 16 & 0.18 & 0.15 & 0.47 & 0.20 \\
\hline Expert 17 & 0.14 & 0.26 & 0.33 & 0.27 \\
\hline \multicolumn{5}{|l|}{ Expert 18} \\
\hline Local Weights & 0.18 & 0.26 & 0.36 & 0.20 \\
\hline Max & 0.27 & 0.49 & 0.57 & 0.34 \\
\hline Min & 0.05 & 0.12 & 0.13 & 0.07 \\
\hline St. Dev & 0.06 & 0.12 & 0.12 & 0.09 \\
\hline Disagreement & \multicolumn{4}{|c|}{0.10} \\
\hline
\end{tabular}

Table 10. Individual weights and disagreements for Technical Barriers 
The above table shows the expert judgments, local weights and disagreement, along with the minimum and maximum expert judgments for each barrier for Technical Barriers. The disagreement among experts for Technical Barriers is 0.10, which can be considered high. The highest disagreement barriers are Charging Time and Range, both with a standard deviation of 0.12 .

\subsubsection{Environmental Barriers}

\begin{tabular}{|c|c|c|c|}
\hline \multirow[t]{2}{*}{ PERSPECTIVES } & \multicolumn{3}{|c|}{ ENVIRONMENTAL } \\
\hline & $\begin{array}{c}\text { Battery } \\
\text { Production }\end{array}$ & \begin{tabular}{|c} 
Battery \\
Disposal
\end{tabular} & $\begin{array}{c}\text { Electricity } \\
\text { Source }\end{array}$ \\
\hline Expert 1 & 0.43 & 0.27 & 0.31 \\
\hline Expert 2 & 0.21 & 0.31 & 0.48 \\
\hline Expert 3 & 0.17 & 0.05 & 0.78 \\
\hline Expert 4 & 0.33 & 0.27 & 0.40 \\
\hline Expert 5 & 0.12 & 0.10 & 0.78 \\
\hline Expert 6 & 0.22 & 0.12 & 0.66 \\
\hline Expert 7 & 0.34 & 0.32 & 0.34 \\
\hline Expert 8 & 0.69 & 0.12 & 0.19 \\
\hline Expert 9 & 0.35 & 0.28 & 0.37 \\
\hline Expert 10 & 0.23 & 0.63 & 0.14 \\
\hline Expert 11 & 0.33 & 0.33 & 0.33 \\
\hline \multicolumn{4}{|l|}{ Expert 12} \\
\hline Expert 13 & 0.47 & 0.25 & 0.28 \\
\hline Expert 14 & 0.17 & 0.34 & 0.49 \\
\hline \multicolumn{4}{|l|}{ Expert 15} \\
\hline \multicolumn{4}{|l|}{ Expert 16} \\
\hline Expert 17 & 0.07 & 0.81 & 0.12 \\
\hline Expert 18 & 0.29 & 0.20 & 0.51 \\
\hline Local Weights & 0.29 & 0.29 & 0.41 \\
\hline Max & 0.69 & 0.81 & 0.78 \\
\hline Min & 0.07 & 0.05 & 0.12 \\
\hline St. Dev & 0.16 & 0.20 & 0.21 \\
\hline Disagreement & & 0.19 & \\
\hline
\end{tabular}

Table 11. Individual weights and disagreements for Environmental Barriers 
It is important to note that Environmental Barriers has the highest disagreement in this study.

Experts differed on the criticality of the Environmental Barriers. The standard deviation of Battery Production, Battery Disposal, and Electricity Source are 0.16, 0.20, 0.21. Particularly the latter two causes the high disagreement. One of the main reasons underlying this difference as Expert 4, Expert 17, Expert 18 stated at our interview is that due to the novelty of this technology the real consequences of battery disposal is still unknown.

Others held the view that if the electricity is not acquired from clean sources, EV merely exchanges one problem with another. According to results, Electricity Source is the most important environmental barrier. 


\subsubsection{Economic Barriers}

\begin{tabular}{|c|c|c|c|c|}
\hline PERSPECTIVES & \multicolumn{4}{|c|}{ ECONOMIC } \\
\hline EXPERTS & $\begin{array}{r}\text { Initial } \\
\text { Cost }\end{array}$ & $\begin{array}{c}\text { Battery } \\
\text { Cost }\end{array}$ & $\begin{array}{c}\text { Relative } \\
\text { Cost }\end{array}$ & $\begin{array}{l}\text { Limited } \\
\text { Models } \\
\text { Quantity }\end{array}$ \\
\hline Expert 1 & 0.50 & 0.17 & 0.20 & 0.14 \\
\hline Expert 2 & 0.40 & 0.28 & 0.19 & 0.13 \\
\hline Expert 3 & 0.32 & 0.32 & 0.11 & 0.26 \\
\hline Expert 4 & 0.21 & 0.33 & 0.17 & 0.30 \\
\hline Expert 5 & 0.23 & 0.33 & 0.21 & 0.23 \\
\hline Expert 6 & 0.18 & 0.46 & 0.26 & 0.09 \\
\hline Expert 7 & 0.25 & 0.27 & 0.23 & 0.25 \\
\hline Expert 8 & 0.39 & 0.26 & 0.21 & 0.14 \\
\hline Expert 9 & 0.25 & 0.18 & 0.30 & 0.27 \\
\hline Expert 10 & 0.13 & 0.35 & 0.20 & 0.32 \\
\hline Expert 11 & 0.33 & 0.22 & 0.25 & 0.20 \\
\hline Expert 12 & 0.38 & 0.21 & 0.16 & 0.25 \\
\hline \multicolumn{5}{|l|}{ Expert 13} \\
\hline Expert 14 & 0.53 & 0.25 & 0.16 & 0.07 \\
\hline \multicolumn{5}{|l|}{ Expert 15} \\
\hline \multicolumn{5}{|l|}{ Expert 16 } \\
\hline Expert 17 & 0.34 & 0.34 & 0.23 & 0.10 \\
\hline \multicolumn{5}{|l|}{ Expert 18} \\
\hline Local Weights & 0.32 & 0.28 & 0.21 & 0.20 \\
\hline Max & 0.53 & 0.46 & 0.30 & 0.32 \\
\hline Min & 0.13 & 0.17 & 0.11 & 0.07 \\
\hline St. Dev & 0.12 & 0.08 & 0.05 & 0.08 \\
\hline Disagreement & & & 0.08 & \\
\hline
\end{tabular}

Table 12. Individual weights and disagreements for Economic Barriers

Economic Barriers have the least disagreement among experts according to results. Initial cost has the only slightly high standard deviation by 0.12 . Initial cost is the most important barrier among Economic Barriers. 


\subsubsection{Political Barriers}

\begin{tabular}{|c|c|c|c|}
\hline \multirow{2}{*}{\begin{tabular}{|r} 
PERSPECTIVES \\
EXPERTS \\
\end{tabular}} & \multicolumn{3}{|c|}{ POLITICAL } \\
\hline & $\begin{array}{l}\text { Technology } \\
\text { Resistance }\end{array}$ & $\begin{array}{c}\text { Political } \\
\text { Resistance }\end{array}$ & $\begin{array}{c}\text { Shareholders } \\
\text { Pressure }\end{array}$ \\
\hline Expert 1 & 0.20 & 0.29 & 0.51 \\
\hline Expert 2 & 0.46 & 0.22 & 0.32 \\
\hline Expert 3 & 0.86 & 0.09 & 0.05 \\
\hline Expert 4 & 0.45 & 0.25 & 0.30 \\
\hline Expert 5 & 0.57 & 0.23 & 0.19 \\
\hline Expert 6 & 0.39 & 0.23 & 0.37 \\
\hline Expert 7 & 0.35 & 0.35 & 0.30 \\
\hline Expert 8 & 0.23 & 0.17 & 0.60 \\
\hline Expert 9 & 0.21 & 0.40 & 0.39 \\
\hline Expert 10 & 0.48 & 0.13 & 0.40 \\
\hline Expert 11 & 0.31 & 0.27 & 0.43 \\
\hline Expert 12 & 0.33 & 0.33 & 0.33 \\
\hline \multicolumn{4}{|l|}{ Expert 13} \\
\hline \multicolumn{4}{|l|}{ Expert 14} \\
\hline \multicolumn{4}{|l|}{ Expert 15} \\
\hline \multicolumn{4}{|l|}{ Expert 16 } \\
\hline \multicolumn{4}{|l|}{ Expert 17} \\
\hline \multicolumn{4}{|l|}{ Expert 18} \\
\hline Local Weights & 0.40 & 0.25 & 0.35 \\
\hline $\operatorname{Max}$ & 0.86 & 0.40 & 0.60 \\
\hline Min & 0.20 & 0.09 & 0.05 \\
\hline St. Dev & 0.18 & 0.09 & 0.14 \\
\hline Disagreement & & 0.14 & \\
\hline
\end{tabular}

Table 13. Individual weights and disagreements for Political Barriers

The disagreement at this section is 0.14 which can be considered high.

The reason why the disagreement is high is mainly caused by expert judgments on (Entrenched) Technology Resistance and Shareholders' Pressure. The standard deviations of these two barriers are 0.18 and 0.14 respectively. Experts were mostly in agreement that 
Political Resistance is the least important barrier, however they differed on which barrier is the most important one.

\subsubsection{Results}

In summary, the barriers will be explained in three groups.

1) Most Critical Barriers (5)

2) Medium Level Barriers (6)

3) Low Level Barriers (7)

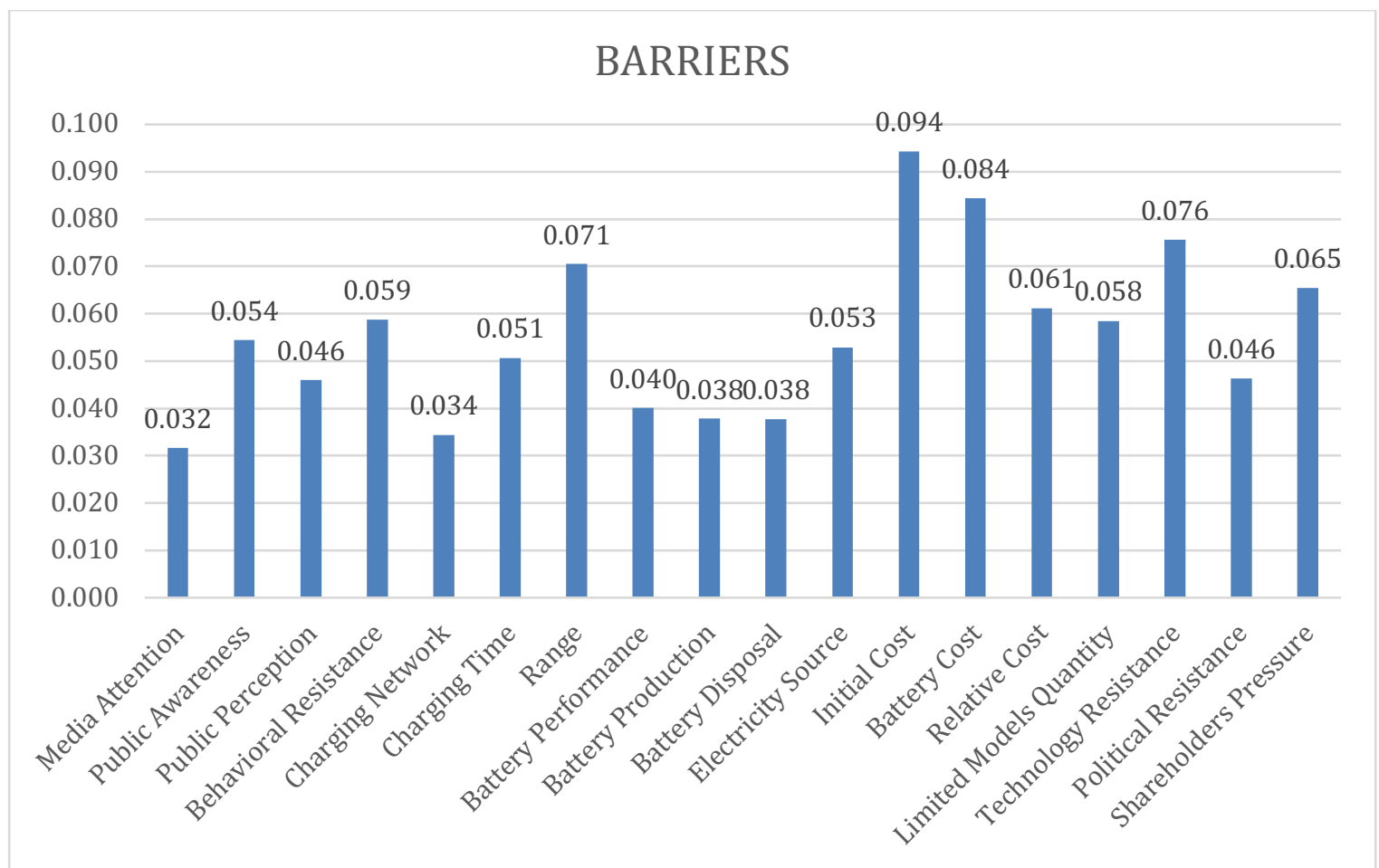

Figure 8. Relative Importance Weights for the Barriers

As shown in the above figure, expert judgments indicate that initial cost is the most important challenge for EV adoption. Cost was one of the major concerns that had been identified in literature. Based on the technology adoption literature, as previously mentioned, cost is an exogenous driver to diffusion. Those who come to probit models from the literature on 
epidemics will naturally focus in the first instance on learning and search costs. We divided cost into initial costs and battery cost in our model. This was confirmed by the experts when the model was being validated by majority of the experts. Initial Cost was evaluated as the most important barrier with relative importance value of 0.094 , followed by Battery Cost with a relative importance of 0.084 . The deficit is noteworthy between 2 barriers related to cost. Battery cost has been raised as a main concern in the literature [300]. It was stated that "battery cost structure is mostly based on labor cost (which are high), electronic parts, and volatility of key metals' price that prevents manufacturing cost to decrease" [39]. However, Tesla has built and dedicated the factory building for its battery packs. "The Gigafactory measures in at 5.5 million square feet, easily making it the biggest building in the world in terms of its physical footprint. The closest building to the Gigafactory is Boeing's Everett factory in Washington state with a square footage of 4.3 million" [301]. The previous discussion in the literature suggested that the high production costs may still exist and the governments' price subsidizing as a solution are debatable [115]. According to Global EV outlook 2017, even advanced lithium-ion technology currently has a high cost although it has the potential for cost reduction in the future [302]. The battery cost, being the second most important barrier, confirms the claims, that were raised in the literature.

The third most important barrier is technology resistance which represents entrenched technology (ICE)'s resistance to EV deployment in order to protect its market share. Although EV has little market share in most of the world, the trend indicates that especially in countries with substantial policy support, it can exponentially gain market share. Global EV outlook's data in 2017 reveals that EV in Norway doubled its market share in 2 years (2014-2016). In 
the US, it still has less than $1 \%$ market share even though the automotive giants view $\mathrm{EV}$ as a threat [303], [304].

Range, which was one of the most mentioned challenges for EV has taken the 4th place by 0.071. In recent publications, range was seen as the number one challenge for EV. Those who rated high scores on Range are mainly from NGOs and academicians. Majority of manufacturers, high level executives and engineers (including EV owners) rated range with average scores as a barrier. Manufacturers, and those who specialize in battery technologies not seeing Range as the most important barrier may be due to recent advancements in the current and upcoming battery technology. Another reason may be that currently EV passed a certain period where the current EV owners already experienced the EV range in their daily commute and the anxiety that was voiced previously is no longer viewed as an issue.

The $5^{\text {th }}$ most important barrier is shareholders' pressure, where investors want EV manufacturers to release models when the product is still immature, in hopes of cash inflow. EV manufacturers, especially those that are considered startups are in need of prompt cash inflow in order to survive in the relentless automotive sector. Shareholders' pressure has been discussed as a critical challenge for new products in the technology adoption literature and is valid virtually for all disruptive technologies as they enter the market. This barrier has been confirmed by majority of the experts and receiving a relatively high score can be considered as another notable finding of our study. These 5 critical barriers stated above should be focused as most important challenges for EV adoption by policy makers, manufacturers, and governments. Also, NGOs should spend their efforts mostly by focusing on these 5 barriers. 
The relative importance of the other barriers such as limited models and quantity, relative cost (gas price vs electricity cost), electricity source, charging time, behavioral resistance, and public awareness range between 0.051-0.061. They can be considered as mid-level criticality after the first 5 barriers. These results are not surprising. The reason may be that experts viewing removing gas usage from roads is a greater challenge than regulating cleanliness of the electricity that come from power plants.

Tesla, Nissan leaf, Chevrolet's Volt \& Bolt, Volvo's announcement to make all models Electric or Hybrid starting in 2019 may be the underlying reasons for public awareness not to have a higher relative importance [305].

The quantity of available EVs is not as great a challenge as it was 5 years ago. Many automotive giants have already announced or released their EV models including Mercedes and BMW. This may be one of the reasons for limited models \& quantity to be in the average importance.

The introduction of superchargers that reduce charging time on the roads to 45 minutes $(80 \%$ tank fullness), residential charging options, and new chemistries that reduce the charging time for low performance EV may prevent charging time to climb up in the importance levels.

Finally, media attention, public perception, charging network, battery performance, battery production \& battery disposal environmental issues, and political resistance received importance levels between 0.032-0.046. These barriers will be considered as low-level barriers.

Among these barriers, the most interesting finding is that charging network received 0.034 as the second lowest barrier. Charging station network has been viewed as one of the major challenges by the literature along with range. Among the experts, almost all academicians, 
NGOs, majority of executive levels, EV owners, and engineers rated charging station with very low importance. One of the potential reasons is the improvement of residential charging. Second reason may be customers' direct experience with their EVs in their daily commute. Third reason may be the recent charging network deployment. Tesla has recently released the charging network map of its current and upcoming stations. The network that covers majority of the country, especially the metropolitan cities may have been one of the underlying factors for charging network to be one of the least critical barriers. Majority of the environmental barriers are expected to take lower levels of criticality due to widespread belief that the environmental issues that $\mathrm{EV}$ will has to address is less critical than the environmental issues that EV will remove by its widespread use.

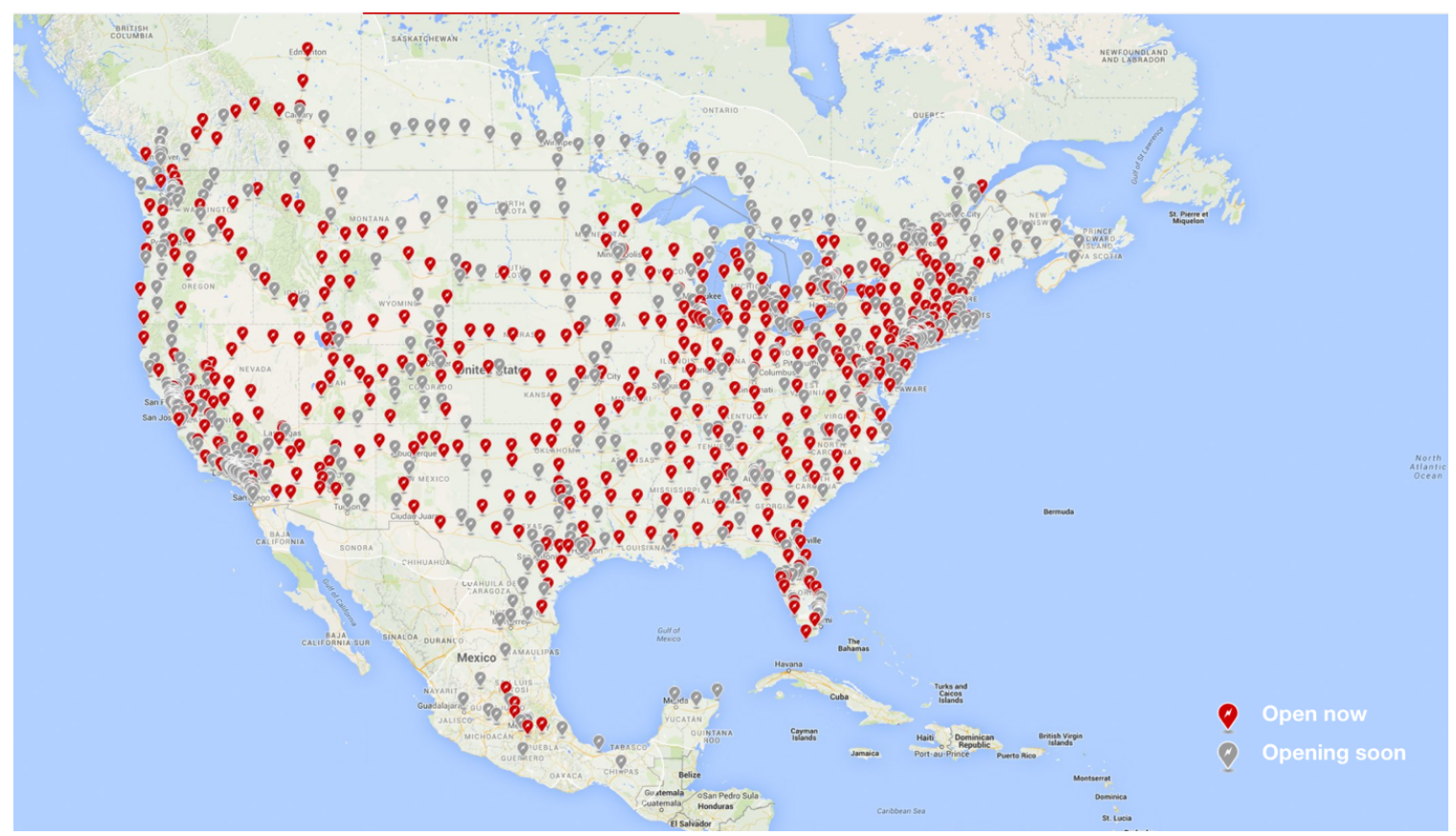

Figure 9. Tesla supercharger charging map[306] 
Finally, political resistance has a lower relative value than technology resistance and shareholders pressure among the political barriers. The lobbying activities for and against EV may be lowering the importance level of this barrier.

\subsubsection{Disagreement}

The disagreement at this level is measured among the 5 perspective level categories. The experts' disagreement for their judgments in social, technical, environmental, economic and technical barriers. The mean of the standard deviation of the expert judgments on barriers have been used to measure the disagreements in each category.

The technical level barriers received the lowest disagreement, which is 0.08. Since the acceptable limit for disagreement is 0.1 , this is considered an acceptable level of disagreement. Given that experts from Academia, NGOs, manufacturing provided their judgments, having low disagreement on this level is an important output of this study.

The results show that Social and Technical Barriers received a borderline disagreement. Both perspectives taking 0.1 can be still considered an acceptable level of disagreement.

The disagreement on the Political group barriers is 0.14 and this is more than the threshold (0.1). One of the main factors enabling this disagreement to occur is that when political resistance received close judgment from different expert segments, technology resistance and shareholders pressure received opposite importance levels between academicians and manufacturers/executive level experts. Since manufacturers/executive level face shareholders pressure in their daily work life, it is understandable that they hold shareholders pressure as more of a critical challenge than academicians do. 
Finally, the disagreement among environmental barriers is the greatest disagreement with 0.18 . Although this is not a far-fetched disagreement, it still requires attention from stakeholders. We believe that the primary reason for the disagreement is that the environmental effect of $\mathrm{EV}$ is still not known precisely. The environmental engineers still are not fully sure of the environmental impact of EV due to the initial phase of the technology. That said, majority of environmental engineers rated the electricity source as the most important environmental barrier along with some academicians. Other group of academicians held that battery production related issues are more important than that of electricity source.

\subsubsection{F-Test}

F-test was used as a secondary measure for disagreement at Barriers level to analyze disagreement among experts.

\subsection{Social Barriers}

Table 14 shows the disagreement among experts at Social barriers.

\begin{tabular}{|l|c|c|c|c|}
\hline Source of Variation & Sum of Square & Deg. of freedom & Mean Square & F-test value \\
\hline Between Subjects: & 0.14 & 3 & .047 & $\mathbf{2 . 8 1}$ \\
\hline Between Conditions: & 0.00 & 11 & 0.000 & \\
\hline Residual: & 0.55 & 33 & 0.017 & \\
\hline Total: & $\mathbf{0 . 6 9}$ & 47 & & \\
\hline Critical F-value with degrees of freedom 3 \& 33 at 0.01 level: & $\mathbf{4 . 4 4}$ \\
\hline Critical F-value with degrees of freedom 3 \& 33 at $\mathbf{0 . 0 2 5}$ level: & $\mathbf{3 . 5 4}$ \\
\hline Critical F-value with degrees of freedom 3 \& 33 at 0.05 level: & $\mathbf{2 . 8 9}$ \\
\hline Critical F-value with degrees of freedom 3 \& 33 at 0.1 level: & $\mathbf{2 . 2 6}$ \\
\hline
\end{tabular}

Table 14. F-Test values for Social Barriers

F-Test value is 2.81 for Social Barriers level. level. Therefore there is some disagreement among experts in Social Barriers but Null hypothesis is still rejected at 0.1 . 


\subsection{Technical Barriers}

Table 15 shows the disagreement among experts at Technical barriers.

\begin{tabular}{|l|c|c|c|c|}
\hline Source of Variation & Sum of Square & Deg. of freedom & Mean Square & F-test value \\
\hline Between Subjects: & 0.32 & 3 & .106 & $\mathbf{7 . 7 9}$ \\
\hline Between Conditions: & 0.00 & 15 & 0.000 & \\
\hline Residual: & 0.61 & 45 & 0.014 & \\
\hline Total: & $\mathbf{0 . 9 3}$ & $\mathbf{6 3}$ & & \\
\hline Critical F-value with degrees of freedom 3 \& 45 at $\mathbf{0 . 0 1}$ level: & $\mathbf{4 . 2 5}$ \\
\hline Critical F-value with degrees of freedom 3 \& 45 at $\mathbf{0 . 0 2 5}$ level: & $\mathbf{3 . 4 2}$ \\
\hline Critical F-value with degrees of freedom 3 \& 45 at 0.05 level: & $\mathbf{2 . 8 1}$ \\
\hline Critical F-value with degrees of freedom 3 \& 45 at 0.1 level: & $\mathbf{2 . 2 1}$ \\
\hline
\end{tabular}

Table 15.F-Test values for Technical Barriers

F-Test value is 7.79 for Technical Barriers. The null hypothesis is rejected at 0.01 . Disagreement does not exist at Technical Barriers.

\subsection{Environmental Barriers}

Table 16 shows the disagreement among experts at Environmental barriers.

\begin{tabular}{|l|c|c|c|c|}
\hline Source of Variation & Sum of Square & Deg. of freedom & Mean Square & F-test value \\
\hline Between Subjects: & 0.14 & 2 & .07 & 1.3 \\
\hline Between Conditions: & 0.00 & 14 & 0.000 & \\
\hline Residual: & 1.50 & 28 & 0.053 & \\
\hline Total: & 1.64 & 44 & & \\
\hline Critical F-value with degrees of freedom 2 \& 28 at 0.01 level: & $\mathbf{5 . 4 5}$ \\
\hline Critical F-value with degrees of freedom 2 \& 28 at 0.025 level: & $\mathbf{4 . 2 2}$ \\
\hline Critical F-value with degrees of freedom 2 \& 28 at 0.05 level: & $\mathbf{3 . 3 4}$ \\
\hline Critical F-value with degrees of freedom 2 \& 28 at 0.1 level: & $\mathbf{2 . 5}$ \\
\hline
\end{tabular}

Table 16. F-Test values for Environmental Barriers 
F-Test value is 1.3 for Environmental Barriers. The null hypothesis cannot be rejected even at the 0.1 level.

There is disagreement in Environmental Barriers. Disagreement here resulted as the highest among other STEEP barriers, which is consistent with our findings in the original inconsistency measurement method (0.19).

\subsection{Economic Barriers}

Table 17 shows the disagreement among experts at Economic barriers.

\begin{tabular}{|l|c|c|c|c|}
\hline Source of Variation & Sum of Square & Deg. of freedom & Mean Square & F-test value \\
\hline Between Subjects: & 0.15 & 3 & .049 & $\mathbf{5 . 0 8}$ \\
\hline Between Conditions: & 0.00 & 13 & 0.000 & \\
\hline Residual: & 0.38 & 39 & 0.010 & \\
\hline Total: & $\mathbf{0 . 5 2}$ & $\mathbf{5 5}$ & & \\
\hline Critical F-value with degrees of freedom 3 \& 39 at 0.01 level: & $\mathbf{4 . 3 3}$ \\
\hline Critical F-value with degrees of freedom 3 \& 39 at $\mathbf{0 . 0 2 5}$ level: & $\mathbf{3 . 4 7}$ \\
\hline Critical F-value with degrees of freedom 3 \& 39 at $\mathbf{0 . 0 5}$ level: & $\mathbf{2 . 8 5}$ \\
\hline Critical F-value with degrees of freedom 3 \& 39 at 0.1 level: & $\mathbf{2 . 2 3}$ \\
\hline
\end{tabular}

Table 17. F-Test values for Economic Barriers

F-Test value is 5.08 for Economic Barriers. As seen in the above table the null hypothesis is rejected at 0.01. There is no disagreement in Economic Barriers.

\subsection{Political Barriers}

Table 18 shows the disagreement among experts at Political barriers. 
Source of Variation Sum of Square Deg. of freedom Mean Square F-test value

\begin{tabular}{|c|c|c|c|c|}
\hline Between Subjects: & 0.15 & 2 & .076 & 2.46 \\
\hline Between Conditions: & 0.00 & 11 & 0.000 & \\
\hline Residual: & 0.68 & 22 & 0.031 & \\
\hline Total: & 0.84 & 35 & & \\
\hline \multicolumn{4}{|c|}{ Critical F-value with degrees of freedom $2 \& 22$ at 0.01 level: } & 5.72 \\
\hline \multicolumn{4}{|c|}{ Critical F-value with degrees of freedom $2 \& 22$ at 0.025 level: } & 4.38 \\
\hline \multicolumn{4}{|c|}{ Critical F-value with degrees of freedom $2 \& 22$ at 0.05 level: } & 3.44 \\
\hline \multicolumn{4}{|c|}{ Critical F-value with degrees of freedom $2 \& 22$ at 0.1 level: } & 2.56 \\
\hline
\end{tabular}

Table 18. F-Test values for Political Barriers

F-Test value is 2.46 for Political Barriers level. The null hypothesis is cannot be rejected at 0.1 level. There is strong disagreement at Political barriers level.

\subsubsection{Inconsistency}

The individual inconsistency at this level is acceptable for the most part.

There is one measured inconsistency that is above 0.1. One of them by a CEO (Expert on Social level which is 4 barriers. Although 0.12 is not a very high inconsistency particularly when 4 elements are compared, it requires a more detailed analysis. For barriers level, there is one high inconsistency surpassing 0.1 , and 3 inconsistencies are close to 0.1 (all 3 are 0.07 ). We investigated these three inconsistencies using RSV.

\subsubsection{1. $\quad$ RSV (Root of the Sum of Variances)}

The original inconsistency measure recommended by Kocaoglu [265] was calculated at the mean of the $\mathrm{n}$ standard deviations for $\mathrm{n}$ ! orientations of each of the $\mathrm{n}$ decision elements. The acceptable limit was 0.1 for any number of elements. A more robust measure was developed by Abbas [256] in his dissertation. It is the RSV (Square root of the sum of variances) for $n$ elements calculated for $n$ ! values obtained for each element. The acceptable limits of the RSV vary as $\mathrm{n}$ varies and as the $\alpha$ level (the probability of randomness in the expert's judgment) 
varies as shown in Table 19. The original measure is conservative for $n \geq 5$. We are using RSV in this research.

We used RSV in our research when high inconsistency is indicated by the original inconsistency measure. The original inconsistency method used the 0.1 threshold regardless of the number of elements, therefore when experts were flagged as inconsistent (by being over 0.1), we employed RSV to investigate whether they are considered consistent by RSV inconsistency measure.

The first inconsistency to be analyzed is Expert 7's inconsistency on Social Barriers. Using RSV, Expert 7's inconsistency is 0.2380 .

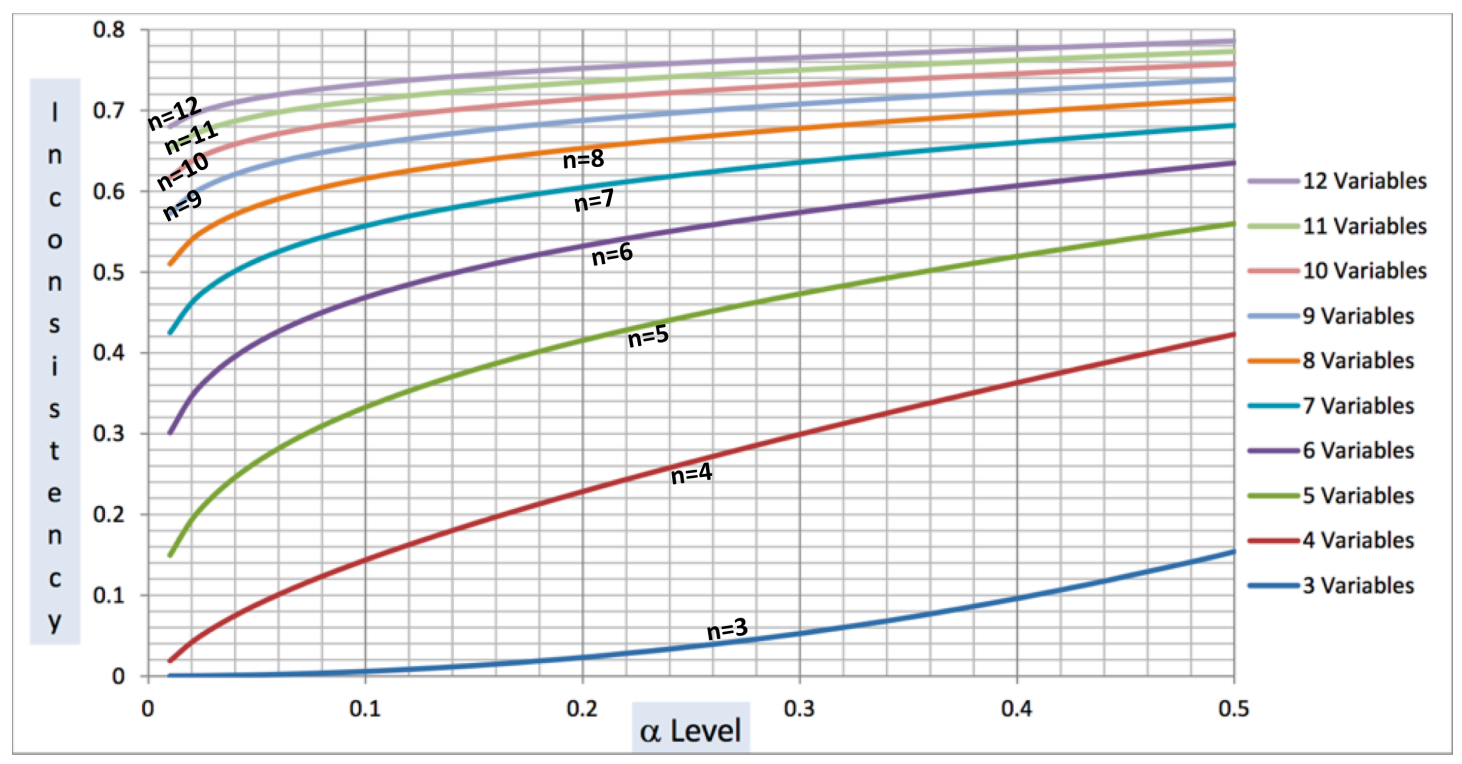

Figure 10. Inconsistency Threshold Limits for 3 - 12 Decision Variables [256]

When the curve for 4 elements is followed in Figure 10, it can be seen that the inconsistency 0.238 corresponds to approximately $\alpha=0.21$. This means there is 0.21 probability that there is randomness in the judgments provided by Expert 7 on Social level elements. The threshold limits from Figure 10 are tabulated by Abbas [256] in Table 19 below. 


\begin{tabular}{|c|c|c|c|c|c|c|c|c|c|c|}
\hline \multirow[b]{2}{*}{ Percentile $(\alpha)$} & \multicolumn{10}{|c|}{ Number of variables } \\
\hline & 3 & 4 & 5 & 6 & 7 & 8 & 9 & 10 & 11 & 12 \\
\hline 0.01 & 0.0001 & 0.0188 & 0.1495 & 0.3012 & 0.4249 & 0.5100 & 0.5723 & 0.6170 & 0.6521 & 0.6800 \\
\hline 0.02 & 0.0002 & 0.0418 & 0.1934 & 0.3462 & 0.4620 & 0.5400 & 0.5961 & 0.6371 & 0.6690 & 0.6945 \\
\hline 0.03 & 0.0005 & 0.0596 & 0.2230 & 0.3745 & 0.4847 & 0.5581 & 0.6105 & 0.6493 & 0.6793 & 0.7034 \\
\hline 0.04 & 0.0009 & 0.0748 & 0.2460 & 0.3955 & 0.5012 & 0.5713 & 0.6211 & 0.6582 & 0.6868 & 0.7100 \\
\hline 0.05 & 0.0014 & 0.0884 & 0.2651 & 0.4124 & 0.5143 & 0.5818 & 0.6295 & 0.6653 & 0.6928 & 0.7152 \\
\hline 0.06 & 0.0021 & 0.1008 & 0.2816 & 0.4266 & 0.5253 & 0.5904 & 0.6365 & 0.6712 & 0.6978 & 0.7196 \\
\hline 0.07 & 0.0028 & 0.1124 & 0.2963 & 0.4390 & 0.5347 & 0.5979 & 0.6425 & 0.6763 & 0.7022 & 0.7234 \\
\hline 0.08 & 0.0037 & 0.1233 & 0.3095 & 0.4499 & 0.5430 & 0.6045 & 0.6478 & 0.6807 & 0.7060 & 0.7267 \\
\hline 0.09 & 0.0046 & 0.1337 & 0.3215 & 0.4597 & 0.5505 & 0.6104 & 0.6526 & 0.6848 & 0.7095 & 0.7298 \\
\hline 0.10 & 0.0057 & 0.1437 & 0.3327 & 0.4686 & 0.5572 & 0.6157 & 0.6569 & 0.6884 & 0.7126 & 0.7325 \\
\hline 0.11 & 0.0069 & 0.1532 & 0.3430 & 0.4769 & 0.5634 & 0.6206 & 0.6609 & 0.6918 & 0.7155 & 0.7350 \\
\hline 0.12 & 0.0083 & 0.1625 & 0.3528 & 0.4845 & 0.5691 & 0.6252 & 0.6646 & 0.6949 & 0.7182 & 0.7374 \\
\hline 0.13 & 0.0097 & 0.1714 & 0.3620 & 0.4916 & 0.5745 & 0.6294 & 0.6681 & 0.6978 & 0.7207 & 0.7396 \\
\hline 0.14 & 0.0113 & 0.1801 & 0.3706 & 0.4983 & 0.5795 & 0.6334 & 0.6713 & 0.7005 & 0.7231 & 0.7417 \\
\hline 0.15 & 0.0129 & 0.1886 & 0.3789 & 0.5047 & 0.5842 & 0.6371 & 0.6743 & 0.7031 & 0.7253 & 0.7436 \\
\hline 0.16 & 0.0147 & 0.1969 & 0.3868 & 0.5106 & 0.5887 & 0.6406 & 0.6772 & 0.7056 & 0.7274 & 0.7455 \\
\hline 0.17 & 0.0166 & 0.2050 & 0.3944 & 0.5163 & 0.5929 & 0.6440 & 0.6800 & 0.7079 & 0.7294 & 0.7473 \\
\hline 0.18 & 0.0187 & 0.2129 & 0.4016 & 0.5218 & 0.5970 & 0.6472 & 0.6826 & 0.7101 & 0.7313 & 0.7490 \\
\hline 0.19 & 0.0207 & 0.2207 & 0.4086 & 0.5270 & 0.6009 & 0.6502 & 0.6851 & 0.7122 & 0.7332 & 0.7506 \\
\hline 0.20 & 0.0230 & 0.2283 & 0.4154 & 0.5320 & 0.6046 & 0.6532 & 0.6875 & 0.7143 & 0.7350 & 0.7521 \\
\hline 0.21 & 0.0254 & 0.2359 & 0.4219 & 0.5368 & 0.6081 & 0.6560 & 0.6899 & 0.7163 & 0.7367 & 0.7537 \\
\hline 0.22 & 0.0281 & 0.2433 & 0.4282 & 0.5414 & 0.6116 & 0.6587 & 0.6921 & 0.7182 & 0.7383 & 0.7551 \\
\hline 0.23 & 0.0306 & 0.2506 & 0.4343 & 0.5459 & 0.6149 & 0.6614 & 0.6943 & 0.7200 & 0.7399 & 0.7565 \\
\hline 0.24 & 0.0334 & 0.2578 & 0.4403 & 0.5502 & 0.6181 & 0.6639 & 0.6964 & 0.7218 & 0.7415 & 0.7579 \\
\hline 0.25 & 0.0363 & 0.2648 & 0.4461 & 0.5544 & 0.6212 & 0.6664 & 0.6984 & 0.7235 & 0.7430 & 0.7592 \\
\hline
\end{tabular}

Table 19. : Inconsistency Threshold Limits for $3-12$ Decision Variables at $\alpha=0.01$ to $\alpha=0.25[256]$

As seen in Table 19, 0.238 is between 0.21 to $0.22 \alpha$-level for 4 variables (between $0.2359-$ 0.2433). This is interpreted as there is a probability of $\mathbf{0 . 2 1}$ to $\mathbf{0 . 2 2}$ that Expert 7 has randomly provided expert judgments for Technical Barriers. This is high inconsistency, but, when Expert 7's input is removed from the model there is no change in the priorities (policy level). The impact on the social barriers' relative weights are negligible. Therefore, we are not removing Expert 7's inputs.

Moving on to the second highest inconsistency, Expert 16 has an inconsistency at Technical barriers by 0.07 by the original inconsistency method. Using RSV, Expert 16's inconsistency is 0.1608 . Since technical barriers consist of 4 decision elements, values under 4 variables is to be investigated. $\alpha$-level for Expert 16 is between $\mathbf{0 . 1 1}$ and $\mathbf{0 . 1 2}(0.1532$ to 0.1625$)$ according to Table 19. This is interpreted as there is a probability of 0.11 to 0.12 that Expert 16 has 
randomly provided expert judgments for Technical Barriers. When Expert 16's input is removed from the model there is no change in the priorities.

Expert 10 has an inconsistency at Technical barriers by 0.07 by the original inconsistency method. Using RSV measure, Expert 10's inconsistency is 0.1445. Since technical barriers consist of 4 decision elements, values under 4 variables is to be investigated. $\alpha$-level for Expert 10 is between $\mathbf{0 . 1 0}$ and $\mathbf{0 . 1 1}(0.1437$ to 0.1532$)$ according to Table 19 . This is interpreted as there is a probability of 0.10 to 0.11 that Expert 10 has randomly provided expert judgments for Technical Barriers. When Expert 10's input is removed from the model there is no change in the priorities.

Expert 10 has an inconsistency at Economic barriers by 0.07 by the original inconsistency method. Using RSV measure, Expert 10's inconsistency is 0.1430. Since technical barriers consist of 4 decision elements, values under 4 variables is to be investigated. $\alpha$-level for Expert 10 is between $\mathbf{0 . 0 9}$ and $\mathbf{0 . 1 0}$ (0.1337 to 0.1437$)$ according to Table 19 . This is interpreted as there is a probability of 0.09 to 0.10 that Expert 10 has randomly provided expert judgments for Economic Barriers. When Expert 10's input is removed from the model there is no change in the priorities.

Expert 5 has an inconsistency at Economic barriers by 0.07 by the original inconsistency method. Using RSV measure, Expert 5's inconsistency is 0.1307. Since technical barriers consist of 4 decision elements, values under 4 variables is to be investigated. $\alpha$-level for Expert 5 is between $\mathbf{0 . 0 8}$ and $\mathbf{0 . 0 9}(0.1233$ to 0.1337$)$ according to Table 19 . This is interpreted as there is a probability of 0.08 to 0.09 that Expert 5 has randomly provided expert judgments 
for Economic Barriers. When Expert 5's input is removed from the model there is no change in the priorities.

RSV measure shows that majority of the inconsistencies by experts are at an acceptable level, other than Expert 7. Even though the $\alpha$-level is at 0.21-0.22 level, the expert's removal does not affect the priorities.

\subsection{Policies}

\subsubsection{Results}

There are 6 policies that were assessed in this study.

1) Road Privileges

2) GHG

3) Monetary Incentives

4) $R \& D$ incentives

5) RPS

6) Charging Incentives. 


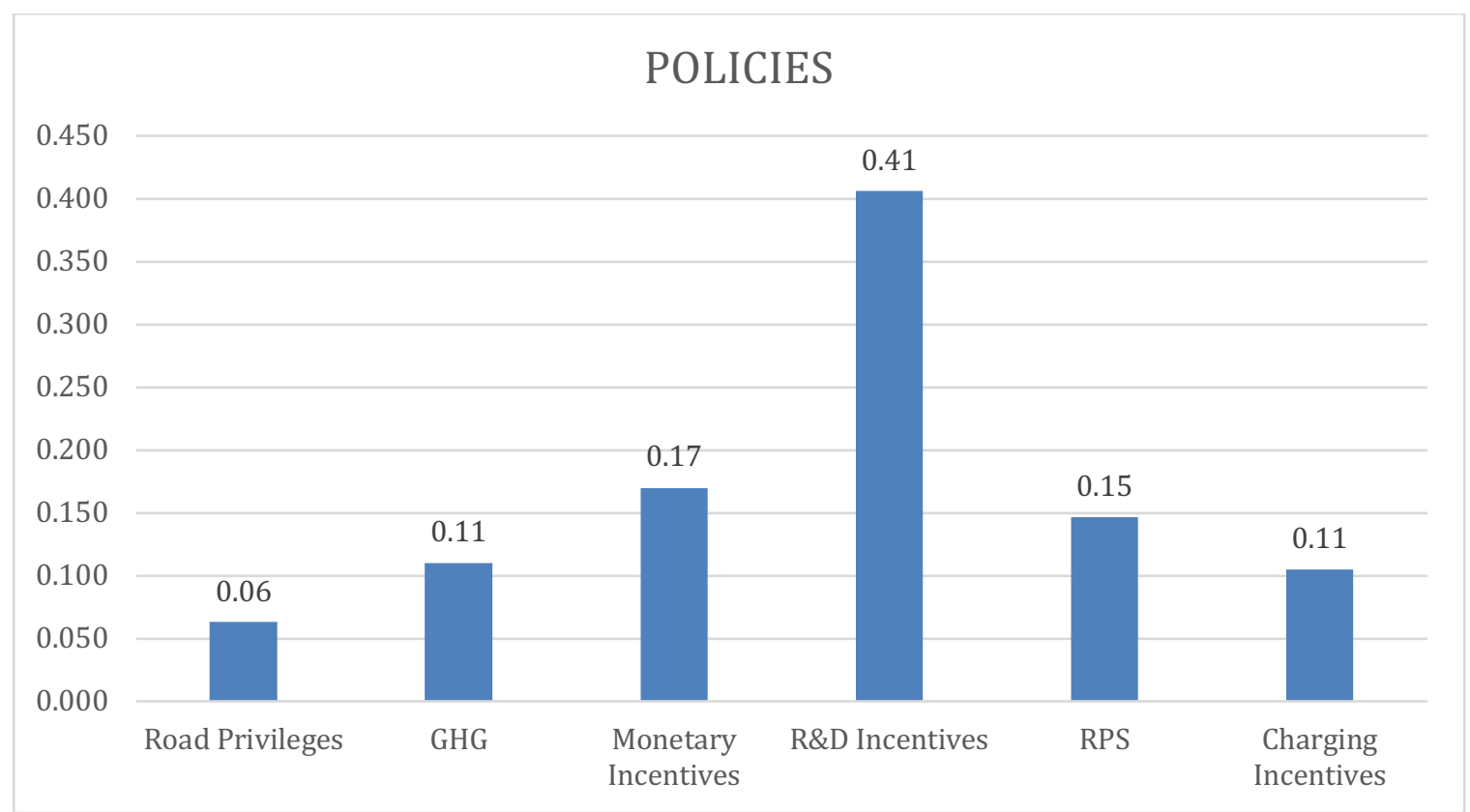

Figure 11. Relative Importance Weights of Policies

The results show that R\&D incentives is the most effective policy to mitigate EV adoption barriers. As shown in Figure 11. It is the policy with the highest relative importance value of 0.41. It is approximately 2.4 times more important than the next policy, Monetary Incentives.

Monetary Incentives is the second most effective policy, and it is better than the following most effective policy, RPS, by only $13 \%$.

GHG and Charging Incentives take identical weights 0.11 and share the $4^{\text {th }}$ place. RPS is more important than GHG \& Charging Incentives by $36 \%$.

Road Privileges is the least effective policy according to the results. Its importance level is 0.06 .

GHG \& Charging Incentives are more important than Road Privileges by 83\%. 
The maximum, $\mathrm{R} \& \mathrm{D}$ incentives, is better than the minimum Road Privileges by 6.83 times. Monetary Incentives is 2.83 , and RPS is 2.5 times more important than Road Privileges.

R\&D incentives generally work at the development stages of the products and systems. The novelty of the EV technology, particularly battery, increase the technical difficulty, along with its high costs. Therefore, startups who produce EV lack the investment. In order to cross the chasm, their products have to be $100 \%$ solution as Moore [102] mentioned in his book, therefore they have a high need in of $\mathrm{R} \& \mathrm{D}$ support. This partially explains why $\mathrm{R} \& \mathrm{D}$ incentives turned out to be way more important than other policies.

\subsubsection{Inconsistency}

The inconsistency of the experts at this level is also measured by the original inconsistency measure. Inconsistency measures are all at negligible levels.

\subsubsection{Disagreement}

F-Test values are calculated for this level. Table 20 shows the values.

\begin{tabular}{|c|c|c|c|c|}
\hline Variation & $\begin{array}{l}\text { Sum of } \\
\text { Squares (SS) }\end{array}$ & $\begin{array}{l}\text { Degree of } \\
\text { Freedom } \\
\text { (df) }\end{array}$ & $\begin{array}{l}\text { Mean } \\
\text { Square(MS) }\end{array}$ & $\begin{array}{l}\text { F-Test } \\
\text { Value }\end{array}$ \\
\hline $\begin{array}{l}\text { Between } \\
\text { Subjects / Criteria } \\
\text { (BS) }\end{array}$ & 0.781 & 5 & 0.156 & 56.40 \\
\hline $\begin{array}{l}\text { Between } \\
\text { Judges/Experts (BJ) }\end{array}$ & 0 & 10 & 0 & \\
\hline Residual (res) & 0.138 & 50 & 0.003 & \\
\hline \multicolumn{4}{|c|}{ F-Critical value with degrees of freedom 5 to $50 @ 0.01$} & 3.41 \\
\hline \multicolumn{4}{|c|}{ F-Critical value with degrees of freedom 5 to $50 @ 0.025$} & 2.83 \\
\hline \multicolumn{4}{|c|}{ F-Critical value with degrees of freedom 5 to $50 @ 0.05$} & 2.4 \\
\hline \multicolumn{4}{|c|}{ F-Critical value with degrees of freedom 5 to $50 @ 0.1$} & 1.97 \\
\hline
\end{tabular}

Table 20. F-Test Values for Policy Level 
As seen in the above table, F-Test value is 56.40 , the null hypothesis is rejected. Disagreement did not occur at the Policy level.

\subsection{Results Validation}

There are 3 types of validation that was done for our study.

1) Content Validity: The content was validated by the experts when initial framework was presented to them. Virtually all experts recognized the importance of the study and confirmed the research content's validity. A total number of 25 experts validated the content.

2) Construct Validity: This was done first by pseudo experts. After creating the model, it was run by 3 pseudo experts for the construct validity. Later, the construct was validated by all 25 experts.

3) Criterion related validity: This was done by 18 experts who provided expert judgments.

Our results were validated by 7 experts who have the overall knowledge of the EV industry. According to their feedback the results were intuitive and appropriate. 


\section{CHAPTER - SENSITIVITY ANALYSIS}

Our calculated results for all perspectives, barriers and policies level are called baseline values. These baseline values will be changed to do the sensitivity test.

In our study, we did not use HDM-SA algorithm, but we tested sensitivity of the results in two ways. First by using extreme changes in priorities of the five perspectives in section 7.1, and then by analyzing the impact of the high differences among the expert subgroups when high disagreement occurred in Barriers (section 7.2).

The following section applies sensitivity analysis to investigate the changes' effect on priorities. Expert judgments led to policy weights shown on Figure 11, which we call baseline values. By making one perspective more important than others we measure how changing conditions would affect the baseline values.

\subsection{Modifying the Perspectives}

In this section, we investigate if and when the dominant perspective is one of the Social, Technical, Environmental, Economic, or Political perspectives, what would the priorities become. In order to do that, one of the STEEP perspectives is assigned a relative importance weight of 0.96 and the other STEEP perspectives are assigned 0.01 as their relative importance. This makes the perspective under investigation the dominant view.

\subsubsection{Dominant Perspective - Social}

Below is the chart for policy priorities if Social is the dominant perspective. 


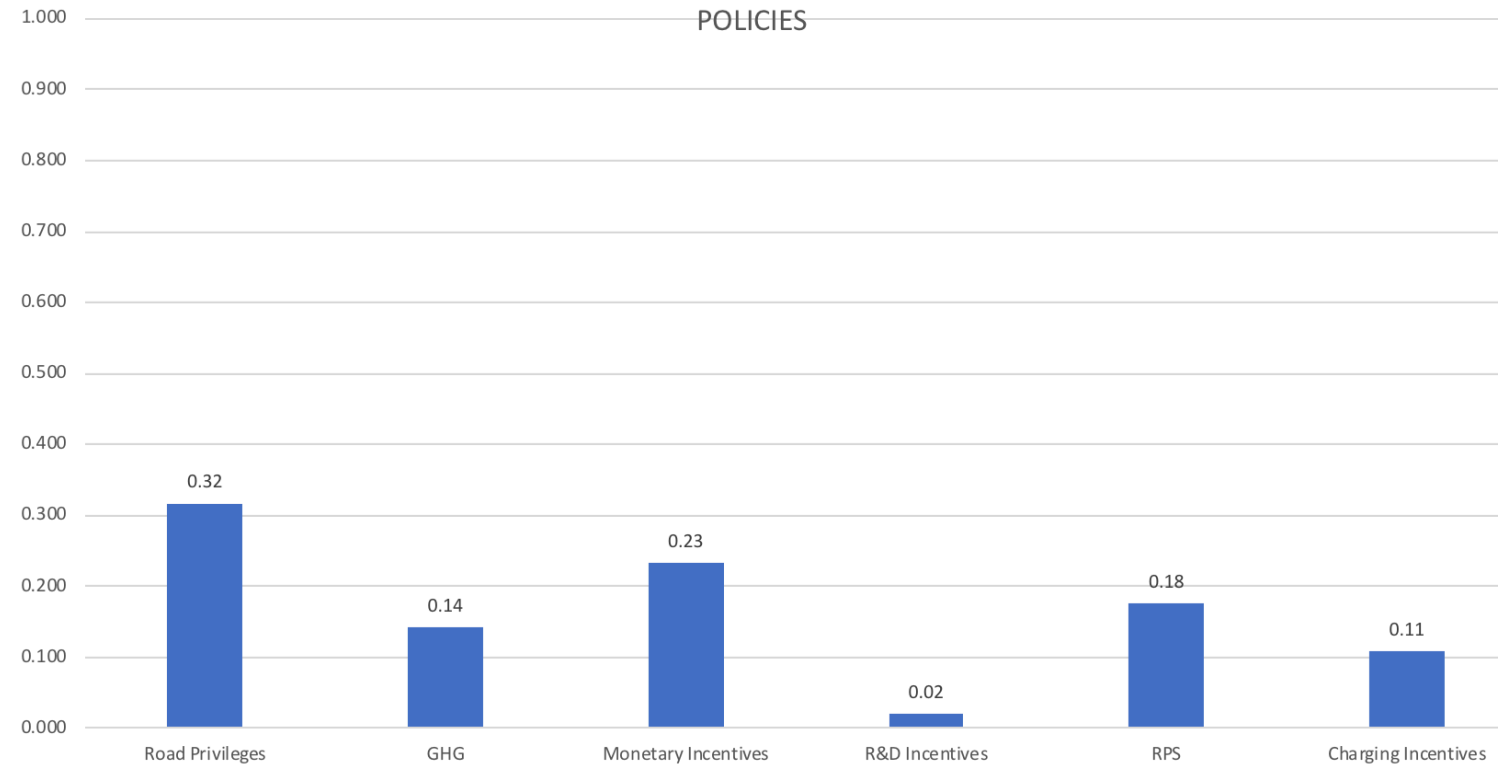

Figure 12. Policy priorities when Social is dominant perspective

As seen in the above chart Road Privileges become the most important policy when a purely Social decision is made. Monetary Incentives become $2^{\text {nd }}$, and RPS becomes the $3^{\text {rd }}$ most important policy. R\&D Incentives, which is the most important policy at the baseline values, become the least important when Social is the dominant perspective.

\subsubsection{Dominant Perspective - Technical}

Below is the chart for policy priorities if Technical is the dominant perspective. 


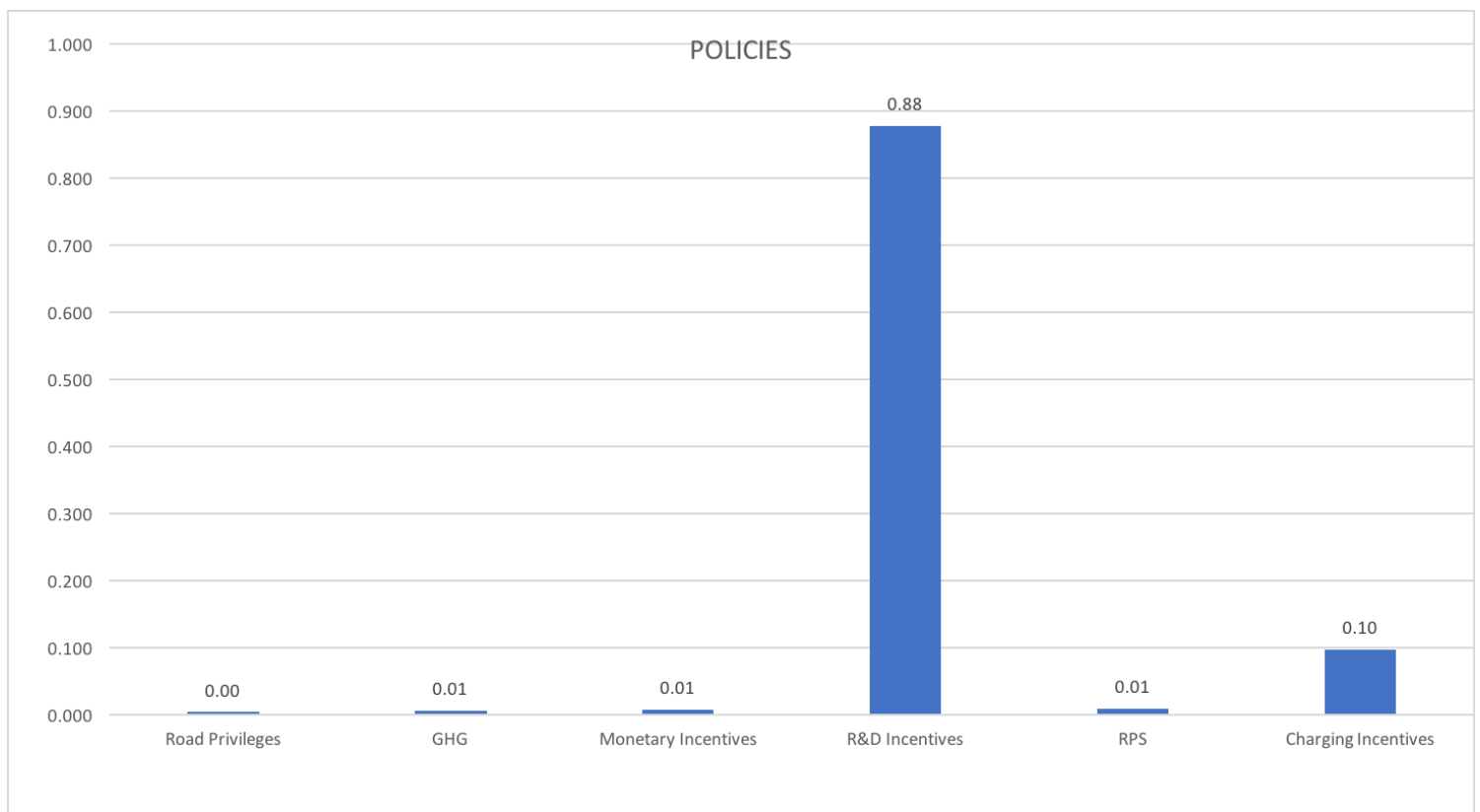

Figure 13. Policy priorities when Technical is dominant perspective

As seen in the above chart R\&D incentives not only remain as the most important policy, but also increases its strength. Charging Incentives becomes the $2^{\text {nd }}$ most important policy and the rest of the policies becomes insignificant.

\subsubsection{Dominant Perspective - Environmental}

Below is the chart for policy priorities if Environmental is the dominant perspective 


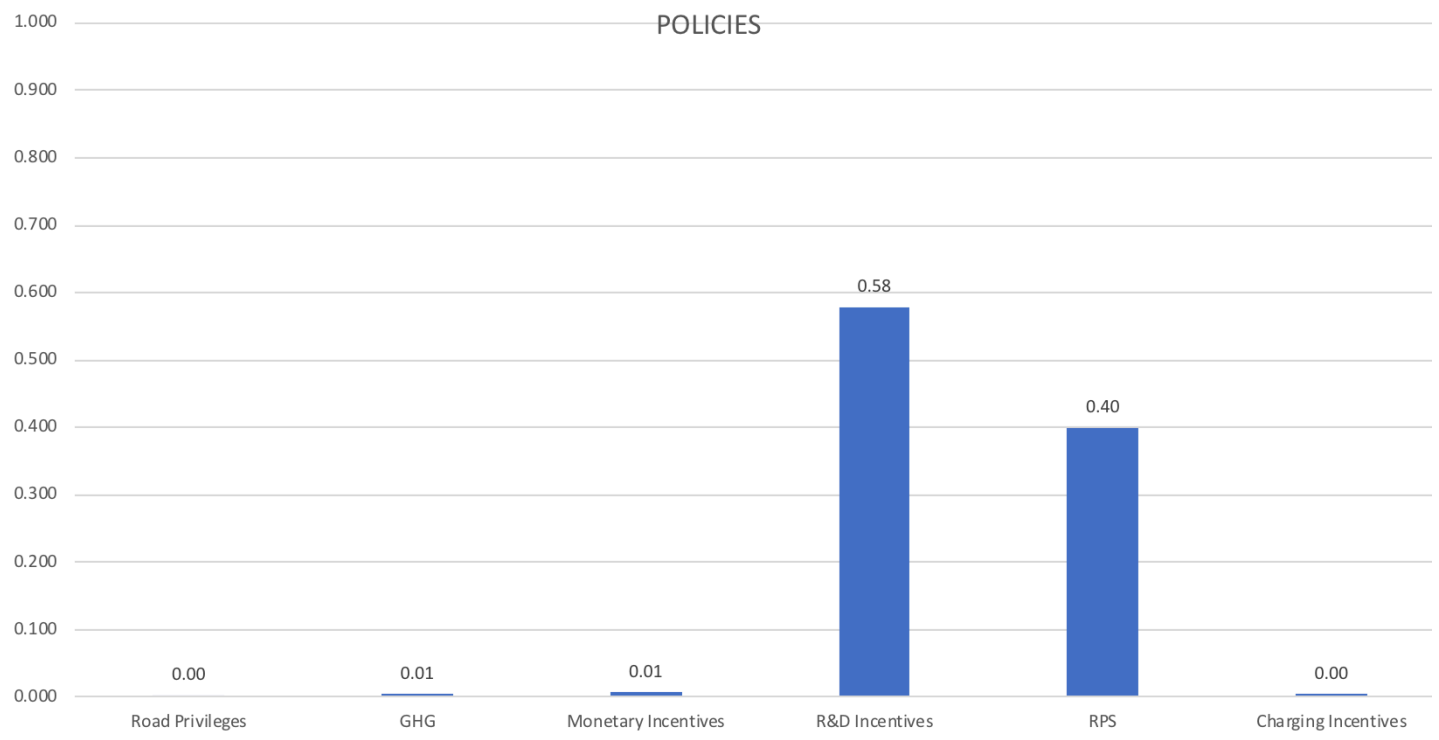

Figure 14. Policy priorities when Environmental is dominant perspective

As seen in the above chart, if Environmental becomes the dominant perspective, $R \& D$ incentives keep its $1^{\text {st }}$ rank and increases its level of importance. RPS becomes the $2^{\text {nd }}$ most important policy. The rest of the policies become insignificant.

\subsubsection{Dominant Perspective - Economic}

Below is the chart for policy priorities if Economic is the dominant perspective. 


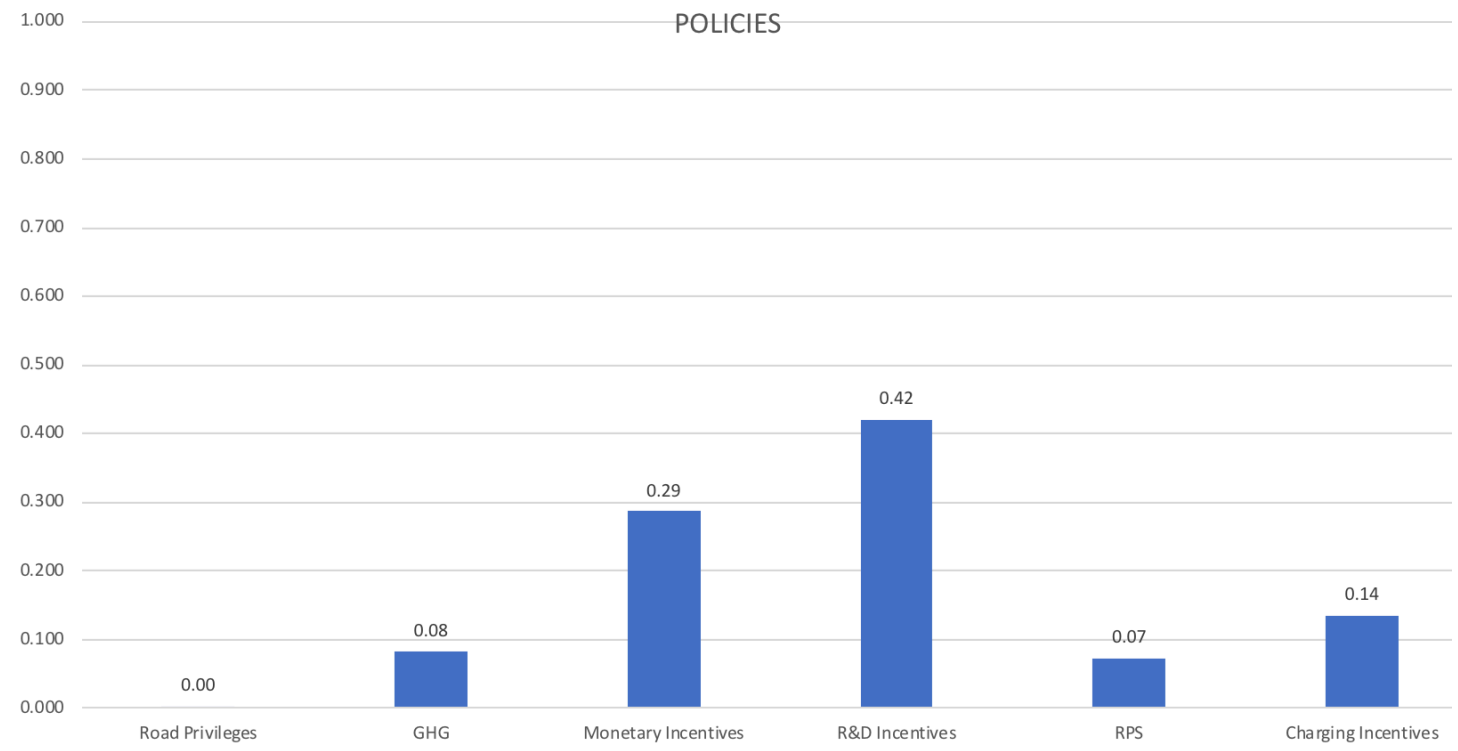

Figure 15. Policy priorities when Economic is dominant perspective

As seen in the above chart, the change in the chart is the least compared to baseline, when Economic becomes the dominant perspective. Monetary incentives gain more importance as it keeps its $2^{\text {nd }}$ rank. RPS becomes the $3^{\text {rd }}$ most important policy.

\subsubsection{Dominant Perspective - Political}

Below is the chart for policy priorities if Political is the dominant perspective. 


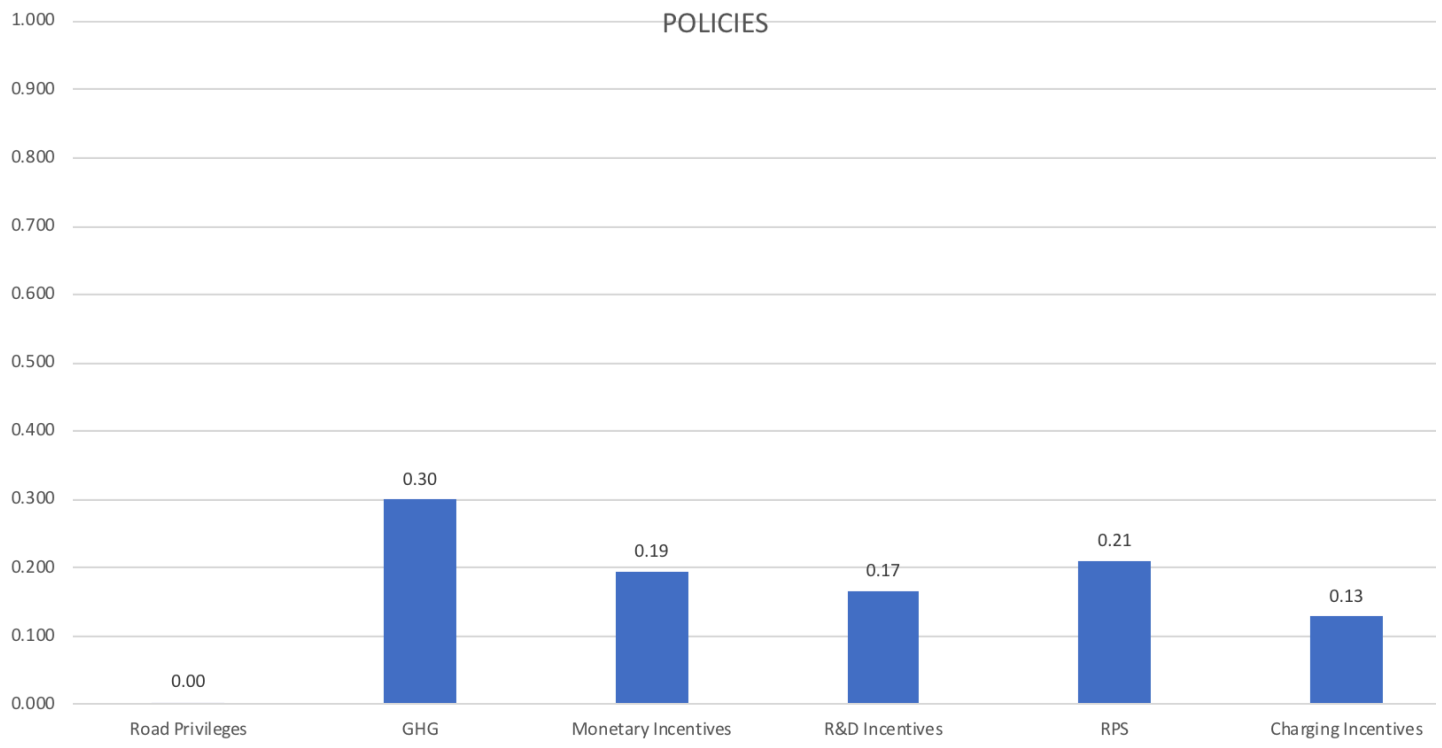

Figure 16. Policy priorities when Political is dominant perspective

As seen in the chart, GHG standards take the lead as the most important policy. RPS becomes the $2^{\text {nd }}$ most important policy. Monetary Incentives become $3^{\text {rd }}$ most important policy. R\&D Incentives, which is the most important policy per baseline values, gets the $4^{\text {th }}$ rank.

Interpreting Figure 16 GHG Standards, RPS and Monetary Incentives have strong relationship with Political Perspective. This means that if political conditions change and political barriers may become more important than they currently are. In this case the above policies should be focused first.

\subsection{Barriers}

In this section, the groups were analyzed based on groups of experts that are in agreement per their expert judgments. Grouping analysis was made based on below principles:

1) Only the barriers under perspectives that received high disagreement (Environmental and Political) were analyzed. 
2) Experts who provided substantially high judgment for a barrier under each perspective were identified.

3) The Experts who have provided high judgments were assigned a Group number. Table 21 summarizes the groups.

4) Each perspective was analyzed individually. First Environmental Barriers grouping analysis, then Political Barriers grouping analysis were implemented.

5) Each group in a perspective was made the sole decision maker by removing the all the rest of expert inputs under that perspective.

6) For Environmental, Group 1, 2 and 3 were individually made sole decision makers by keeping the judgments of one group when removing the others. (i.e. when Group 1 is made the sole decision maker, the inputs of Group 2 and 3 were removed)

7) Policies were observed whether there was any change occurred in the priorities.

8) The same process was repeated for Political Barriers. Political resistance has not received a substantially high score by any of the experts, therefore it was omitted. Experts disagreed whether Technology Resistance or Shareholders' Pressure was the most important barrier. Therefore, Group 4 and Group 5, respectively, were made sole decision makers.

\begin{tabular}{|c|c|c|c|}
\hline PERSPECTIVES & BARRIERS & EXPERTS IN GROUPS & GROUP NAME \\
\hline \multirow{3}{*}{ Environmental } & Battery Production & $1,8,13$ & Group 1 \\
\hline & Battery Disposal & 10,17 & Group 2 \\
\hline & Electricity Source & $2,3,4,5,6,14,18$ & Group 3 \\
\hline \multirow{2}{*}{ Political } & Technology Resistance & $2,3,4,5,10$ & Group 1 \\
\hline & Shareholders' Pressure & $1,8,11$ & Group 2 \\
\hline
\end{tabular}

Table 21. Expert sensitivity analysis groups 


\subsubsection{Environmental - Group 1 Decision}

For Environmental Barriers, first, Group 1 is used for decision making. The results are shown in Figure 17.

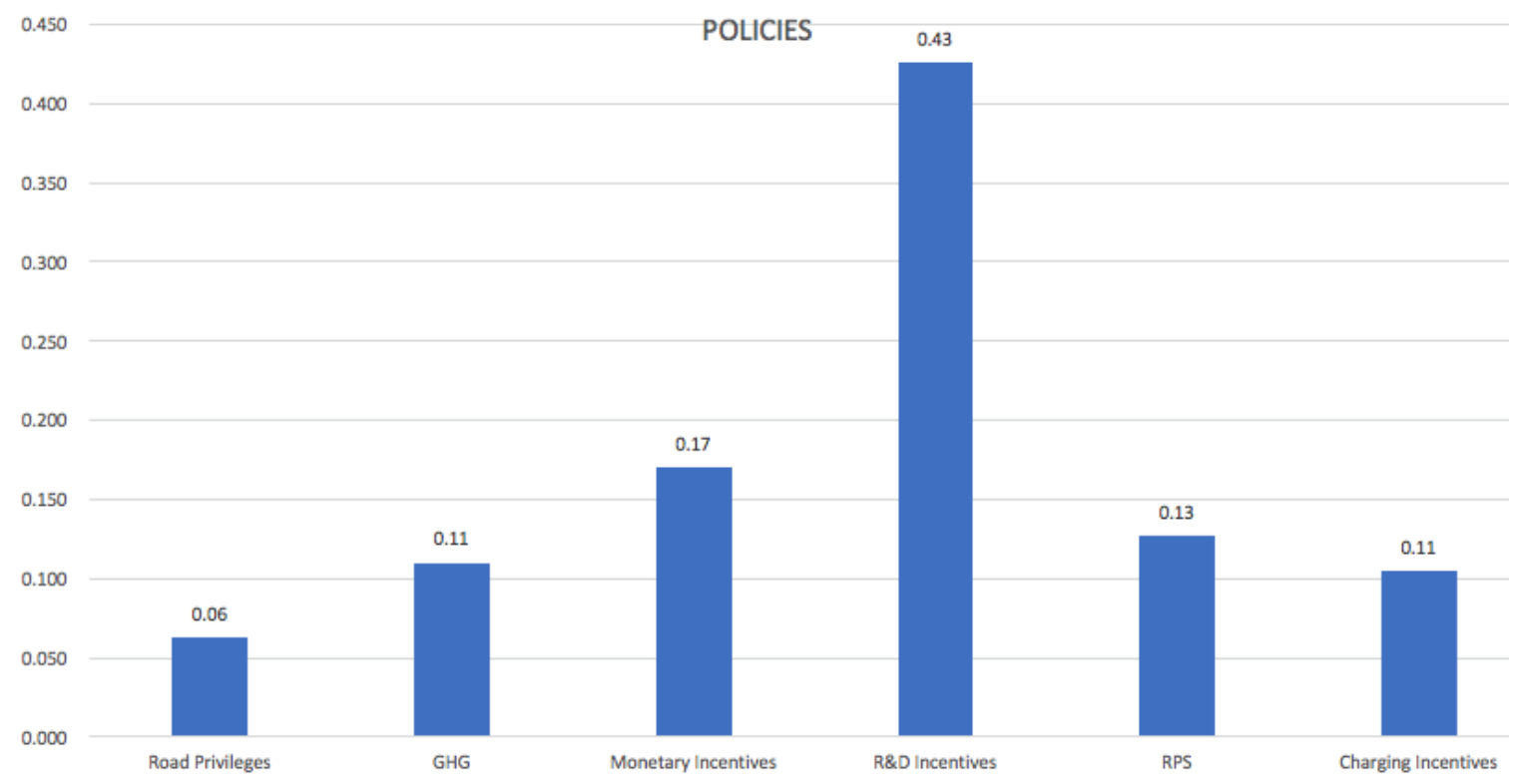

Figure 17. Policy Alternatives’ priorities - Environmental Group 1 Decision

As seen in the chart, all ranks remain the same. No changes are observed on Road Privileges, GHG, Monetary Incentives and Charging Incentives. The change in R\&D incentives and RPS are negligible.

\subsubsection{Environmental - Group 2 Decision}

Group 2's results are shown in Figure 18. 


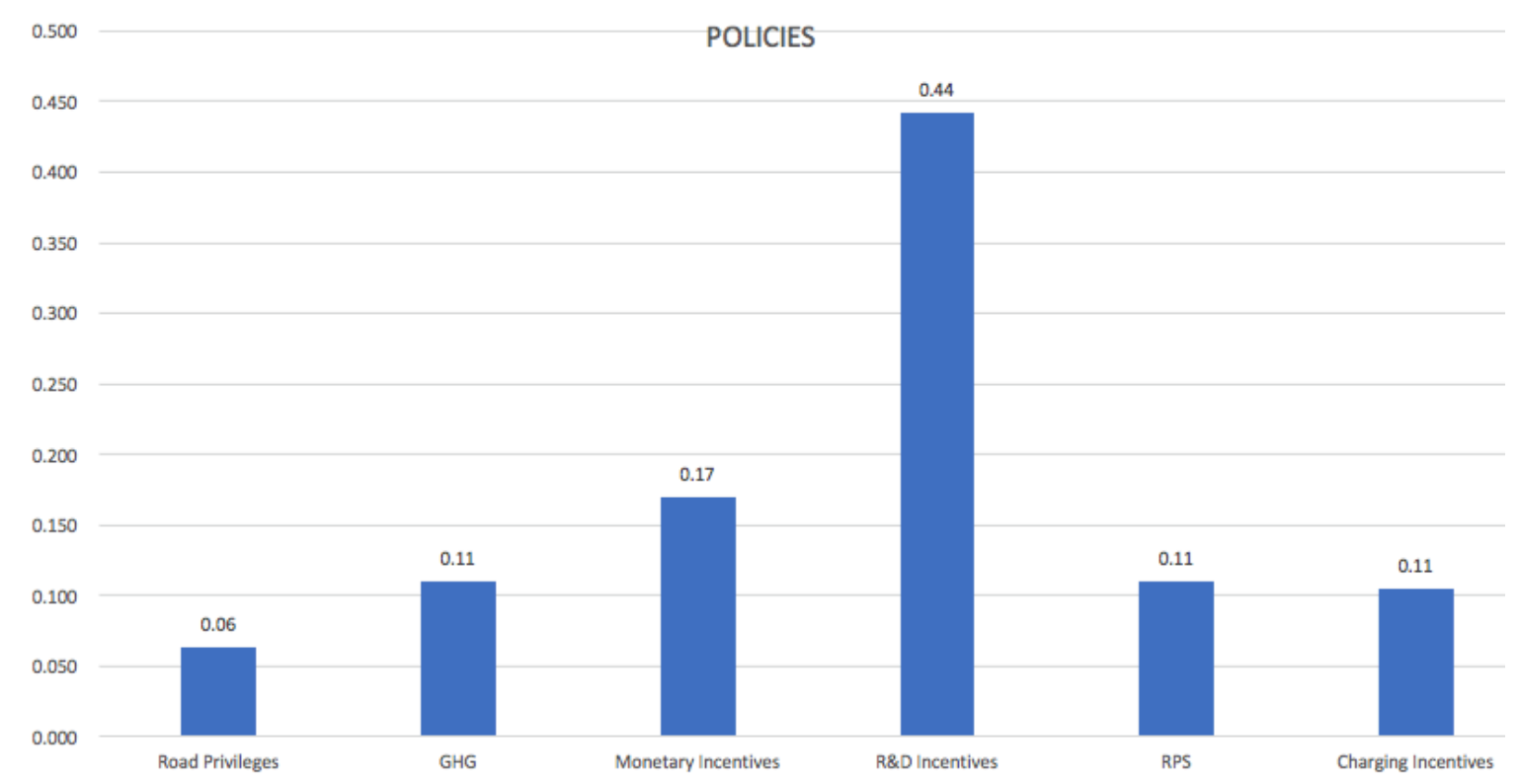

Figure 18. Policy Alternatives' priorities - Environmental Group 2 Decision

As seen in the chart, all ranks remain the same. The only change in weights is again $R \& D$ incentives with a negligible increase, and RPS with a negligible decrease.

\subsubsection{Environmental - Group 3 Decision}

Group 3's results are shown in Figure 19. 


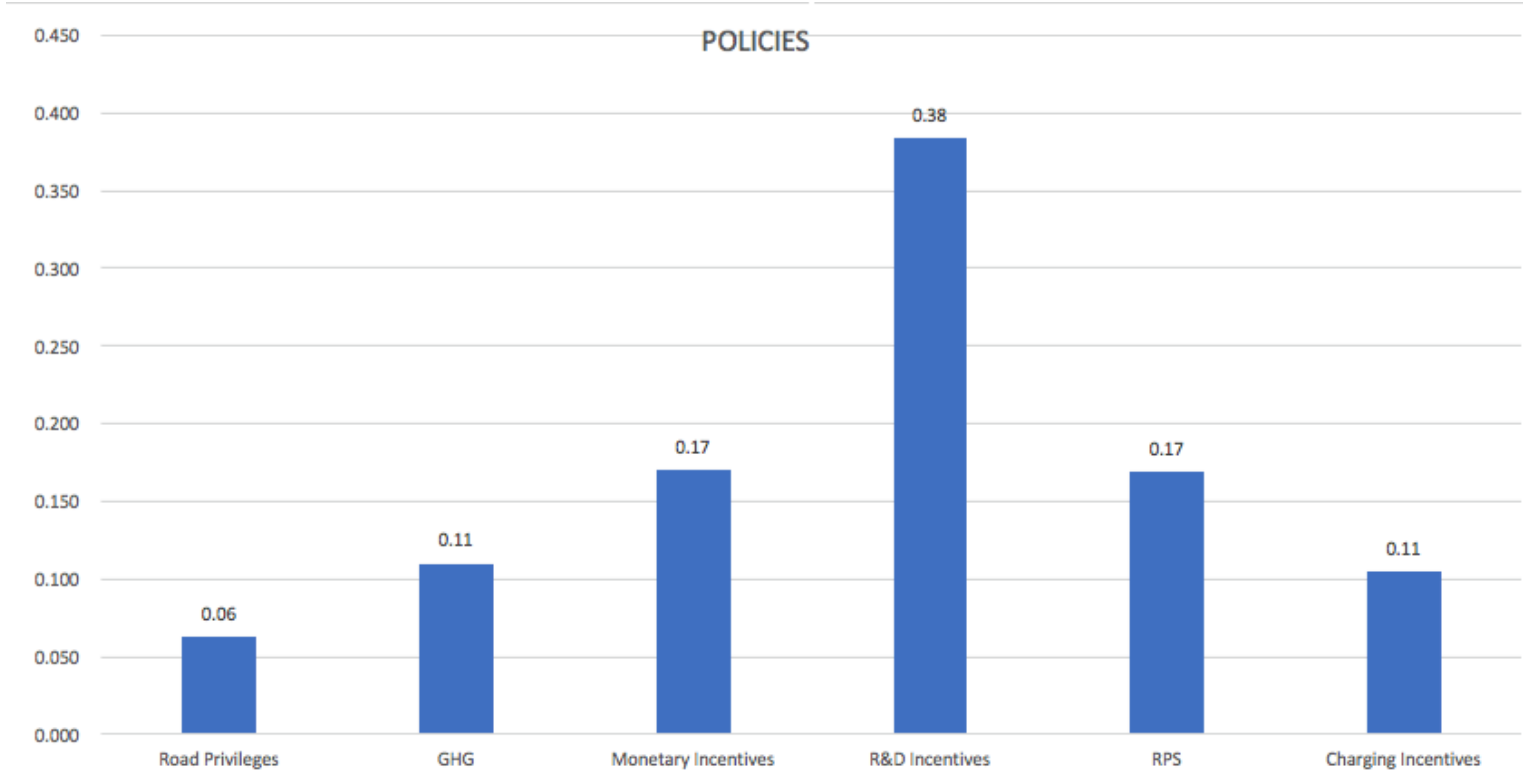

Figure 19. Policy Alternatives’ priorities - Environmental Group 3 Decision

As seen in the chart, all ranks remain the same. The only changes in weights are again $R \& D$ incentives with a negligible decrease and RPS with negligible increase.

As a result of the analysis, different groups' sole decision does not affect the policy priorities. 


\subsubsection{Political - Group 1 Decision}

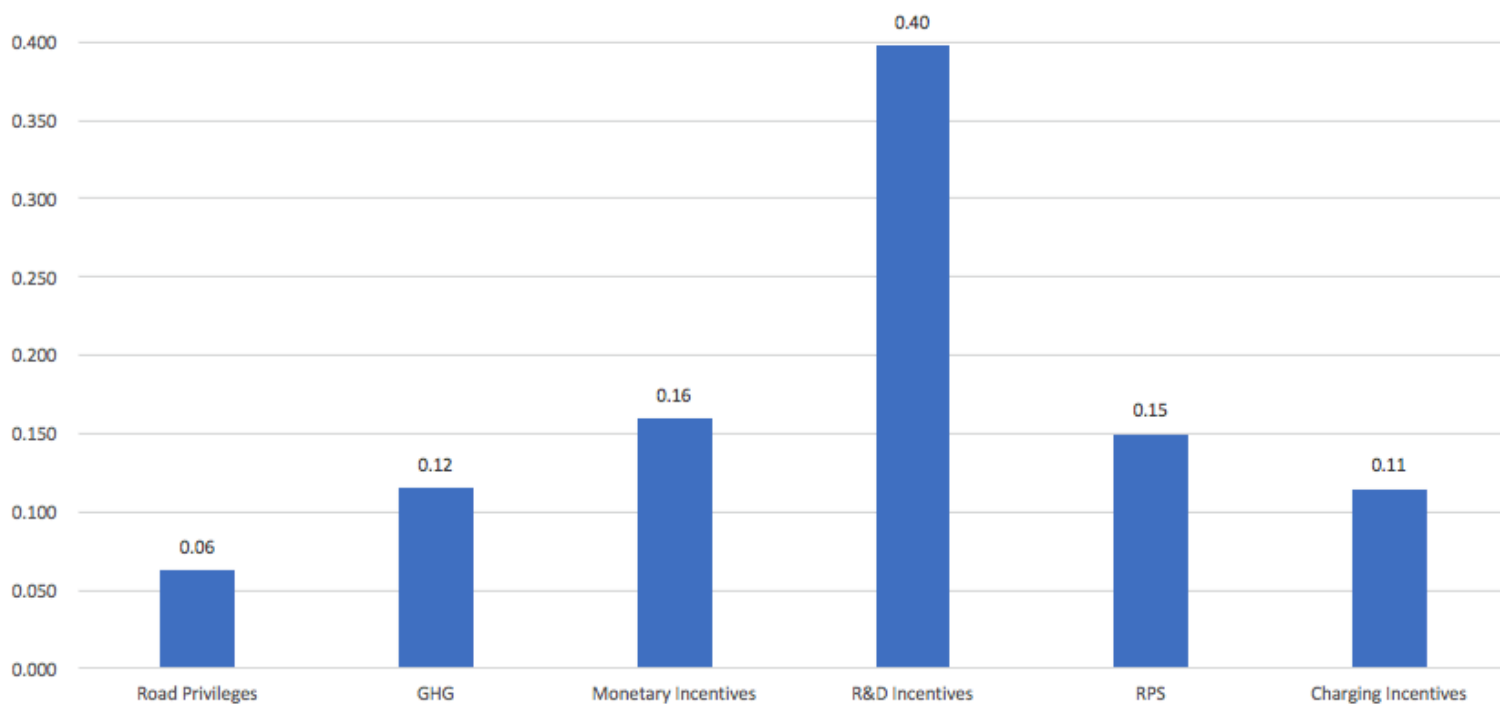

Figure 20. Policy Alternatives’ priorities - Political Group 1 Decision

As seen in Figure 20, all ranks remain the same. The only changes in weights are GHG (increase by 0.01), Monetary Incentives (decrease by 0.01), and R\&D Incentives (decrease by $0.01)$. 


\subsubsection{Political - Group 2 Decision}

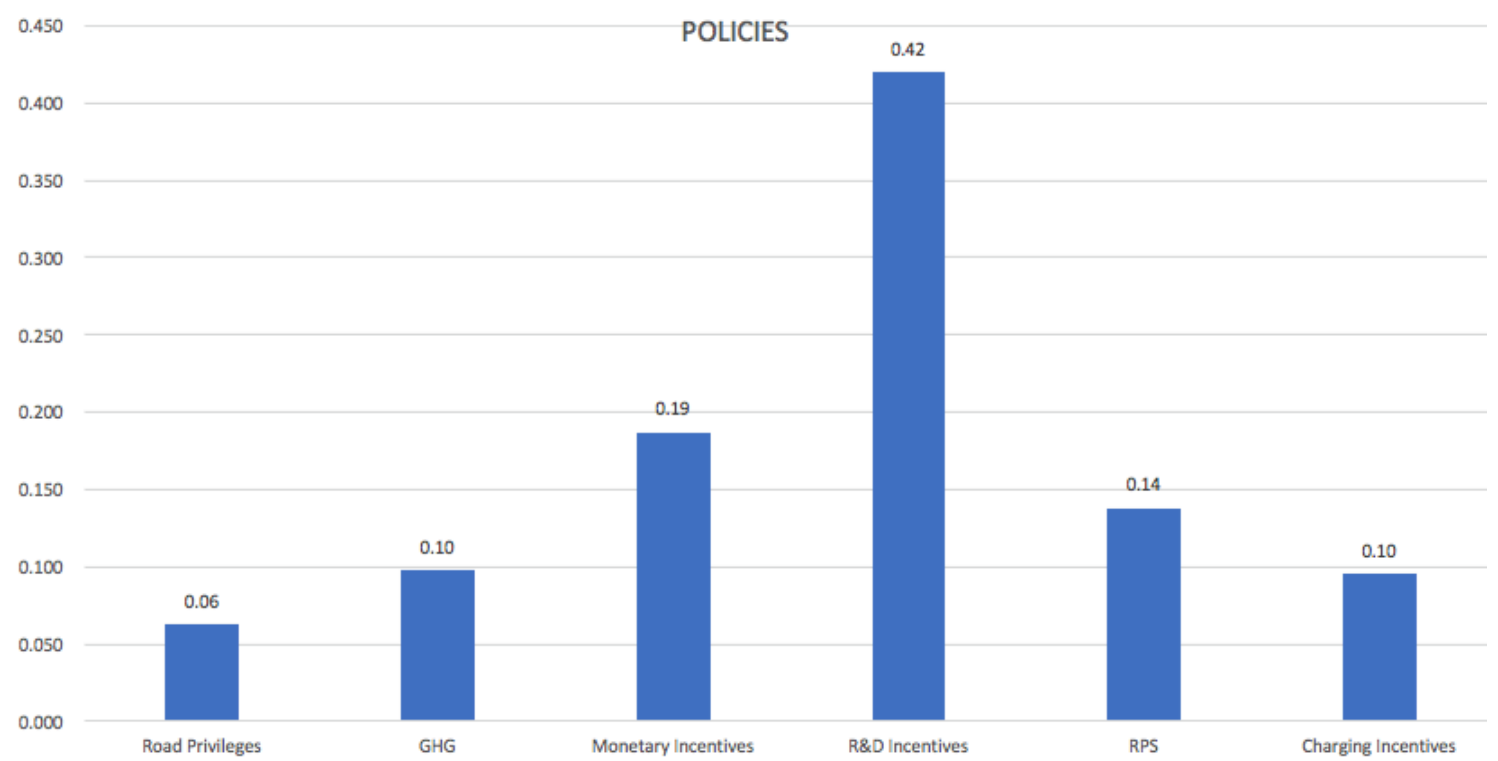

Figure 21. Policy Alternatives’ priorities - Political Group 2 Decision

As seen in Figure 21, all ranks remain the same. The only changes in weights are GHG (decrease by 0.01), Monetary Incentives (increase by 0.02), and R\&D Incentives (increase by $0.01)$.

To summarize the group analysis for Political Barriers, for both groups decisions of Group 1 and 2 , the changes are negligible.

All of the above scenarios show that changing conditions at the perspectives level may dramatically change the results. When priorities change among the Social, Technical, Economic, Environmental and Political perspectives, the relative importance of policies changes as shown above. 


\section{CHAPTER - POLICY EFFECTIVENESS CURVES}

After using the judgment data, we came up with relative importance weights of each policy in mitigating barriers that have been identified in the literature and verified by the experts. We calculated the baseline values for the policies, in other words, the relative importance weights of policies indicating how important one policy is versus another one on a relative basis. However, the baseline results only show the current level of implementation, and policies are partially implemented today. Investigating implementation of policies at various levels is very critical. In our study, there are 6 policies, some of which can vary in terms of monetary rewards involved, while others vary in the number of states adopting them. We came up with a methodology built on the desirability curves concept called "Policy Effectiveness Curves" in order to measure the effect of policies at different levels of implementation. Measuring policies at different implementation levels help us understand when the conditions that baseline values were measured in changes, how much each policies' effectiveness change.

We used the Policy Effectiveness Scores (PES) that were derived from Policy Effectiveness Curves to test the scenarios. These scenarios help us understand how much the baseline results obtained from today's conditions change when policies are enacted at different implementation levels.

If a policy is fully implemented, we give it an effectiveness value of 100 . If it is not implemented at all, its effectiveness value is defined as 0 because it will not have any effectiveness in mitigating the barriers. We went to 9 additional experts, who are either using an EV today or studied to start using an EV, in addition to their expertise in the EV field. They gave us their judgments of relative effectiveness of particular policies at 5 
implementation levels. For policies that measured by their deployment on number of states, we used $0,10,20,30,40$ and 50 states as implementation levels, where 0 states is $0 \%$ effectiveness and 50 states is 100\% effectiveness. These policies are Road Privileges, GHG, RPS and Charging Incentives.

For policies that involve a monetary reward, we used $\$$ amount for implementation levels. R\&D Incentives are based on dollar amount at a span of $\$ 0$ to $\$ 15$ billion, where $\$ 0$ corresponds to $0 \%$ effectiveness and $\$ 15$ billion corresponds to $100 \%$ effectiveness. Monetary Incentives are also based on dollar amount at a span of $\$ 0$ to $\$ 30,000$, where $\$ 0$ corresponds to $0 \%$ effectiveness and $\$ 30,000$ corresponds to $100 \%$ effectiveness.

We will be using PES to test the scenarios, by using a combination of levels of implementation. We then took the mean of their judgments and plotted the curves for each policy. These are called "Policy Effectiveness Curves". They are shown below:

\section{Policy 1: Road Privileges}

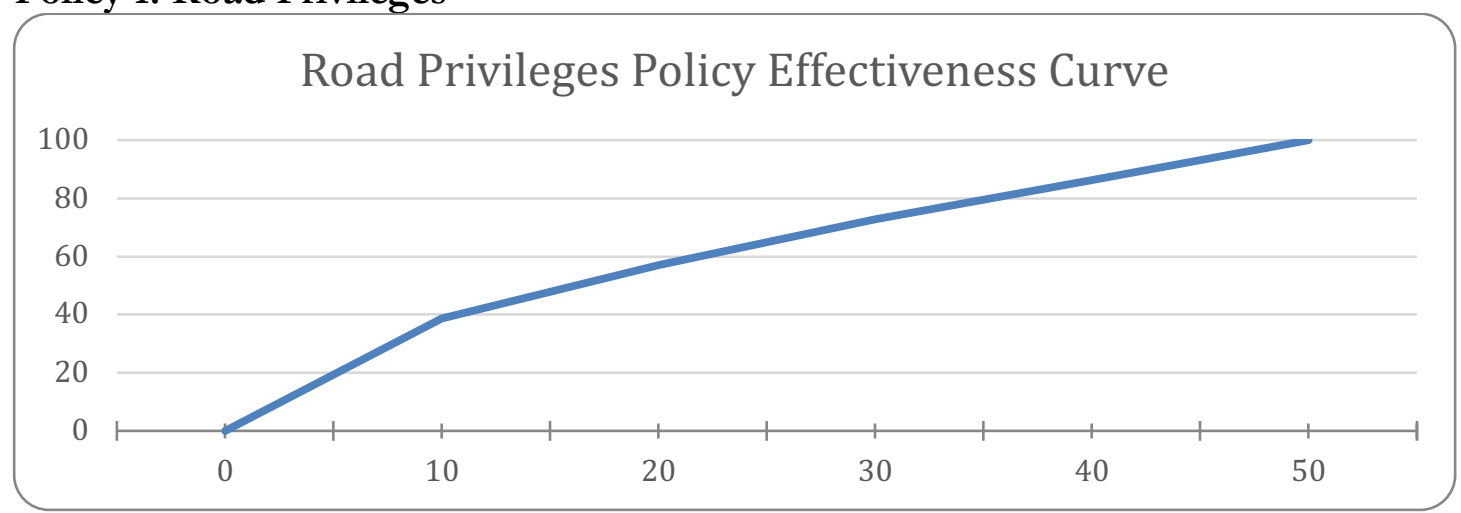

Figure 22. Road Privileges Policy Effectiveness Curves 
Policy 2: GHG

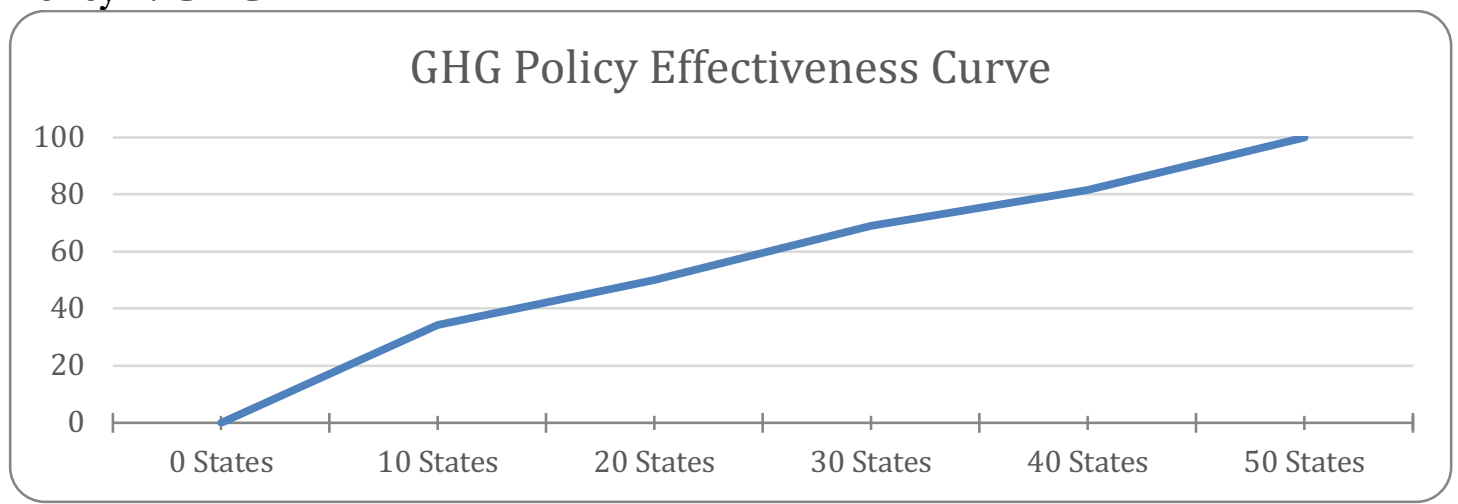

Figure 23. GHG Policy Effectiveness Curve

\section{Policy 3: Monetary Incentives}

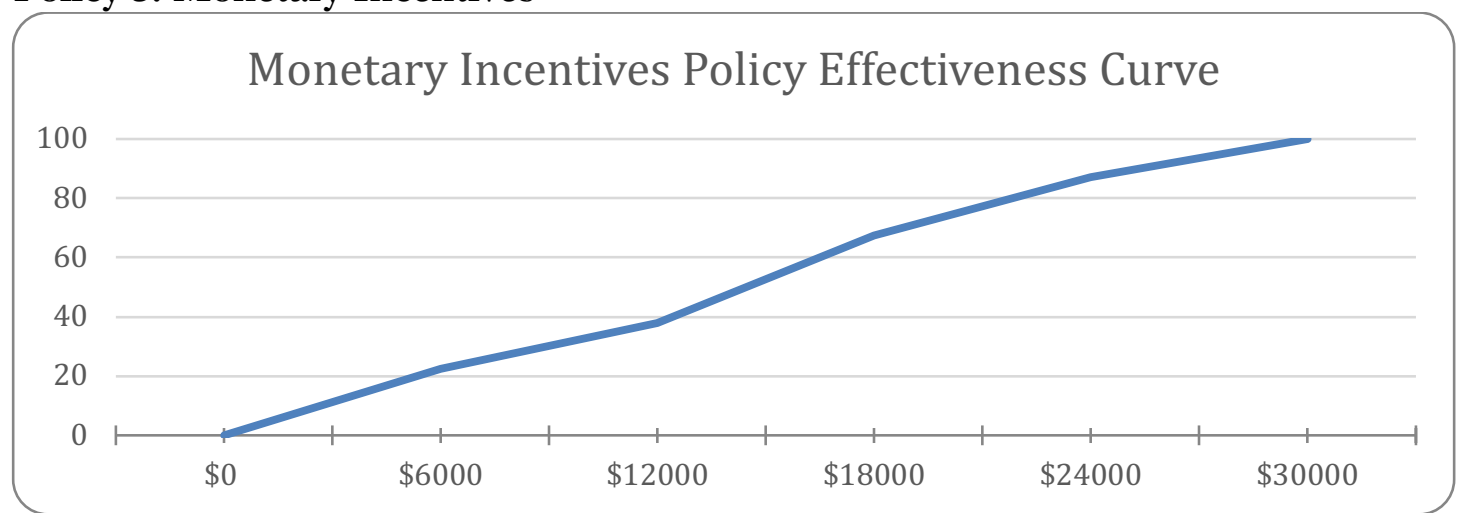

Figure 24. Monetary Incentives Policy Effectiveness Curve

\section{Policy 4: RPS}

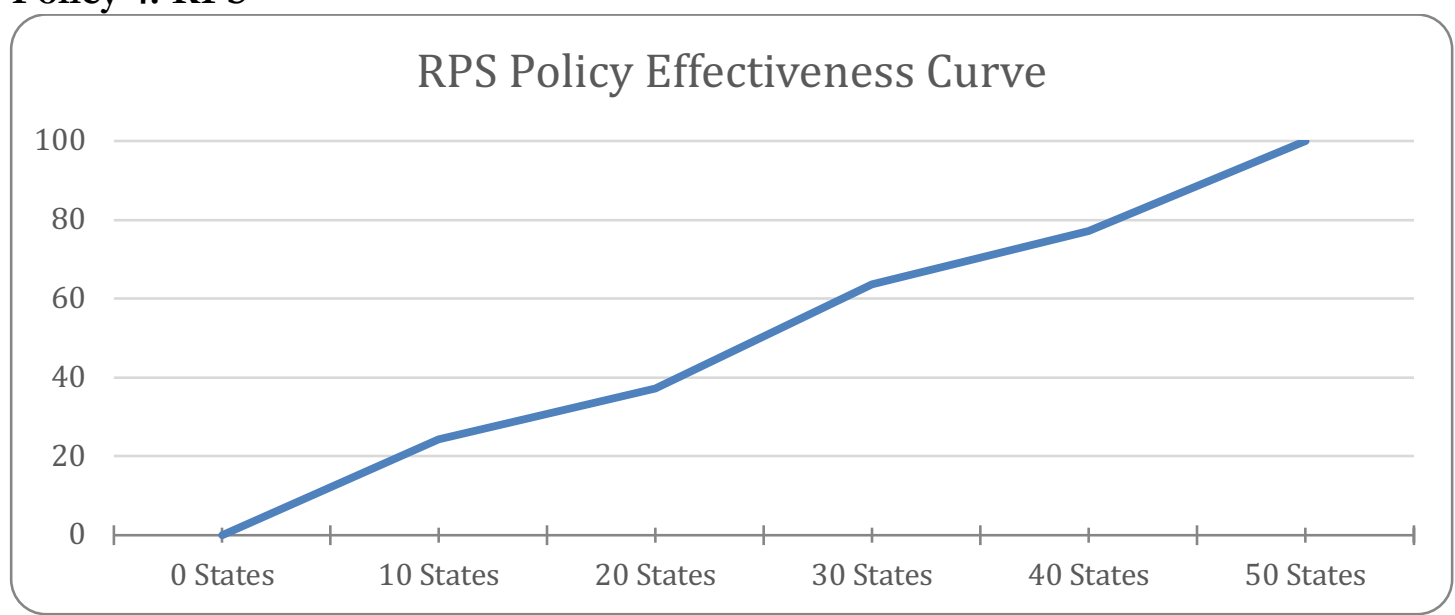

Figure 25. RPS Policy Effectiveness Curve 
Policy 5: R\&D Incentives

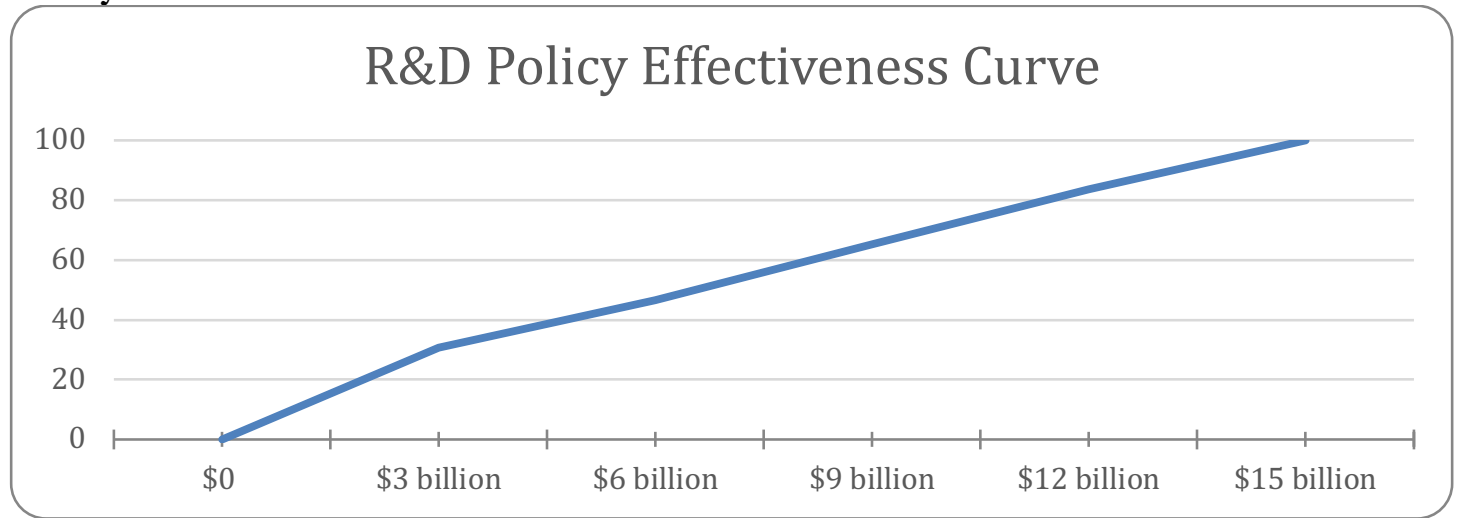

Figure 26. R\&D Policy Effectiveness Curve

\section{Policy 6: Charging Incentives}

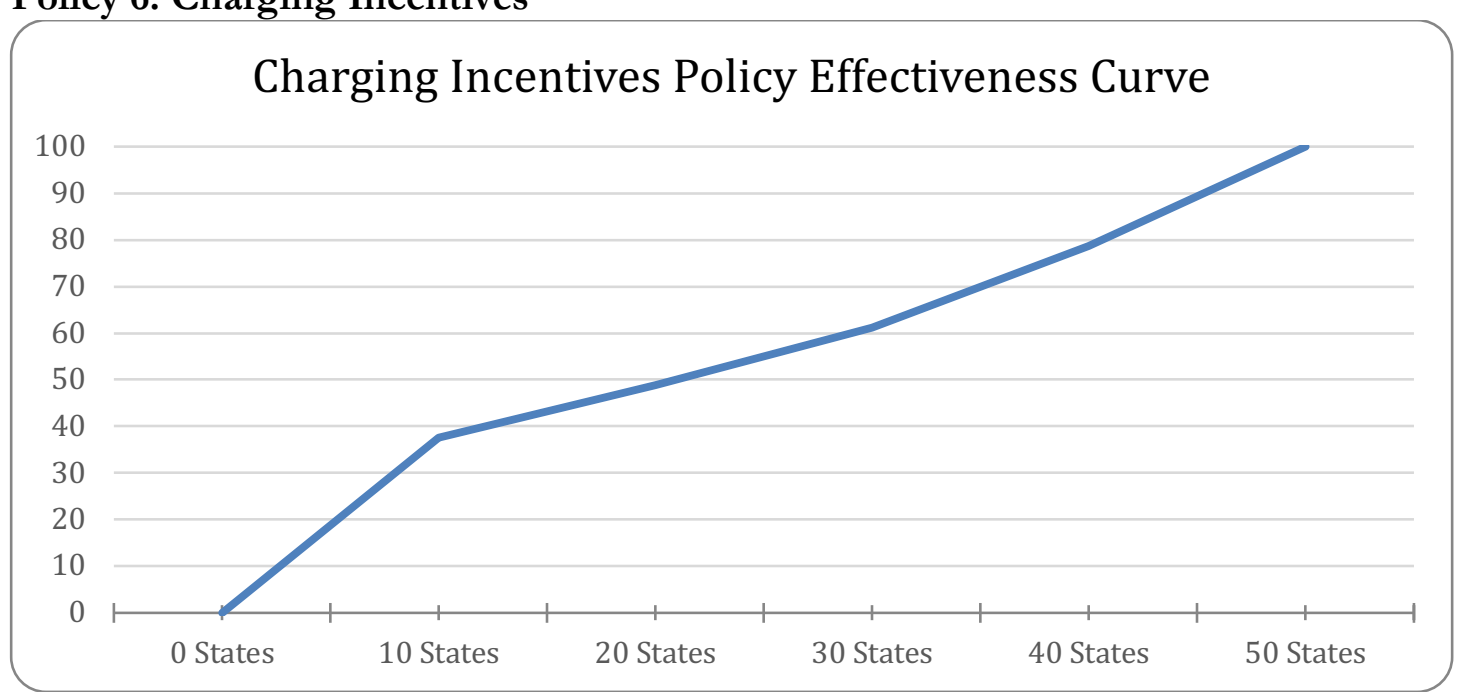

Figure 27. Charging Incentives Policy Effectiveness Curve

Using the Policy Effectiveness Curves, we tested 25 different scenarios by changing the implementation levels of policies. The implementation levels were defined, and the corresponding PES was taken from the Policy Effectiveness Curves. PES was then multiplied by the policy weight and this gave us the policy's weighted relative effectiveness. The sum of the weighted relative effectiveness values of the six policies resulted in the PES for the 
implementation of each policy at a given level, taken all six policies together. The calculations are summarized below:

\section{Equation 1 - Weighted Relative Effectiveness (WRE) Calculation Relative Effectiveness $\times$ Policy Weight $=W R E$}

\section{Equation 2 -Calculation of PES}

When $\mathrm{p}$ denotes each policy;

$P E S=\sum_{p=1}^{6}(W R E)$

\section{Equation 3 - Ratio to Current PES}

Ratio $=P E S_{\text {new }} / P E S_{\text {current }}$

Below section shows various scenarios. In this section, the calculations were made using excel formulas, therefore there may be rounding errors at $\sim 0.01$ levels.

\subsection{Scenarios}

To start scenario analysis, policies' current levels of implementation were determined. First corresponding relative effectiveness was identified for each policy based on their current level of implementation, and then these values were multiplied by policy's baseline weights. The sum of the obtained weighted relative effectiveness for each policy is the baseline PES score.

By combination of various implementation levels of each policy one can come up with infinite number of scenarios. We came up with a logical framework to test some of these scenarios to 
provide guidelines for policy makers. Some of these scenarios included testing policies at their outliers, observing the impact of monetary rewarded policies, and those that require more infrastructural work and so on. We tested 25 scenarios including a suggested scenario in this study.

\section{Scenario 1}

\begin{tabular}{|c|c|c|c|c|c|}
\hline \multirow{2}{*}{ Unit Measure } & \multirow{2}{*}{ Policies } & \multirow{2}{*}{$\begin{array}{l}\text { Policy } \\
\text { Weight }\end{array}$} & \multicolumn{3}{|c|}{$\begin{array}{c}\text { Scenario 1: } \\
\text { Current Status in US Measures }\end{array}$} \\
\hline & & & Unit & Rel Eff & Wght*Rel Eff \\
\hline numberof states & Road Privileges & 0.06 & 13 & 44 & 2.65 \\
\hline numberof states & GHG & 0.11 & 15 & 42 & 4.63 \\
\hline$\$$ amount & Monetary Incentives & 0.17 & $\$ 10,000$ & 33 & 5.56 \\
\hline$\$$ amount & R\&D Incentives & 0.41 & $\$ 4$ & 36 & 14.81 \\
\hline numberof states & RPS & 0.14 & 29 & 61 & 8.53 \\
\hline numberof states & Charging Incentives & 0.11 & 13 & 41 & 4.50 \\
\hline \multicolumn{3}{|c|}{ Policy Effectiveness Score } & \multicolumn{3}{|c|}{40.67} \\
\hline \multicolumn{3}{|c|}{ Ratio to Current } & \multicolumn{3}{|c|}{1} \\
\hline
\end{tabular}

Table 22. Scenario 1

Scenario 1 shows the current day US. Today PES is 40.67 . Scenario 1 is to keep policies as they are at the current levels. Current PES will be used as a reference for comparison of other scenarios. 
Scenario 2

\begin{tabular}{|c|c|c|c|c|c|}
\hline \multirow{2}{*}{ Unit Measure } & \multirow{2}{*}{ Policies } & \multirow{2}{*}{$\begin{array}{c}\text { Policy } \\
\text { Weight }\end{array}$} & \multicolumn{3}{|c|}{$\begin{array}{c}\text { Scenario 2: } \\
100 \% \text { Implementation of all policies }\end{array}$} \\
\hline & & & Unit & Rel Eff & $\begin{array}{r}\text { Wght*Rel } \\
\text { Eff }\end{array}$ \\
\hline numberof states & Road Privileges & 0.06 & 50 & 100 & 6.00 \\
\hline numberof states & GHG & 0.11 & 50 & 100 & 11.00 \\
\hline$\$$ amount & Monetary Incentives & 0.17 & $\$ 30,000$ & 100 & 17.00 \\
\hline$\$$ amount & R\&D Incentives & 0.41 & $\$ 15$ & 100 & 41.00 \\
\hline numberof states & RPS & 0.14 & 50 & 100 & 14.00 \\
\hline numberof states & Charging Incentives & 0.11 & 50 & 100 & 11.00 \\
\hline \multicolumn{3}{|c|}{ Policy Effectiveness Score } & \multicolumn{3}{|c|}{100.00} \\
\hline \multicolumn{3}{|c|}{ Ratio to Current } & \multicolumn{3}{|c|}{2.46} \\
\hline
\end{tabular}

Table 23. Scenario 2

Scenario 2 shows what would be the PES when all policies are at their 100\% implementation.

PES for scenario 2 is 100.00 . Scenario 2 compares the ratio of $100 \%$ implementation with current day, which is $2.46 .100 \%$ means all policies' implementation levels are at their outliers.

This scenario is hypothetical.

\section{Scenario 3}

\begin{tabular}{|c|c|c|c|c|c|}
\hline \multirow[t]{2}{*}{ Unit Measure } & \multirow[t]{2}{*}{ Policies } & \multirow{2}{*}{$\begin{array}{c}\text { Policy } \\
\text { Weight }\end{array}$} & \multicolumn{3}{|c|}{$\begin{array}{l}\text { Scenario 3: } \\
\text { - Full \$ } \\
\text { - No States }\end{array}$} \\
\hline & & & Unit & Rel Eff & $\begin{array}{r}\text { Wght*Rel } \\
\text { Eff }\end{array}$ \\
\hline numberof states & Road Privileges & 0.06 & 0 & 0 & 0.00 \\
\hline numberof states & GHG & 0.11 & 0 & 0 & 0.00 \\
\hline$\$$ amount & Monetary Incentives & 0.17 & $\$ 30,000$ & 100 & 17.00 \\
\hline$\$$ amount & R\&D Incentives & 0.41 & $\$ 15$ & 100 & 41.00 \\
\hline numberof states & RPS & 0.14 & 0 & 0 & 0.00 \\
\hline numberof states & Charging Incentives & 0.11 & 0 & 0 & 0.00 \\
\hline \multicolumn{3}{|c|}{ Policy Effectiveness Score } & \multicolumn{3}{|c|}{58.00} \\
\hline \multicolumn{3}{|c|}{ Ratio to Current } & \multicolumn{3}{|c|}{1.43} \\
\hline
\end{tabular}

Table 24. Scenario 3 
Scenario 3 shows policies with dollar amount set to their full implementation levels, when other policies are set to $0 \%$. When Monetary Incentives and R\&D incentives are at 100\%, PES is 58.00 and Ratio is 1.43 . This is because of the high relative importance weights of these policies.

\section{Scenario 4}

\begin{tabular}{|c|c|c|c|c|c|}
\hline \multirow[t]{2}{*}{ Unit Measure } & \multirow[t]{2}{*}{ Policies } & \multirow[t]{2}{*}{$\begin{array}{l}\text { Policy } \\
\text { Weight }\end{array}$} & \multicolumn{3}{|c|}{$\begin{array}{l}\text { Scenario 4: } \\
\text { - No \$ } \\
\text { - All States }\end{array}$} \\
\hline & & & Unit & Rel Eff & Wght*Rel Eff \\
\hline numberof states & Road Privileges & 0.06 & 50 & 100 & 6.00 \\
\hline numberof states & GHG & 0.11 & 50 & 100 & 11.00 \\
\hline$\$$ amount & Monetary Incentives & 0.17 & $\$ 0$ & 0 & 0.00 \\
\hline$\$$ amount & R\&D Incentives & 0.41 & $\$ 0$ & 0 & 0.00 \\
\hline numberof states & RPS & 0.14 & 50 & 100 & 14.00 \\
\hline numberof states & Charging Incentives & 0.11 & 50 & 100 & 11.00 \\
\hline \multicolumn{3}{|c|}{ Policy Effectiveness Score } & \multicolumn{3}{|c|}{42.00} \\
\hline \multicolumn{3}{|c|}{ Ratio to Current } & \multicolumn{3}{|c|}{1.03} \\
\hline
\end{tabular}

Table 25. Scenario 4

Scenario 4 shows policies with dollar amount set to $0 \%$ implementation and all other policies are set to $100 \%$ implementation level. In other words, when Monetary Incentives and R\&D incentives are set at $0 \%$, and all the rest of policies are deployed in 50 states. PES is 42.00 and Ratio is 1.03. This is very close to the current PES. 
Scenario 5

\begin{tabular}{|c|c|c|c|c|c|}
\hline \multirow{2}{*}{ Unit Measure } & \multirow{2}{*}{ Policies } & \multirow{2}{*}{$\begin{array}{l}\text { Policy } \\
\text { Weight }\end{array}$} & \multicolumn{3}{|c|}{$\begin{array}{l}\text { Scenario 5: } \\
\text { All Policies at 20\% Implementation }\end{array}$} \\
\hline & & & Unit & Rel Eff & Wght*Rel Eff \\
\hline numberof states & Road Privileges & 0.06 & 10 & 39 & 2.31 \\
\hline numberof states & GHG & 0.11 & 10 & 34 & 3.76 \\
\hline$\$$ amount & $\begin{array}{l}\text { Monetary } \\
\text { Incentives }\end{array}$ & 0.17 & $\$ 6,000$ & 23 & 3.83 \\
\hline$\$$ amount & R\&D Incentives & 0.41 & $\$ 3$ & 31 & 12.64 \\
\hline numberof states & RPS & 0.14 & 10 & 24 & 3.40 \\
\hline numberof states & $\begin{array}{l}\text { Charging } \\
\text { Incentives }\end{array}$ & 0.11 & 10 & 38 & 4.13 \\
\hline \multicolumn{3}{|c|}{ Policy Effectiveness Score } & \multicolumn{3}{|c|}{30.06} \\
\hline \multicolumn{3}{|c|}{ Ratio to Current } & \multicolumn{3}{|c|}{0.74} \\
\hline
\end{tabular}

Table 26. Scenario 5

Scenario 5 shows all policies at 20\% implementation level. This yields lower PES than current day scenario (scenario 1).

\section{Scenarios $6 \& 7$}

\begin{tabular}{|c|c|c|c|c|c|c|}
\hline \multirow[b]{2}{*}{ Policies } & \multicolumn{3}{|c|}{$\begin{array}{c}\text { Scenario 6: } \\
\text { All Policies at } 40 \% \\
\text { Implementation } \\
\end{array}$} & \multicolumn{3}{|c|}{$\begin{array}{c}\text { Scenario 7: } \\
\text { All Policies at } 60 \% \\
\text { Implementation } \\
\end{array}$} \\
\hline & Unit & $\begin{array}{l}\text { Rel } \\
\text { Eff }\end{array}$ & $\begin{array}{r}\text { Wght*Rel } \\
\text { Eff }\end{array}$ & Unit & $\begin{array}{l}\text { Rel } \\
\text { Eff }\end{array}$ & $\begin{array}{r}\text { Wght*Rel } \\
\text { Eff }\end{array}$ \\
\hline Road Privileges & 20 & 57 & 3.42 & 30 & 73 & 4.36 \\
\hline GHG & 20 & 50 & 5.50 & 30 & 69 & 7.61 \\
\hline Monetary Incentives & $\$ 12,000$ & 38 & 6.43 & $\$ 18,000$ & 68 & 11.48 \\
\hline R\&D Incentives & $\$ 6$ & 47 & 19.13 & $\$ 9$ & 65 & 26.79 \\
\hline RPS & 20 & 37 & 5.20 & 30 & 64 & 8.90 \\
\hline Charging Incentives & 20 & 49 & 5.36 & 30 & 61 & 6.74 \\
\hline $\begin{array}{l}\text { Policy Effectiveness } \\
\text { Score }\end{array}$ & \multicolumn{3}{|c|}{45.05} & \multicolumn{3}{|c|}{65.87} \\
\hline Ratio to Current & \multicolumn{3}{|c|}{1.11} & \multicolumn{3}{|c|}{1.62} \\
\hline
\end{tabular}

Table 27. Scenarios $6 \& 7$ 
Scenario $6 \& 7$ investigate all policies set at $40 \%$ and $60 \%$ implementation levels, respectively.

The PES scores are 45.05 and 65.87 respectively. The ratio of $40 \%$ is 1.11 , and when all policies are raised to $60 \%$ the effectiveness dramatically increases and the ratio becomes 1.62.

\section{Scenario 8}

\begin{tabular}{|l|r|r|r|}
\hline & \multicolumn{3}{|c|}{ Scenario 8: } \\
\hline Policies & All Policies at 80\% Implementation \\
\hline Road Privileges & Unit & Rel Eff & Wght*Rel Eff \\
\hline GHG & 40 & 86 & 5.18 \\
\hline Monetary Incentives & 40 & 82 & 8.98 \\
\hline R\&D Incentives & $\$ 24,000$ & 87 & 14.82 \\
\hline RPS & $\$ 12$ & 84 & 34.24 \\
\hline Charging Incentives & 40 & 77 & 10.80 \\
\hline Policy Effectiveness Score & 40 & 79 & 8.66 \\
\hline \multicolumn{2}{|c|}{ Ratio to Current } & & $\mathbf{8 2 . 6 8}$ \\
\hline
\end{tabular}

Table 28. Scenario 8

Scenario 8 investigates PES for all polices at 80\% implementation level. In this scenario PES doubles the current day and reaches 82.68 . However, MI reaching $\$ 24,000$ does not seem plausible.

Scenarios $9 \& 10$

\begin{tabular}{|c|c|c|c|c|c|c|}
\hline \multirow[b]{2}{*}{ Policies } & \multicolumn{3}{|c|}{$\begin{array}{c}\text { Scenario 9: } \\
\text { Only Top } 3 \text { Policies at } 100 \% \\
\text { Implementation }\end{array}$} & \multicolumn{3}{|c|}{$\begin{array}{c}\text { Scenario 10: } \\
\text { Only Top } 3 \text { Policies at } 90 \% \\
\text { Implementation }\end{array}$} \\
\hline & Unit & $\begin{array}{l}\text { Rel } \\
\text { Eff }\end{array}$ & $\begin{array}{r}\text { Wght*Rel } \\
\text { Eff }\end{array}$ & Unit & $\begin{array}{l}\text { Rel } \\
\text { Eff }\end{array}$ & $\begin{array}{r}\text { Wght*Rel } \\
\text { Eff }\end{array}$ \\
\hline Road Privileges & 0 & 0 & 0.00 & 0 & 0 & 0.00 \\
\hline GHG & 0 & 0 & 0.00 & 0 & 0 & 0.00 \\
\hline Monetary Incentives & $\$ 30,000$ & 100 & 17.00 & $\$ 27,000$ & 94 & 15.91 \\
\hline R\&D Incentives & $\$ 15$ & 100 & 41.00 & $\$ 13.5$ & 92 & 37.62 \\
\hline RPS & 50 & 100 & 14.00 & 45 & 89 & 12.40 \\
\hline Charging Incentives & 0 & 0 & 0.00 & 0 & 0 & 0.00 \\
\hline Policy Effectiveness Score & \multicolumn{3}{|c|}{72.00} & \multicolumn{3}{|c|}{65.93} \\
\hline Ratio to Current & \multicolumn{3}{|c|}{1.77} & \multicolumn{3}{|c|}{1.62} \\
\hline
\end{tabular}

Table 29. Scenarios $9 \& 10$ 
Scenarios $9 \& 10$ take the top 3 policies that have the highest weights, which are MI, R\&D and RPS. When all the rest of the policies are at $0 \%$, and these policies are at $100 \%$ the PES becomes 72.00 , the ratio is 1.77 .

In Scenario 10, these policies are lowered to $90 \%$ implementation level. The PES becomes 65.93 and ratio becomes 1.62.

\section{Scenario 11}

\begin{tabular}{|l|r|r|r|}
\hline & \multicolumn{3}{|c|}{$\begin{array}{c}\text { Scenario 11: } \\
\text { Only Top 3 Policies at 80\% } \\
\text { Implementation }\end{array}$} \\
\hline & & & \\
Policies & Unit & Rel Eff & Wght* Rel Eff \\
\hline Road Privileges & 0 & 0 & 0.00 \\
\hline GHG & 0 & 0 & 0.00 \\
\hline Monetary Incentives & $\$ 24,000$ & 87 & 14.79 \\
\hline R\&D Incentives & $\$ 12$ & 84 & 34.44 \\
\hline RPS & 40 & 77 & 10.80 \\
\hline Charging Incentives & 0 & 0 & 0.00 \\
\hline Policy Effectiveness Score & \multicolumn{3}{|c|}{$\mathbf{6 0 . 0 3}$} \\
\hline \multicolumn{2}{|c|}{ Ratio to Current } & $\mathbf{1 . 4 8}$ \\
\hline
\end{tabular}

Table 30. Scenario 11

Scenario 11 takes the top 3 policies that has highest weights at $80 \%$ implementation level. PES is 60.03 and ratio is 1.48 . 


\section{Scenario 12}

\begin{tabular}{|l|r|r|r|}
\hline & \multicolumn{3}{|c|}{$\begin{array}{c}\text { Scenario 12: } \\
\text { Only Least important Policies at 100\% } \\
\text { Implementation }\end{array}$} \\
\hline Policies & Unit & Rel Eff & Wght*Rel Eff \\
\hline Road Privileges & 50 & 100 & 6.00 \\
\hline GHG & 50 & 100 & 11.00 \\
\hline Monetary Incentives & $\$ 0$ & 0 & 0.00 \\
\hline R\&D Incentives & $\$ 0$ & 0 & 0.00 \\
\hline RPS & 0 & 0 & 0.00 \\
\hline Charging Incentives & 50 & 100 & 11.00 \\
\hline Policy Effectiveness Score & \multicolumn{3}{|c|}{$\mathbf{2 8 . 0 0}$} \\
\hline \multicolumn{2}{|c|}{ Ratio to Current } & $\mathbf{0 . 6 9}$ \\
\hline
\end{tabular}

Table 31. Scenario 12

Scenario 12 takes the least 3 policies that have the highest weights at $100 \%$ implementation level. This is important to examine the direct effect of least important policies without the highly weighted policies. PES is 28.00 and ratio is 0.69 . From this scenario one can tell that without MI, R\&D and RPS, policies cannot be effective in mitigating the adoption barriers. Scenarios 13 to 24 focus on keeping most policies at the current implementation level while changing certain others. This way we will know what policies should be focused in today's date. 
Scenarios $13 \& 14$

\begin{tabular}{|c|c|c|c|c|c|c|}
\hline \multirow[b]{2}{*}{ Policies } & \multicolumn{3}{|c|}{$\begin{array}{c}\text { Scenario 13: } \\
\text { Everything at the current } \\
\text { level but } \\
\text { Full Road Privileges } \\
\end{array}$} & \multicolumn{3}{|c|}{$\begin{array}{c}\text { Scenario 14: } \\
\text { Everything at the current level } \\
\text { but } \\
\text { Full GHG }\end{array}$} \\
\hline & Unit & Rel Eff & $\begin{array}{r}\text { Wght*Rel } \\
\text { Eff }\end{array}$ & Unit & $\begin{array}{l}\text { Rel } \\
\text { Eff }\end{array}$ & $\begin{array}{r}\text { Wght* Rel } \\
\text { Eff }\end{array}$ \\
\hline Road Privileges & 50 & 100 & 6.00 & 13 & 44 & 2.64 \\
\hline GHG & 15 & 42 & 4.63 & 50 & 100 & 11.00 \\
\hline Monetary Incentives & $\$ 10,000$ & 33 & 5.56 & $\$ 10,000$ & 33 & 5.56 \\
\hline R\&D Incentives & $\$ 4$ & 36 & 14.81 & $\$ 4$ & 36 & 14.81 \\
\hline RPS & 29 & 61 & 8.53 & 29 & 61 & 8.53 \\
\hline Charging Incentives & 13 & 41 & 4.50 & 13 & 41 & 4.50 \\
\hline Policy Effectiveness Score & \multicolumn{3}{|c|}{44.02} & \multicolumn{3}{|c|}{47.03} \\
\hline Ratio to Current & \multicolumn{3}{|c|}{1.08} & \multicolumn{3}{|c|}{1.16} \\
\hline
\end{tabular}

Table 32. Scenarios $13 \& 14$

Scenario 13 investigates the effect of Road Privileges when it is at 100\% implementation level.

As all the other policies are kept at current level of implementation, road privileges' effect would be minimal even if it is deployed in all of the 50 states. PES becomes 44.02 and the ratio becomes 1.08. This change is minimal and focusing on more Road privileges' does not seem a favorable option.

Scenario 14 investigates the effect of GHG when it is at 100\% implementation level. As all the other policies are kept at current day's effectiveness, GHG's effect would be minimal even if it is deployed in all 50 states. PES becomes 47.03 and ratio becomes 1.16. 


\section{Scenario 15}

\begin{tabular}{|l|r|r|r|}
\hline \multicolumn{1}{|c|}{} & \multicolumn{3}{|c|}{$\begin{array}{c}\text { Scenario 15: } \\
\text { Everything at the current level but } \\
\text { Full MI }\end{array}$} \\
\hline Policies & & & \\
\hline Road Privileges & Unit & Rel Eff & Wght*Rel Eff \\
\hline GHG & 13 & 44 & 2.64 \\
\hline Monetary Incentives & 15 & 42 & 4.63 \\
\hline R\&D Incentives & $\$ 30,000$ & 100 & 17.00 \\
\hline RPS & $\$ 4$ & 36 & 14.81 \\
\hline Charging Incentives & 29 & 61 & 8.53 \\
\hline Policy Effectiveness Score & 13 & 41 & 4.50 \\
\hline \multicolumn{2}{|c|}{ Ratio to Current } & & $\mathbf{5 2 . 1 0}$ \\
\hline
\end{tabular}

Table 33. Scenario 15

Scenario 15 investigates the effect of MI when it is at 100\% implementation level. As all the other policies are kept at current implementation levels, MI's effect would be low even though it was set at the highest level. PES becomes 52.10 and the ratio becomes 1.28. Increasing MI to $\$ 30,000$ and only being able to increase PES by 8 , ramping MI to $100 \%$ does not seem favorable. 
Scenarios $16 \& 17$

\begin{tabular}{|c|c|c|c|c|c|c|}
\hline \multirow[b]{2}{*}{ Policies } & \multicolumn{3}{|c|}{$\begin{array}{c}\text { Scenario 16: } \\
\text { Everything at the current level } \\
\text { but } \\
\text { Full R\&D }\end{array}$} & \multicolumn{3}{|c|}{$\begin{array}{c}\text { Scenario 17: } \\
\text { Everything at the current } \\
\text { level but } \\
\text { Full RPS }\end{array}$} \\
\hline & Unit & $\begin{array}{l}\text { Rel } \\
\text { Eff }\end{array}$ & $\begin{array}{r}\text { Wght*Rel } \\
\text { Eff }\end{array}$ & Unit & $\begin{array}{l}\text { Rel } \\
\text { Eff }\end{array}$ & $\begin{array}{r}\text { Wght*Rel } \\
\text { Eff }\end{array}$ \\
\hline Road Privileges & 13 & 44 & 2.64 & 13 & 44 & 2.64 \\
\hline GHG & 15 & 42 & 4.63 & 15 & 42 & 4.63 \\
\hline Monetary Incentives & $\begin{array}{r}\$ 10,00 \\
0\end{array}$ & 33 & 5.56 & $\begin{array}{r}\$ 10,0 \\
00\end{array}$ & 33 & 5.56 \\
\hline R\&D Incentives & $\$ 15$ & 100 & 41.00 & $\$ 4$ & 36 & 14.76 \\
\hline RPS & 29 & 61 & 8.53 & 50 & 100 & 14.00 \\
\hline Charging Incentives & 13 & 41 & 4.50 & 13 & 41 & 4.50 \\
\hline $\begin{array}{l}\text { Policy Effectiveness } \\
\text { Score }\end{array}$ & \multicolumn{3}{|c|}{66.86} & \multicolumn{3}{|c|}{46.09} \\
\hline Ratio to Current & \multicolumn{3}{|c|}{1.64} & \multicolumn{3}{|c|}{1.13} \\
\hline
\end{tabular}

Table 34. Scenarios $16 \& 17$

Scenario 16 investigates the effect of R\&D Incentives when it is at 100\% implementation level.

As all the other policies are kept at current levels, R\&D's effect would be considerably high when it is set at 100\% implementation level. PES becomes 66.86 and the ratio becomes 1.64. Increasing $\mathrm{R} \& \mathrm{D}$ to $\$ 15$ billion and get a high impact shows that $\mathrm{R} \& \mathrm{D}$ should be one of the first policies to focus on.

Scenario 17 investigates the effect of RPS Incentives when it is at 100\% implementation level. As all the other policies are kept at current levels, RPS's effect would be relatively low when it is deployed at 50 states. PES becomes 46.09 and the ratio becomes 1.13. However, it is important to note that the current RPS implementation level is around 60\%. Nonetheless, focusing only on RPS to deploy it to 50 states and yet getting only 1.13 shows that RPS alone is not very critical. 


Scenario 18
\begin{tabular}{|l|r|r|r|}
\hline & \multicolumn{3}{|c|}{$\begin{array}{c}\text { Scenario 18: } \\
\text { Everything at the current level but } \\
\text { Full CI }\end{array}$} \\
\hline Policies & & & $\begin{array}{r}\text { Wght*Rel } \\
\text { Eff }\end{array}$ \\
\hline Road Privileges & Unit & Re1 Eff & 6.00 \\
\hline GHG & 50 & 100 & 4.63 \\
\hline Monetary Incentives & 15 & 42 & 5.56 \\
\hline R\&D Incentives & $\$ 10,000$ & 33 & 14.81 \\
\hline RPS & $\$ 4$ & 36 & 8.53 \\
\hline Charging Incentives & 29 & 61 & 11.00 \\
\hline Policy Effectiveness Score & 50 & 100 & \multicolumn{3}{|c|}{$\mathbf{5 0 . 5 3}$} \\
\hline \multicolumn{2}{|r|}{ Ratio to Current } & \multicolumn{3}{|c|}{$\mathbf{1 . 2 4}$} \\
\hline
\end{tabular}

Table 35. Scenario 18

Scenario 18 investigates the effect of CI when it is at 100\% implementation level. As all the other policies are kept at current levels, CI's effect would be high when it is deployed at 50 states. PES becomes 50.53 and the ratio becomes 1.24. However, it is important to note that the current level of CI is around 25\%. Setting it to $100 \%$ means to deploy it in 37 more states. As it is fundamentally an infrastructural facilitation, increasing it has a significant impact on EV adoption. 
Scenarios $19 \& 20$

\begin{tabular}{|c|c|c|c|c|c|c|}
\hline \multirow[b]{2}{*}{ Policies } & \multicolumn{3}{|c|}{$\begin{array}{c}\text { Scenario 19: } \\
\text { Everything at the current level } \\
\text { but } \\
\text { Economic Incentives at } 100 \%\end{array}$} & \multicolumn{3}{|c|}{$\begin{array}{c}\text { Scenario 20: } \\
\text { Everything at the current } \\
\text { level but } \\
\text { MI \& R\&D@80\% }\end{array}$} \\
\hline & Unit & $\begin{array}{l}\text { Rel } \\
\text { Eff }\end{array}$ & $\begin{array}{r}\text { Wght*Rel } \\
\text { Eff }\end{array}$ & Unit & Rel Eff & $\begin{array}{r}\text { Wght*Rel } \\
\text { Eff }\end{array}$ \\
\hline Road Privileges & 13 & 44 & 2.64 & 13 & 44 & 2.64 \\
\hline GHG & 15 & 42 & 4.63 & 15 & 42 & 4.63 \\
\hline Monetary Incentives & $\$ 30,000$ & 100 & 17.00 & $\$ 24,000$ & 87 & 14.79 \\
\hline R\&D Incentives & $\$ 15$ & 100 & 41.00 & $\$ 12$ & 84 & 34.44 \\
\hline RPS & 29 & 61 & 8.53 & 29 & 61 & 8.53 \\
\hline Charging Incentives & 13 & 41 & 4.50 & 13 & 41 & 4.50 \\
\hline $\begin{array}{l}\text { Policy Effectiveness } \\
\text { Score }\end{array}$ & \multicolumn{3}{|c|}{78.30} & \multicolumn{3}{|c|}{69.53} \\
\hline Ratio to Current & \multicolumn{3}{|c|}{1.93} & \multicolumn{3}{|c|}{1.71} \\
\hline
\end{tabular}

Table 36. Scenarios 19 \&20: Economic Decision

Scenario 19 focuses on increasing MI and R\&D and keeping rest of the policies at their current levels. Pushing economic policies to their highest implementation level in scenario 19, then $80 \%$ in scenario 20 shows the importance level of these policies based on their PES curves. Scenario 19 shows they would increase PES to 78.30 and ratio to 1.93, and scenario 20 results in 69.53 PES and 1.71 ratio. By only focusing on these 2 policies PES can be substantially increased. 


\begin{tabular}{|l|r|r|r|}
\hline & \multicolumn{3}{|c|}{$\begin{array}{c}\text { Scenario 21: } \\
\text { Everything at the current level } \\
\text { but }\end{array}$} \\
& \multicolumn{3}{|c|}{ MI \&Full R\&D @60\% } \\
\hline Policies & Unit & Rel Eff & Wght*Rel Eff \\
\hline Road Privileges & 13 & 44 & 2.65 \\
\hline GHG & 15 & 42 & 4.63 \\
\hline Monetary Incentives & $\$ 18,000$ & 68 & 11.48 \\
\hline R\&D Incentives & $\$ 9$ & 65 & 26.79 \\
\hline RPS & 29 & 61 & 8.53 \\
\hline Charging Incentives & 13 & 41 & 4.50 \\
\hline Policy Effectiveness Score & \multicolumn{3}{|c|}{$\mathbf{5 8 . 5 6}$} \\
\hline \multicolumn{2}{|c|}{ Ratio to Current } & $\mathbf{1 . 4 4}$ \\
\hline
\end{tabular}

Table 37. Scenario 21

Scenario 21, similar to scenarios 19 and 20 shows the economic policies at a level of $60 \%$ effectiveness. PES is 58.56 and ratio 1.44 .

Scenarios $22 \& 23$

\begin{tabular}{|c|c|c|c|c|c|c|}
\hline \multirow[b]{2}{*}{ Policies } & \multicolumn{3}{|c|}{$\begin{array}{c}\text { Scenario 22: } \\
\text { Everything at the current } \\
\text { level: but Environmental } \\
\text { Boost }\end{array}$} & \multicolumn{3}{|c|}{$\begin{array}{c}\text { Scenario 23: } \\
\text { Everything at the current } \\
\text { level: but Infrastructure } \\
\text { Boost }\end{array}$} \\
\hline & Unit & $\begin{array}{c}\text { Rel } \\
\text { Eff }\end{array}$ & $\begin{array}{r}\text { Wght*Rel } \\
\text { Eff }\end{array}$ & Unit & Rel Eff & $\begin{array}{r}\text { Wght*Rel } \\
\text { Eff }\end{array}$ \\
\hline Road Privileges & 13 & 44 & 2.65 & 50 & 100 & 6.00 \\
\hline GHG & 50 & 100 & 11.00 & 15 & 42 & 4.62 \\
\hline Monetary Incentives & $\$ 10,000$ & 33 & 5.56 & $\$ 10,000$ & 33 & 5.56 \\
\hline R\&D Incentives & $\$ 4$ & 36 & 14.81 & $\$ 4$ & 36 & 14.81 \\
\hline RPS & 50 & 100 & 14.00 & 29 & 61 & 8.53 \\
\hline Charging Incentives & 13 & 41 & 4.51 & 50 & 100 & 11.00 \\
\hline Policy Effectiveness Score & \multicolumn{3}{|c|}{52.52} & \multicolumn{3}{|c|}{50.52} \\
\hline Ratio to Current & \multicolumn{3}{|c|}{1.29} & \multicolumn{3}{|c|}{1.24} \\
\hline
\end{tabular}

Table 38.Scenarios 22\&23

Scenarios 22 and 23 emphasize support on certain group of policies. We boost the implementation level of policies that support a certain aspect, to $100 \%$, and we keep the rest 
of the policies at their current level. This type of set up shows when each aspect of barriers is tackled through its highly correlated policies, what the impact on PES becomes.

Scenario 22 boosts GHG and RPS as these 2 policies are strongly related to environment. When environmental policies are set to 100\% implementation level, PES becomes 52.52, and Ratio becomes 1.29.

Scenario 23 boosts Road Privileges and Charging incentives as these are Infrastructure related policies. When Infrastructure boost policies are set to $100 \%$ implementation level, PES becomes 50.52, and Ratio becomes 1.24 .

Scenarios 22 and 23 are comparable from an impact standpoint.

\section{Scenario 24}

\begin{tabular}{|l|r|r|r|}
\hline & \multicolumn{3}{|c|}{$\begin{array}{c}\text { Scenario 24: } \\
\text { Everything at the current but } \\
\text { Suggested Scenario }\end{array}$} \\
\hline Policies & Unit & Rel Eff & Wght*Rel Eff \\
\hline Road Privileges & 30 & 73 & 4.38 \\
\hline GHG & 30 & 69 & 7.59 \\
\hline Monetary Incentives & $\$ 18,000$ & 68 & 11.48 \\
\hline R\&D Incentives & $\$ 12$ & 84 & 34.44 \\
\hline RPS & 40 & 77 & 10.78 \\
\hline Charging Incentives & 40 & 79 & 8.69 \\
\hline Policy Effectiveness Score & \multicolumn{3}{|c|}{$\mathbf{7 7 . 3 6}$} \\
\hline \multicolumn{1}{|c|}{ Ratio to Current } & \multicolumn{3}{|c}{} \\
\hline
\end{tabular}

Table 39.Scenario 24: Suggested Scenario

Scenario 24 focuses on the most effective interval of policy implementation levels, when they are moved from one data point to the next. As resources are limited, it is unrealistic that all policies can be brought to their 100\% implementation level. Some policies' 100\% 
implementation may never be reached as the adoption can reach a point when that policy is not needed anymore. As an example, when adoption reaches a point at which EV is a viable option to ICE, monetary incentives may be removed. Scenario 24 investigates the steepest incline of the policy effectiveness curves from one data point to the other and suggests that level if that data point is at a higher level of implementation than that of the current level of the policy. From each PES curve, we have identified the ideal state of Road Privileges to be 30 states, GHG to be 30 states, Monetary Incentives to be $\$ 18,000, \mathrm{R} \& \mathrm{D}$ Incentives to be $\$ 12$, RPS to be 40 states, and Charging Incentives 40 states. These data points are all at a higher policy implementation than that of current date. They are also at the steepest incline at their curve. The PES is 77.36 and the ratio is 1.90 . This means this suggested scenario almost doubles the current scenario.

Scenario 25

\begin{tabular}{|l|r|r|r|}
\hline & \multicolumn{3}{|c|}{ Scenario 25: } \\
\hline & All policies next implementation level \\
\hline Policies & Unit & Rel Eff & Wght*Rel \\
\hline Road Privileges & 20 & 57 & 3.42 \\
\hline GHG & 20 & 50 & 5.50 \\
\hline Monetary Incentives & $\$ 12,000$ & 38 & 6.46 \\
\hline R\&D Incentives & $\$ 6$ & 47 & 19.27 \\
\hline RPS & 30 & 64 & 8.96 \\
\hline Charging Incentives & 20 & 49 & 5.39 \\
\hline Policy Effectiveness Score & \multicolumn{3}{|c|}{$\mathbf{4 9 . 0 0}$} \\
\hline \multicolumn{2}{|c|}{ Ratio to Current } & $\mathbf{1 . 2 0}$ \\
\hline
\end{tabular}

Table 40. Scenario 25: Next Implementation levels

Scenario 25 investigates PES and ratio by bringing each policy to the next implementation level than the current one. Road Privileges are taken from 13 states to 20 states, GHG is from 
15 states to 20 states, $\mathrm{MI}$ from $\$ 10,000$ to $\$ 12,000, \mathrm{R} \& \mathrm{D}$ Incentives from $\$ 4$ billion to $\$ 6$ billion, RPS from 29 states to 30 states, and Charging Incentives from 13 states to 20 states. This shows what would be the impact of taking policies to the next implementation level in the short run. PES becomes 49 and ratio to current becomes 1.20.

Below table summarizes some of the highlight scenarios. Scenario logic shows the main logic underlying the scenario, scenario details shows the implementation level of each policies in each scenario. Scenarios in this table were sorted in a descending order with respect to PES.

\begin{tabular}{|c|c|c|c|c|c|c|c|c|c|}
\hline \multirow{2}{*}{ Scenario Logic } & \multirow{2}{*}{ Scenario } & \multicolumn{6}{|c|}{ Scenario Details } & \multirow{2}{*}{$\begin{array}{l}\text { PES } \\
\text { Score }\end{array}$} & \multirow{2}{*}{ Ratio } \\
\hline & & $\mathbf{R P}$ & GHG & MI & $\mathrm{R} \& \mathrm{D}$ & RPS & CI & & \\
\hline $\begin{array}{l}\text { Full } \\
\text { implementation }\end{array}$ & Scenario 2 & $100 \%$ & $100 \%$ & $100 \%$ & $100 \%$ & $100 \%$ & $100 \%$ & 100.00 & 2.46 \\
\hline $\begin{array}{l}\text { Suggested } \\
\text { scenario }\end{array}$ & Scenario 24 & $60 \%$ & $60 \%$ & $60 \%$ & $80 \%$ & $80 \%$ & $80 \%$ & 77.36 & 1.90 \\
\hline $\begin{array}{l}\text { Top policies } \\
\text { @100\% }\end{array}$ & Scenario 9 & $0 \%$ & $0 \%$ & $100 \%$ & $100 \%$ & $100 \%$ & $0 \%$ & 72.00 & 1.77 \\
\hline $\begin{array}{l}\text { Top policies } \\
\text { @ } 90 \%\end{array}$ & Scenario 10 & $0 \%$ & $0 \%$ & $90 \%$ & $90 \%$ & $90 \%$ & $0 \%$ & 65.93 & 1.62 \\
\hline $\begin{array}{l}\text { All policies } \\
\text { @60\% }\end{array}$ & Scenario 7 & $60 \%$ & $60 \%$ & $60 \%$ & $60 \%$ & $60 \%$ & $60 \%$ & 65.87 & 1.62 \\
\hline $\begin{array}{l}\text { \$ policies } \\
\text { @100\% } \\
\text { State deploym't } \\
@ 0 \%\end{array}$ & Scenario 3 & $0 \%$ & $0 \%$ & $100 \%$ & $100 \%$ & $0 \%$ & $0 \%$ & 58.00 & 1.43 \\
\hline $\begin{array}{l}\text { Next } \\
\text { implementation } \\
\text { level }\end{array}$ & Scenario 25 & $40 \%$ & $40 \%$ & $40 \%$ & $40 \%$ & $60 \%$ & $40 \%$ & 49.00 & 1.20 \\
\hline $\begin{array}{l}\text { All policies } \\
@ 40 \%\end{array}$ & Scenario 6 & $40 \%$ & $40 \%$ & $40 \%$ & $40 \%$ & $40 \%$ & $40 \%$ & 45.05 & 1.11 \\
\hline $\begin{array}{l}\$ \text { policies@0\% } \\
\text { State deploym’t } \\
@ 100 \%\end{array}$ & Scenario 4 & $100 \%$ & $100 \%$ & $0 \%$ & $0 \%$ & $100 \%$ & $100 \%$ & 42.00 & 1.03 \\
\hline Current scenario & Scenario 1 & $26 \%$ & $30 \%$ & $33 \%$ & $27 \%$ & $58 \%$ & $26 \%$ & 40.67 & 1.00 \\
\hline $\begin{array}{l}\text { Least policies at } \\
\text { @100\% }\end{array}$ & Scenario 12 & $100 \%$ & $100 \%$ & $0 \%$ & $0 \%$ & $0 \%$ & $100 \%$ & 28.00 & 0.69 \\
\hline
\end{tabular}

Table 41. Summary of Scenario Scores \& Ratios 


\section{CHAPTER - CONCLUSION, CONTRIBUTIONS, LIMITATIONS \& FUTURE WORK}

\subsection{Conclusion}

The literature has yet to suggest a decision-making tool on EV adoption, that can provide guidelines to policy makers, EV manufacturers and other EV stakeholders. Due to scarce historical data, this research will bring to surface the cumulative knowledge of all EV stakeholders and will be guidelines for EV policies and strategies.

Our research studied one of the most important but challenging topics of today, EV adoption. EV transition is a very complex phenomenon and its stakeholders are very diverse. Because there are no historical data for EV sales, we used HDM to quantify expert judgments on EV Adoption barriers and policies.

The first output of our research is a comprehensive list of EV adoption barriers under 5 perspectives. This is the first time in the literature that all of EV adoption barriers were consolidated in one report.

One of the outputs of this research, the relative importance of barriers to EV adoption, can be input to the decision making of stakeholders.

This research also points out the most important policy groups and specific policies that can help EV progress; therefore provides guidelines for policy makers and scholars of Technology Policy. 


\subsubsection{Discussion on Perspectives}

The quantified expert judgments resulted in the relative weights of perspectives. Results showed that Economic barriers were the most important barriers by a relative importance weight of 0.30 . They were 1.5 times more important than the following up perspective Technical barriers. Technical barriers received a relative importance weight of 0.20.

There was emphasis on the barriers from both of these perspectives in the literature. When range, charging network were discussed often times under technical barriers, battery costs and initial costs were discussed that are under economic barriers. Our results show that technical challenges are really not the most important barrier that hinder EV Adoption. Therefore, governments and policy makers should focus on mitigating Economic barriers to accelerate EV Adoption.

This means manufacturers and NGOs should focus on spending much more effort in alleviating. The technical barriers received much criticism in the media and academia, however, our results show that the outreach department of manufacturers should be first prioritized in the betterment of economic barriers. Manufacturers should then focus on the betterment of technical barriers. The technical perspective is still one of the most important areas to improve in order to accelerate EV adoption.

This also gives guidelines to governments and policy makers. According to our results, governments should spend the most money and effort on tailoring policies that can effectively mitigate economic barriers. 


\subsubsection{Discussion on Barriers}

Another output of our research was the relative importance weights of barriers. Although there is an increasing number of studies in the literature about EV adoption barriers in the recent years, the literature has yet to offer a study that quantifies the EV adoption barriers with a wholistic approach. Our results show that Initial Cost is the most important barrier for EV adoption followed by Battery Cost, Technology Resistance and Range, respectively. Range has been emphasized as one of the most important barriers by many scholars in the literature, and one of the highlights of our study is that it is $4^{\text {th }}$ most important barrier.

Technology Resistance was mentioned in a limited number of studies, it was never emphasized as being one of the most important barriers. Because studies on EV adoption barriers usually focus on only the consumer aspect, barriers that are directly related to the systematic change are dismissed most of the time. Therefore, it is another highlight of our research that Technology Resistance is the $3^{\text {rd }}$ most important barrier among 18, that needs to be tackled in order to accelerate EV adoption.

When shoveling more money into manufacturers may alleviate the initial cost, range and battery cost can be mitigated with monetary support on R\&D improvements. However, entrenched technologies' resistance can be dealt with different ways. Policy makers should keep in mind that the resistance to EV will continue to hinder adoption until it crosses the chasm. When EV reaches that point, EV manufacturers will not need as much support from government in dealing with incumbent ICE companies.

Another major finding of our paper is that charging network and charging time are some of the least important barriers. This is in line with the recent developments in the battery 
technology, and an important contribution to the literature. Although enhancement in charging technology and the infrastructure will continue to be a need as the number of vehicles increase, this is not where manufacturers should turn most of their attention at this point in adoption.

\subsubsection{Discussion on Policies}

The relative importance weights of policies were another output of our study. Although policies that are enacted by governments to help EV adoption are known, their actual effectiveness in mitigating the linked barriers were never studied in the literature. Because majority of the studies focus only on the consumer aspect of EV adoption, they dismiss the fact that manufacturers are not fully ready for this transition. Our results showed that R\&D incentives by far is the most effective policy in mitigating the EV Adoption barriers. Although monetary incentives that are directly given to consumers is the second most effective policy, the governments' support to the manufacturers is more critical at this point. Previous research suggested that up-front price reduction is the most powerful incentive in promoting EV adoption [131]. Therefore, this is one of the critical contributions of our study to the literature.

It is also important to point out that RPS became the third most effective policy. This shows that transitioning to a more sustainable, clean energy source is critical to EV transition. RPS standards are already deployed in 29 states, and other states have plans to enact these standards. This will not only support EV, but also will help governments establish a more sustainable energy infrastructure for the future.

Our research also found that the highest disagreement among experts are at Environmental and Political barriers. This means that policy makers should focus more on understanding and 
explaining the consequences of these barriers thoroughly in order to be on the same page with other stakeholders. As mentioned above, EV transition is a complex phenomenon and needs all its stakeholders to be in sync in proving the most effective solutions.

\subsubsection{Discussion on Policy Effectiveness Curves \& Scenarios}

Last but not least, our contribution to the literature was the use of desirability curves concept under policy effectiveness curves. Although identifying the current effectiveness level of policies was already an important contribution, it was also critical to investigate whether it is possible to exploit these policies at different implementation levels. We suggested that taking the implementation level of Road Privileges to 30 states, GHG to 30 states, RPS to 40 states, Charging Incentives to 40 states, when making Monetary incentives $\$ 18,000$, and $R \& D$ incentives $\$ 12$ billion will be the most effective at the same time doable scenario.

\subsubsection{Guidelines to EV Stakeholders}

As a result of the scenarios that were derived from policy effectiveness curves, we are suggesting some guidelines to EV stakeholders.

Guidelines to Governments: Based on the 25 scenarios generated, one can easily argue that implementing all policies at 100\% level is hypothetical. As governments are extra careful in the way they spend resources, it is important to look at the most effective scenarios. Below are the guidelines to governments as a result of scenarios:

- We are suggesting Scenario 24 especially for governments for a number of reasons:

- Implementation of all policies at $100 \%$ is not realistic.

Implementing the most effective policies will increase the efficiency of resources. 
- Merely implementing the top policies at $100 \%$ as in scenario 9 (even though this may be unrealistic), is not as effective increasing all policies to certain levels.

- Current implementation level of monetary incentives is insufficient to accelerate adoption as EV prices are still very high.

- Some of these changes are infrastructural and make take longer than others. When increasing road privileges may require less effort for governments, deploying RPS, or forcing GHG standards may take longer time to implement. Governments should set these goals ahead of time.

- R\&D Incentives are core to EV adoption. In any scenario, R\&D Incentives should be pushed higher as much as possible. All technology adoption and technology diffusion literature we covered (in Section 3.4 and 3.5) suggest that in order for disruptive technologies to cross the chasm, a market leader and competition is critical. Currently Tesla is the leader of EV industry, however other companies should be supported with $\mathrm{R} \& \mathrm{D}$ Incentives to provide healthy competition.

- Governments should start to push all policies to next implementation level from current day as in Scenario 25, if Scenario 24 is not immediately doable. Scenario 25 pushes all policies to $40 \%$ except RPS. This will result in $20 \%$ betterment in the policy effectiveness.

Guidelines to Manufacturers: A C-level executive from a major EV manufacturer mentioned that "lack of investment" is what hinders EV adoption the most. Our results confirm this statement. Below are the guidelines for manufacturers.

- Manufacturers should spend effort on getting as much R\&D support as possible. 
- Their policy \& government relations offices should work hand in hand with governments to set goals for infrastructural betterments ahead of time.

- Mitigating consumer-oriented perspectives is not merely enough to accelerate EV adoption. Incentives that are directly customer facing, such as monetary incentives and road privileges have limited effectiveness on their own. Manufacturers should also focus on infrastructural policies.

\subsection{Limitations}

This study has two basic limitations:

1. Expert judgments are quantified; therefore, results are partially based solely on their judgments rather than any quantitative data. It is because no quantitative data are available to measure the effectiveness of policies due to novelty of the technology.

2. Due to variety of state level policy alternatives, only a set of policies, regulations and incentives have been used in the model.

\subsection{Future Work}

1. After policies are implemented, their impacts on removing the barriers can be studied in the future.

2. The study can be extended to study the effects of local and regional policies on the removal of barriers at the state level.

3. Although RPS is enacted at several states, the percentage that is pushed for clean energy are at different levels for each state throughout the US. A future research can study clean energy production at a certain percentage $(60 \%, 80 \%$ etc.) throughout the US and examine its effectiveness. 
4. An infinite number of scenarios can be generated based on the policy curves. This study limits the number of scenarios to 25 in order to show the use of Policy curves. A future research can generate more scenarios and provide guidelines for other geographies. 


\section{REFERENCES}

[1] M. Ustaoglu and B. Yildiz, "Information Technology's Effect on Turkey's Foreign Trade: An Investigation For The Last Decade," Procedia-Social and Behavioral Sciences, vol. 24, pp. 781-789, 2011.

[2] D. Sperling and D. Gordon, Two billion cars: driving toward sustainability. Oxford University Press, 2009.

[3] A. A. Fawcett, K. V. Calvin, C. Francisco, J. M. Reilly, and J. P. Weyant, "Overview of EMF 22 US transition scenarios," Energy Economics, vol. 31, pp. S198-S211, 2009.

[4] T. Hughes, "Technological momentum," in Does Technology Drive History?: The Dilemma of Technological Determinism, M. R. Smith and L. Marx, Eds. Cambridge, MA: MIT Press, 1994, pp. 101-113.

[5] H. A. Bonges III and A. C. Lusk, "Addressing electric vehicle (EV) sales and range anxiety through parking layout, policy and regulation," Transportation Research Part A: Policy and Practice, vol. 83, pp. 63-73, 2016.

[6] D. Kessler. (2009). Obama Kills Hydrogen Car Funding. Available: https://www.treehugger.com/cars/obama-kills-hydrogen-car-funding.html

[7] Marketwire. (2015). Europe's Charging Network Is Growing: Charging Stations in Norway, Finland, Sweden, Denmark, France and Switzerland Now Available for Use With Intercharge. Available: http://www.marketwired.com/press-release/europes-charging-networkis-growing-charging-stations-norway-finland-sweden-denmark-2065004.htm

[8] B. Wilson, J. Dobrovolny, and M. Lowry, "A critique of how technology adoption models are utilized," Performance Improvement, vol. 38, no. 5, pp. 24-29, 1999.

[9] S. R. Barley, "What can we learn from the history of technology?," Journal of Engineering and Technology Management, vol. 15, no. 4, pp. 237-255, 1998.

[10] R. S. Trends, "Report of the President's Research Committee," ed: New York: McGraw-Hill Book Company, Inc, 1933.

[11] D. L. Greene, S. Park, and C. Liu, "Analyzing the transition to electric drive vehicles in the US," Futures, vol. 58, pp. 34-52, 2014. 
[12] B. K. Sovacool and R. F. Hirsh, "Beyond batteries: An examination of the benefits and barriers to plug-in hybrid electric vehicles (PHEVs) and a vehicle-to-grid (V2G) transition," Energy Policy, vol. 37, no. 3, pp. 1095-1103, 2009.

[13] C. U. Herman, A. (2016). Refineries Push Gas Higher. Available: http://abcnews.go.com/Business/IndustryInfo/story?id=3176143\&page=1

[14] O. Egbue and S. Long, "Barriers to widespread adoption of electric vehicles: An analysis of consumer attitudes and perceptions," Energy Policy, vol. 48, pp. 717-729, 2012.

[15] USEIA, "Annual Energy Outlook 2012 with Projections to 2035," U.S. Energy Information Administration, Washington, DC,2012, vol. DOE/EIA-0383.

[16] N. Nakicenovic, World energy outlook 2007: China and India insights. IEA/OECD, 2007.

[17] IEA, Energy Technology Perspectives 2012. OECD Publishing, 2012.

[18] G. Mom, The electric vehicle: Technology and expectations in the automobile age. JHU Press, 2012.

[19] M. Benson. (2008). Council OKs tougher tailpipe-emissions rules. Available: http://archive.azcentral.com/news/articles/2008/05/07/20080507cleancar0507.ht $\underline{\mathrm{ml}}$

[20] P. Jaramillo and C. Samaras, "Comparing life cycle GHG emissions from coal-toliquids and plug-in hybrids," CEIC Working Paper 07-04 (June)2007.

[21] (2007). The Next Generation of Hybrid Cars: Plug-in Hybrids Can Help Reduce Global Warming and Slash Oil Dependency.

[22] USEPA, "INVENTORY OF U.S. GREENHOUSE GAS EMISSIONS AND SINKS:," in "1990 - 2009," U.S. Environmental Protection Agency, Washington, DC2011, Available:

http://www3.epa.gov/climatechange/Downloads/ghgemissions/US-GHGInventory-2011-Complete Report.pdf.

[23] B. Canis, "Battery manufacturing for hybrid and electric vehicles: Policy issues," 2011: Congressional Research Service, Library of Congress. 
[24] M. Knowles, "Through-life management of electric vehicles," Procedia CIRP, vol. 11, pp. 260-265, 2013.

[25] B. Van Bree, G. P. Verbong, and G. J. Kramer, "A multi-level perspective on the introduction of hydrogen and battery-electric vehicles," Technological Forecasting and Social Change, vol. 77, no. 4, pp. 529-540, 2010.

[26] K. S. Gallagher and E. Muehlegger, "Giving green to get green? Incentives and consumer adoption of hybrid vehicle technology," Journal of Environmental Economics and Management, vol. 61, no. 1, pp. 1-15, 2011.

[27] Z. ZigBee, "Electric Vehicle (V2G) Report 2010 - Smart Grid Insights - Zpryme \& ZigBee Alliance | Plug In Hybrid | Electric Vehicle," ed, 2018.

[28] M. E. Kahn, "Do greens drive Hummers or hybrids? Environmental ideology as a determinant of consumer choice," Journal of Environmental Economics and Management, vol. 54, no. 2, pp. 129-145, 2007.

[29] A. K. Srivastava, B. Annabathina, and S. Kamalasadan, "The challenges and policy options for integrating plug-in hybrid electric vehicle into the electric grid," The Electricity Journal, vol. 23, no. 3, pp. 83-91, 2010.

[30] M. Weiss, M. K. Patel, M. Junginger, A. Perujo, P. Bonnel, and G. van Grootveld, "On the electrification of road transport-Learning rates and price forecasts for hybrid-electric and battery-electric vehicles," Energy Policy, vol. 48, pp. 374-393, 2012.

[31] K. Sikes, T. Gross, Z. Lin, J. Sullivan, T. Cleary, and J. Ward, "Plug-in hybrid electric vehicle market introduction study: final report," Oak Ridge National Laboratory (ORNL)2010.

[32] J. Voelcker. (2016, 10 April). Plug-In Electric Car Sales For 2015 Fall Slightly From 2014. Available: https://www.greencarreports.com/news/1101751_plug-in-electric-carsales-for-2015-fall-slightly-from-2014

[33] J. J. Romm and A. A. Frank, "Hybrid vehicles gain traction," Scientific American, vol. 294, no. 4, pp. 72-79, 2006.

[34] K. Lebeau, J. Van Mierlo, P. Lebeau, O. Mairesse, and C. Macharis, "The market potential for plug-in hybrid and battery electric vehicles in Flanders: A choice-based conjoint analysis," Transportation Research Part D: Transport and Environment, vol. 17, no. 8, pp. 592-597, 2012. 
[35] E. Adoption.com. (2018). EV Market Share - Electric vebicle US market share - EV Adoption. Available: http://evadoption.com/ev-market-share

[36] D. L. P. Greene, Sangsoo; Liu, Changzheng, "Analyzing the Transition to Electric Drive in California," The Howard H. Baker JR Center for Public Policy2013, Available: https://www.theicct.org/sites/default/files/publications/Transition-toElectric-Drive-2013-report.FINAL .pdf.

[37] K. S. Gallagher, A. Grübler, L. Kuhl, G. Nemet, and C. Wilson, "The energy technology innovation system," Annual Review of Environment and Resources, vol. 37, pp. 137-162, 2012.

[38] D. G. Groves and R. J. Lempert, "A new analytic method for finding policy-relevant scenarios," Global Environmental Change, vol. 17, no. 1, pp. 73-85, 2007.

[39] B. Yildiz, M. Ustaoglu, and A. Incekara, "Investigating Turkey's EV Technology Adoption Level: How Would Turkey Cross the Chasm Through Policies?," Review of Contemporary Business Research, vol. 3, no. 1, pp. 11-34, 2014.

[40] L. Sjoberg, "Why do people demand risk reduction," ESREL-98: Safety and reliability, pp. 751-758, 1998.

[41] B. Lane and S. Potter, "The adoption of cleaner vehicles in the UK: exploring the consumer attitude-action gap," Journal of cleaner production, vol. 15, no. 11, pp. 1085$1092,2007$.

[42] E. Rogers, "Diffusion of Innnovations Fifth Edition edn," ed: Free Press, New York, 2003.

[43] J. Voelcker. (2013). Plug-In Electric Car Sales Triple In 2012 As Buyers, Models Increase. Available: http://www.greencarreports.com/news/1081419 plug-in-electric-carsales-triple-in-2013-as-buyers-models-increase

[44] T. Payton, "The electric car-some problems of driver attitudes and product fit," Journal of the Market Research Society, vol. 30, no. 1, pp. 73-85, 1988.

[45] D. Diamond, "The impact of government incentives for hybrid-electric vehicles: Evidence from US states," Energy Policy, vol. 37, no. 3, pp. 972-983, 2009.

[46] R. Durst, "PowerPoint Presentation - OregonAPEM_FallForum2010_RickDurstPresentation.pdf," ed, 2018. 
[47] Y. Zhang, Y. Yu, and B. Zou, "Analyzing public awareness and acceptance of alternative fuel vehicles in China: The case of EV," Energy Policy, vol. 39, no. 11, pp. 7015-7024, 2011/11/01/ 2011.

[48] M. Modahl, Now or never: How companies must change today to win the battle for internet consumers. HarperCollins Publishers, 1999.

[49] G. Moore, "Crossing the Chasm: Marketing and Selling High-Tech Products to Mainstream CustomersHarper Business Essentials," New York, NY, 1991.

[50] J. D. Oliver and D. E. Rosen, "Applying the Environmental Propensity Framework: A Segmented Approach to Hybrid Electric Vehicle Marketing Strategies," Journal of Marketing Theory and Practice, vol. 18, no. 4, pp. 377-393, 2010/09/01 2010.

[51] J. D. Westaby, "Behavioral reasoning theory: Identifying new linkages underlying intentions and behavior," Organizational behavior and human decision processes, vol. 98, no. 2, pp. 97-120, 2005.

[52] J. T. Gourville, "Eager sellers \& stony buyers," Harvard Business Review, vol. 84, no. 6, pp. 98-106, 2006.

[53] C. C. Rolim, G. N. Gonçalves, T. L. Farias, and Ó. Rodrigues, "Impacts of electric vehicle adoption on driver behavior and environmental performance," Procedia-Social and Behavioral Sciences, vol. 54, pp. 706-715, 2012.

[54] M. A. P. Taylor, P. J. Pudney, R. Zito, N. Holyoak, A. R. Albrecht, and R. Raicu, "Planning for electric vehicles in Australia-can we match environmental requirements, technology and travel demands," 2010.

[55] D. Hall and N. Lutsey, "Emerging best practices for electric vehicle charging infrastructure," Washington, DC: The International Council on Clean Transportation (ICCT), 2017.

[56] K. K. Schefter, Becky, "Accelerating EV Adoption," ed: Edison Electric Institute, 2018.

[57] T. Charge, "Establishing California Leadership in the Plugin Electric Vehicle Marketplace," The California Plug-in Electric Vebicle Collaborative, p. 21, 2010.

[58] W. Sierzchula, S. Bakker, K. Maat, and B. van Wee, "The influence of financial incentives and other socio-economic factors on electric vehicle adoption," Energy Policy, vol. 68, pp. 183-194, 2014. 
[59] T. Sweda and D. Klabjan, "An agent-based decision support system for electric vehicle charging infrastructure deployment," in Vebicle Power and Propulsion Conference (VPPC), 2011 IEEE, 2011, pp. 1-5: IEEE.

[60] Z. Rezvani, J. Jansson, and J. Bodin, "Advances in consumer electric vehicle adoption research: A review and research agenda," Transportation research part D: transport and environment, vol. 34, pp. 122-136, 2015.

[61] S. G. Wirasingha, N. Schofield, and A. Emadi, "Plug-in hybrid electric vehicle developments in the US: Trends, barriers, and economic feasibility," in Vehicle Power and Propulsion Conference, 2008. VPPC'08. IEEE, 2008, pp. 1-8: IEEE.

[62] A. Santos, N. McGuckin, H. Y. Nakamoto, D. Gray, and S. Liss, "Summary of travel trends: 2009 national household travel survey," 2011.

[63] K. T. Chau and Y. S. Wong, "Overview of power management in hybrid electric vehicles," Energy Conversion and Management, vol. 43, no. 15, pp. 1953-1968, 2002/10/01/ 2002.

[64] G. A. Moore, Crossing the Chasm: Marketing and Selling Dismptive Products to Mainstream Customers. HarperCollins, 2002.

[65] J. Mandel. (2007). Battery developers fueling plug-in hybrids' race to market. Available: https://www.eenews.net/greenwire/2007/09/18/stories/57395

[66] F. Soares, P. R. Almeida, J. A. P. Lopes, R. Garcia-Valle, and F. Marra, "State of the Art on Different Types of Electric Vehicles," in Electric Vehicle Integration into Modern Power Networks: Springer, 2013, pp. 1-13.

[67] A. Perner and J. Vetter, "Lithium-ion batteries for hybrid electric vehicles and battery electric vehicles," in Advances in Battery Technologies for Electric Vehicles, B. Scrosati, J. Garche, and W. Tillmetz, Eds. Waltham, MA: Elsevier Science, 2015.

[68] J. Axsen, K. S. Kurani, and A. Burke, "Are batteries ready for plug-in hybrid buyers?," Transport Policy, vol. 17, no. 3, pp. 173-182, 2010.

[69] M. González and L. d. Prada, "Environmental impacts of widespread shifting towards electricity based mobility," Green eMotion,2015.

[70] T. Seager, B. Landi, T. Hawkins, and M. Szilagyi, "Application of LifeCycle Assessment to Nanoscale Technology: Lithium-ion Batteries for Electric Vehicles," in "Design for the Environment Program EPA's Office of Pollution Prevention and 
Toxics," United States Environmental Protection Agency2013, Available:

http://www.epa.gov/sites/production/files/2014-

01/documents/lithium batteries lca.pdf.

[71] K. Spence. (2014). Tesla Motors' Dirty Little Secret Is a Major Problem. Available: https://www.fool.com/investing/general/2014/01/19/tesla-motors-dirty-littlesecret-is-a-major-proble.aspx

[72] S. Jewell and S. M. Kimball, "Lithium Advance Release, 2013 Minerals Yearbook," in "Mineral Commodity Summaries 2015," US Department of the Interior2015, Available: http://dx.doi.org/10.3133/70140094.

[73] SQM, "Salar Brines," ed, 2018.

[74] Nicnas.gov.au. (2007). Australian Inventory of Chemical Substances (AICS) - NICNAS. Available: http://www.nicnas.gov.au/regulation-and-compliance/aics

[75] W. Australia, "Approved Criteria for Classifying Hazardous Substances [NOHSC: 10008 (1999)]," ed: AGPS, 1999.

[76] D. A. Notter et al., "Contribution of Li-ion batteries to the environmental impact of electric vehicles," Environmental science \& technology, vol. 44, no. 17, pp. 6550-6556, 2010.

[77] H. Aral and A. Vecchio-Sadus, "Toxicity of lithium to humans and the environment-a literature review," Ecotoxicology and Environmental Safety, vol. 70, no. 3, pp. 349-356, 2008.

[78] A. V.-S. H. Aral, "Lithium: Environmental Pollution and Health Effects," Reference Module in Earth Systems and Environmental Sciences, vol. Encyclopedia of Environmental Health, pp. 499-508, 2011.

[79] G. Majeau-Bettez, T. R. Hawkins, and A. H. Strømman, "Life cycle environmental assessment of lithium-ion and nickel metal hydride batteries for plug-in hybrid and battery electric vehicles," Environmental science \& technology, vol. 45, no. 10, pp. 45484554, 2011.

[80] J. K. Boyce and M. E. Riddle, "Cap and Dividend: A State-by-State Analysis," Political Economy Research Institute University of Massachusetts, Amberst, 2009. 
[81] D. Anair, A. Mahmassani, and F.-c. Savings, "State of charge, Electric Vehicles' Global Warming Emissions and Fuel-Cost Savings across the United States," Union of Concerned Scientists," 2012.

[82] D. Gordon, D. Sperling, and D. Livingston, "Policy Priorities for Advancing the US Electric Vehicle Market," 2012.

[83] M. Beaudin, H. Zareipour, A. Schellenberglabe, and W. Rosehart, "Energy storage for mitigating the variability of renewable electricity sources: An updated review," Energy for Sustainable Development, vol. 14, no. 4, pp. 302-314, 2010.

[84] S. Nykamp, M. G. Bosman, A. Molderink, J. L. Hurink, and G. J. Smit, "Value of storage in distribution grids-Competition or cooperation of stakeholders?," Smart Grid, IEEE Transactions on, vol. 4, no. 3, pp. 1361-1370, 2013.

[85] D. EPRI, "Electricity Energy Storage Technology Options-A White Paper Primer on Applications, Costs and Benefits," ed: Report, 2010.

[86] B. Dunn, H. Kamath, and J.-M. Tarascon, "Electrical energy storage for the grid: a battery of choices," Science, vol. 334, no. 6058, pp. 928-935, 2011.

[87] B. Battke, T. S. Schmidt, D. Grosspietsch, and V. H. Hoffmann, "A review and probabilistic model of lifecycle costs of stationary batteries in multiple applications," Renewable and Sustainable Energy Reviews, vol. 25, pp. 240-250, 2013.

[88] Tesla. Tesla Powerwall [Online]. Available: https://www.tesla.com/powerwall

[89] Tesla. (2018). Press Kit | Tesla. Available: https://www.tesla.com/presskit/teslaenergy

[90] P. Krause, O. Wasynczuk, S. D. Sudhoff, and S. Pekarek, Analysis of electric machinery and drive systems. John Wiley \& Sons, 2013.

[91] R. Ozaki and K. Sevastyanova, "Going hybrid: An analysis of consumer purchase motivations," Energy Policy, vol. 39, no. 5, pp. 2217-2227, 2011.

[92] A. Brooker, M. Thornton, and J. Rugh, "Technology improvement pathways to costeffective vehicle electrification: Preprint," 2010. 
[93] E. Chéron and M. Zins, "Electric vehicle purchasing intentions: The concern over battery charge duration," Transportation Research Part A: Policy and Practice, vol. 31, no. 3, pp. 235-243, 1997.

[94] F. Nemry, G. Leduc, and A. Muñoz, "Plug-in Hybrid and Battery-Electric Vehicles: State of the research and development and comparative analysis of energy and cost efficiency," Joint Research Centre (Seville site)2009.

[95] F. Kley, M. Wietschel, and D. Dallinger, "Evaluation of European electric vehicle support schemes," Paving the Road to Sustainable Transport. New York: Routledge, pp. 7595, 2012.

[96] M. Catenacci, E. Verdolini, V. Bosetti, and G. Fiorese, "Going electric: Expert survey on the future of battery technologies for electric vehicles," Energy Policy, vol. 61, pp. 403-413, 2013.

[97] NRC, "Overcoming Barriers to Electric-Vehicle Deployment: Interim Report," Committee on Overcoming Barriers to Electric-Vehicle Deployment; Board on Energy and Environmental Systems; Division on Engineering and Physical Sciences; Transportation Research Board; National Research Council, Washington, DC2013.

[98] D. Roberts, "Within a decade, electric vehicles could be cheaper than gasoline vehicles. Then, watch out," Vox, 2016/03/04/ 2016.

[99] J. H. S. Berthelsen and A. Arteaga, "What relationship exists between oil prices, lithium prices and electric vehicle Growth: Is lithium really becoming a substitute for oil?," BI Norwegian Business School, 2016.

[100] M. Nilsson and B. Nykvist, "Governing the electric vehicle transition - Near term interventions to support a green energy economy," Applied Energy, vol. 179, pp. 13601371, 2016/10/01/ 2016.

[101] M. Åhman, "Government policy and the development of electric vehicles in Japan," Energy Policy, vol. 34, no. 4, pp. 433-443, 2006/03/01/ 2006.

[102] G. A. Moore, "High Tech Marketing Illusion," in Crossing the Chasm: Marketing and Selling Technology Project. HarperCollins, 2009, pp. 7-19.

[103] Api.org. (2012). Motor Fuel Taxes. Available: http://www.api.org/oil-and-naturalgas/consumer-information/motor-fuel-taxes 
[104] G. Putrus, P. Suwanapingkarl, D. Johnston, E. Bentley, and M. Narayana, "Impact of electric vehicles on power distribution networks," in Vehicle Power and Propulsion Conference, 2009. VPPC'09. IEEE, 2009, pp. 827-831: IEEE.

[105] K. Clement-Nyns, E. Haesen, and J. Driesen, "The impact of charging plug-in hybrid electric vehicles on a residential distribution grid," IEEE Transactions on power systems, vol. 25, no. 1, pp. 371-380, 2010.

[106] L. P. Fernandez, T. G. San Román, R. Cossent, C. M. Domingo, and P. Frias, "Assessment of the impact of plug-in electric vehicles on distribution networks," IEEE transactions on power systems, vol. 26, no. 1, pp. 206-213, 2011.

[107] S. Shafiee, M. Fotuhi-Firuzabad, and M. Rastegar, "Investigating the impacts of plugin hybrid electric vehicles on power distribution systems," IEEE Transactions on Smart Grid, vol. 4, no. 3, pp. 1351-1360, 2013.

[108] C. Walsh, S. Carroll, and A. Eastlake, "UK electric vehicle range testing and efficiency maps," SAE Technical Paper2011.

[109] J. C. L. Høj, M. L. Agerskov, M. F. Jensen, and P. Lading, "Next generation range extension-2 Glimpses of the future," in Electric Vehicle Symposium and Exbibition (EVS27), 2013 World, 2013, pp. 1-8: IEEE.

[110] R. M. Krause, S. R. Carley, B. W. Lane, and J. D. Graham, "Perception and reality: Public knowledge of plug-in electric vehicles in 21 US cities," Energy Policy, vol. 63, pp. 433-440, 2013.

[111] L. B. Lave and H. L. Maclean, "Are hybrid vehicles worth it?," IEEE Spectrum, vol. 38, no. 3, pp. 47-50, 2001.

[112] G. Pasaoglu, A. Zubaryeva, D. Fiorello, and C. Thiel, "Analysis of European mobility surveys and their potential to support studies on the impact of electric vehicles on energy and infrastructure needs in Europe," Technological Forecasting and Social Change, vol. 87, pp. 41-50, 2014.

[113] N. Nigro, J. Ye, and M. Frades, "Assessing the Electric Vehicle Charging Network in Washington State," Center for Climate and Energy Solutions report, 2014.

[114] M. Duvall, "Comparing the benefits and impacts of hybrid electric vehicle options for compact sedan and sport utility vehicles," Final Report, vol. 1006892, 2002. 
[115] N. S. Pearre, W. Kempton, R. L. Guensler, and V. V. Elango, "Electric vehicles: How much range is required for a day's driving?," Transportation Research Part C: Emerging Technologies, vol. 19, no. 6, pp. 1171-1184, 2011.

[116] M. K. Hidrue, G. R. Parsons, W. Kempton, and M. P. Gardner, "Willingness to pay for electric vehicles and their attributes," Resource and Energy Economics, vol. 33, no. 3, pp. 686-705, 2011.

[117] M. Anderman. (2007). Briefing to the U.S. Senate Committee on energy and natural resources Press Room - TBC. Available:

https://www.totalbatteryconsulting.com/press/Briefing-to-the-US-Senate-

Committee-on-energy-and-natural-resources.html

[118] K. Parks, P. Denholm, and T. Markel, "Costs and emissions associated with plug-in hybrid electric vehicle charging in the Xcel Energy Colorado service territory," National Renewable Energy Laboratory (NREL), Golden, CO.2007.

[119] G. Offer, D. Howey, M. Contestabile, R. Clague, and N. Brandon, "Comparative analysis of battery electric, hydrogen fuel cell and hybrid vehicles in a future sustainable road transport system," Energy policy, vol. 38, no. 1, pp. 24-29, 2010.

[120] A. Emadi, S. S. Williamson, and A. Khaligh, "Power electronics intensive solutions for advanced electric, hybrid electric, and fuel cell vehicular power systems," IEEE Transactions on Power Electronics, vol. 21, no. 3, pp. 567-577, 2006.

[121] R. Dyerson and A. Pilkington, "Gales of creative destruction and the opportunistic incumbent: The case of electric vehicles in California," Technology Analysis \& Strategic Management, vol. 17, no. 4, pp. 391-408, 2005.

[122] A. Bergek, C. Berggren, T. Magnusson, and M. Hobday, "Technological discontinuities and the challenge for incumbent firms: Destruction, disruption or creative accumulation?," Research Policy, vol. 42, no. 6-7, pp. 1210-1224, 2013.

[123] M. Kane, "These U.S. States Charge Electric Car Fees To Make Up For Lost Gas Tax Revenue," ed, 2018.

[124] J. Dow. (2017). Electrek. Available: https://electrek.co/2017/01/17/yearly-ev-feesto-replace-lost-gas-tax-revenue-are-less-reasonable-than-they-seem-indiana-thelatest-to-scapegoat-evs 
[125] E. Lorentzen, P. Haugneland, C. Bu, and E. Hauge, "Charging infrastructure experiences in Norway-the worlds most advanced EV market," in EVS30 Symposium. Stuttgart, Germany, EN, 2017.

[126] F. Leurent and E. Windisch, "Triggering the development of electric mobility: a review of public policies," European Transport Research Review, vol. 3, no. 4, pp. 221235, 2011.

[127] L. Jin, S. Searle, and N. Lutsey, "Evaluation of state-level US electric vehicle incentives," The International Council on Clean Transportation, 2014.

[128] P. Z. Lévay, Y. Drossinos, and C. Thiel, "The effect of fiscal incentives on market penetration of electric vehicles: A pairwise comparison of total cost of ownership," Energy Policy, vol. 105, pp. 524-533, 2017.

[129] N. Wang, L. Tang, and H. Pan, "Effectiveness of policy incentives on electric vehicle acceptance in China: A discrete choice analysis," Transportation Research Part A: Policy and Practice, vol. 105, pp. 210-218, 2017.

[130] E. G. McDermott, "Examining the effects of policy interventions on increasing electric vehicle adoption in California," 2017.

[131] K. Y. Bjerkan, T. E. Nørbech, and M. E. Nordtømme, "Incentives for promoting battery electric vehicle (BEV) adoption in Norway," Transportation Research Part D: Transport and Environment, vol. 43, pp. 169-180, 2016.

[132] E. Iea, "Global EV outlook," Electric vebicles initiative of the clean energy. Ministerial, Paris. OpenURL, 2013.

[133] (2010). Tax Credits, Appliance Rebates, and the End of 2010. Available: https://www.energy.gov/energysaver/articles/tax-credits-appliance-rebates-andend-2010

[134] M. Salisbury, "Policies to Promote Electric Vehicles in the Southwest," Southwest Energy Efficiency Project (SWEEP), Colorado2013.

[135] Irs.gov. (2008). Plug-In Electric Drive Vebicle Credit (IRC 30D). Available: https://www.irs.gov/Businesses/Plug-In-Electric-Vehicle-Credit-IRC-30-and-IRC$\underline{30 \mathrm{D}}$

[136] Oregon.gov, "State of Oregon: Oregon Department of Energy - Welcome to the Oregon Department of Energy's Website," ed, 2018. 
[137] (2017). State Efforts To Promote Hybrid And Electric Vehicles. Available: http://www.ncsl.org/research/energy/state-electric-vehicle-incentives-statechart.aspx

[138] I. IA-HEV, "International Energy Agency, Electric Vehicles Initiative," EV City Casebook, 2012.

[139] (2017). Renewable Portolio Standard Policies. Available: http://www.dsireusa.org/resources/detailed-summary-maps/rps-carveout-map/

[140] Oregon.gov, "State of Oregon: Energy in Oregon - Renewable Portfolio Standard," ed, 2018.

[141] P. A. Geroski, "Models of technology diffusion," Research policy, vol. 29, no. 4, pp. 603-625, 2000.

[142] E. Katz, "Theorizing diffusion: Tarde and Sorokin revisited," The Annals of the American Academy of Political and Social Science, vol. 566, no. 1, pp. 144-155, 1999.

[143] E. M. Rogers, "New product adoption and diffusion," Journal of consumer Research, pp. 290-301, 1976.

[144] V. Carr Jr, "Technology adoption and diffusion," The Learning Center for Interactive Technology, 1999.

[145] D. W. Surry. (1997). Diffusion Theory \& Instructional Technology. Available: http://www2.gsu.edu/ wwwitr/docs/diffusion

[146] D. W. Surry and J. D. Farquhar, "Diffusion theory and instructional technology," Journal of Instructional Science and Technology, vol. 2, no. 1, pp. 24-36, 1997.

[147] E. M. Rogers, "Elements of Diffusion," in Diffusion of innovations, vol. 183rd ed. no. 20) New York: Free Press: MacMillan Publishing, 1983, pp. 12-15.

[148] D. H. Stamatis, Six Sigma and Beyond: The Implementation Process (no. v. 7). CRC Press, 2016.

[149] G. Tarde, "The laws of imitation, trans," EC Parsons. New York: Henry, Holt, 1903.

[150] B. Ryan and N. C. Gross, "The diffusion of hybrid seed corn in two Iowa communities," Rural sociology, vol. 8, no. 1, p. 15, 1943. 
[151] E. M. Rogers and D. K. Bhowmik, "Homophily-heterophily: Relational concepts for communication research," Public opinion quarterly, vol. 34, no. 4, pp. 523-538, 1970.

[152] E. M. Rogers and L. Svenning, "Modernization among peasants: the impact of communication," Modernization among peasants: the impact of communication., 1969.

[153] G. L. Lilien, A. Rangaswamy, and C. Van den Bulte, "12. Diffusion Models: Managerial Applications and Software," New-product diffusion models, 2000.

[154] E. Rogers, "Diffusion of Innovations. New York. A Division of Simon \& Schuster," ed: Inc, 1995.

[155] H. Braverman, Labor and monopoly capital: The degradation of work in the twentieth century. NYU Press, 1998.

[156] J. Ellul and J. Wilkinson, The technological society. Jonathan Cape, 1964.

[157] W. J. Orlikowski, "The duality of technology: Rethinking the concept of technology in organizations," Organization science, vol. 3, no. 3, pp. 398-427, 1992.

[158] E. Burkman, "Factors Affecting Utilization," in Instructional Technology: Foundations, R. M. Gagne, Ed.: Taylor \& Francis, 2013, pp. 429-455.

[159] G. A. Moore, "High-Tech Marketing Enlightenment," in Crossing the Chasm: Marketing and Selling Technology ProjectRevised ed.: HarperCollins, 2009, p. 30.

[160] W. Geoghegan, "Whatever happened to instructional technology?," in Paper presented at the 22nd Annual Conference of the International Business Schools Computing Association, 1994: International Business Schools Computing Association.

[161] N. Meade and T. Islam, "Modelling and forecasting the diffusion of innovation-A 25-year review," International Journal of forecasting, vol. 22, no. 3, pp. 519-545, 2006.

[162] V. Mahajan, E. Muller, and Y. Wind, New-product diffusion models. Springer Science \& Business Media, 2000.

[163] N. Meade and T. Islam, "Technological forecasting-Model selection, model stability, and combining models," Management Science, vol. 44, no. 8, pp. 1115-1130, 1998. 
[164] J. Fisher and R. Pry, "A Simple Substitution Model of Technological Change: Technological Forecasting and Social Change," vol. 3, no. 4, p. 540, 1988.

[165] K. U. Rao and V. Kishore, "A review of technology diffusion models with special reference to renewable energy technologies," Renewable and Sustainable Energy Reviews, vol. 14, no. 3, pp. 1070-1078, 2010.

[166] V. Mahajan and R. A. Peterson, "Models for innovation diffusion. Series: Quantitative applications in the social sciences," Sara Miller McCune, Sage Publications, Inc, p. 87, 1985.

[167] A. Suwa and J. Jupesta, "Policy innovation for technology diffusion: a case-study of Japanese renewable energy public support programs," Sustainability science, vol. 7, no. 2, pp. 185-197, 2012.

[168] K. U. Rao, "Diffusion modelling of selected renewable energy technologies in India," Biosources, Teri, 2010.

[169] J. D. Farquhar and D. W. Surry, "Adoption analysis: An additional tool for instructional developers," Programmed Learning and Educational Technology, vol. 31, no. 1, pp. 19-25, 1994.

[170] G. O. Collantes, "Incorporating stakeholders' perspectives into models of new technology diffusion: The case of fuel-cell vehicles," Technological Forecasting and Social Change, vol. 74, no. 3, pp. 267-280, 2007.

[171] P. Lund, "Market penetration rates of new energy technologies," Energy Policy, vol. 34, no. 17, pp. 3317-3326, 2006.

[172] K. U. Rao and V. Kishore, "Wind power technology diffusion analysis in selected states of India," Renewable Energy, vol. 34, no. 4, pp. 983-988, 2009.

[173] P. Purohit and T. C. Kandpal, "Renewable energy technologies for irrigation water pumping in India: projected levels of dissemination, energy delivery and investment requirements using available diffusion models," Renewable and Sustainable Energy Reviews, vol. 9, no. 6, pp. 592-607, 2005.

[174] R. Peter, B. Ramaseshan, and C. Nayar, "Conceptual model for marketing solar based technology to developing countries," Renewable Energy, vol. 25, no. 4, pp. 511524, 2002. 
[175] V. Gray, "Innovation in the states: A diffusion study," American political science review, vol. 67 , no. 04 , pp. 1174-1185, 1973.

[176] J. C. Fisher and R. H. Pry, "A simple substitution model of technological change," Technological forecasting and social change, vol. 3, pp. 75-88, 1972.

[177] F. M. Bass, "Comments on "a new product growth for model consumer durables the bass model"," Management science, vol. 50, no. 12_supplement, pp. 1833-1840, 2004.

[178] F. Bass, "A New Product Growth Model for Consumer Durables," Management Science, 15 (January), 215-227.(1980)," The Relationship Between Diffusion Rates, Experience Curves, and Demand Elasticities for Consumer Durables Technical Innovations," Journal of Business, vol. 53, pp. 51-67, 1969.

[179] P. Jain, "A Guide For Understanding Information Cascades," ed, 2018.

[180] P. Jain, "A Guide to Understanding Information Cascades," ed, 2018.

[181] D. Easley and J. Kleinberg, Networks, crowds, and markets: Reasoning about a bighly connected world. Cambridge University Press, 2010.

[182] J. Sarkar, "Technological diffusion: alternative theories and historical evidence," Journal of economic surveys, vol. 12, no. 2, pp. 131-176, 1998.

[183] D. D’Orazio. (2015). Tesla loses fight with dealers to sell its cars in Texas. Available: https://www.theverge.com/2015/5/31/8694673/tesla-loses-fight-to-sell-cars-intexas

[184] D. Noland. (2015). Tesla loses fight with dealers to sell its cars in Texas. Available: https://www.greencarreports.com/news/1087815 tesla-underground-texasfranchise-rules-make-model-s-owners-skirt-the-law

[185] M. Karshenas and P. L. Stoneman, "Rank, stock, order, and epidemic effects in the diffusion of new process technologies: An empirical model," The RAND Journal of Economics, pp. 503-528, 1993.

[186] S. Davies, The diffusion of process innovations. CUP Archive, 1979.

[187] R. Dixon, "Hybrid corn revisited," Econometrica: Journal of the Econometric Society, pp. 1451-1461, 1980. 
[188] R. A. Chatterjee and J. Eliashberg, "The innovation diffusion process in a heterogeneous population: A micromodeling approach," Management science, vol. 36, no. 9, pp. 1057-1079, 1990.

[189] V. K. Narayanan, "Managing technology and innovation for competitive advantage," 2000 .

[190] S. Jacobsson and A. Johnson, "The diffusion of renewable energy technology: an analytical framework and key issues for research," Energy policy, vol. 28, no. 9, pp. 625-640, 2000.

[191] S. Reddy and J. P. Painuly, "Diffusion of renewable energy technologies—barriers and stakeholders' perspectives," Renewable Energy, vol. 29, no. 9, pp. 1431-1447, 2004.

[192] T. D. Tsoutsos and Y. A. Stamboulis, "The sustainable diffusion of renewable energy technologies as an example of an innovation-focused policy," Technovation, vol. 25, no. 7 , pp. 753-761, 2005.

[193] S. Dasgupta, S. Lall, D. Wheeler, and W. B. D. R. G. E. Infrastructure, Policy Reform, Economic Growth, and the Digital Divide: An Econometric Analysis. World Bank, East Development Research Group, Infrastructure and Environment, 2001.

[194] T. Berger, "Agent-based spatial models applied to agriculture: a simulation tool for technology diffusion, resource use changes and policy analysis," Agricultural economics, vol. 25, no. 2-3, pp. 245-260, 2001.

[195] M. H. MacDougall, Simulating computer systems: techniques and tools. MIT press, 1989.

[196] N. Matloff, "Introduction to discrete-event simulation and the simpy language," Davis, CA. Dept of Computer Science. University of California at Davis. Retrieved on August, vol. 2, p. 2009, 2008.

[197] J. W. Forrester, "Industrial dynamics: a major breakthrough for decision makers," Harvard business review, vol. 36, no. 4, pp. 37-66, 1958.

[198] J. W. Forrester, "Industrial dynamics-after the first decade," Management Science, vol. 14, no. 7, pp. 398-415, 1968.

[199] G. P. Richardson, "Qualitative Simulation Modeling and Analysis," in Qualitative Simulation Modeling and Analysis, P. A. Fishwick, H. A. Simon, and P. A. Luker, Eds.: Springer New York, 2012, pp. 144 -158. 
[200] J. J. Uhran Jr and W. I. Davisson, "The structure of NDTRAN_A systems simulation language," Systems, Man and Cybernetics, IEEE Transactions on, no. 6, pp. 837-846, 1984.

[201] G. P. Richardson and A. I. Pugh III, Introduction to system dynamics modeling with DYNAMO. Productivity Press Inc., 1981.

[202] R. Coyle, "Comment on 'System dynamics and operational research: An appraisal'," European journal of operational research, vol. 23, no. 3, pp. 403-406, 1986.

[203] T. Higuchi and M. D. Troutt, "Dynamic simulation of the supply chain for a short life cycle product-Lessons from the Tamagotchi case," Computers \& Operations Research, vol. 31, no. 7, pp. 1097-1114, 2004.

[204] J. P. Sáenz, N. Celik, S. Asfour, and Y.-J. Son, "Electric utility resource planning using continuous-discrete modular simulation and optimization (CoDiMoSO)," Computers \& Industrial Engineering, vol. 63, no. 3, pp. 671-694, 2012.

[205] Y. H. Lee, M. K. Cho, S. J. Kim, and Y. B. Kim, "Supply chain simulation with discrete-continuous combined modeling," Computers \& Industrial Engineering, vol. 43, no. 1, pp. 375-392, 2002.

[206] J. C. Martinez, "STROBOSCOPE: State and resource based simulation of construction processes," 1996.

[207] V. Puri, "Incorporation of continuous activities into activity cycle diagram based discrete event simulation for construction operations," Purdue University, 2012.

[208] J. B. Homer, "A dynamic model for analyzing the emergence of new medical technologies," Massachusetts Institute of Technology, 1983.

[209] M. Paich and J. D. Sterman, "Boom, bust, and failures to learn in experimental markets," Management Science, vol. 39, no. 12, pp. 1439-1458, 1993.

[210] G. H. Orcutt, S. Caldwell, R. F. Wertheimer, and U. Institute, Policy Exploration Through Microanalytic Simulation. Urban Institute, 1976.

[211] P. L. Madoma, "What is wrong with the implementation of auto pollution policy in Zimbabwe? A system dynamics perspective," 2011. 
[212] M. A. Vasarhelyi, Counterintuitive Economic Consequences of Accounting Policies: A Dynamic Analysis. Columbia University, Graduate School of Business, 1980.

[213] P. K. Mohapatra, "Modal control theory and industrial dynamics - a dual approach to the design of policy decisions in a multistage production-inventory system," Mathematics and Computers in Simulation, vol. 21, no. 2, pp. 141-149, 1979.

[214] A. M. Bassi, "An integrated approach to support energy policy formulation and evaluation," 2009.

[215] J. Hines and J. House, "The source of poor policy: controlling learning drift and premature consensus in human organizations," System Dynamics Review, vol. 17, no. 1, pp. 3-32, 2001.

[216] A. K. Graham and P. M. Senge, "A long-wave hypothesis of innovation," Technological Forecasting and Social Change, vol. 17, no. 4, pp. 283-311, 1980.

[217] P. M. Milling, "Modeling innovation processes for decision support and management simulation," System Dynamics Review, vol. 12, no. 3, pp. 211-234, 1996.

[218] F. H. Maier, "New product diffusion models in innovation management-A system dynamics perspective," System Dynamics Review, vol. 14, no. 4, pp. 285-308, 1998.

[219] N. Dalkey and O. Helmer, "An experimental application of the Delphi method to the use of experts," Management science, vol. 9, no. 3, pp. 458-467, 1963.

[220] W. N. Dunn, Public Policy Analysis. Taylor \& Francis, 2015.

[221] T. U. Daim, G. Rueda, H. Martin, and P. Gerdsri, "Forecasting emerging technologies: Use of bibliometrics and patent analysis," Technological Forecasting and Social Change, vol. 73, no. 8, pp. 981-1012, 2006.

[222] R. U. Ayres, "What have we learned?," Technological Forecasting and Social Change, vol. 62, no. 1, pp. 9-12, 1999.

[223] S. Ewton, "Assessment of the impacts of e-commerce technologies on overall business processes: An analytic Delphi process," ProQuest Dissertations Publishing, 2002. 
[224] N. Gerdsri, "An analytical approach on building a technology development envelope (TDE) for roadmapping of emerging technologies," ProQuest Dissertations Publishing, 2005.

[225] M. Adler and E. Ziglio, Gazing Into the Oracle: The Delphi Method and Its Application to Social Policy and Public Health. Jessica Kingsley Publishers, 1996.

[226] R. J. Lempert, Shaping the Next One Hundred Years: New Methods for Quantitative, LongTerm Policy Analysis. RAND Corporation, 2003.

[227] I. A. Jillson, "III. B. 3. The national drug-abuse policy delphi: Progress report and findings to date," The Delphi method: Techniques and applications, p. 124, 1975.

[228] M. Turoff and S. R. Hiltz, "Computer based Delphi processes," Gaqing into the oracle: The Delphi method and its application to social policy and public health, pp. 56-85, 1996.

[229] M. Turoff, "The design of a policy Delphi," Technological forecasting and social change, vol. 2, no. 2, pp. 149-171, 1970.

[230] H. A. Linstone and M. Turoff, The Delphi method: Techniques and applications. AddisonWesley Reading, MA, 1975.

[231] P. J. Schoemaker, "Scenario planning: a tool for strategic thinking," Sloan management review, vol. 36, no. 2, p. 25, 1995.

[232] T. J. Postma and F. Liebl, "How to improve scenario analysis as a strategic management tool?," Technological Forecasting and Social Change, vol. 72, no. 2, pp. 161$173,2005$.

[233] D. McCollum and C. Yang, "Achieving deep reductions in US transport greenhouse gas emissions: Scenario analysis and policy implications," Energy Policy, vol. 37, no. 12, pp. 5580-5596, 2009.

[234] B. A. Bryan, N. D. Crossman, D. King, and W. S. Meyer, "Landscape futures analysis: assessing the impacts of environmental targets under alternative spatial policy options and future scenarios," Environmental Modelling \& Software, vol. 26, no. 1, pp. 83-91, 2011.

[235] W. R. Huss and E. J. Honton, "Scenario planning-What style should you use?," Long range planning, vol. 20, no. 4, pp. 21-29, 1987. 
[236] A. Volkery and T. Ribeiro, "Scenario planning in public policy: Understanding use, impacts and the role of institutional context factors," Technological forecasting and social change, vol. 76, no. 9, pp. 1198-1207, 2009.

[237] W. K. Härdle and L. Simar, Applied Multivariate Statistical Analysis. Springer Berlin Heidelberg, 2015.

[238] R. Muirhead, "An Introduction to Multivariate Statistical-Analysis," T. Anderson, Ed., ed: Amer Statistical Assoc 1429 Duke St, Alexandria, VA 22314, 1986.

[239] P. Mukhopadhyay, Multivariate statistical analysis. World Scientific, 2009.

[240] W. W. Cooper, L. M. Seiford, and J. Zhu, Data envelopment analysis. Springer, 2004.

[241] L. Cherchye, "Using data envelopment analysis to assess macroeconomic policy performance," Applied Economics, vol. 33, no. 3, pp. 407-416, 2001.

[242] J. Karkazis and E. Thanassoulis, "Assessing the effectiveness of regional development policies in Northern Greece using data envelopment analysis," SocioEconomic Planning Sciences, vol. 32, no. 2, pp. 123-137, 1998.

[243] P. Knight, Conspiracy nation: The politics of paranoia in postwar America. NYU Press, 2002.

[244] K. Perusich, "Fuzzy cognitive maps for policy analysis," in Technology and Society Technical Expertise and Public Decisions, 1996. Proceedings., 1996 International Symposium on, 1996, pp. 369-373: IEEE.

[245] C. Eden and F. Ackermann, "Cognitive mapping expert views for policy analysis in the public sector," European Journal of Operational Research, vol. 152, no. 3, pp. 615-630, 2004.

[246] J. A. Hart, "Cognitive maps of three Latin American policy makers," World Politics, vol. 30, no. 01, pp. 115-140, 1977.

[247] "HSOR.org: What is OR," ed, 2018.

[248] R. L. Keeney, Examining corporate policy using multiattribute utility analysis. IIASA, 1975.

[249] R. L. Keeney and T. L. McDaniels, "A framework to guide thinking and analysis regarding climate change policies," Risk. Analysis, vol. 21, no. 6, pp. 989-1000, 2001. 
[250] R. L. Keeney, D. Von Winterfeldt, and T. Eppel, "Eliciting public values for complex policy decisions," Management Science, vol. 36, no. 9, pp. 1011-1030, 1990.

[251] R. L. Keeney, "Energy policy and value tradeoffs," 1975.

[252] R. L. Keeney, "Framing public policy decisions," International Journal of Technology, Policy and Management, vol. 4, no. 2, pp. 95-115, 2004.

[253] T. L. Saaty, "How to make a decision: the analytic hierarchy process," European journal of operational research, vol. 48, no. 1, pp. 9-26, 1990.

[254] D. F. Kocaoglu, "Decision Making course notes, Portland State University," 2013.

[255] J. P. Guilford, Psychometric methods, 2nd ed (Psychometric methods, 2nd ed.). New York, NY, US: McGraw-Hill, 1954, pp. ix, 597-ix, 597.

[256] M. S. Abbas, "Consistency Analysis for Judgment Quantification in Hierarchical Decision Model," Ph.D. Dissertation, ETM, Portland State University, 2016.

[257] P. E. Shrout and J. L. Fleiss, "Intraclass correlations: uses in assessing rater reliability," Psychological bulletin, vol. 86, no. 2, p. 420, 1979.

[258] H. Chen and D. F. Kocaoglu, "A sensitivity analysis algorithm for hierarchical decision models," European Journal of Operational Research, vol. 185, no. 1, pp. 266-288, 2008.

[259] H. Chen, "Sensitivity analysis for hierarchical decision models," Ph.D. Dissertation, ETM, Portland State University, 2007.

[260] P. Bastani, J. B. Heywood, and C. Hope, "The effect of uncertainty on US transportrelated GHG emissions and fuel consumption out to 2050," Transportation Research Part A: Policy and Practice, vol. 46, no. 3, pp. 517-548, 2012.

[261] J. Shanteau and T. R. Stewart, "Why study expert decision making? Some historical perspectives and comments," Organizational Behavior and Human Decision Processes, vol. 53, no. 2, pp. 95-106, 1992.

[262] J. L. Mumpower and T. R. Stewart, "Expert judgement and expert disagreement," Thinking \& Reasoning, vol. 2, no. 2-3, pp. 191-212, 1996. 
[263] M. A. Meyer and J. M. Booker, Eliciting and analyzing expert judgment: a practical guide. SIAM, 2001.

[264] J. M. Booker and M. A. Meyer, "Sources of and effects of interexpert correlation: an empirical study," Systems, Man and Cybernetics, IEEE Transactions on, vol. 18, no. 1, pp. 135-142, 1988.

[265] D. F. Kocaoglu, "A participative approach to program evaluation," Engineering Management, IEEE Transactions on, no. 3, pp. 112-118, 1983.

[266] N. Gerdsri and D. F. Kocaoglu, "A quantitative model for the strategic evaluation of emerging technologies," Engineering and Technology Management Department, Portland State University, Portland, OR, vol. 97201, 2004.

[267] E. Brunswik, The conceptual framework of psychology (no. 10). Univ of Chicago Pr, 1952.

[268] J. H. Boose and B. R. Gaines, "Knowledge acquisition for knowledge-based systems: Notes on the state-of-the-art," in Knowledge Acquisition: Selected Research and Commentary: Springer, 1989, pp. 131-148.

[269] G. A. Miller, "The magical number seven, plus or minus two: Some limits on our capacity for processing information," Psychological review, vol. 101, no. 2, p. 343, 1994.

[270] K. R. Hammond, Human judgement and social policy: Irreducible uncertainty, inevitable error, unavoidable injustice. Oxford University Press, 1996.

[271] A. A. Marcus, "Risk, uncertainty, and scientific judgement," Minerva, vol. 26, no. 2, pp. 138-152, 1988.

[272] M. E. Doherty, "Traditional Explanations for Expert Disagreement," in Social Judgement Theoryno. v. 2): Psychology Press, 1996, p. 194.

[273] B. Brehmer, "Social judgment theory and the analysis of interpersonal conflict," Psychological Bulletin, vol. 83, no. 6, p. 985, 1976.

[274] L. Rappoport and D. A. Summers, "The cognitive conflict paradigm," in Human Judgment and Social InteractionIn L. Rappoport \& D.A. Summers ed. New York: Holt, Rinehart and Winston, 1973, pp. 188-205. 
[275] T. R. Stewart, "Scientists' uncertainty and disagreement about global climate change: A psychological perspective," International Journal of Psychology, vol. 26, no. 5, pp. 565573, 1991.

[276] K. R. Hammond and L. Adelman, "Science, values, and human judgment," Science, vol. 194, no. 4263, pp. 389-396, 1976.

[277] L. B. Statistics, "Correlation | Boundless Statistics," ed, 2018.

[278] D. J. Sheskin, Handbook of parametric and nonparametric statistical procedures. crc Press, 2003.

[279] G. G. Koch, "Intraclass correlation coefficient," in Encyclopedia of statistical sciences, vol. 4, S. Kotz and N. L. Johnson, Eds. New York: John Wiley \& Sons, 1982, pp. 213217.

[280] N. J. Sheikh, "Assessment of Solar Photovoltaic Technologies Using Multiple Perspectives and Hierarchical Decision Modeling," Ph.D. Dissertation, ETM, 2013.

[281] K. Phan, "Innovation measurement: A decision framework to determine innovativeness of a company," 2013.

[282] L. Rokach and O. Maimon, "Clustering methods," in Data mining and knowledge discovery handbook: Springer, 2005, pp. 321-352.

[283] D. M. Blei, "Hierarchical clustering," Lecture Slides, February, 2008.

[284] A. N. e. a. Soloshenko, "Thematic Clustering Methods Applied to News Texts Analysis," in Knowledge-Based Software Engineering: 11th Joint Conference, JCKBSE 2014, Volgograd, Russia, September 17-20, 2014. Proceedings, A. Kravets, M. Shcherbakov, M. Kultsova, and T. Iijima, Eds.: Springer International Publishing, 2014, p. 297.

[285] J. J. Shen, "Using cluster analysis, cluster validation, and consensus clustering to identify subtypes," 2007.

[286] L. Chan, "Developing a Strategic Policy Choice Framework for Technological Innovation: Case of Chinese Pharmaceuticals," 2013.

[287] T. U. Daim, Hierarchical Decision Modeling: Essays in Honor of Dundar F. Kocaoglu. Springer, 2015. 
[288] A. Saltelli et al., Global sensitivity analysis: the primer. John Wiley \& Sons, 2008.

[289] C.-T. Ho, "Strategic evaluation of emerging technologies in the semiconductor foundry industry (Special case: Semiconductor foundry industry in Taiwan)," Ph.D. Dissertation, ETM, Portland State University, 2004.

[290] J. J. Winebrake and B. P. Creswick, "The future of hydrogen fueling systems for transportation: an application of perspective-based scenario analysis using the analytic hierarchy process," Technological Forecasting and Social Change, vol. 70, no. 4, pp. 359-384, 2003.

[291] K. W. Chase, J. Gao, S. P. Magleby, and C. D. Sorensen, "Including geometric feature variations in tolerance analysis of mechanical assemblies," IIE transactions, vol. 28, no. 10, pp. 795-807, 1996.

[292] H. Chen, J. C. Ho, and D. F. Kocaoglu, "A strategic technology planning framework: a case of Taiwan's semiconductor foundry industry," Engineering Management, IEEE Transactions on, vol. 56, no. 1, pp. 4-15, 2009.

[293] R.Hegazy and M.I.Mohamad, "The Role of the Sensitivity Coefficient on the Authenticity of the Unc," International Journal of Advanced Research in Electrical, Electronics and Instrumentation Engineering, vol. 2, no. 8, 2013.

[294] T. Saaty, "The analytic hierarchy process (AHP) for decision making," in Kobe, Japan, 1980.

[295] A. Mahmood, "Software implementation of hierarchical decision modeling and hierarchical decision modeling sensitivity analysis," 2011.

[296] C.-L. Hwang and M.-J. Lin, Group decision making under multiple criteria: methods and applications. Springer Science \& Business Media, 2012.

[297] C. Hwang and K. Yoon, "Multiple attribute decision making, in lecture notes in economics and mathematical systems 186," ed: Berlin: Springer-Verlag, 1981.

[298] Y.-M. Wang and Y. Luo, "On rank reversal in decision analysis," Mathematical and Computer Modelling, vol. 49, no. 5, pp. 1221-1229, 2009.

[299] P. Gerdsri, "A systematic approach to developing national technology policy and strategy for emerging technologies," Ph.D. Dissertation, ETM, Portland State University, 2009. 
[300] Z.-Y. She, Qing Sun, J.-J. Ma, and B.-C. Xie, What are the barriers to widespread adoption of battery electric vehicles? A survey of public perception in Tianjin, China. 2017, pp. 29-40.

[301] Y. Heisler. (2016). 11 mindblowing facts about Tesla's Gigafactory. Available: http://bgr.com/2016/08/08/tesla-gigafactory-size-cost-elon-musk/

[302] (2017). Global EV Outlook.

[303] D. W. Hull, David. (2016). Tesla battles GM over right to sell cars in Indiana. Available: http://www.autonews.com/article/20160224/RETAIL07/160229922/tesla-battlesgm-over-right-to-sell-cars-in-indiana

[304] F. Lambert. (2017). Automakers are still trying to stop Tesla from selling its cars directly to customers. Available: https://electrek.co/2017/06/22/tesla-automakers-direct-sales/

[305] L. Wamsley. (2017). All New Volvo Models Will Be Electric Or Hybrid Starting In 2019. Available: https://www.npr.org/sections/thetwo-way/2017/07/05/535596277/allnew-volvo-models-will-be-electric-or-hybrid-starting-in-2019

[306] Tesla. (2018). 1,130 Supercharger Stations with 8,496 Superchargers. Available: https://www.tesla.com/supercharger 


\section{APPENDIX - DESCRIPTIONS OF BARRIERS AND POLICIES}

\begin{tabular}{|c|c|c|}
\hline ABBREVIATION & BARRIER & SOCIAL BARRIERS \\
\hline Med Attn & $\begin{array}{l}\text { Negative } \\
\text { Media } \\
\text { Attention: }\end{array}$ & $\begin{array}{l}\text { Media criticizing EV due to range, drivability, braking behavior, } \\
\text { and practical design and doubts about reducing negative } \\
\text { effects of transportation sector to environment. }\end{array}$ \\
\hline Pub Aw & $\begin{array}{l}\text { Public } \\
\text { Awareness }\end{array}$ & $\begin{array}{l}\text { General Public awareness of EV's current position in the } \\
\text { market, drivability, cost effectiveness, performance and } \\
\text { positive environmental effects. }\end{array}$ \\
\hline Pub Per'n & $\begin{array}{l}\text { Negative } \\
\text { Public } \\
\text { Perception }\end{array}$ & $\begin{array}{l}\text { Public Perception about EV is not a viable alternative to ICE } \\
\text { (Conventional Cars). }\end{array}$ \\
\hline Beh Res & $\begin{array}{l}\text { Behavioral } \\
\text { Resistance }\end{array}$ & $\begin{array}{l}\text { The necessary change in behavior due to innate nature of EV, } \\
\text { such as having to consider range and charging stations, driving } \\
\text { more carefully with regen brakes, the quietness of the car etc. }\end{array}$ \\
\hline \multicolumn{3}{|r|}{ TECHNICAL BARRIERS } \\
\hline Chrg Net & $\begin{array}{l}\text { Charging } \\
\text { Network }\end{array}$ & $\begin{array}{l}\text { Insufficient charging network. Charging stations and } \\
\text { residential charging facilities pose a barrier for wide adoption. }\end{array}$ \\
\hline Chrg Time & $\begin{array}{l}\text { Charging } \\
\text { Time }\end{array}$ & $\begin{array}{l}\text { Long charging time incomparable to ICE where consumers can } \\
\text { fuel up their cars in 5-10 mins average. Whereas EV taking 7- } \\
10 \text { hours for a full charge. }\end{array}$ \\
\hline Range & Range & $\begin{array}{l}\text { Despite the improvements, majority of EV's distance on a full } \\
\text { charge being incomparable to ICE. This poses a barrier for } \\
\text { consumers adoption decision. }\end{array}$ \\
\hline Batt Perf & $\begin{array}{l}\text { Battery } \\
\text { Performance }\end{array}$ & $\begin{array}{l}\text { Limitations to Power Density that affect Acceleration and } \\
\text { Energy Density that affect range }\end{array}$ \\
\hline \multicolumn{3}{|r|}{ ENVIRONMENTAL BARRIERS } \\
\hline Batt Prod & $\begin{array}{l}\text { Battery } \\
\text { Production }\end{array}$ & $\begin{array}{l}\text { Production of the vehicle: taking into account the raw } \\
\text { materials and manufacturing and assembly process ("cradle"). } \\
\text { Such as salar brines etc. }\end{array}$ \\
\hline Batt Disp & $\begin{array}{l}\text { Battery } \\
\text { Disposal }\end{array}$ & $\begin{array}{l}\text { Dismantling or the end-of-life analysis. Including the disposal } \\
\text { of materials and the disposal process. }\end{array}$ \\
\hline Elc. Src & $\begin{array}{l}\text { Original } \\
\text { Power } \\
\text { Source }\end{array}$ & $\begin{array}{l}\text { The originating source of the electricity that of the power } \\
\text { plant use to generate, which will be used in the EVs. }\end{array}$ \\
\hline \multicolumn{3}{|r|}{ ECONOMIC BARRIERS } \\
\hline In'l Cost & Initial Cost & Initial costs of manufacturing EV. \\
\hline Batt Cost & Battery Cost & Costs related to battery \\
\hline
\end{tabular}




\begin{tabular}{|c|c|c|}
\hline Rel Cost & Relative Cost & $\begin{array}{l}\text { Relative Energy Costs, The relative cost of (high) electricity } \\
\text { cost vs. (low) Oil price that play role into buyers' decision to } \\
\text { adopt the car. }\end{array}$ \\
\hline Mod\&Qnty & $\begin{array}{l}\text { Limited } \\
\text { Models and } \\
\text { Quantity }\end{array}$ & $\begin{array}{l}\text { The limited models of EV from various manufacturers. (This } \\
\text { hinders to fulfill needs of wide audience, and is therefore a } \\
\text { barrier for wide adoption of EV.) }\end{array}$ \\
\hline \multicolumn{3}{|r|}{ POLITICAL BARRIERS } \\
\hline Tech Res & $\begin{array}{l}\text { Entrenched } \\
\text { Technology } \\
\text { Resistance } \\
\end{array}$ & $\begin{array}{l}\text { The resistance caused by the incumbent conventional gas } \\
\text { auto industry }\end{array}$ \\
\hline Pol Res & $\begin{array}{c}\text { Political } \\
\text { Resistance }\end{array}$ & EV not having the support of law \& Policy makers \\
\hline \multirow[t]{8}{*}{ Shr Pres } & $\begin{array}{l}\text { Shareholders } \\
\text { Pressure }\end{array}$ & $\begin{array}{l}\text { Due to competing against giant automakers in the industry, } \\
\text { the shareholders pressure on manufacturers to be profitable } \\
\text { while the product is not mature enough to be introduced in } \\
\text { the market. }\end{array}$ \\
\hline & \multicolumn{2}{|r|}{ POLICIES } \\
\hline & $\begin{array}{l}\text { Road } \\
\text { Privileges }\end{array}$ & $\begin{array}{l}\text { The Road Privileges given or suggested to be given to EV users } \\
\text { such as HOV access, removal of road index fees etc. }\end{array}$ \\
\hline & GHG & $\begin{array}{l}\text { The GHG standards that many states adopted after Californian } \\
\text { standards that requires vehicles on road cannot exceed to } \\
\text { emit a certain amount of GHG. }\end{array}$ \\
\hline & $\begin{array}{l}\text { Monetary } \\
\text { Incentives }\end{array}$ & $\begin{array}{l}\text { The incentives given to EV owners by federal governments } \\
\text { and states. The federal government gives } \$ 7500 \text {, plus many } \\
\text { states give rebates that varies between } \$ 1000-\$ 3500 \text {, plus } \\
\text { tax credit. }\end{array}$ \\
\hline & $\begin{array}{c}\text { R\&D } \\
\text { Incentives }\end{array}$ & $\begin{array}{l}\text { The } R \text { \& } D \text { Incentives given by the governments to EV } \\
\text { manufacturers }\end{array}$ \\
\hline & $\begin{array}{l}\text { Renewable } \\
\text { Portfolio } \\
\text { Standards } \\
\text { (RPS) }\end{array}$ & $\begin{array}{l}\text { Some states require a certain percentage of electricity to be } \\
\text { generated from clean energy sources. }\end{array}$ \\
\hline & $\begin{array}{l}\text { Charging } \\
\text { Incentives }\end{array}$ & $\begin{array}{l}\text { This includes the incentives given for charging stations, and } \\
\text { residential charging facilities, electric utilities etc. }\end{array}$ \\
\hline
\end{tabular}

